\title{
Security market regulation : an empirical investigation of trading suspension and insider trading restriction
}

Citation for published version (APA):

Kabir, R. (1991). Security market regulation : an empirical investigation of trading suspension and insider trading restriction. [Doctoral Thesis, Maastricht University]. Maastricht University. https://doi.org/10.26481/dis.19910117rk

Document status and date:

Published: 01/01/1991

DOI:

10.26481/dis.19910117rk

Document Version:

Publisher's PDF, also known as Version of record

\section{Please check the document version of this publication:}

- A submitted manuscript is the version of the article upon submission and before peer-review. There can be important differences between the submitted version and the official published version of record.

People interested in the research are advised to contact the author for the final version of the publication, or visit the DOI to the publisher's website.

- The final author version and the galley proof are versions of the publication after peer review.

- The final published version features the final layout of the paper including the volume, issue and page numbers.

Link to publication

\footnotetext{
General rights rights.

- You may freely distribute the URL identifying the publication in the public portal. please follow below link for the End User Agreement:

www.umlib.nl/taverne-license

Take down policy

If you believe that this document breaches copyright please contact us at:

repository@maastrichtuniversity.nl

providing details and we will investigate your claim.
}

Copyright and moral rights for the publications made accessible in the public portal are retained by the authors and/or other copyright owners and it is a condition of accessing publications that users recognise and abide by the legal requirements associated with these

- Users may download and print one copy of any publication from the public portal for the purpose of private study or research.

- You may not further distribute the material or use it for any profit-making activity or commercial gain

If the publication is distributed under the terms of Article $25 \mathrm{fa}$ of the Dutch Copyright Act, indicated by the "Taverne" license above, 


\section{SECURITY MARKET REGULATION}

An empirical investigation of trading suspension and insider trading restriction 


\section{SECURITY MARKET REGULATION}

An empirical investigation of trading suspension and insider trading restriction

\section{PROEFSCHRIFT}

ter verkrijging van de graad van doctor aan de Rijksuniversiteit Limburg te Maastricht, op gezag van de Rector Magnificus, Prof. mr. M.J. Cohen, volgens het besluit van het College van Dekanen, in het openbaar te verdedigen op donderdag, 17 januari 1991 om 16.00 uur

door

Rezaul Kabir 
Pronotores:

Prof. Dr. Th.J. Vermaelen

Prof. Dr. C.C.P. Wolff

Beoordelingscommissie:

Prof. Dr. F.C. Palm (voorzitter)

Prof. Dr. M.J.L. Jonkhart, Erasmus Universiteit Rotterdam

Prof. Dr. P.W. Moerland, Katholieke Universiteit Brabant

\section{CIP-GEGEVENS KONINKLIJKE BIBLIOTHEEK, DEN HAAG}

Kabir, Rezaul

Security market regulation: an empirical investigation of trading suspension and insider trading restriction /

Rezaul Kabir, - Maastricht: Datawyse, - Ill.

Proefschrift Maastricht. - Met lit. opg.

ISBN 90-5291 042-1

SISO 345.7 UDC 336.76(043.3) NUGI 683

Trefw.: aandelenmarkt; financiering; regulering.

Omslag foto: De vloer van de Amsterdamse Effectenbeurs

Grafisch ontwerp binnenwerk: Aad van Mourik, Maastricht Layout: Jan Hulscher, Berchem

Produktie: Datawyse, Maastricht

(C) 1990, Rezaul Kabir

Behoudens uitzonderingen door de Wet gesteld, mag zonder schriftelijke toestemming van de rechthebbende op de auteursrechten, c.q. de rechthebbende gemachtigd namens deze op te treden, niets uit deze uitgave worden vermenigvuldigd en/of openbaar gemaakt door middel van druk, fotokopie, micro-film of anderzins. No part of this book may be reproduced in any form, by print, photoprint, micro-film or any other means without a written permission from the publisher. 


\section{ACKNOWLEDGEMENTS}

This dissertation could not have been completed without the contribution of many others. Any merits it may have are also attributable to them.

My sincere gratitude and appreciation go to Professor Christian Wolff who painstakingly read earlier drafts on several occasions. Almost every page of this dissertation reflects his advice, comments and suggestions. Gratitude is also extended to Professor Theo Vermaelen without whose assistance a substantial part of this dissertation could not have been completed. Insightful discussions with him is deeply appreciated.

I am also grateful to the members of the evaluation committee - Professor Marius Jonkhart, Professor Pieter Moerland and Professor Franz Palm - with each of whom I had very useful discussions.. Many of their comments have already led to improvements in this dissertation. The remaining comments will be used to extend the dissertation.

My sincere thanks go to former Professor Paul van Loon and Professor Elroy Dimson. With the former, I had fruitful discussions in the early stages of this research. I am indebted to him for first suggesting that I pursue an academic career in the Netherlands. The latter gave helpful comments on an earlier draft of chapter four. I also wish to thank Robert Ysenbout (Amro Bank), Laury Bollen, Ron Dekker, Paul Diederen, Diony van de Heuvel, Huub Meijers, René Olie, and many others from the University of Limburg for contributing in one way or another towards successful completion of the research.

Valuable research assistance was provided by Dulce Delfin-Elazegui, Marcel Driessen, Etienne Fourage, Monique Smeets, Richard Stals, Anja Velraeds and Janine Wijenbergh. I owe a special debt to each of them.

I would like to thank Stockdata for making available some data for this research. Financial support for printing the dissertation from 'Stal Stichting', Faculty of Economics and Business Administration, and 'BE-fonds Financiering' is also gratefully acknowledged.

Finally, I would like to thank my wife, Rita, whose patience, support, and understanding were very essential during these busy years. The arrival in this period of Laurens has been a pleasure. I would also like to thank my relatives who provided emotional support from thousands of kilometers away.

My apologies to those who have been inevitably but inadvertently not mentioned. Needless to say, I alone bear the responsibility of remaining errors, and would be pleased to learn of any. 


\section{TABLE OF CONTENTS}

Acknowledgements

List of Tables

List of Figures

CHAPTER 1

1.1 Introduction

1.2 Regulation and The Regulatory System

1.2.1 Regulation Defined

1.2.2 The Regulatory System

1.3 Theory of Regulation

1.3.1 The 'Public Interest' Theory of Regulation

1.3.2 The 'Capture' Theory of Regulation

1.3.3 The 'Economic' Theory of Regulation

1.3.4 Conclusions

1.4 Public and Private Regulation

2.1 Introduction

2.2 Principal Focus of Security Regulation

2.3 Security Regulation in the Netherlands

2.3.1 Public Regulation

2.3.2 Private Regulation

2.4 Security Regulation in the United Kingdom

2.4.1 Public Regulation

2.4.2 Private Regulation

2.5 Security Regulation in the European Economic Community

CHAPTER 3

\section{EXISTING EMPIRICAL EVIDENCE ON SECURITY REGULATION}

3.1 Introduction

3.2 Disclosure Regulation

3.3 Insider Trading Regulation

3.4 Trading Suspension Regulation

3.5 Market Making Regulation

3.6 Margin Regulation

3.7 Conclusions 
CHAPTER 4

TRADING SUSPENSION ON THE LONDON STOCK

4.1 Introduction

4.2 Trading on the London Stock Exchange

4.3 Suspension of Security Trading

4.3.1 Institutional Practice

4.3.2 Theoretical Insights

4.4 Description of the Sample of Trading Suspensions 30

4.5 Research Design

4.5.1 Methodology 33

4.5.2 Sample Selection $\quad 36$

4.6 Empirical Results 37

$\begin{array}{lll}\text { 4.6.1 Market Model } & 37\end{array}$

4.6.2 Market Adjusted Model $\quad 40$

4.6.3 Returns from Estimated Alpha $\quad 42$

4.6.4 Non-Merger Sample 44

4.6.5 Infrequent Trading $\quad 46$

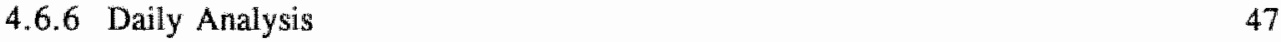

4.6.7 Small Firm Effect

4.7 Conclusions

Appendices $\quad 54$

CHAPTER 5 TRADING SUSPENSION ON THE AMSTERDAM STOCK EXCHANGE

5.1 Introduction 61

5.2 Trading on the Amsterdam Stock Exchange 61

5.3 The Practice of Trading Suspension 65

5.4 An Empirical Analysis of Trading Suspension 65

5.5 Two Examples of Trading Suspension 68

$\begin{array}{lll}5.6 & \text { Research Design } & 70\end{array}$

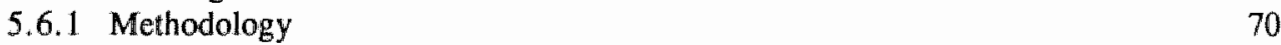

$\begin{array}{ll}\text { 5.6.2 Sample Selection and Data } & 70\end{array}$

5.7 Empirical Results 71

5.7.1 Market Model $\quad 71$

$\begin{array}{lr}\text { 5.7.2 Market Adjusted Model } & 73\end{array}$

$\begin{array}{ll}\text { 5.7.3 Serial Correlation Adjustment } & 76\end{array}$

$\begin{array}{ll}\text { 5.7.4 Trading Volume Analysis } & 78\end{array}$

$\begin{array}{lll}5.8 \text { Conclusions } & 80\end{array}$

$\begin{array}{ll}\text { Appendices } & 81\end{array}$ 
6.1 Introduction

6.2 The Model Code to Prevent Insider Dealing

6.3 Regulation of Insider Trading

6.3.1 Theoretical Insights

6.3.2 The Hypotheses

6.4 Sample Selection and Data

6.5 Trading Volume Analysis

6.5.1 Methodology

6.5.2 Results: Annual Earnings

6.5.3 Results: Semi-Annual Earnings

6.6 Stock Retum Analysis

6.6.1 Methodology

6.6.2 Results: Annual Earnings

6.6.3 Results: Semi-Annual Earnings

6.7 Conclusions

(Summary in Dutch)

BIBLIOGRAPHY 


\section{LIST OF TABLES}

Table 4.1

Table 4.2

Table 4.3

Table 4.4

Table 4.5

Table 4.6

Table 4.7

Table 4.8

Table 4.9

Table 4.10

Table 4.11

Table 4.12
Statistical Highlights on the London Stock Exchange Annual Distribution of Trading Suspensions on the London Stock Exchange

Distribution of Length of Trading Suspensions

Distribution of Companies ever Affected by End-of-Month

Trading Suspension, and later on Disappeared from Exchange

Listing due to Various Reasons (Period: Jan. '70 - Mar.' 88 )

Industry Classification of Firms Being Affected by

Trading Suspension

Selection of Working Sample

Average Abnormal Returns Around Trading Suspensions;

$($ Sample size $=83$ )

Average Abnormal Returns Around Trading Suspensions;

(Sample size $=83$ )

Average Abnormal Returns Around Trading Suspensions

( $\alpha$ estimated, $\beta=1$; Sample size $=83$ )

Average Abnormal. Returns Around Trading Suspensions

$($ Sample size $=55)$

Average Abnormal Returns Around Trading Suspensions

$($ Sample size $=83)$

Average Abnormal Returns Around Trading Suspensions

(Daily data, Sample size $=44$ )

50

54

Appendix 4.A Summary Statistics from the Market Model

Appendix 4.B Descriptive Statistics of Average Abnormal Returns,

Monthly Data

56

Appendix 4.C

Alternative Estimation of Beta

58

Descriptive Statistics of Average Abnormal Returns, Daily Data 59

Highlights on the Amsterdam Stock Exchange

Yearly Distribution of Trading Suspensions on the

Amsterdam Stock Exchange

66

67

$\begin{array}{ll}\text { Reasons for Trading Suspension } & 67 \\ \text { Industry Classification of Trading Suspension } & 68\end{array}$

Average Abnormall Returns Around Trading Suspension;

Market Model (Figures in percent)

Average Abnormal Returns Around Trading Suspension;

Market Adjusted Model (Figures in percent)

Average Abnormal Returns Around Trading Suspension;

Serial Correlation Adjustment (Figures in percent)

Table 5.9

Average Daily Trading Volume of Suspended Shares

(Figures in percent)

Appendix 5.A Summary Statistics from the Market Model 81

Appendix 5.B Summary Statistics with Serial Correlation Adjustment 83

Table 6.1

Table 6.2

Table 6.3

Table 6.4

Table 6.5
Selection of Working Sample

Monthly Distribution of Earnings Announcements

Descriptive Statistics of EPS and DPS

Average dailly trading volume of stocks on the Amsterdam

Stock Exchange (Figures in percent of shares outstanding)

100

Abnormal trading volume around annual earnings announcements

(Total Sample) 1
7

1

2

2

(6)

\section{(1)}

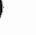

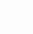

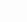

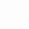

56

3

6

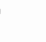

. 8 
Table 6.6 Average abnormal daily trading volume around annual eamings announcements (t-statistic within parentheses)

Table 6.7 Abnormall trading volume around anwual earnings announcements of small firm.s

Table 6.8 Average abnormal daily trading volume for small firms around ammal carnings announcements (l-statistic within parentheses)

Table 6.9 Abnormal trading volume around semi annual earnings announcements (Total Sample)

Table 6.10 Average abnormal daily trading volume around semi-annual earnings announcements (t-statistic within parentheses)

Table 6.12 Average abnormal daily trading volume for small firms around semi-annual earnings announcements (t-statistic within parentheses)

Table 6.13 Number of firms with earnings changes relative to the previous year

Table 6.14 Average and cumulative average abnormal returns around annual earnings announcements (total sample)

Table 6.15 Average and cumulative average abnormal returns around annual earnings announcements of smal. firms

Table 6.16 Average and cumulative average abnormal returns around semi-annual

Table 6.17 Average and cumulative average abnormal retums around semi-annual earnings announcements of small firms 


\section{LIST OF FIGURES}

Figure 1.1

Figure 4.1

Figure 4.2

Figure 4.3

Figure 4.4

Figure 4.5

Figure 4.6

Figure 4.7

Figure 5.1

Figure 5.2

Fingure 5.3

Figure 5.4

Figure 6.1

Figure 6.2

Figure 6.3

Figure 6.4

Figure 6.5

Figure 6.6

Figure 6.7

Figure 6.8

Figure 6.9
The Regulatory System

Average abnormal returns (upper panel) and cumulative abnormal returns (lower panel) around trading suspension (Market Model Returns)

Average abnormal returns (upper panel) and cumulative abnormal retums (lower panel) around trading suspension (Market-Adjusted Returns)

Average abnormal returns (upper panel) and cumulative abnormal returns (lower panel) around trading suspension

(Returns from Estimated Alpha)

Average abnormal returns (upper panel) and cumulative abnormal returns (lower panel) around trading suspension (Non-Merger Sample)

Average abnormal returns (upper panel) and cumulative abnormal returns (lower panel) around trading suspension (Scholes-Williams Method)

Average abnormal returns (upper panel) and cumulative abnormal returns (lower panel) around trading suspension (Dimson Method)

Average abnormal returns (upper panel) and cumulative abnormal returns (lower panel) around trading suspension (Daily Sample)

Daily closing prices of AMEV (upper pannel) and Hoogovens (lower panel) around trading suspension

Average abnormal returns (upper panel) and cumulative abnormal returns (lower panel) around trading suspension (Market Model)

Average abnormal returns (upper panel) and cumulative abnormal returns (lower panel) around trading suspension (Market-Adjusted Model)

Average abnormal returns (upper panel) and cumulative abnormal returns (lower panel) around trading suspension

(Serial Correlation Adjustment)

Cumulative average abnormal trading volume (as a percentage of total shares outstanding) around annual earnings announcements

Cumulative average abnormal trading volume (as a percentage of total shares outstanding) around annual earnings announcements of small firms

Cumulative average abnormal trading volume (as a percentage of total shares outstanding) around semi-annual earnings announcements

Cumulative average abnormal trading volume (as a percentage of total shares outstanding) around semi-annual earnings announcements of small firms

Cumulative abnormal returns around annual earnings announcements

Cumulative abnormal returns around annual earnings announcements (small firms)

Cumulative abnormal returns around semi-annual earnings announcements

Cumulative abnormal returns around semi-annual earnings announcements of small firms 



\section{CHAPTER}

\section{1}

REGULATION: INTRODUCTION AND OVERVIEW

\subsection{INTRODUCTION}

This dissertation focuses on the issues related to security market regulation, and intends to serve two purposes: to provide a brief discussion on regulation in general and security regulation in particular; and to investigate empirically the impacts of two specific types of security market regulation, namely trading suspension and insider trading regulation.

\subsection{REGULATION AND THE REGULATORY SYSTEM}

\subsubsection{Regulation Defined}

There is no universally accepted definition of regulation. Usually regulation involves a conscious altempt by an economic unit to influence the behaviour of another unit or units (Needham, 1983). This definition of regulation is too general, since almost every economic activity is regulated to some degree. Mitnick (1980) describes regulation as a sort of interference inwolving a diversion from what otherwise would occur. Whether these interferences are judged to be good or bad will depend on the value system used to evaluate the effects produced by the regulation.

By the term regulation one means, in most cases, government regulation. According to Kahn (1970), "the essence of regulation is the explicit replacement of competition with governmental orders as the principal institutional device for assuring good performance. The regulatory agency determines specifically who should be permitted to serve; and when it licenses more than one supplier, it typically imposes rigid limitations on their freedom to compete. So the two prime requirements of competition as the governing market institution freedom of entry and independence of action - are deliberately replaced. Instead the government determines price, quality and conditions of service, and imposes an obligation to serve" (p. 20).

Most of us would agree that a government should interfere against the acts of say, theft, murder, violence, etc. But there is less agreement on the desirability of other types of government interference, say, in pricing a product or a service, providing subsidies or tariff protection to an industry, supervising activities of diverse financial intermediaries, providing company information to investors and other groups, limiting shop opening hours, etc. One"s 
attitude on the desirability of any type of these regulations depends on the perceived objectives the regulation wants to achieve, the type of regulatory instruments used, and the costs involved with such regulation.

\subsubsection{The Regulatory System}

As mentioned earlier, regulation may be considered as the intentional restriction of an individual"s or ain organisation's choice of activity by an entity not directly involved in performance of the activity. It is, therefore, interesting to see how a regulatory system functions. Figure 1.1 depicts the common regulatory system within an economy. Here it is assumed that one regulatory agency created by the legislature tries to regulate some industry, whose activities have an impact on some group of consumers as well as, perhaps, other groups interested in the effects of the industry"s production.

Figure 1.1

The Regulatory System

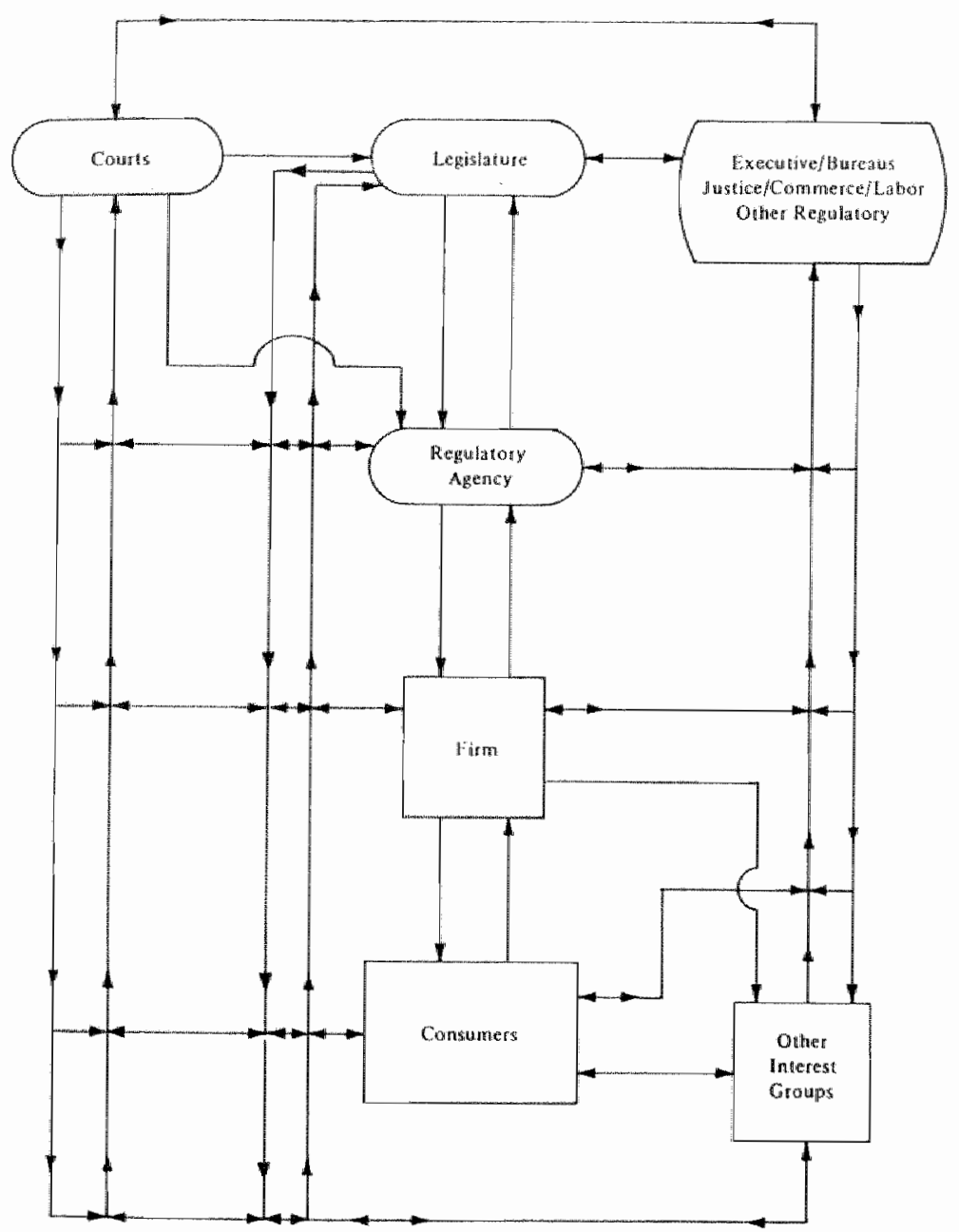

Source: Mitnick, 1980, p. 35. 
The activities of the regulated industry may be protested and/or affected in various ways by the relevant consumer and other interest groups, who, along with the industry, may also suggest or request actions by the agency, and may suggest changes of the regulation to the legislature. Agency actions may also be appealed in the courts who may direct the agency to alter its behaviour. The agency may also request changes in its mandate. Other administrative units may also request the legislature for changes in the regulation.

Once regulation is imposed, it necessarily implies decision-making about its enforcement. Otherwise the inherent objectives of regulation can not be achieved. Enforcement activity in regulation can be seen in terms of a compliance system or a deterrance system (Reiss, 1984). The principal objective of a compliance enforcement system is to secure conformity with law by means of ensuring compliance, or by taking action to prevent potential law violations without the necessity to detect, process, and penalise violators. Thus a complance system is primarily concemed with preventing violations and remedying underlying problems. On the other hand, the principal objective of deterrent enforcement system is to secure conformity with law by detecting violation of law, determining who is responsible for the violation, and penalising violators to deter violations in the future. Thus a deterrance system is primarily concerned with detecting offenses and punishing violators. Usually regulatory systems are seen organised as a mixture of both compliance and deterrance systems.

\subsection{THEORY OF REGULATION}

Severall theories have been proposed in the literature to explain the existence of regulation. None of these seems to be successful in adequately characterising regulation prevalent in diverse industries. Yet these theories, put together, provide a good representation of various viewpoints in describing regulatory origins. The following sections give an overview of three dominant theories together with evidence on their empirical validity.

\subsubsection{The 'Public Interest' Theory of Regularion}

Until the early $1960 \mathrm{~s}$, the generally accepted view of why regulation comes into existence was the 'public interest' theory. This theory says that regulation is a governmental response to public demands for the correction of inefficient or inequitable practices by individuals and organisations. Here regulation is regarded as an attempt by governments to 'improve' the allocation of resources and/or income distribution which would otherwise occur in unregulated markets. This wiew on regulation is essentially based on two assumptions. One is that economic markets are extremely fragile and apt to operate very inefficiently if left alone; the other is that government can act in an efficient way. The inefficiency of markets may result from monopolistic practices, externalities, or imperfections in the distribution of information. So the recognition that market processes might operate inefficiently led to the conclusion that, in principle at least, government action was justifiable to correct for this inefficiency.

As Posner (1974) argues, were this theory correct, one would find regulation imposed mainly in highly concentrated industries (where the danger of monopoly is greatest) and in industries that generate substantial external costs or benefits (Phillips, 1975). But one does not find such evidence. Regulation is not positively correlated with the prestence of external economies or diseconomies or with monopolistic market structure. The 'public interest' theory is also viewed as vague and indeterminate because views of the public interest are often vague, indefinable and conflicting. Usually some people benefit and some are harmed by any policy measure, and the problem of defining what is meant by 'public interest' in these cases boils down to a value judgment about whose interests and evaluations of the policy measures should be taken into account by policy makers (Needham, 1983). 


\subsubsection{The "Capture' Theory of Regulation}

By the 1970s, the "public interest" concept as a credible standard for interpreting regulatory behaviour had few defenders. As Pltzman (1981) observes, "the public-interest view became more clearly a normative paradigm. Its underlying welfare economics remained a valid way of organising discussion about what regulators ought to be doing, but any belief that regulators often did what they should was now severely tempered ${ }^{\text {in }}$ (p. 371). The attention of economists inevitably shiffed from an exclusive preoccupation with the alleged market failures, to a closer consideration of collective decision-making process. Thus came the "capture theory" which holds the wiew that over time the regulatory mechanism comes to be dominated by the regulated parties so that regulation serves their interests rather than the public interest. The assumption behind such a view is that regulation is the result of efforts of the regulated industries to escape the reality of market competition and to obtain government assistance in order to protect their interests.

The merit of the "capture theory" is that it directed attention away from the acceptance of the self-proclaimed intention of regulators to serve the public interest to the examination of their actual behaviour and intentions. The theory makes it explicit whose interests lie behind demand for regulation. But this theory also ignores a good deal of empirical evidence showing that the interests served by the regulators are also those of consumer groups, environmentalists, etc., rather than solely those of the regulated industries themselves. Another point is that not all groups in society would be expected to be equally pllaced in terms of their ability to manipulate the regulators. No reason is suggested for characterising the interaction between the regulatory agency and the regulated firm by conquest. No reason is also suggested as to why the regulated industry should be the only interest group able to influence the regulator. Peltzman (1976) also argues that the complete capture of the regulator must inevitably arouse opposition from other groups who are adversely affected, and a more likely outcome of the regulatory process will be a balancing of opposing interests.

\subsubsection{The 'Economic' Theory of Regulation}

The empirical evidence in our society offers few clear patterns of regulatory behaviour except that it demonstrates the inadequacy of either the "public interest" or the "capture' hypothesis. Neither of these attempts to explain how or why regulators are motivated to behave as hypothesised. In 1971, Stigler proposes a theory which views the phenomenon of regulation as a product whose allocation is governed by the forces of demand and supply.

Thus, regulation is a device for transferring income to well-organised groups if the groups will return the favour with votes and contributions to the politicians. The supply and demand framework to the occurrence of regulation can be explained by using the economic theory of cartel modified to include the political process. Like cartelisation, regulation can protect industries by bringing about shared rules for behaviour - rules which ensure higher than competitive rates, protection from potential competitors, and so on.

Posner (1974) terms Stigler's proposition as 'the economic theory of regulation". His reasoning is as follows: "viewing regulation as a product allocated with basic principles of supply and demand directs attention to factors bearing on the value of regulation to particular individuals or groups, since, other things being equal, we can expect a product to be supplied to those who value it the most. It also directs our attention to the factors bearing on the cost of obtaining regulation" (p. 344).

According to Stigler, the demand for regulation comes from the benefits that the state can provide to improve the economic status of economic groups. In this context, he mentions four benefits which an industry may seek of the state. These are, a direct subsidy of money, control over entry, power to affect substitutes and complements, and ability to fix prices. The supply of regulation is made possible by the politicians who are assumed to be interested in successful 
elections, which require votes and resources. Since the benefits politicians can provide through regulation are easy to identify by the receiver groups, these groups will be ready to incur the costs. At the same time, the industry which seeks political power must go to the appropriate seller. Regulation can result from the interactions of these forces of demand and supply. Because political decisions are infrequent, global, coercive, and made simultaneously, one sees such a decision process as fundamentally different from that of the ordinary market. That's why many industries are also able to use the political machinery to their own end. The main point behind Stigler's argument is that the regulatory process goes beyond purely economic phenomena, that "the problem of regulation is the problem of discovering when and why an industry (or other group of like-minded people) is able to use the state for its purposes, or is singled out by the state to be used for alien purposes." (Stigler, 1971, $\mathrm{p}^{*} 4$ ).

Though the economic theory of regulation seems to replace the term 'capture' by the terminologies of demand and supply, important differences exist. According to this theory, people in their political behaviour should not be assumed to be motivated by fundamentally different forces than in their private choice-making behaviour. People seek to advance their self-interest and do so rationally. Thus, the 'capture' of the regulator is not an accident, but it resullts from a market for regulation. So it is possible that the 'capture" takes place by interest groups other than the regulated firms.

Empirical evidence in the USA provide support to the view that economic regulation is well explained as a product supplied to interest groups (Stigler, 1971; Jordan, 1972; Jarrell, 1978; James, 1983; Cornett and Tehranian, 1990). Posner (1974) finds that the economic theory can be used to explain why we observe protective legislation in areas like agriculture, labour, and profession. He has also enumerated a number of reservations regarding the economic theory of regulation (pp. 352-355). Amongst others, he observes that the economic theory has not been refined to the point where it enables us to predict specific industries in which regulation will be found. Stigler (1971) himself acknowledges that the central tasks of the theory of economic regulation are to explain who will receive the benefits or burdens of regulation, what form regulation will take, and the effects of regulation upon the allocation of resources (p. 3 ).

\subsubsection{Conclusions}

We can conclude from the abowe discussion that there is not yet a theory that can explain each and every regulation. Each of the above mentioned theories can be used for possible explanation of regulations prevailing in almost all aspects of economic activities. According to Joskow and Noll (1981), "social scientists have not yet shown convincingly that they understand what political purposes are served by regulation, why some industries are regulated and others are not, and why regulatory controls rather than other policy instruments are selected. Until answers to questions like these are forthcoming, the theory of regulation serves as a convenient way of organising historical material, but not one that is particularly rich in predictive value" (pp. 39-40). At the same time we have to keep in mind that regulation is a complex and dynamic process involving not only economic but also legal and political factors. These problems led McCraw (1975) to comment that regulation is so broad a topic that its proper study compels the use of methods from many disciplines.

\section{4}

\section{PUBLIC AND PRIVATE REGULATION}

Two types of rule-making authorities usually exist which influence the activities of a market. The first type consists of public sector institutions which derive their authority from the government. They establish rules and regulations, and failure to comply may make an agent subject to fine or imprisonment. One typical public sector institution in the Netherlands is, for 
example, the Ministry of Finance. Ut formulates different rules and conditions related to the financial markets.

The second type of rulemaking authorities consists of private sector institutions which derive support from the general acceptance of their decisions by the members. Failure to comply does not have any legal consequences, but may result in disciplinary actions. Most stock exchanges are typical examples of such private sector institutions.

Both private sector and public sector regulations are intermelated in the sense that the presence of effective private regulation eliminates to a large extent the need for public regulations. But this sort of dual authority system sometimes lacks explicit guidelines on allocation of regulatory responsibilities (Lipton, 1985). The private regulatory bodies will, of course, seek to ensure that all legal requirements are complied with. 


\section{CHAPTER}

2

\section{SECURITY REGULATION: FOCUS AND PRACTICE}

\section{$2.1 \quad$ INTRODUCTION}

The securities market is the complex of institutions and mechanisms through which funds are dealt with. Usually securities like shares, bonds, warrants, rights, convertibles, are issued in exchange of these funds. Thus one can identify securities market as an arrangement which helps these securities to be exchanged. The securities market can be characterised in different ways: money and capital market, primary and secondary market, debt and equity market (Dougall and Gaumnitz, 1986). While in the primary securities market, transactions involve the sale of new financial securities, most of the day-to-day transactions in securities markets take place in the secondary market. This kind of classification of securities markets is especially relevant, as most regulatory systems adopt a different approach to regulation in the primary market compared with the approach applied to the secondary market.

\subsection{PRINCIPAL FOCUS OF SECURITY REGULATION}

Security regulation is usually concerned with the different methods which are employed either directly or indirectly to exercise supervision in the securities market. We have seen in chapter one that government agencies are mostly involved in various regulatory measures. A country"s government usually adopts diverse actions in order to influence market participants' behaviour as well as the securities market in general. Through a number of means, it tries to influence the flow of savings toward specific objectives thereby intervening in the market and altering the function of financial markets (Van Horne, 1984, ch. 9). An Organisation for Economic Cooperation and Development (OECD) publication states: "In all OECD countries it is viewed as a legitimate function of government to exercise some degree of surveillance over securitiesrelated activities as part of the duty of government to create an environment in which productive economic activity can take place" $(1988$, p. 21$)$.

Though the benefits are readily apparent and always cited, 'true costs' of government interventions are seldom considered. Many public regulations are also intended to reduce the amount of fraud, manipulation or deception in financial transactions. It is to be noted that regulatory activities on securities markets differ significantly from those applied in other areas. Worth to mention here is the stock market which lives with a blend of public and private 
regulations. Private authorities also issue directives in order to achieve proper disclosure of corporate information, orderly markets, and investor confidence.

The principal focus of security regulation is directed at the following three aspects:

a. Issuance of Securities

b. Trading of Securities, and

c. Financial Intermediation.

a. The process by which an issuer offers and sells its securities to the public has been one important area of regulatory activities. The public offering and sale of securities is prevented unless 'adequate' information about them is made available. This sort of influence is exercised over the issuer mainly through the company law, the securities act, and the system of prudential supervision with regard to financial institutions. These laws require disclosure of information as a means of investor protection. The idea behind the requirement is that better information about the issuer enhances the security pricing mechanism, thus protecting investors from price manipulations and corporate mismanagement. If the investors themselves must assess the quality of the investment, then the issuer must provide the necessary information. Thus, regulation exists which subjects dealing on the primary market to some form of approval or authorisation.

b. Regulations on trading of securities establish and enforce certain rules and codes of conduct, although the area of secondary trading is mainly left to self-regulatory bodies. The size of the secondary market is enormous in relation to the new issue market. Proponents of regulation in this area argue that by preventing large, frequent, or sudden changes in the price of outstanding securities, regulation improves the quality of the information provided by their prices, and thus increase the social value provided by the existence of a securities market. Different types of regulations can be identified under this heading. Periodic accounting disclosure requirements are intended to serve the purpose of protecting investors from fraud and misrepresentation. Legislations are imposed to prevent insiders profiting, allegedly at the expense of shareholders. The authorities have the power to suspend trading in securities suspected of possible manipulation or other violations of securities laws. Regulations also exist against corporate repurchases of their own securities, and certain mergers and takeover bids.

c. Financial intermediation is the process through which the differing needs of ultimate buyers and savers are reconciled. In the process of financial intermediation, numerous institutions are involved. These include banks, insurance companies, investment companies, pension funds, brokerage houses, etc. Financial intermediaries transform funds in such a way as to make them more attractive in the sense that additional customer-oriented services like risk reduction, maturity intermediation, contracting-cost reduction, information production, etc . are provided (Campbell, 1988, pp. 311-317). These intermediaries are uswally subjected to tighter regulation than other types of business organisations. "The intended purpose is to maintain stability of the financial system, and to protect depositors and investors against losses. There are regulations concerning establishment, activities, and management to which these institutions are submitted. For example, in the Netherlands, legislation requires the obtaining of a licence to offer brokerage services in connection with securities transactions. Other regulations of financial intermediaries include requirements for disclosure of information, restrictions on entry and mergers, and limitations on capital-asset ratios. Controls exist on the kind and quality of assets financial intermediaries may acquire, whereas examination procedures try to ensure that the legislations are properly followed.

${ }^{1}$ See Kane (1981) for a discussion on banking regulation. 


\section{3 \\ SECURTTY REGULATION IN THE NETHERLANDS}

\subsubsection{Public Regulation}

While the Amsterdam Stock Exchange was founded in 1876, the first formal public regulation concerning the Dutch securities market did not appear until 1914 with the outbreak of the First World War. At that time the Stock Exchange was closed from Iuly 29 on. Faced with excep tional circumstances, the government introduced in September 1914, the Stock Exchange Act ("Beurswet") which brought the Exchange under the supervision of the Minister of Agriculture, Industry, and Trade (later the Minister of Finance).

The Stock Exchange Act empowered the responsible Minister to issue directives concerning the opening and closing of stock exchanges, the quotation of prices, the manner in which business was transacted on the floor, etc. In operating the Act, the Minister was assisted by a Committee of Experts, and a Supporting. Committee for the Implementation of the Act. The latter was instituted following the reopening of the Exchange on February 1915 in order to represent the government and supervise the proceedings. Later on, the Stock Exchange Trading Decree of 1947 required that all purchases and sales of securities should be made through a member of the Exchange.

These regulations remained the only formal link between the government and the securities sector for a long period. In 1983, the Stock Exchange Listing Decree ("Beschikking Bewrsnotering") was issued. It required any change in the rules for securities transactions to be submitted before the Minister of Finance. The Minister was also empowered to decide whether or not a security will have a listing on the Stock Exchange.

Then in 1985, the Securities Transactions Act ("Wet Effectenhandel") was adopted. The purpose of the Act is to prevent undesirable developments with respect to securities transactions. The Act provides protection for the public against misleading investments offers, and thus, increases confidence in the Dutch capital market. The Act provides a system of prohibitions and licences relating to securities transactions taking place outside the Stock Exchange. It also stipulates conditions for public offering and trading in any security. The Act has no effective impact on the operations of the Stock Exchange which, while endorsing the Act, regards it as an important step in promoting the reputation of Amsterdam as a financial centre. Here it may be important to mention that an institution comparable to the Securities and Exchange Commission in the United States does not exist in the Netherlands.

The important measures from the Securities Transactions Act are the following:

a. It is prohibited to offer securities unless the offer is made to persons who deal or invest in securities professionally, or unless it is made within private circles. The prohibition does not apply if the securities offered are officially quoted on a recognised stock exchange or if a prospectus on the securities is made available which meets the requirements as laid down later on by the Securities Transactions Decree ("Besluit Effectenhandel") of 1986.

b. It is prohibited to offer to act as a broker in securities transactions, unless the offer is made, to persons who regularly issue securities or who deal or invest in them professionally, or within private circles, or by a licensed person. This prohibition does not apply to members of a recognised stock exchange acting as brokers with regard to securities officially quoted on that stock exchange.

c. It is prohibited to invite participation in an investment fund by persons who do not deal or

\footnotetext{
"Amsterdam Stock Exchange, "A Century of Stocks and Shares", 1986.
} 
invest in securties professionally, unless the invitation is issued within the priwate circles or by a licensed person. This prohibition also does not apply if participations in the fund are officially quoted on recognised stock exchange.

d. Licences are granted if the applicant demonstrates that a number of conditions are met with regaid to expertise and trustworthiness, financial guarantees, business management and information to be supplied to the public.

It appears that there is now a growing tendency to extend public regulation of the Dutch securtites market into new areas. The government has, since February 1989, adopted the Law on Insider Trading which makes securities trading based on inside information a criminal offence. The Inspection Bureau of the government conducts preliminary inquiries into possible violations. If any violation is determined or seriously suspected, then the case is reported to the Public Prosecutor. Anyone found involved with transaction based on inside information could be punished by imprisonment and fines.

With effect from February 1989, The Securities Board of the Netherlands (STE : "Stichting Toezicht Effectenverkeer") assumed the responsibility as the supervisory body for all securities exchanges on behalf of the Minister of Finance. The STE appraises various rules of exchanges and supervises them on the basis of two criteria: the adequate functioning of the market, and the position of investors. The government is now working on a new securities regulation bill already approved by the lower house of parliament in June 1990, and is expected to become law in early 1991. This bill will replace the old legislation of 1914. Under the new legislation, the STE will also take on the responsibility for supervising off-exchange trading between nonmembers. The STE will be able to reclaim the costs of supervision from the securities market, and from non-members. The STE will also be permitted to request information or to initiate an inquiry into securities transactions. A second bill - the Collective Investment Institutions Bill which has been presented to parliament in May 1990 will require all investment institutions to obtain a licence before gaining access to the market. These two bills together will replace the 1985 Act, and will form a broad legal framework for regulation of the entire Dutch securities industry.

The Dutch gowernment has, in 1990 , presented another bill to the parliament to regulate obligatory disclosure of shareholdings in listed companies. This legislation requires shareholders to disclose any holding in publicly listed companies that exceeds $10 \%$ of the number of shares outstanding. It also prowides for disclosure of interests at thresholds of $10 \%, 25 \%, 50 \%$ and $66.6 \%$, whether shareholders increase or decrease their stakes. The proposed bill allows seven days for the initial disclosure by shareholders to the Finance Minister and the company involved, after which there remains another nine days for public disclosure. The responsibility for supervision of the act will be delegated to the Securities Board of the Netherlands, and failure to meet disclosure requirements will be a criminal offence. However, the Minister could exempt a company if public disclosure were in conflict with the public interest or seriously damaging to the company.

\subsubsection{Private Regulation}

Although the world"s first stock market began its operations in Amsterdam at the beginning of the seventeenth century, it was not until the late nineteenth century that securities trading really began to assume its present form, with the formal establishment of the Amsterdam Stock Exchange Association ("Vereniging voor de Effectenhandel") in 1876. The Association is the private regulatory authority in securities transactions in the Netherlands . Its principal aims are to advance the general interest of securities trading in the Netherlands, and to maintain a central securities market to the benefit of the national economy in general and the Dutch capital 
market in particular. ${ }^{3}$

Since January 1990 , there has been a reorganisation of the Stock Exchange. A distinction is now made between the association sphere (Stock Exchange Association) and the operational sphere (Amsterdam Stock Exchange). The Association develops general policy and formulates rules under which the Exchange operates. The function of the Exchange is to provide services in support of the securities trade, and basically covers three areas: trading, operation, and commercial affair. The Exchange is managed by a team of four managing directors who report to the Council of the Stock Exchange Association. The Council consists of 16 members who are elected by the general members and a chairman. The Chairman is an independent, nonmember of the Exchange. He is also the Chief Executive. Four members of the Council represent listed companies and investors. The other 12 members of the Council represent the three categories of member firms which exist within the Stock Exchange: banks, brokers ("commissionairs"), and specialists or jobbers ("hoeklieden"). The day to day management of the Association is in the hands of the Executive Committee, composed of the Chairman and three Council members.

The Council of the Stock Exchange decides whether securities will be given an official listing or not, how the Exchange should operate, who will be the members, whether at prospectus provides sufficient information with respect to the securities to be issued, how the security issuing institution should make adequate information available to the public, etc. The Stock Exchange membership requirements include a certain minimum capital, independence and expertise.

The Stock Exchange has adopted a number of rules which contain requirements for listing and securities transactions. The rules of the Stock Exchange relating to the requirements for listing on the official market, and securities transactions ("fondsenreglement") include the following:

a. An application for the admittance of a security must be made to the Stock Exchange. It shall submit the application to the Minister of Finance. Such submission shall be accompanied by advice given by the Exchange to the Minister as to whether it is advisable that the security be admitted.

b. A security shall not be admitted until after a prospectus has been published. Such a prospectus shall give a faithful picture with regard to the state of affairs in the issuing institution.

c. The issuing institution whose security has been admitted shall have the obligation to ensure that the necessary facilities and information are made available in order to enable the security holders to exercise their rights; to make its Annual Accounts, Annual Report and Half-Yearly Report available to the public; to inform, as soon as it has knowledge thereof, the public of any new changes that have taken place in the structure of the substantial participations in its share capital; to issue immediately a publication relating to every fact concerning the issuing institution of which it must be assumed that it will effect a substantial influence on the price.

d. All and every item of information must be made available to the public by the issuing institution of a security that has been admilted, must be published in one or more Dutch daily newspapers with a nation-wide or large circulation, or in any other equivalent manner approved by the Exchange.

${ }^{3}$ Annual Report of the Amsterdam Stock Exchange, 1989. 
Recently the Ansterdam Stock Exchange has taken an initiative allong with the Ministry of Finance, to prevent misuse of inside information. Since 1987, the Model Code to Prevent Insider Dealing is in force for all listed companies. The Code prohibits managing directors of frrms from making any transaction while possessing price-sensitive information. The Code also imposed restrictions on these top employees from trading directly or indirectly in securities of their own firms. These restrictions are valid for a period of: two months preceding a preliminary announcement of annual results; 21 days preceding announcement of half-yearly or quarterly results of dividends; one month preceding the publication of a prospectus for a share issue. Top employees are also not allowed to trade within six months of a transaction. The Code requires Company Chairmen to maintain a register containing information on share ownership of the top officials of the firm. This register remains available for inspection by Stock Exchange officials only. In order to detect violations of the Code, a Stock Watch committee looks for 'abnormal' movements in prices and trading volume. If a violation is found, the company's name is made public; in case of serious violation the company is reprimanded. This sanction of the Exchange is mild compared to the earlier mentioned law on insider trading adopted in 1989 by the Dutch parlliament which imposes fines and even jail terms for insiders.

In an effort to limit the takeover defenses (alleged to be among the world's strongest), the Amsterdam Stock Exchange proposed in 1988 to limit each company to two defensive mechanisms - instead of three or four, as is often the case - and to limit the voting power of preferred shares to one-third of the total. There were strong protests against the proposal and some companies threatened to puil out of the Exchange. Afterwards, a compromise was reached, and it was decided that the reforms would apply only to companies listed after October 1989, and a more elaborate regulation will become effective in 1992, following developments within the European Community. Meanwhile, the Stock Exchange is trying to persuade older members to discard some of their takeover defenses.

\subsection{SECURITY REGULATION IN THE UNITED KINGDOM}

\subsubsection{Public Regulation}

Siatutory regulation of the securities market in the United Kingdom is supervised primarily by the Department of Trade, and the major Acts of relevance are the Companies Act and the Prevention of Fraud (Inwestments) Act (Brealey, 1985). Through the Companies Act, the Department supervises the filing of prospectuses and the legal continuous disclosure requirements, and has the power to investigate the affairs of companies. The Department is also responsible for bringing prosecutions in the event of breach of provisions of the Prevention of Fraud (Investments) Act of 1958, which prescribes the circulation of information inviting the sale or purchase of securities subject to stringent controls on the persons who may circulate such information, and on the standard of information. Under the Act, it is an offence for a person or institution to carry on the business of dealing in securities unless exempted by the Act or licensed by the Department of Trade. Amongst the more important exemptions are members of the Stock Exchange or of a recognised association of dealers of securities, some 400 'exempted dealers' (primarily banks and insurance companies) and other specified financial institutions, including the Bank of England. Individuals not exempted can apply to the Department of Trade for a licence. The Fair Trading Act of 1973 developed procedures and powers for investigating and preventing major merger transactions. The Companies Act of 1976 introduced a number of reforms of UK company law, of which the most important in relation to securities law is the tightening of disclosure requirements of company directors' dealings, and substantial shareholdings. 
The above mentioned regulatory structure in the United Kingdom could not keep pace with the rapidly changing structure of the securities and investments industry. Thus, the U.K. govermment adopted a new legislation called The Financial Services Act in 1986 replacing the old Prevention of Fraud (Investments) Act. The Act lays down comprehensive rules for the entire securities industry. The conduct of investment business without authorisation has become a criminal offence in the United Kingdom, carrying the penalty of fines and imprisonment. The main provisions of the Act are based on the concept of self-regulation (by authorised bodies and persons) within a statutory framework. Supervisory powers under the Act are delegated by the Department of Trade and Industry to the Securities and Investments Board. The Board authorises a number of Self-Regulating Organisations (SROs) which, in turn, authorise and regulate their members. An SRO is required to ensure the effective monitoring and enforcement of its rules, exercise discipline over members, provide safeguards for investors, and 'promote and maintain high standards of integrity and fair dealing' (Thomas, 1989, p. 184).

\subsubsection{Private Regulation}

In the United Kingdom the principal securities market is the London Stock Exchange, which is an independent association of stockbrokers and stockjobbers. The Exchange, formally created in 1802, was merged with the international security dealers in 1986 to form what is now officially called the International Stock Exchange of the United Kingdom and the Republic of Ireland. Thus, a single organisation now covers a wide range of domestic and international securities related business. All persons who deal in or make a market in listed securities on the Stock Exchange are required to be members of the Stock Exchange. As such, they are subject to the rules laid down by the Exchange for their conduct and may be liable to fine or suspension for breach of those rules.

The Stock Exchange determines the conditions upon which securities are admitted to listing and permitted to trade on the Exchange. On an on-going basis, the Stock Exchange requires any company whose securities are listed to observe certain rules and procedures with regard to publication of accounts and disclosure of information to shareholders. Audited annual reports are required to be filed with the Stock Exchange within six months of the end of the company's financial year. Interim reporting requires the publication of semi-annuall reports within four months of the end of the period concerned. A listed firm must notify shareholders of any major new development that may be expected to produce a substantial effect on its security price. The various sanctions which the Stock Exchange can impose are refusal of listing of new securities, suspension of the listing of the existing securities, and fines, censure or expulsion of a member.

The Stock Exchange has also introduced in 1977 the 'Model Code for Securities Transactions by Directors of Listed Companies". The Code requires that directors refrain from dealing in the two months preceding any regular announcement of results and dividends, whether or not the information is price sensitive. The restriction also applies to dealings prior to any announcement of matters of an exceptional nature involving unpublished price sensitive information.

The Panel on Takeovers and Mergers, established in 1968, administers the City Code on Takeovers and Mergers. This Code is not a legislative document, but lays down a set of general principles and specific rules regarding the conduct of a takeover bid for a public company, and the information to be contained in an offer document. The Panel is supported by the Stock Exchange, and other bodies.

Besides the Stock Exchange and the Panel on Takeovers and Mergers, the Council for the Securities Industry was established in 1978. It has the role of coordinating self-regulation among all users and practitioners in the securities industry and ensuring that the supervision of the securities markets operates satisfactorily and in the public interest. 


\section{5 \\ SECURITY REGULATION IN THE EUROPEAN ECONOMIC COMMUNITY}

The European Community, with its twelve Member States, is at present in the process of creating a single market where free movement of goods and services as well as capital can take place. There are proposals to liberalise all categories of capital movements like direct investments, funancial loans, and money and capital market transactions, and to harmonise different legidations of individual countries regarding security transactions. A considerable effort is made to develop an integrated securities market where it will be possible, without much complication, trom one country to issue or invest in securities in another member country. Until now several relevant directives (community acts) have been adopted by the Buropean Community." These are briefly discussed in the following paragraphs.

The first directive (79/279/EEC), adopted in 1979, coordinates the conditions for the admission of securities to of licial stock exchange listing. The directive sets out the conditions that must be met by issuers of securities, including the minimum issue price, the company's period of existence, free negotiability, sufficient distribution and the provision of appropriate information for investors. "The second directive (80/390/EEC), adopted in 1980, lays down the items of information which must be published when securities are admitted to stock exchange listing. According to the third directive $(82 / 121 / \mathrm{EEC})$, adopted in 1982 , companies are obliged to publish certain information (for example, semi-annual reports) on a regular basis. Another Community directive in $1982(82 / 148 / \mathrm{EEC})$ sets the final date as Jully 1986 before which these measures are to be adopted by all member countries.

A new directive (87/345/EEC) was adopted in 1987 with the aim to ensure that listing particulars approved in one Member State are automatically recognised on stock exchanges of other Member States without the need for additional approwal. The Council of Ministers of the Community reached agreement on the next directive $(88 / 627 / \mathrm{EEC})$ in 1988 . It requires that investors and the public be informed of major shareholdings, changes in holdings above or below certain thresholds, and changes in voting rights for listed companies. The requirement comes into effect when a holding reaches $10 \%, 20 \%, 33.3 \%, 50 \%$, and $66.6 \%$. The Member States may apply a single threshold of $25 \%$ in place of the $20 \%$ and $33.3 \%$ thresholds, and $75 \%$ in place of the $66.6 \%$ threshold.

Two more directives were adopted in 1989 . The first one $(89 / 298 / \mathrm{EEC})$ coordinates the requirements for the content and distribution of the prospectus to be published when securities are offered to the public. The second one (89/592/EEC) coordinates different regulations on insider trading restrictions within the whole European Community. People who trade on inside information about a company with which they are closely associated are considered offenders. The ditective allows fines to be set independently by each Member State.

Besides these already adopted directives concerning securities market, there are now more proposals under consideration for eventual adoption as Council directives. One such proposal is concerned with public takeover bids within the European Community. Its main provisions include banning partial public takeover bids, obliging a partial bidder (from 30\%) to extend his bid to all the stocks, ensuring that a bidder states in advance his intentions regarding the assets and activities of the company concemed, and banning publicly listed companies from thwarting a bid by selling important assets or issuing new shares to a third party unless the company won shareholder approval. A bid could also be suspended to allow time to call a shareholder meeting for such a vote. It seems that the efforts of the European Conmunity aimed at creating a unified securities market will be faced with many debates as well as regulatory changes because of differing views among the Member States.

"The European Financial Common Market, European Documentation, Office for Official Publications of the European Communities, No. 4, 1989. 


\subsection{INTRODUCTION}

The purpose of this chapter is to review some of the empirical work undertaken to analyse the effects of different security regulations. In such analysis, not all empirical studies were devoted to comparing regulatory situation with that of an unregulated environment. In situations where an unregulated environment was not a viable and practical alternative, the issue involved evaluating specific regulations solely from data dealing with regulated operations. This methodology is not necessarily inferior to the comparative approach because, in some instances, regulation has been in force for such a long time that studies of the effects of imposition of regulation have questionable current relevance. Most of the studies reviewed in this chapter pertain to the United States stock market, which has received considerable attention in the literature.

\subsection{DISCLOSURE REGULATION}

Most of the regulations on securities markets come in the form of financial disclosure requirements of corporations whose stocks are traded in the market. The U.S. Securities Act of 1933 required disclosure of information in primary distribution of securities. The principal vehicle used to accomplish this purpose was the requirement to fille a registration statement, and issue a prospectus to the public when issuing new securities.

Stigler (1964a) was the first to provide quantitative evidence on the effects of mandatory registration of new issues. He raised the following question: how did investors fare before and after the Securities and Exchange Commission (SEC) was given control over the registration of new issues? He took a sample of new issues of industrial stocks in the pre-regulatory period of 1923-28, and in the post-regulatory period of 1949-55, and measured the values of these issues (compared to their offering price) in five subsequent years. In both periods the performance of the new issue prices was adjusted for mowements in the market. He finds no large differences in the relative market values of new issues in the periods before and after the SEC registration requirement. This leads Stigler to conclude that the regulation of the SEC had no important effect on the quality of new securities sold to the public.

Stigler's paper led to very critical replies from Friend and Herman (1964), and Robbins and Werner (1964). Friend and Herman accused Stigler of complete disregard of happenings of 
early 1930s, and considerable number of errors in data regarding inclusion and exclusion of stock issues and listing of prices. They computed the results and came to the opposite conclusion that new issues performance was superior in the post-SEC period. Stigler (1964b) replied with equal force in another paper "that the SEC review procedures had not significantly improved the market performance of new issues relative to outstanding issues. The data revisions and the new analysis do not call for amendment of this conclusion" (p. 419). Whatever confusion remains about the results, Stigler should be commended for being able to show first that it is possible to study the effects of public policies, and not merely to assume that they exist and are beneficial.

The effects of 1933 Securities Act have also been studied by Jarrell (1981) and Simon (1989). Jarrell's findings are consistent with those of Stigler. But Simon's findings differ in some respects. Disaggregating new equity issues into seasoned and unseasoned ones, Simon finds that only unseasoned issues floated on exchanges other than New York Stock Exchange (NYSE) earn greater returns following the 1933 Act. In all other cases, new-issues investors earn no abnormal returns. However, the dispersion of abnormal returns are smaller for all issues in the post-SEC period. This reduction in variance reflects increased availability of quality information, and may be linked to post-SEC improvements.

Another dimension of security regulation is to require disclosure, on a regular basis, of predominantly financial reports for firms which have publicly traded securities outstanding. The Securities Exchange Act of 1934 in the United States requires firms to file with the SEC three types of financial statements within a stipulated period. The first refers to annual reports like balance sheets, income statements and supporting documents. The second refers to less detailed semi-annual statements. The third type of report must be filed at the end of any month in which what the SEC calls 'significant' events like major changes in control of corporation, legal liability, or value of assets, have occurred. Underlying these requirements was the belief that mandatory disclosure of financial data was necessary for the fair and efficient operation of the capital market, i.e. helping investors with information needed to make an informed decision. This argument implies that the accounting statements, as prepared by the corporations and then filed with the SEC, convey relevant information.

But is such information relevant for investors? Do the required accounting numbers affect the timing and content of information reported to the capital market? Empirical work has often led to the conclusion that much of the capital market's reaction to accounting numbers is anticipatory, and that the market uses a broad-based information set in interpreting the information content of reported accounting numbers. Ball and Brown (1968) assess the usefulness of annual income numbers as published by 261 NYSE firms over the 1957-65 period. Their conclusion is that although the information content of annual income number of firms is considerable, it does not rate highly as a timely medium since most of its content is captured by faster media. Their conclusion seems not surprising because of the fact that accounting information reflects the past only. The market has other sources of information like interim reports, activities of analysts and insiders, etc. Very similar results are obtained by Beghin (1984) who analyses stock market reactions to announcements of annual earnings of Belgian corporations. He, too, concludes that earnings announcements contain information, but most of the information was already impounded into stock prices. Foster $(1986$, ch. 11) reviews other evidence which also supports the conclusion that no mechanistic relationship exists between reported accounting numbers and security prices.

Benston (1969) investigated whether statements filed with the Securities and Exchange Commission are meaningful to investors and sufficiently timely to be of value. He constructed a model in which changes in stock prices are a function of previously unexpected changes in accounting data, changes in dividend payments, changes in general market conditions, and changes specific to an industry. His idea was that if a corporation's financial statements contain 
unanticipated information, the expectations of investors about the present value of the corporation should change, and this change would be reflected in a change in the price of the corporation"s stock. His study covered 483 companies traded on the New York Stock Exchange in 1964. His findings show that there probably is some positive relationship between the rate of change in reported accounting data and stock prices; although the magnitude of such relationship is very limited (p. 39-40).

In another paper, Benston (1973) tests the effect of disclosure legislation by examining its differential impact on the securities of corporations that were and were not affected by the legislation. He distinguishes two samples: 290 NYSE corporations which disclosed required sales data and 176 which did not. If disclosure of the sales data as required by the regulation was meaningful to investors, the effects should be observed in the market returns of the securities in the period after the law was effective. 'Investors would then alter their previous estimates of the relative value and/or riskiness of the firms. The results obtained by Benston indicate little change in the riskiness for those corporations affected by the Securities Act. He also finds that the mandatory disclosure did not lead to a revaluation of returns for stocks of disclosure and non-disclosure firms. Benston concludes from his findings that the disclosure provisions of the US Securities Act of 1934 were of no apparent value to investors because these had no measurable positive effect.

Friend and Westerfield (1975) criticise Benston both for apparent shortcomings in his procedure and for the conclusion he draws from the evidence. A lot of disagreement rested upon what constitutes an economically significant effect of disclosure. Replying to criticisms, Benston (1975) emphasises that an economically significant relationship between share prices and published financial statements is necessary but not sufficient support for the hypothesis that mandated disclosure is beneficial in some way.

The informational content of mandatory financial disclosure has also been assessed by Hawawini and Michel (1987). They examine the Royal Decree on Accounting Standards and Financial Reporting of 1976 (later on revised by the Royal decree of 1983) in Belgium. The Decree defines the form and content of the annual accounts, the valuation rules, and the prescribed disclosure thereof. They take a sample of 100 firms. Half of these belong to a control group (these firms were not affected by the legislation because they had been disclosing all or some of the required data on a voluntary basis ${ }^{2}$ prior to the enactment of the Decree); and the other half to an experimental group (these firms revised their reporting practices and increased the disclosure of financial data only after the legislation's requirement becante effective). Hawawini and Michel then attempt to measure the effects of mandatory financial disclosure on the mean returns, wariability of returns and systematic risk of the firms affected by the legisllation.

The empirical findings show that no significant statistical differences exist between the returns of the experimental group and the control group. Hawawini and Michel then test whether the legislation has induced any price-offsetting effects within a group. They find that firms with low relative-risk, and that report (after the legislation took effect) unexpectedly smaller eamings, were experiencing significantly negative differential returns. The stockholders of these firms suffered a significant loss of wealth. Apparently no significant gain in wealth was observed for other stockholders. It was also observed that the price adjustment of these firms affected by the legislation occurred in full prior to the date at which firms had to

\footnotetext{
"In his previous study, Benston (1969) found sales the only relatively important accounting number compared to cash flow, net operating income, net income after all deductions and additions.
}

${ }^{2}$ Evidence on credibility of voluntary disclosures compared to mandatory disclosures is provided by Pownall and Waymire (1989). 
disclose. Thus it was not the publication of companies" financial statements according to the specification of the legislation that was responsible for the observed price adjustment.

The above discussion should not give the impression that benefits of disclosure regulations were not seen by anyone. Seligman (1985) recently justified the presence of regulatory overight. He suggests that without mandatory disclosure requirements ${ }_{3}$ voluntary disclosure practices would be lesss uniform, more likely to omit information material to investors, and more ofter employed in securities fraud. He concludes that the SEC has performed a credible role as it directly contributed to the standardisation of financial statements by requiring the disclosure of material data, thus making comparisons among financial reports possible. In a socio-historical study, Merino and Neimark (1982) observe that the securities acts were designed to maintain the ideological, social, and economic status quo while restoring. confidence in the existing system and its institutions.

Whatever doubts may exist about the benefits of disclosure requirements, we now pay attention to the evidence regarding the total costs to society of such a regulatory program. Even if the benefits are modest, the existence of mandatory disclosures can be still considered justified if the costs are sufficiently small. ${ }^{3}$ Philips and Jecher (1981) have tried to estimate all disclosure-related costs of about 10,000 registered firms in 1975 . The total costs of $\$ 225$ million, which includes $\$ 12$ million as costs of administering periodic disclosures, need to be weighed against social benefits. Earlier evidence suggests that investors did not benefit from those required disclosures. So Philips and Jecher conclude, "if there are no other social benefits to the regulatory program, the SEC disclosure system fails the cost-benefit test of social desirability: public interest is not well served" ( $p .44)$. They, of course, did not forget to identify other groups in society who clearly benefit from the regulatory actions: security lawyers, financial analysts, auditors, and printers. It appears that regulation favours relatively small but well-organised groups that have a high per capita stake in regulation, at the expense of relatively large but poorly-organised groups with a lower per capita stake. The abovementioned costs, although they appear to be borne directly by corporations, are indirectly passed on to the customers, employees, owners and suppliers.

The London weekly 'The Economist' in its June 13, 1987 issue reported an estimate of regulatory costs of UK financial markets. It is suggested that regulation under the 1986 Financial Services Act in the UK is going to cost around $\$ 200$ millions a year in people paperwork and new technology. This figure is an estimate of direct outlays only. A number of hidden cost items of regulation are not included.

Thus far, we have viewed disclosures as useful to provide investors with information. There exists another belief that required disclosures will prewent fraud and misrepresentation of financial data. With respect to fraudulent activity in the preparation of financial statements by accountants prior to the legislation in the United States, Benston (1969) finds no major evidence in the literature. From 1934 omwards, regulations in the United States made it possible for investors to sue an accountant because of false or misleading financial statements. A consequence of this change in the law appears to be that financial statements are more misleading than they were (Benston, 1973, p. 135). The reasons include accountants following conservative practices so that it is difficult to sue them successfully; the SEC insisting on historically based accounting procedures in fact discouraged price level adjustments and other revaluations of assets and liabilities. No documentation by the Securities and Exchange Commission is available that shows that regulatory actions have actually reduced the amount of security price manipulation and fraud.

${ }^{3}$ Ross (1979) discusses the direct costs and the hidden costs of disclosure regulations. 
The problem of information disclosures takes us to the problem of insider trading which is another dimension of regulatory activities involved with the securities market. Securities laws take the position that those endowed with inside information about the value of publicly traded securities should not personally profit from that information at the expense of other investors. So anyone in possession of valuable information is required to donate the information to other trading partners or else abstain from trading.

Some economists have taken a different position from that of the regulators. Starting with the idea that security market allocates capital efficiently onlly if information is rapidly reflected in security prices, they advocate that outsiders will be better off if insiders are allowed to trade. Manne (1966) suggests that if, for any reason, the current market price of a security is known to be incorrect in terms of all available information, insiders will have an incentive to correct the market price of that security. In this case, the presence of regulation will only lengthen the time between the production of information and its release to the market. Demsetz (1969) also questions the desirability of regulation to disclose inside information. He finds that since private sources employ vast sums of money to acquire information about a particular security, it is hard to believe that a regulatory agency with probably meagre resources can accomplish much. By increasing the cost of using the direct and obvious methods of capturing some of the value of inside information, the regulatory agency will encourage insiders to rely in greater degree on less direct and more time consuming methods. Besides, John and Mishra (1990) argue that trading by corporate insiders (subject to disclosure regulation) should be viewed as a signalling activity for conveying their private information to the stock market.

Here it may be mentioned that little doubt exists about the superior performance of insiders in capital market transactions. Several authors, including Finnerty (1976), lend support to the conclusion that insiders can and do identify profitable as well as unprofitable situations, and therefore, are able to earn higher than average profits from their market transactions. Finnerty"s research involves constructing an insider buy portfolio and a sell portfolio for each month during the period 1969-71, and then comparing individual portfolio returns with market returns. His results indicate that insiders, probably because of their access to privileged information, outperform the market with their stock selections. Sharp market reaction around the dates of insider trading has also been reported by Pope et al. (1990).

Given that insiders using special information earn abnormal returns, what can regulation do about it? There has been a lot of speculation about the consequences of effective insider regulation. In one study, Jaffe (1974a) analyses data covering 200 firms in the United States during the period 1962-68, and finds that insiders possess special information, and that trading on inside information is widespread. Securities regulations, thus, could not stop trading by insiders. In another study, Jaffe (1974b) tries to examine empirically the effects of insider trading immediately before and after three regulatory changes in the United States. These changes were: penalising brokerage firms for trading with secret information (1961); indicting officials of a firm for trading on, as well as suppressing, information (such indictment being viewed as an extension of regulatory law as of 1965); and, finally, punishing speculation on special information (1966). Jaffe compares the profitability and trading volume of insiders immediately before and after each of these regulatory changes. His results suggest that the average profitability of insider trades before an event was not significantly different from the average profitability of insider trades after that event. His results also do not suggest that the regulatory changes influenced the volume of insider trading.

Givoly and Palmon (1985) produced evidence showing that mere occurrence of insider trading generates abnormal returns. While analysing the link between insider trading and subsequent news disclosure, they find no tendency for insiders" purchase transactions to precede good news or for sale transactions to precede bad news. Rather, according to Givoly 
and Palmon the profitability of insider trading follows from the tendency of investors to follow.

Our survey of empirical evidence tends to support the view that regulation banning insider trading can not be effuctive. Vermaelen (1986) points out that "a law which can not be easily enforced will redistribute wealth from people with high moral standards (who obey the law out of principle) to people with lower moral standards (who ignore the law because the probability of being caught is small). Such redistribution does not seem to be socially desirable" (p. 439).

One question may come to mind: why is insider trading regulation ineffective? Jaffe (1974b) advances some suggestions. He argues that the nature of regulations and their enforcement are to blame. While insiders, on average, reaped excess returns of approximately four percent per trade, as obtained from Jaffe's results, movements in stock prices of this order are likely to be due to events undetectable by a regulatory agency. Demsetz (1969) thinks that there is little a regulatory agency can do to eliminate completely the profits associated with the possession of valuable information. He points to the existence of different less obvious insider trading devices like the sale of information to outsiders, use of friends, relatives and agents, etc.

\section{$3.4 \quad$ TRADING SUSPENSION REGULATION}

Now we shall look at the empirical evidence concerning another dimension of regulatory action in the security market. This comes from the authority of regulatory bodies to suspend trading of securities in organised exchanges. Thus, a sudden compulsory break occurs in the normal process of buying and selling securities. When it is believed by the authority that a security is being traded with insufficient information, or important information is being expected which might affect the security's price, trading is suspended in order to allow wide dissemination of the information to all investors." Several questions may be raised on this issue. How can the authority verify that indeed circumstances have arisen in which a normal market can not be maintained? Does the occurrence of suspension lead to a normal functioning of the market? What are the consequences of the decision to suspend securities trading? These are points which require investigation, and some research results have already been reported.

Kryzanowski (1978) examines the effectiveness of trading suspensions in the Canadian securities market. From a total of 388 suspensions that took place on Canada"s four major stock exchanges during the period of Jan. 1967 to Dec. 1973, he took a sample of 34 stocks. These stocks were alleged to have been manipulated, and therefore were suspended from trading. His results show that manipulation has indeed been successful in causing an abnormal upward movement in stock prices in the pre-suspension period. The implication of this finding is that the Canadian authorities could not detect manipulation in time. Through trading suspension the authorities then deflate prices of those stocks by publishing information, but the procedure of disseminating information is found to be not effective enough.

Very similar results are found by Howe and Schlarbaum (1986) while investigating the Securities and Exchange Commission initiated trading suspensions in the United States. They examine a sample of 49 stock prices from the period Feb. 1959 to May 1979. These companies were listed on either the New York Stock Exchange or the American Stock Exchange. Their results show that suspensions coincide with substantial devaluations of the suspended securities, with the striking characteristic that the downward trend continues even after the reinstatement of trading. Not only does the devaluation of securities persist after suspension, but suspension also marks the beginning of a substantial downward trend of the affected securities. These two studies, therefore, show the inadequacy of the trading suspension method as an effective way of equitable information dissemination in securities market. Otherwise there would not have been continuous price readjustments once trading is reinstated.

Kyle (1988) discusses the specific arguments for trading suspensions on the futures market. 


\subsection{MARKET MAKING REGULATION}

Investors in many countries are usually not permitted to be present in the actual security trading process. They must gain access to the market by dealing through one of a limited number of persons who have the right to be present where trading takes place. This right is obtained by having a membership on the exchange. Market makers are those members of an exchange who, besides facilitating buying or selling securities at stated prices, remain ready to trade on their own account when other traders are not available in the market. The activities of the market makers tend to improve the market's continuity as well as the transaction-to-transaction stability of security prices. According to Tinic and West (1976), the demand for the services of market makers represents a desire on the part of investors to engage in immediate transactions, while the supply is determined by the behaviour of inventory carrying costs and the nature of risks in combination with the competitive and/or regulatory climate.

Although the quality of market making is difficult to measure, two important criteria have been mentioned by Smidt (1971) for evaluating market making performance. These are the size of the bid-ask spread (the difference between the highest bid price and the lowest offer price), and liquidity in depth (large quantity of stock can be traded at a unit price not too different from the price at which a small quantity could be traded). According to these criteria, an efficient market making system would supply adequate depth of liquidity at narrow bid-ask spreads. The question is whether the existing practices at various stock exchanges tend to accomplish an efficient market making system.

Here, too, we find that most of the empirical work was performed in the United States, specially in relation to the New York Stock Exchange. There, the Exchange was characterised by stringent barriers to entry and rules and regulations designed to stifle competition. The limited number of members were able to develop a trading system based on cooperative pricing practices, and to introduce a series of commission rate increases. The Exchange maintained minimum commission rates, and prohibited price cutting from 1792 until 1975 . When combined with a limitation on the number of memberships in stock exchange, the policy of minimum commissions represented a classic cartel price fixing arrangement.

The system of fixed commission rates in the United States was abolished in 1975 by the Securities Acts Amendments. Since then, all commission rates became freely negotiable. The effects of this deregulation in the New York Stock Exchange are analysed in detail by Stoll (1979). He finds that investors have benefited from a substantial reduction in commission rates and from increased diversity of services offered. Reduction in commissions produced a loss in revenue for brokerage firms, although not as great as thought earlier. Adjustment of member firms to competitive rates has been relatively easy because of a surge in stock market activity. Similar conclusions are drawn by Eisenach and Miller (1981). They support earlier finding that price deregullation in the securities brokerage industry has brought lower prices for most classes of services. The trend in commissions following deregulation has been downward as competitive rates started to appear. An estimate of the SEC, as reported by Eisenach and Miller, shows that price competition saved consumers of brokerage services nearly $\$ 700$ millions in the first twenty months following the deregulation. This happened without any major adverse effect on the securities industry which was feared by many.

Very similar changes have also taken place at the London Stock Exchange and the Amsterdam Stock Exchange. In October 1986, the London Stock Exchange has abolished the practice of fixed commissions and abandoned the system of single capacity trading (under which brokers were separated from jobbers). Evidence suggests that such deregulation has delivered many benefits to investors and firms. For investors, commission rates paid to brokers have fallen 
significantly while the average spread has also fallen significantly. ${ }^{5}$ Lower transaction costs and a more competitive environment have generated increased turnover, too. In July 1990, minimum commissions charged on securities transactions on the Amsterdam Stock Exchange hawe beer scrapped too. It is expected that smaller transactions will get more attention from market intermediaries because in the previous system larger transactions produced most of their income.

The use of borrowed funds to purchase securities is limited by regulation in many countries. Security regulation fixes the maximum amount of credit that any broker-dealer can provide to a customer. When investors buy stock on margin, they buy some shares with cash and borrow to pay for additionall shares; using the paid shares as collateral. The imposition of margin requirements is designed to promote three objectives: to reduce "excessive" credit in the stock market and leave more for productive uses; to protect buyers of stocks from going too far into debt and suffering therefrom; and to reduce fluctuations in the stock market due to forced selling of securities when prices drop and to overly easy purchases when prices rise.

In the United States, the Securities Exchange Act of 1934 gave the Federal Reserve Board the authority to promulgate regulation and to fix from time to time the margin level. The Federal Reserve was given this authority because it was in general responsible for regulating money supply and credit. Investigation and enforcement of margin rules lie in the hands of the securities regulatory agencies. The Federal Reserve Board has varied the minimum margin to be supplied by purchasers on many occasions since 1934. An important issue with margin requirements is whether a regulatory agency is in a better position to decide on the maximum amount of credit to be made available to the stock market investors, or whether banks and brokers themselves are in a better position to decide which borrower gets how much credit and when.

Moore (1966) came up with the idea to look at the evidence on the supposed effects of margin regulation. His empirical results suggest that investors do not use credit in a destabilising way. If investors with credit increase stock price fluctuations, then, Moore argues, there should be more credit available for the stock market. But in fact what actually happens is the reverse. So it is possible that margin requirements may actually inhibit stabilising influences. Moore suggests two reasons which probably account for the failure of margin regulation to fulfil its objectives. First, people can borrow for other purposes and then devote the funds to the stock market. Second, borrowers do not use credit as freely when stock market is rising as they do when the market is falling. Recently, Hardouvelis (1990) provides evidence that higher margin requirements are associated with lower stock price volatility and smaller deviations of stock prices from their fundamental values. His analysis shows that margin requirements could be effective in diminishing destabilising speculative activity.

The question whether margin policy changes have an effect on stock price has been anallysed by Largay and West (1973). Using U.S. data from the 1933-66 period covering 19 changes in margins - 12 increases and seven decreases - they find an almost negligible relationship between changes in margin requirements and stock price behaviour. This result must be surprising for those who believed that margin changes reflected the authorities' concern for the stock market and the economy. If that was a sensible argument then margin changes should have an influence on investors' expectations and, thus, on stock price movements. The efficacy of intervention in the security market via margin changes has also been questioned by Grube, Joy, and Panton (1979), and Hsieh and Miller (1990).

5 Precise figures on these results are presented in an article published in Bank of England Quarterly Bulletin, Feb. 1987, pp. 54-65. 


\subsection{CONCLUSIONS}

Out of plethoric rules and regulations existing in the security industry, this chapter thas taken a curious glance at a few of them. The objective has been to assess the accomplishment of some regulatory goalls with the help of empirical studies. The above survey does not intend to suggest that security regulation, as a whole, has no blessings. Rather, we find the belief that regulation is a guaranteed cure to some of the problerns in the security market an overly simplistic one. In fact, it seems that many regulations, although inspired by superb justification, could not achieve their intended objectives. Sometimes they appear even mutually inconsistent: regulation like mandatory issuing of prospectuses encourages disclosure while regulation restricting insider trading thwarts it. 



\section{CHAPTER}

4

TRADING SUSPENSION ON THE LONDON STOCK EXCHANGE

\subsection{INTRODUCTION}

As the admittance of securities to trading on a stock exchange is quite an important event to the issuing firm, the suspension of securities from trading is perhaps even more important. Because, this time, it is not only the firm concerned but also the investors and the market makers who are affected. Trading suspension involves a sudden compulsory break in the normal process of buying and selling securities on a stock exchange.. Someone who intends to buy or sell a security can not do so if trading of the security in question does not take place. The price of the security during a particular period is no longer allowed to be determined by the usual market mechanism.

Suspension, presumably, does not happen under normal circumstances. The authorities, who take the decision to halt trading of a certain security, use this particular regulatory measure because of several known or unknown reasons. The listing rules of the London Stock Exchange (now officially named the International Stock Exchange) state "The Committee may at any time and in such circumstances as they think fit suspend or cancell a listing. The Committee will not hesitate to do so to protect investors and to ensure an orderly market." Such emergence of circumstances needs to be interpreted in the broadest possible way. It could be an imbalance between supply and demand in a security, a pending corporate news announcement, suspicion on a firm's financial and business operations, the possibility of insider trading, security price manipulation, price fluctuations of an unusual kind, or even an attempt to assassinate a country's head of government. 2

Now one can put forward questions as to the aptness as well as the validity of the authority's own judgment that something remarkable is going on of which not all market participants are aware. How can the Stock Exchange (or any other authority) verify that indeed circumstances have arisen in which an uninterrupted normal trading of a security in the market

'Section 1, Chapter 4 of Admission of Securities to Listing, Council of the Stock Exchange, England, 1984.

${ }^{2}$ Here it is worthwhile to mention that suspension of trading is different from cancellation of trading. The continuation of a suspension for a prolonged period without the issuer of the concerned security taking adequate action to obtain restoration of trading may lead to eventual cancellation. The measure can also be taken directly in some other situations. 
can not be maintained? Even if it is found that the belief of the authority is correct, how can the Exchange justify its action? Does the very act of suspension lead to the occurrence of a "normal" market? What are the consequences of such actions for the frrm concerned and the investors? These are few issues which need thorough investigation before one can form an opinion on the application of suspension measure.

In fact, some attention on these issues has already been given by a few researchers. But the evidence does not conclusively show that normal securities trading is restored through suspension. Hopewell and Schwartz (1976) examine about 1000 New York Stock Exchange initiated trading suspensions occurring between February 1974 and June 1975. Almost three suspensions took place per trading day, and most of these was confrned to one-day suspension. Analysing these suspensions, Hopewell and Schwartz could detect the presence of presuspension anticipatory price behaviour among the securities. These securities typically undergo relatively large price adjustments over the suspension period. Their results also show that price adjustments are virtually complete at the end of the suspension day. The stock market seems to react efficiently to trading suspensions. Very similar results are presented by Hopewell and Schwartz (1978) in their second paper.

From a total of 388 suspensions that took place on Canada's four major stock exchanges during the period of January 1967 to December 1973, Kryzanowski (1978) analyses a sample of 34 stocks. These stocks were alleged to have been manipulated, and therefore, were suspended from trading. His results show that manipulation has indeed been effective in causing an abnormal upward movement in stock prices in the pre-suspension period. Through trading suspension the authorities then deflate prices of those stocks by publicising information, but the procedure of disseminating information is found to be not effective enough. In an extended analysis, Kryzanowski (1979) funds that prices continue to decline following the reopening of trading in case of suspension associated with bad news. However, the opposite does not happen in the case of good news. The stock market appears to react efficiently to suspensions associated with favourable information, but inefficiently to those with unfavourable public information.

Investigating Securities and Exchange Commission (SEC) initiated trading suspensions in the United States, Howe and Schlarbaum (1986) take a sample of companies from the period February 1959 to May 1979. These companies were listed on either the New York Stock Exchange or the American Stock Exchange. Based on their findings, Howe and Schlarbaum conclude, "SEC-initiated suspensions coincide with substantial devaluations of the suspended securities; nearly 80 percent of the securities studied experienced negative abnormal returns over the suspension period. Suspensions are, on average, "bad news." In addition, longer suspensions are significantly correlated with greater devaluations. Finally, significant and prolonged negative abnormal returns are observed in the postsuspension period, an apparent violation of semi-strong form market efficiency" (p. 332).

A study on trading suspensions in Sweden was performed by De Ridder (1988). He finds no anticipatory price behaviour prior to suspension on the Stockholm Stock Exchange (a finding notably different from the previous studies), but a significant share price increase with the occurrence of trading suspensions. In the period after suspension no abnormal return could be detected. An efficient market reaction to new information released during trading suspension seems to take place. In an extended analysis, Fabozzi and Ma (1988), examining the over-thecounter market activities for stocks suspended by the New York Stock Exchange, observe greater volatility but no abnormal profit opportunities. Their findings do not support the proposition that suspensions should be mandatory for all trading locations.

Besides these less than conclusive results regarding share price behaviour around the suspension period, no study has yet been done on trading suspensions on the London Stock Exchange although this particular phenomenon is widely prevalent, and sometimes in a unique manner. For example, it is not at all uncommon on the London Stock Exchange for trading 
suspensions remaining in force for several weeks and even months. Most of these suspensions involve small companies with a market value of less than 5 million pounds.

This chapter, therefore, investigates the phenomenon of trading suspensions on the London Stock Exchange (LSE), and is organised in the following manner. The next section provides some general information on security trading on the LSE. Section 3 presents a discussion on the practice and the theory of trading suspension. Various aspects of the sample of trading suspensions on the LSE are described in section 4. The next section outlines the research design as well as the working sample, while the results of this study are presented in section 6. The chapter ends with some concluding remarks.

\subsection{TRADING ON THE LONDON STOCK EXCHANGE}

The London Stock Exchange has become almost as big as all the other European stock exchanges put together. The Exchange is a self-regulating institution, and is governed by a Council comprised of and selected by Exchange members. The rules and regulations of the Stock Exchange, which are the responsibility of the Council of the Stock Exchange, include, for example, the admission and activities of members, operations of the Exchange, listing of securities, market services, and settlement systems.

Table 4.1

Statistical Highlights on the London Stock Exchange

A. Market Capitalisation of

Listed Securities

Government Bonds

frn

UK Equities

145,306

International Equities

412,716

853,007

B. Average Daily Value of Transactions

Government Bonds

UK Equities

fin

International Equities

C. Average Dally Number of Bargains

Government Bonds

UK Equities

International Equities

* Not all Stock Exchange Automated Quotations international transactions are currently reported to the Exchange. 
At the beginning of 1989 some 7145 securities with a total market capitalisation of 1633 billion pounds are listed on the Exchange." As we can see from table 4.1 , the UK government bond market accounts for most of the trading in terms of value outstanding. However, in terms of trading volume, government bonds represent only a small portion of the trading activity. Apart from about 2550 listed companies (one of the highest numbers in the world) of which almost 600 from owerseas, sone 440 companies are quoted on the Unlisted Securities Market, the market for maller companies created in 1980. Besides the listed and the unlisted market, a new market termed 'Third Market' has been established to provide access for a wider range of companies: About 60 companies are quoted on the Third Market.

For decades the London Stock Exchange was characterised by the "single capacity" system of separation between brokers and jobbers. Brokers were intermediaries, acting as agents bringing together buyers or sellers with the jobbers who fulfil the market making function. Since October 1986, this compulsory distinction between stockbrokers and stockjobbers does not exist anymore. All firms (whether market makers or brokers-dealers) are now able to act in dual capacity - they are able to deal directly with investors, or to act as agent, putting a deal together for a negotiated commission on a client's behalf. To support the new dealing system, a screen-based price dissemination system known as the Stock Exchange Automated Quotations (SEAQ) system was developed. This has changed the method of trading on the Exchange. SEAQ screens, carrying the quotes of individual market makers, are available to both member firms and major investors. (Under the previous system, prices were quoted verbally.) The screens are limited to information dissemination; they are not intended to conduct dealings. But when a deal is done, the market maker is obliged to enter details of the deal into the computer system.

Equities quoted on the London Stock Exchange are divided into four categories in order to reflect the different conditions prevailing in the market. These are:. (a) alpha stocks - the most actively traded equities. Market makers are obliged to maintain continuous firm two-way prices during the mandatory SEAQ trading hours. (b) beta stocks - somewhat less actively traded equities. Although market makers must still display continuous firm quotes, details of trades are published on the following day. (c) gamma stocks - market makers are obliged to maintain indicative two-way prices for gamma equities, but must quote firm prices on inquiry. (d) delta stocks - the least liquid equities for which price quotes are not shown on the screen.

Until October 1986, brokers on the London Stock Exchange used to charge fixed commissions. Since then a system of negotiated commissions has been in effect. It appears that increased competition has brought commission rates down substantially, and in many cases, institutional investors now choose to deal directly with firms on a net-of-commission basis. By mid 1987, commission income was same as in 1986, but with approximately double the number of transactions and half the commission rate. During 1988, some of the market conditions changed sharply. Turnover has fallen, and this has put pressure on the levels of revenue of market makers.

In January 1989, the Stock Exchange approved some revisions to its share dealing system prevailing since October 1986. The new rules, among other things, will abolish the obligation market makers have to deal with each other. The commitment that regularly forced firms to take on large blocks of shares at umprofitable prices, and the need to publish security prices immediately for trades of more than one hundred thousand pounds do not hold anymore. These revisions seem to mark a reversal in Stock Exchange's previous strategy to improve trading efficiency by increasing the flow of information.

${ }^{3}$ Quality of Markets Quarterly, Stock Exchange, London, Winter 1988/89. 


\subsubsection{Institutional Practice}

As mentioned earlier, a listing on the London Stook Exchange may be suspended at any time and in such circumstances as found lit by the authority. Usually the measure is adopted due to failure by the issuer of security to comply with the listing obligations. One of the principal objects of continuing obligations is to secure immediate release of information which might reasonably be expected to have a material effect on market activity in, and prices of, listed securities. Consequently, the Exchange suspends security trading pending an announcement, or publication of facts on the reorganisation of a company, or clarification of the position of a firm. Suspension may also take place with or without the request of the issuer of the security, or pending the removal of a suspension on an overseas stock exchange. If a firm's market capitalisation and shareholding position is such that an adequate market in the security can not be maintained, then trading is suspended too. The procedure for lifting suspensions depends on the circumstances, and the authority has the right to impose such conditions as they consider appropriate.

This sort of practice can be compared with that in the United States. There, two layers of institutions exist which administer enforcement of trading suspension. One is the stock exchange itself, and the other is the Securities and Exchange Commission (SEC). The New York Stock Exchange (NYSE) usually suspends trading of an individual security when there is a substantial imbalance of orders in the security, or when there is a significant pending or actual corporate news announcement. The first kind of suspension always originates from the request of the specialist, while the second can originate from several sources like the listed company, the exchange's own stock watch department, or the specialist. These suspensions occur, on average, twice or thrice daily, and last on a few occasions more than a day. On the other hand, the SEC has also the power to suspend trading in any or all securities on stock exchanges. It usually happens when there is alleged violation of securities laws. The frequency of SEC suspensions is low, roughly one-tenth that of the NYSE.

\subsubsection{Theoretical Insights}

We have already seen several reasons to suspend exchange trading in a security. These reasons have one thing in common: alleged emergence of a situation where insufficient dissemination of actual information prevails. The act of suspension, irrespective of the real reason, allso produces a common effect: making all concerned alert of something unusual, Once the suspension period is over, there is not necessarily a common effect. That depends on market evaluation of the suspension, and of the new information.

When is a measure like temporary trading suspension beneficial? Theoretically, if the authorities are able to correctly identify the precise moment when it could be established that the market indeed does not possess the right information regarding a particular security, then a temporary suspension of trading of the same security might help make that piece of information available to the market participants. Thus, one expects trading suspensions to be associated with the release of new and material information to the market. Before the occurrence of suspension, one remains confident (in a semi-strong form efficient market) that the market prices of securities reflect all publicly available information as the authorities are constantly monitoring all listed stocks. The suspension measure is assumed to take place at such a moment that the price of the security does not yet incorporate the new information. The very announcement of suspension alerts the market to something unusual regarding the security.

Trading suspension remains in force until the authorities believe that new information related to the security has been released and the market has had sufficient time to properly evaluate the new information. Once the suspension period is over and trading of the security is 
reinstated, the price of the security, if the rnarket is efficient in the semi-strong form, should reflect market evaluation of the newly released information. One can then consider the trading suspension measure as an effective one. The behaviour of the security price during the post-suspension period is expected to be different depending on whether the newly released information is interpreted by the market as good or bad news.

Although considerations leading to the decision to suspend security trading seem appealing, doubts may arise about the application of this particular measure. The decision to suspend trading together with its consequences should, in fact, be compared with the consequences of an uninterrupted trading. According to Hopewell and Schwartz (1978), trading suspension imposes a set of opportunity losses and gains on those market participants who would have otherwise engaged in transactions during this period. Evaluation of these costs and benefits depends upon the judgment exercised. Under what circumstances is an uninterrupted security trading then undesirable? Mendelson (1972) observes that continuity in trading has its merits, but there is no virtue in providing facilities for wild trading on half digested information and misinformation. Therefore, if trading of securities is halted, then it involves a trade-off between a short postponement of execution against more accurate pricing.

But how can one know beforehand which information would lead to correct pricing and which would not? Why not let the security market decide on it? Stigler (1964a), questioning stock exchange's practice of trading suspensions, notes the following: "To prevent a trade is no function of the Exchange, and any defense must lie in a desire to avoid "unnecessary" price fluctuations. An unnecessary price fluctuation is surely mot one called for by the conditions of supply and demand of the week, even though the fluctuations may reflect supply and demand of the hour. This suspension of trading means that the exchange officials know the correct price change when there is a flood of buy or sell orders." (p. 130). Stigler is pointing to the fact that no damage is done if some investors who, after successful searching, possess a piece of information and try to translate that information into security price, or if others who do not possess the information try to speculate on it. In such circumstances, an interruption of continuous trading would only delay incorporation of that information into the price. And such delays would onlly help the 'free riders': investors who only reap the benefits, if any, from information released once a trading suspension takes place, but do not bother to incur any cost to collect it.

In sum, operational criteria to evaluate the costs and benefits of trading suspensions are hard to find. But, as a whole, security trading suspension can be considered effective if it happens prior to any kind of anticipation by market participants, and new and material information is revealed as well as widely disseminated during the period of suspension. Investigating security prices before and after trading suspension would help us to ascertain whether suspension is effective in practice. On the other hand, trading suspensions can be considered imprudent if the securities market itself could have tackled information dissemination efficiently in the sense that no false trading occurs.

\subsection{DESCRIPTION OF THE SAMPLE OF TRADING SUSPENSIONS}

In order to collect information on the trading suspensions, we use two sources. The first one is the Stock Exchange Quarterly which publishes a list of all trading suspensions. This list includes information regarding company name, industry classification, type of security involved, broad reason, date of suspension, and sometimes, date of restoration. The second one is the London Share Price Database (LSPD). " The LSPD file contains quite detailed information on the UK stock market, but identifies only those suspensions which occur, or

"I am indebted to Jeremy Smithers and Christian Wolff for their kind assistance in obtaining the data. 
remain effective, at the end of each month. Thus information regarding securities which are suspended for a short period within any month are not collected at all. This obviously limits the size of the sample, but still presents valuable information on trading suspensions on the LSE.

The distribution of trading suspensions on the LSE over calendar years is shown in table 4.2. We find that, between January 1971 and March 1988, the Stock Exchange suspended trading of securities on 1902 accasions. This means an average frequency of 110 trading suspensions per year, or 9 suspensions per month. These suspensions are spread evenly over the different quarters of the year. On the other hand, during the same time period the LSPD lists $401(21.1 \%)$ trading suspensions. This indicates that there were on average 2 suspensions which occur or remain effective at the end of a month. From the LSPD, we could collect detailed information on 426 trading suspensions taking place between Jamuary 1970 and March 1988. In total, 364 different companies were involved. Among these, 311 (85\%) experienced suspension onlly once, while $44(12 \%)$ were affected twice, and $9(3 \%)$ companies had their securities suspended on three occasions.

Table 4.2

Annual Distribution of Trading Suspensions on the London Stock Exchange

\begin{tabular}{|c|c|c|c|c|c|}
\hline Year & Total & LSPD & Year & Total $^{\mathrm{a}}$ & LSPD \\
\hline 1970 & na. & 25 & 1980 & 136 & 14 \\
\hline 1971 & 67 & 16 & 1981 & $\mathbb{1 5 2}$ & 32 \\
\hline 1972 & 104 & 30 & 1982 & $\mathbb{1 1 6}$ & 22 \\
\hline 1973 & 90 & 18 & 1983 & 97 & 22 \\
\hline 1974 & 65 & 13 & 1984. & $\mathbb{1 0}$ & 29 \\
\hline 1975 & 92 & 13 & 1985 & 100 & 41 \\
\hline 1976 & 64 & 15 & 1986 & 107 & 39 \\
\hline 1977 & 129 & 16 & 1987 & 158 & 43 \\
\hline 1978 & 127 & 21 & $1988(\mathrm{Jan}-\mathrm{Mar})$ & 48 & 5 \\
\hline 1979 & 140 & 22 & & & \\
\hline \multirow[t]{2}{*}{ Sub-total } & 878 & 179 & Sub-total & 1024 & 247 \\
\hline & & & TOTAL & 1902 & 426 \\
\hline
\end{tabular}

a These figures are collected from several issues of "The Stock Exchange Quarterly.

Information regarding time length of these 426 end-of-month trading suspensions is presented in table 4.3. We observe that on $122(29 \%)$ occasions suspension continued for at most two months (as represented by one datapoint only) while the remaining 304 (71\%) cases were suspensions lasting definitely more than one month (more than one datapoint is present). "This phenomenon is unique. It perhaps reflects issues of fundamenval nature within the concerned firm (not mere release of specific information). We have not come across any evidence on any other stock exchange of so many trading suspensions lasting so many days or even months. The evidence provided by Hopewell and Schwartz (1978) shows that on the New York Stock Exchange only $15 \%$ of total trading suspensions last for more than a single day. Securities experiencing suspensions of longer than one week are very uncommon. 
Table 4.3

Distribution of Length of Trading Suspensions

\begin{tabular}{cc}
\hline & \\
\hline Datapoints* & Number \\
\hline 1 & 122 \\
2 & 70 \\
3 & 48 \\
4 & 27 \\
5 & 27 \\
6 & 19 \\
7 & 17 \\
8 & 6 \\
9 & 4 \\
10 & 3 \\
11 & 3 \\
12 and more & 80 \\
& $\frac{3}{4}$ \\
\hline
\end{tabular}

*Suspension on $n$ consecutive points means:

(n-1) months $<$ length of suspension $<(n+1)$ months.

Table 4.4

Distribution of Companies ever Affected by End-of-Month Trading Suspension, and later on Disappeared from Exchange Listing due to Various Reasons (Period: Jan.'70 - Mar.'88)

\begin{tabular}{lrr}
\hline Reason & Number & $\%$ \\
\hline Acquisition/Takeover/Merger & 107 & 29 \\
Liquidation & 31 & 9 \\
Receiver appointed/Liquidation & 39 & 11 \\
Voluntary Liquidation & 10 & 3 \\
Automatic Cancellation & 12 & 3 \\
Quotation Cancelled for Unknown Reasons & 14 & 4 \\
Suspension/Cancellation witli shares acquired later & 6 & 2 \\
Other Reasons & 7 & 2 \\
& -226 & 62 \\
Firms still Listed & 138 & 38 \\
Total Number of Affected Firms & -364 & 100 \\
\hline
\end{tabular}

Another interesting phenomenon that we find in our sample is that as much as $62 \%$ of the companies affected by the suspension measure have later on (could be several years) disappeared from the stock exchange listing. There are various reasons for this fact. These are 
mentioned in table 4.4. We see that the most important reasons for non-survival were acquisition/takeover/merger, and hiquidation-related phenomena. These events might provide an ex-post clue as to a possible reason behind the trading suspension decision. There were some cases of disappearance from listing due to automatic cancellation - a security remaining suspended for more than three years; some due to shares acquired afterwards - during suspension these shares were traded in the over-the-counter market."

We have also investigated the presence of any industry bias in our sample of trading. suspensions. The results are shown in table 4.5 . From our sample of 364 firms, we see that except industrial holding companies, no other particular industry was especially vulnerable to the suspension measure. The two extreme percentages for industrial holding companies and investment trusts reflect comparatively smaller (23) and larger (209) number of listed companies, respectively.

Table 4.5

Industry Classification of Firms Being Affected by Trading Suspension

\begin{tabular}{lcc}
\hline Industry Type & Number & $\begin{array}{l}\text { \% of Total } \\
\text { Listed }\end{array}$ \\
\hline Contracting \& Construction & 16 & 17.6 \\
Electricals & 9 & 22.5 \\
Electronics & 12 & 10.1 \\
Misc. Mechanical Engineering & 12 & 15.0 \\
Leisure & 11 & 15.1 \\
Clothing & 18 & 36.7 \\
OI & 14 & 28.0 \\
Industrial Holding Companies & 13 & 56.5 \\
Agencies & 10 & 13.2 \\
Investment Trusts & 12 & 5.7 \\
Property & 29 & 24.0 \\
Misc. Financial Trusts & 21 & 21.0 \\
Diverse & 187 & 18.3 \\
TOTAL/AVERAGE & 364 & 17.7 \\
\hline
\end{tabular}

\subsection{RESEARCH DESIGN}

\subsubsection{Methodology}

In order to investigate the effects of suspension of securities trading, we follow the standard event study methodology (Brown and Warner, 1980; 1985) using alternative model specifications. Therefore, it is important first to determine how returns on securities whose risks differ from one another could be explained. In the finance literature, attention in this respect has already been given to a number of models. One of the most widely used is the Market Model

${ }^{s}$ For an empirical analysis of delisted firms, see Sanger and Peterson (1990). 
which is not as intellectually appealing as the Capital Asset Pricing Model or the Arbitrage Pricing Theory (Copeland and Weston, 1988, Ross et al, 1990), but empirically performs quite well: Brown and Warner (1980), after examining various methodologies, conclude: "beyond a simple; one-factor market model, there is no evidence that more complicated methodologies convey any benefit. In fact, we have presented evidence that more complicated methodologies can actually make the researcher worse off, .." (p. 249). In their second article on event study methodologies, Brown and Wamer (1985) reinforce the previous conclusion. The use of the Market Model in event studies, originated by Fama et al. (1969), is still widespread in empirical work (see, for example, Warner and Watts (1988), Mikkelson and Partch (1988), Linm and Pinegar (1988), Franks and Harris (1989)). The usefulness of the Market Model in describing European capital markets has also been emphasised by Hawawini (1984).

The Market Model posits that returns of stocks tend to go up and down together with returns of the market. In other words, the model explains the price movements of one security vis-àvis the price movements of all other securities. Mathematically, the return on a security is linearly related to the return on the market. The relationship is written as:

$$
\mathbb{R}_{\mathrm{it}}=\alpha_{\mathrm{i}}+\beta_{\mathrm{il}} \mathrm{R}_{\mathrm{mt}}+\mathrm{e}_{\mathrm{il}},
$$

where

$R_{i t}=$ the rate of return on security $i$ in period $t$ defined as $\left(P_{t}-P_{t-1}+D_{t}\right) / P_{t-1}$ where $P_{t}$ is the security price at the end of period $t$, and $D_{t}$ is the amount of dividends received at the end of period $t$

$\mathbb{R}_{\mathrm{mt}}=$ the rate of return on the market portfolio in period $t$

$\alpha_{\mathrm{i}}, \beta_{\mathrm{i}}=$ security-i-specific and time-independent parameters

$\mathrm{e}_{\mathrm{it}}=$ random disturbance term for security in period $\mathrm{t}$.

The parameter $\beta_{\mathrm{i}}$ is viewed as an estimate of the systematic risk of security $\mathrm{i}$, and is defined as $\operatorname{Cov}\left(\mathrm{R}_{\mathrm{i}}, \mathrm{R}_{\mathrm{m}}\right) / \operatorname{Var}\left(\mathrm{R}_{\mathrm{m}}\right)$. The model assumes that the random disturbance terms are serially uncorrelated with zero expected values and constant variances. The expected return on security $i$ is then given by:

$$
\mathbb{E}\left(R_{i t}\right)=\alpha_{i}+\beta_{i} E\left(R_{m i}\right)
$$

Thus the model states that, ex ante, the best prediction for the return on security $i$ in period $t$ is simply $\alpha_{i}+\beta_{i} R_{\text {mit }}$. One part of the return on the security, $\beta_{i} \mathbb{E}\left(R_{m t}\right)$, is presumed to be related to market-wide variables, whereas the other part of the return, $\alpha_{i}$, is independent of the market. As Fama (1976) notes, there is no theory behind the Market Model. It is just a statistical description of the return generation process, and any model of equilibrium expected returns must be consistent with it.

Now, having specified the return generating process, we proceed to the next step of measuring the market's reaction to the event under consideration. One could argue that when unexpected firm-specific events occur, these will cause the actual return on the security , $\mathbb{R}_{\text {it, }}$, to be different from the expected return, and it will be reflected in the disturbance term. Thus $\mathrm{e}_{\mathrm{it}}$ is presumed to be due to the effects of factors more specific to the security. So in our case, if suspension of trading of a security is associated with some sort of abnormal behaviour, then this would be reflected in the error term during the period surrounding suspension. Our estimate for the abnormal return (AR) (also termed residual or excess return) for $\mathrm{i}$ in $\mathrm{t}$ will be

$$
A R_{\mathrm{it}}=\mathrm{R}_{\mathrm{it}}-\left(\hat{\alpha}_{\mathrm{it}}+\hat{\beta}_{\mathrm{i}} \mathrm{R}_{\mathrm{mt}}\right)
$$


where $\hat{\alpha}_{i}$ and $\hat{\beta}_{\mathrm{i}}$ are the estimated coefficients obtained from data which exclude observations surrounding the event under examination, and $t$ is a time index covering the period surrounding suspension. Here it is assumed that the coefficients remain unchanged in period $t$ A.R it is interpreted as the deviation in period $t$ of the return of suspended stock $i$ from its normal relationship with the market. The accuracy of this estimated deviation obviously depends upon the validity of the model used as well as the parameter estimates.

Besides finding the excess returns using the Market Model, two other approaches are also used in this study. This is done in order to test whether the model specification could improperly influence the results. The first one is estimating market-adjusted excess retum for each stock. This is done in the following manner:

$$
A R_{\mathrm{it}}=R_{\mathrm{it}}-\mathrm{R}_{\mathrm{mt}}
$$

In this approach there is no special risk adjustment. It is assumed that each security has a $\beta$ equal to one. Behind the assumption of using a beta equal to one rest two ideas. First, one can mistrust the accuracy of $\alpha$ and $\beta$ estimates. Second, the security under consideration is one of many available in the market, and therefore, could be regarded as somewhat similar to the average of all companies. Investors then expect only an average return from such a security.

The second approach to calculating excess returns is simply a variant of the first one. Here each security's $\alpha$ is estimated through regression, but $\beta_{\mathrm{i}}$ is kept equal to one. The equation can be written in the following manner:

$$
A R_{i t}=R_{i t}-\left(\hat{\alpha}_{i}+R_{m i}\right) \text {. }
$$

The idea in this case is to give recognition to each security's specific return characteristics, as for example, size of the firm (Schwert, 1983). (The Market Model does not make prediction regarding the value of $\alpha$; it could be any number).

The above estimates of abnormal returns for the security are unrelated to the general market movements, but closely related to firm-specific events. Suspension of trading could be only one of many other specific events happening at a particular time. Therefore, it is necessary to neutralise the effects of security-specific events other than the event under consideration. And this is done through cross-sectional averaging of the abnormal returns for each period. Such a calculation may be justified on the following grounds. If an event such as trading suspension occurs at different points in time for different companies, then a cross-sectional average of the abnormal returns will be effective in neutralising firm-specific returns unrelated to the event under examination. On the other hand, if the event occurs at one time for all the companies, then the effects of other events may not cancel each other out through averaging, as these have a chance of being dependent on each other. The cross-sectional averages of the abnormal returns (AAR) are calculated by

$$
A A R_{t}=(1 / n) \sum_{i=1}^{n} A R_{i t}
$$

where $\mathrm{AR}_{\mathrm{it}}$ is the abnormal return for security $\mathrm{i}$ in period $\mathrm{t}$, and $\mathrm{n}$ is the number of suspensions in the sample. The estimate AAR gives us an indication of average abnormal return realised by stockholders of suspended firms.

We are interested to see whether these average abnormal returns around the time of

\footnotetext{
However, there exist good reasons to expect this not to be true.
} 
suspension are significantly different from zero returns. If these are indeed statistically significant, then this would indicate the existence of extraordinary gains or losses around trading suspensions. We perform, therefore, a t-test. The t-statistic is obtained by dividing the average abnormal return by its standard error which is equal to the estimation period standard deviation across securities divided by the square root of the number of securities in the sample. It is written as follows:

$$
A A R_{l} /\left(\sigma / n^{1 / 2}\right) \text {. }
$$

We are also interested in examining the cumulative effects of abnormal returns. Therefore, the above averages are cumulated over a period of time surrounding the suspension event in order to obtain the Cumulative Average Abnormal Return (CAAR):

$$
\text { CAAR }=\sum_{t=k}^{1} A_{t=k}
$$

The cumulative reaction of stock prices to trading suspension is investigated by analysing the behaviour of these CAARs.

\subsubsection{Sample Selection}

As mentioned earlier, we collected data from the London Share Price Database which lists only end-of-month trading suspensions. Out of these suspensions we use a working sample consisting of 83 non-randomly selected cases. The following table shows how we select the sample.

Table 4.6

Selection of Working Sample

Total number of suspensions in the database
(Jan. 1970 to Mar 1988 )
less
Suspended securities without a window of at
least 72 monthly observations
less
Other suspensions within the window
Number of Suspensions in the sample

"A detailed overview of event study research as a methodology is provided by Bowman (1983). Insights on potential problems of applying a particular methodology are discussed by Collins and Dent (1984), and Thompson (1985). 
The choice of using a window of six years - three years before and three years after - is made in order to obtain, on the one hand, a reasonable number of trading suspensions in the sample, and on the other hand, allow relatively accurate estimation of the parameters involved. In fact, the use of a six-year history of monthly returns is not unconventional in empirical research. ${ }^{8}$

The 83 trading suspensions included in the sample took place in the period 1970-82, and involved 78 different companies. Of these, $43(55 \%)$ are still listed on the London Stock Exchange. The rest 35 (45\%) firms disappeared from stock exchange listing, but after at least three years of trading. Out of these 35 disappeared companies, 24 were due to mergers and acquisitions, and 8 were due to liquidation. Our sample of trading suspensions has only five companies with suspension taking place twice. A total of 73 firms experienced suspension on only one occasion. Conceming the duration of trading suspension in the sample, we find that $20 \%$ lasted for more than six months. Another unique characteristic is that $75(90 \%)$ of these trading suspensions occurred in case of firms with less than five million pounds sterling of market capitalisation. Only 8 suspensions took place for companies with a capitalisation of more than five million pounds. Trading suspension tends to occur most frequently in the case of small firms. Although one may not think of any direct relationship between some reasons for trading suspension (like corporate news announcement, publication of particulars on reorganisation, lifting of suspension on an overseas stock exchange) and the size of a firm, it is possible that small firms are more vulnerable to other reasons (like mergers and acquisitions, insider trading).

\subsection{EMPIRICAL RESULTS}

The following paragraphs provide the results obtained from the methodologies described earlier. As mentioned, we use monthly retums data with a window of six years. ${ }^{ \pm 0}$ Parameters are estimated by regressing individual stock returns on the market returns using the ordinary least squares technique. The returns are continuously compounded returns, and are adjusted for dividend payments and capital structure changes. The data we use exclude those around trading suspensions. Estimates of abnormal returns are obtained for months -5 to +5 , and then the cumulative abnormal returns are calculated. We define month 0 as the month in which a trading suspension occurs. Month -1 represents one month immediately before the month in which trading suspension takes place, while month +1 represents one month after the month in which trading is reinstated. The return on the Financial Times - Actuaries All Share Index, a market value-weighted arithmetic index covering around 750 stocks and over $80 \%$ of the aggregate UK capitalisation, is used to calculate the market return.

\subsubsection{Market Model}

The results obtained from the Market Model are presented in table 4.7. The sample includes all 83 trading suspensions. The estimated abnormal returns are also shown graphically in figure 4.1. We observe that there is a continuous upward trend in the cumulative abnormal return before suspension. The average abnormal returns for the group of suspended securities are all

\footnotetext{
For example, Dimson and Marsh (1986), Beckers (1988), Franks and Harris (1989) use 60 morths data for parameter estimation.

The period ends in 1982 because we need to have at least 36 monthly observations after suspension for parameters estimation.

the use of monthly data is justified considering the long-term nature of trading suspensions in the sample.
} 
positive in the five months before suspension. These abnormal returns are also statistically significant in all five pre-suspension months. It is particularly noteworthy that in each of the wo consecutive months before trading suspension significant large abnormal returns of $5-6 \%$ on average are obtained. This indicates that something extra-ordinary was going on in the market. This could suggest that some investors were already anticipating positive news about the security in the pre-suspension period, or that insider trading was taking place. The existence of pre-suspension abnormal returns also suggests that the action of exchange authorities came late. By the tome trading was suspended the stock prices had already increased by 19\%. It appears that the stock exchange authority becomes conscious of some abnormal happening and then considers taking the suspension measure once it finds out that the share concemed had undergone a substantial price increase, or that gradual release of new information had already started.

Table 4.7

Average Abnormal Returns Around Trading Suspensions; $($ sample size $=83$ )

\begin{tabular}{|c|c|c|c|c|c|c|c|}
\hline Month & $A A R$ & $t(A A R)$ & CAAR & Month & $A A R$ & $t(\mathrm{AAR})$ & CAAR \\
\hline-5 & 0.007 & $2.382^{*}$ & 0.007 & +1 & 0.110 & $34.833^{*}$ & 0.110 \\
\hline-4 & 0.039 & $12,302^{*}$ & 0.046 & +2 & -0.025 & $-8.019 *$ & 0.085 \\
\hline-3 & 0,025 & $7895^{\circ}$ & 0,071 & +3 & 0.010 & $3.261^{*}$ & 0.095 \\
\hline-2 & 0.063 & $20.039 *$ & 0.134 & +4 & -0.002 & -0.606 & 0.093 \\
\hline-1 & 0.054 & $17.177^{*}$ & 0.188 & +5 & 0.017 & $5.447^{*}$ & 0.110 \\
\hline
\end{tabular}

Asterisk indicates significance at the $5 \%$ level.

After the suspension period, as trading of securities is reinstated, a more noteworthy event takes place. Stock prices shoot up, on average, by as much as $11 \%$ in the first month of post suspension trading. This could indicate that even though new information might have been released during the suspension period, it was not widely disseminated among all the investors. The very purpose of trading suspension - ensuring equitable information dissemination among all investors so that opportunities for some to earn extraordinary profits disappear - seems not to be achieved. The presence of large abnormal returns in the month immediately following trading suspension could also suggest inefficient lagged adjustment to new information released during the suspension period. Suspensions could also be considered as a signalling mechanism through which information about the future is communicated. There is also some evidence of overreaction on the trading suspension event during the first post-suspension month, as we observe a significantly negative average abnormal return in month $+2 .{ }^{\text {.1 }}$

"A substantial increase in the variance of returns around event period takes place (see appendix 4.B). The most obvious implication of this is that the procedure followed in performing t-tests will result in more frequent rejection of the null hypothesis. 
Figure 4.1

Average abnormal returns (upper panel) and cumulative abnormal returns (lower panel) around trading suspension (Market Model Returns)
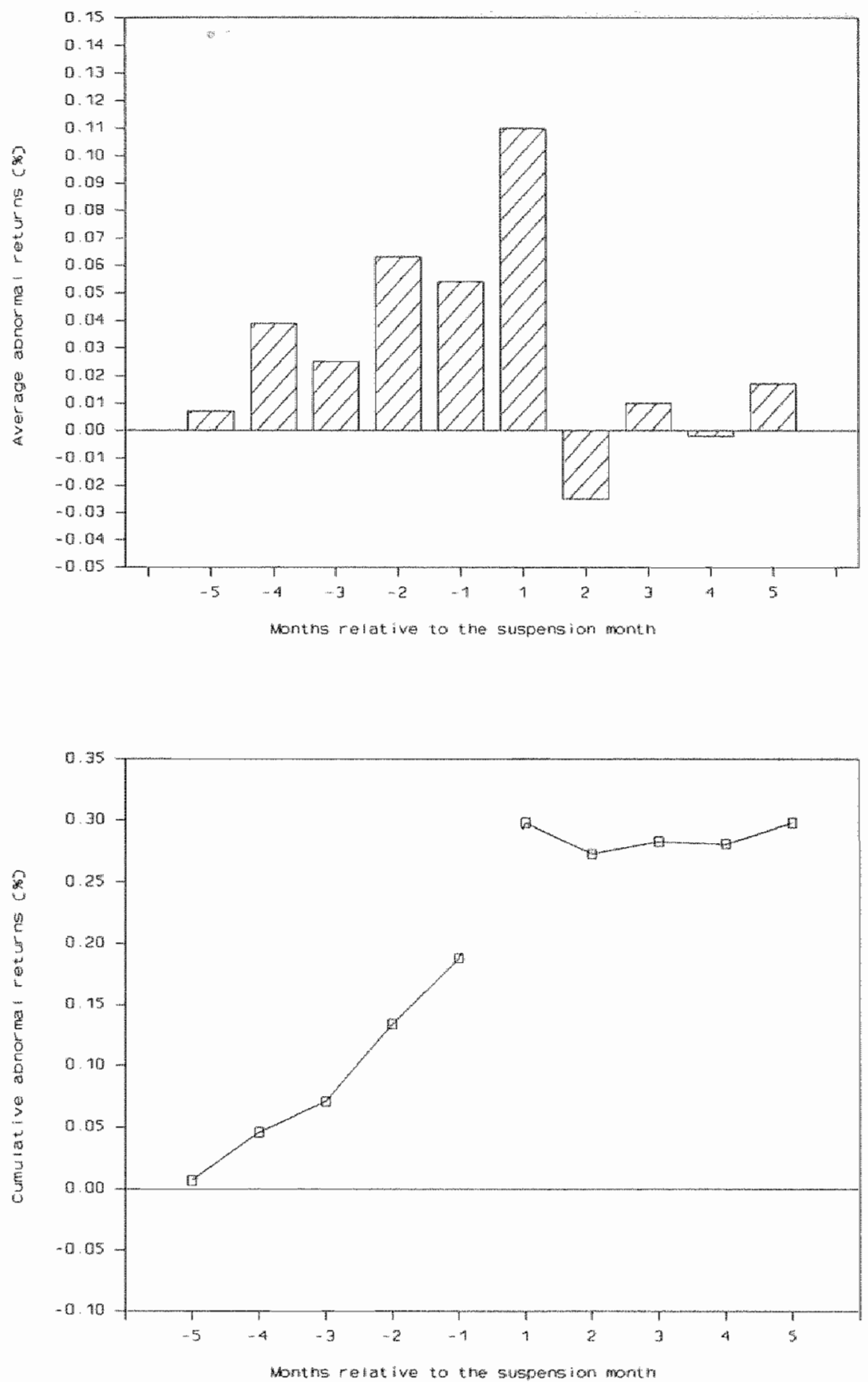


\subsubsection{Market Adjusted Model}

In order to see whether the above findings are influenced by the Market Model specifications, the performance of stocks around the time of trading suspension are also analysed using the market-adjusted returns. The results, presented in table 4.8 , are similar to those obtained from the Market Model. One earns significant positive excess returns before trading suspension, and in the month following reinstatement of trading a more pronounced rise in excess return is detected.

Table 4.8

Average Abnormal Returns Around Trading Suspensions; (Sample size $=83)^{\mathrm{a}}$

\begin{tabular}{cccccccc}
\hline Month AAR t(AAR) CAAR & Month & AAR & t(AAR) & CAAR \\
\hline-5 & 0.012 & $-3.647^{*}$ & -0.012 & +1 & 0.099 & $31.208^{*}$ & 0.099 \\
-4 & 0.027 & $8.551^{*}$ & 0.015 & +2 & -0.032 & $-10.009 *$ & 0.067 \\
3 & 0.007 & $2.221^{*}$ & 0.022 & +3 & 0.002 & 0.613 & 0.069 \\
2 & 0.055 & $17.140^{*}$ & 0.077 & +4 & -0.008 & $-2.535^{*}$ & 0.061 \\
1 & 0.043 & $13.631^{*}$ & 0.120 & +5 & 0.010 & $3.233^{*}$ & 0.071 \\
\hline
\end{tabular}

Asterisk indicates significance at the $5 \%$ level. 
Figure 4.2

Average abnormal returns (upper panel) and cumulative abnormal retums (lower panel) around trading suspension (Market-Adjusted Returns)
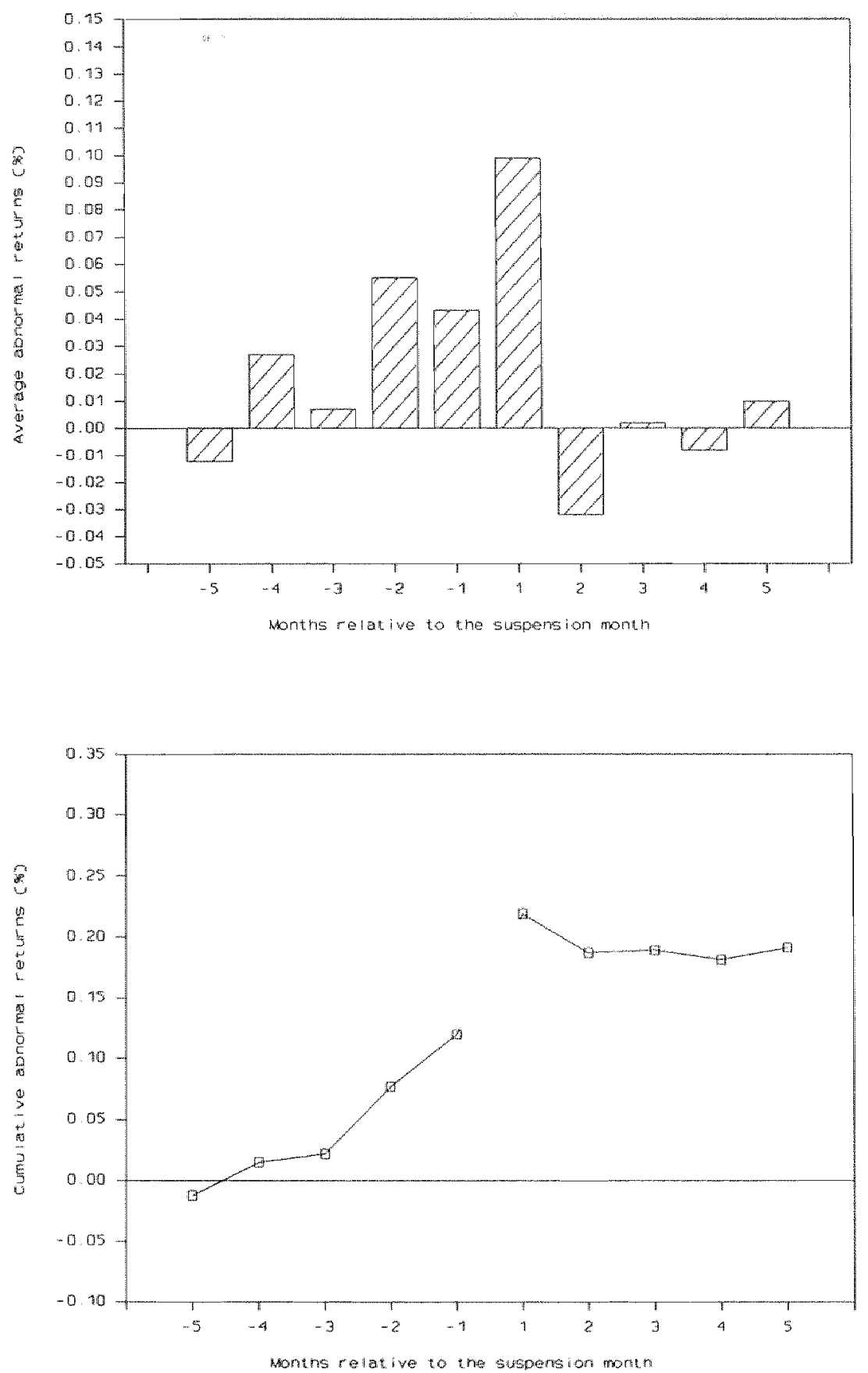


\subsubsection{Retums from Estimated Alpha}

Our analysis continues to check the robustness of the model used. We estimate the $\alpha$ coefficient for each stock from the usual regression, but now assume that the stocks in our sample have average risk $(\beta=1)$. The abnornal returns estimated are presented in table 4.9 , and plotted in figure 4.3. Once again, the findings are qualitatively similar to the previous ones. Significant positive abnormal returns occur in months immediately surrounding trading suspersion suggesting that the action taken by the Exchange authorities comes late, and equitable information dissemination during the time of suspension does not take place.

Table 4.9

Average Abnormal Returns Around Trading Suspensions

$(\alpha \text { estimated, } \beta=1 \text {; Sample size }=83)^{\mathrm{a}}$

\begin{tabular}{|c|c|c|c|c|c|c|c|}
\hline Month & AAR & $t(A A R)$ & CAAR & Month & AAR & $t(A \mathbb{R})$ & CAAR \\
\hline-5 & $-0,005$ & -1.691 & 0.005 & +1 & 0.106 & 32.922 * & 0.106 \\
\hline 4 & 0.033 & $10.421 *$ & 0.028 & +2 & -0.026 & $-8.012 *$ & 0.080 \\
\hline-3 & 0,013 & $4.137^{*}$ & 0.041 & +3 & 0.008 & $2.540^{*}$ & 0.088 \\
\hline-2 & 0.061 & $18.951^{*}$ & 0.102 & +4 & -0.002 & -0.590 & 0.086 \\
\hline-1 & 0.050 & $15.466^{*}$ & 0.152 & +5 & 0.016 & $5.139 *$ & 0.102 \\
\hline
\end{tabular}

${ }^{a}$ Asterisk indicates significance at the $5 \%$ level. 
Figure 4.3

Average abnormal retums (upper panel) and cumulative abnormal returns (lower panel) around trading suspension (Returns from Estimated Alpha)
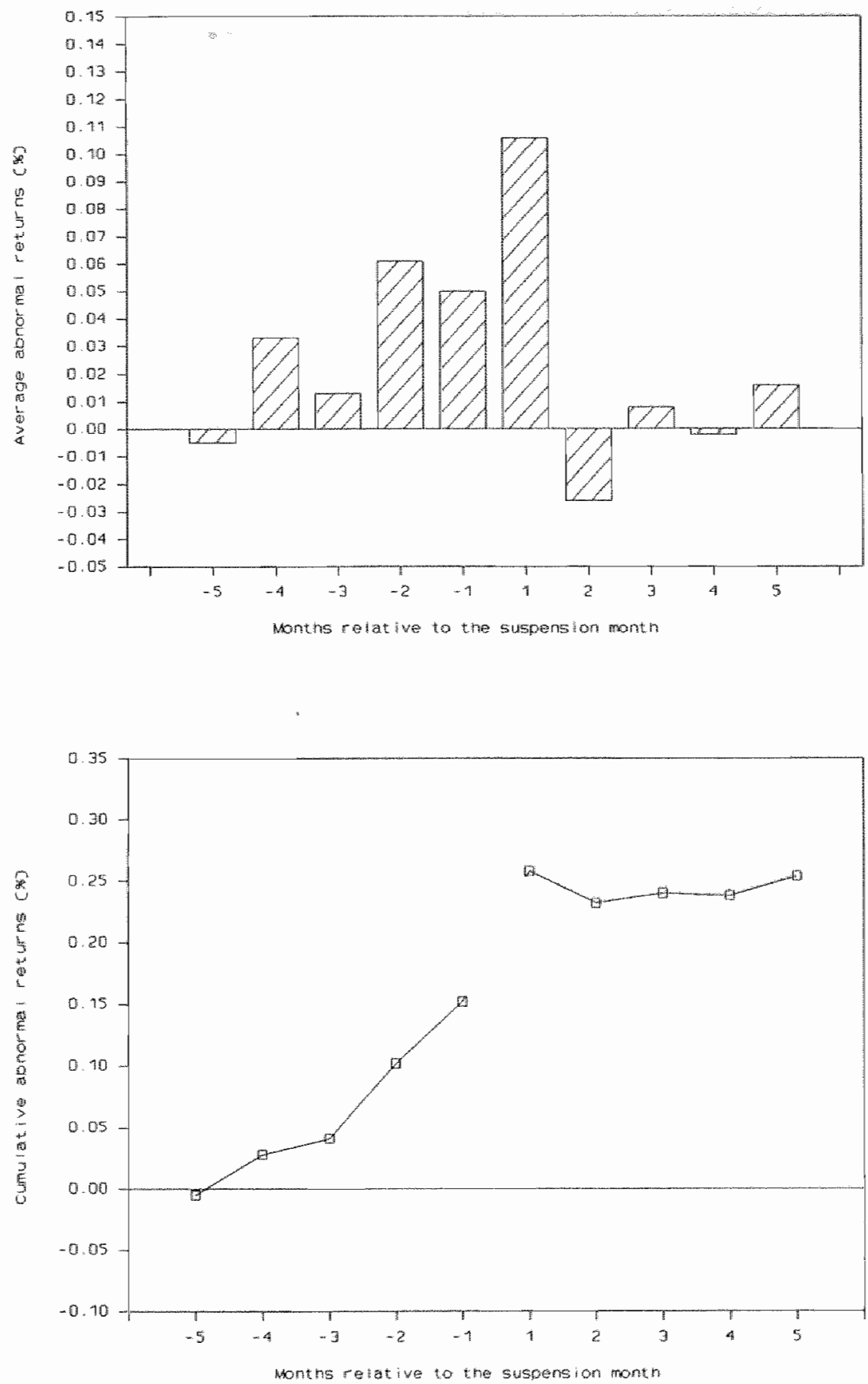


\subsubsection{Non-Merger Sample}

One may point out that the sample of trading suspensions contains an unusually large number of furms which are inwolved in merger and acquisition activities. In fact, there were 24 firms in our sample of 78 which disappeared from the stock exchange listing at a later stage due to merger/acquisition. One would then be inclined to think that the abnormal returns found in our. analysis could perhaps be due to the anticipation of future merger and/or acquisition. Therefore, in order to eliminate such an obvious abnormal return tendency, we eliminate all trading suspensions related to these 24 firms from our initial sample. The analysis is then carried out for a sample consisting of 55 trading suspensions. Here we should mention that those 24 firms had their securities traded for at least another three years. It is highly unlikely that share prices start showing abnormal behaviour more than 36 months before any merger or acquisition really takes place. Nevertheless, we analyse the sample to eliminate any remaining doubts. We use the Market Model to estimate parameters, and the results obtained are presented in table 4.10. We find that the earlier conclusions are not changed at all. (The estimated abnormal return in the month following the suspension month is even higher compared to the previous cases).

Table 4.10

Average Abnormal Returns Around Trading Suspensions (Sample size $=55$ )

\begin{tabular}{cccccccc}
\hline Month AAR t(AAR) CAAR & Month & AAR & t(AAR) & CAAR \\
\hline-5 & -0.002 & -0.569 & -0.002 & +1 & 0.129 & $32.587 *$ & 0.129 \\
-4 & 0.053 & $13.458^{*}$ & 0.051 & +2 & -0.039 & $-9.762^{*}$ & 0.090 \\
-3 & 0.022 & $5.422^{*}$ & 0.073 & +3 & -0.001 & -0.138 & 0.089 \\
-2 & 0.065 & $16.456^{*}$ & 0.138 & +4 & -0.008 & $-2.019 *$ & 0.081 \\
-1 & 0.020 & $5.057^{*}$ & 0.158 & +5 & 0.019 & $4.803^{*}$ & 0.100 \\
\hline
\end{tabular}

asterisk indicates significance at the $5 \%$ level. 
Figure 4.4

Average abnormal returns (upper panel) and cumulative abnormal retums (lower panel) around trading suspension (Non-Merger Sample)
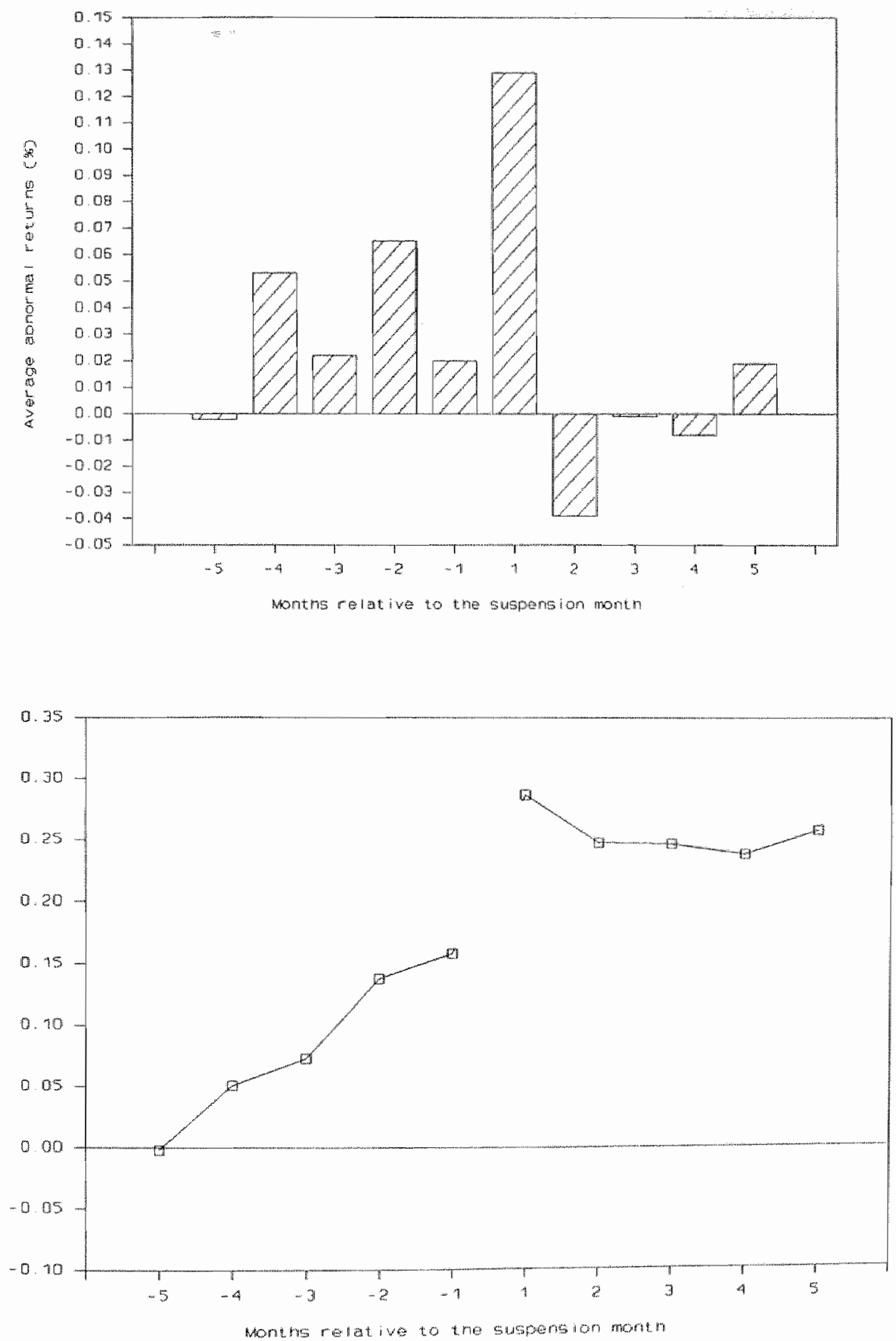


\subsubsection{Infrequent Troding}

When shares are traded infrequently on a stock exchange, standard measurement of the riskiness of these shares is subject to bias, and therefore, the return on such shares is not measured accurately. The relatively infrequently traded shares have a downward biased systematic risk, while those traded relatively frequently have upward biased estimates." Several methods of calculating unbiased estimates of stock betas have been suggested in the literature. We employ in this study the two most widely used methods as proposed by Scholes and Williams (1977) and Dimson (1979). Here it should be mentioned that the use of monthly data involwes less problems compared to the use of daily data in which case infrequent share trading could be a severe problem.

According to Scholes and Williams (1977), by regressing the returns on a security against market returns from the previous, current, and subsequent periods, and then dividing the sum of the three coefficients by one plus twice the autocorrelation of the market returns, one can obtain an unbiased estimator of beta. Mathematically, one can write:

$$
\mathrm{B}_{\mathrm{i}}=\underset{n=-1}{\stackrel{+1}{ \pm} \mathrm{b}_{\mathrm{i}, \mathrm{n}}} /\left(1+2 \rho_{\mathrm{m}}\right)
$$

where

$\mathrm{B}_{\mathrm{i}} \quad$ = estimate of true beta of security $\mathrm{i}$

$b_{i, n}=$ observed security beta in period $n$

$\rho_{\mathrm{m}}=$ market autocorrelation coefficient.

On the other hand, Dimson's (1979) suggestion to estimate beta involves simultaneously regressing the security returns against lagged, matching and leading market returns, and then aggregating the slope coefficients. In other words, the Dimson estimator is:

$$
B_{i}=\sum_{n=0}^{1} b_{i, n}
$$

where the notation is the same as before.

The similarity of this estimator with that of the Scholes-Williams is that both prescribe the introduction of lagged and leading terms into the Market Model. On the other hand, the principal differences are that the Dinson beta is estimated simultaneously using multiple regression while the Scholes-Williams beta is estimated independently, and that the former estimator uses multiperiod leads and lags while the latter is restricted to one period only. Following Dimson's suggestion that with montllly U.K. data one leading and several lagged market terms are needed if risk measures are to take account of infrequent trading, we use one lead and three lags in our estimation of Dimson beta.

Our separate estimation of systematic risk produces the following result: while the average beta obtained from the simple regression method is 0.58 , that from using the Scholes-Williams procedure and the Dimson method is 0.56 and 0.76 , respectively (see appendix 4.C). Using both Scholes-Williams betas and Dimson betas, we once again obtain the Market Model returns for our sample of 83 trading suspensions. These returns are presented in table 4.11 .

The upward bias follows because the mean beta of all securities is by definition unity (Dimson, 1979). 
Table 4.11

Average Abnormal Returns Around Trading Suspensions (Sample size $=83)^{\mathrm{a}}$

\begin{tabular}{|c|c|c|c|c|c|c|}
\hline Month & $\begin{array}{l}\text { A Schole } \\
\text { AAR }\end{array}$ & $\begin{array}{l}\text { es Willam } \\
\qquad(A A R)\end{array}$ & $\begin{array}{l}\text { Method } \\
\text { CAAR }\end{array}$ & AAR & $t(A A R)$ & CAAR \\
\hline-5 & 0.007 & $2.215^{*}$ & 0.007 & 0.000 & 0.000 & 0.000 \\
\hline-4 & 0.040 & $12,469 \%$ & 0.047 & 0.040 & 12.484 & 0.040 \\
\hline-3 & 0.021 & $6.465 \%$ & 0.068 & 0.021 & $6.757 *$ & 0.061 \\
\hline-2 & 0.060 & $18,921 *$ & 0.128 & 0.059 & 18.397 & 0.120 \\
\hline-1 & 0.054 & $16.996^{*}$ & 0.182 & 0.059 & $18.412^{*}$ & 0.179 \\
\hline+1 & 0.109 & $34,362^{\circ}$ & 0.109 & 0.108 & $33.878^{*}$ & 0.108 \\
\hline+2 & -0.024 & $-7.489 *$ & 0.085 & -0.028 & -8.790 & 0,080 \\
\hline+3 & 0.008 & $2.375 *$ & 0.093 & 0.010 & $3.195 *$ & 0.090 \\
\hline+4 & -0.002 & 0.757 & 0.091 & -0.007 & $-2.058^{*}$ & 0.083 \\
\hline+5 & 0.016 & $4.951 *$ & 0.107 & 0.018 & 5.714 & 0.101 \\
\hline
\end{tabular}

Asterisk indicates significance at the $5 \%$ level.

The previously obtained findings are confirmed as there is little change in the estimated abnormal returns. Trading suspensions are associated with significant positive abnormal returns. Within a span of four trading months, starting from two months prior to the suspension month until one month after the month of trading reinstatement, some investors were able to earn a total return of $22 \%$. The magnitude of abnormal returns decreases to a large extent, as found earlier, from the third post-suspension month.

\subsubsection{Daily Analysis}

Besides using monthly returns, we computed daily returns to analyse short-term behaviours surrounding trading suspension. Since no such returns file was available, daily closing prices were collected from the Financial Times, and thus, share returns were computed for a period of ten days before and ten days after each trading suspension. These prices were adjusted for dividends and capital changes, if any. It was possible to calculate returns for 44 suspensions only. The sample has now become smaller because share prices of many firms were not found in the Financial Times. They were either not reported, or company name has changed since then, or a complete price history was difficult to obtain. 
Figure 4.5

Average abnormal returns (upper panel) and cumulative abnormal returns (lower panel) around trading suspension (Scholes-Williams Method)
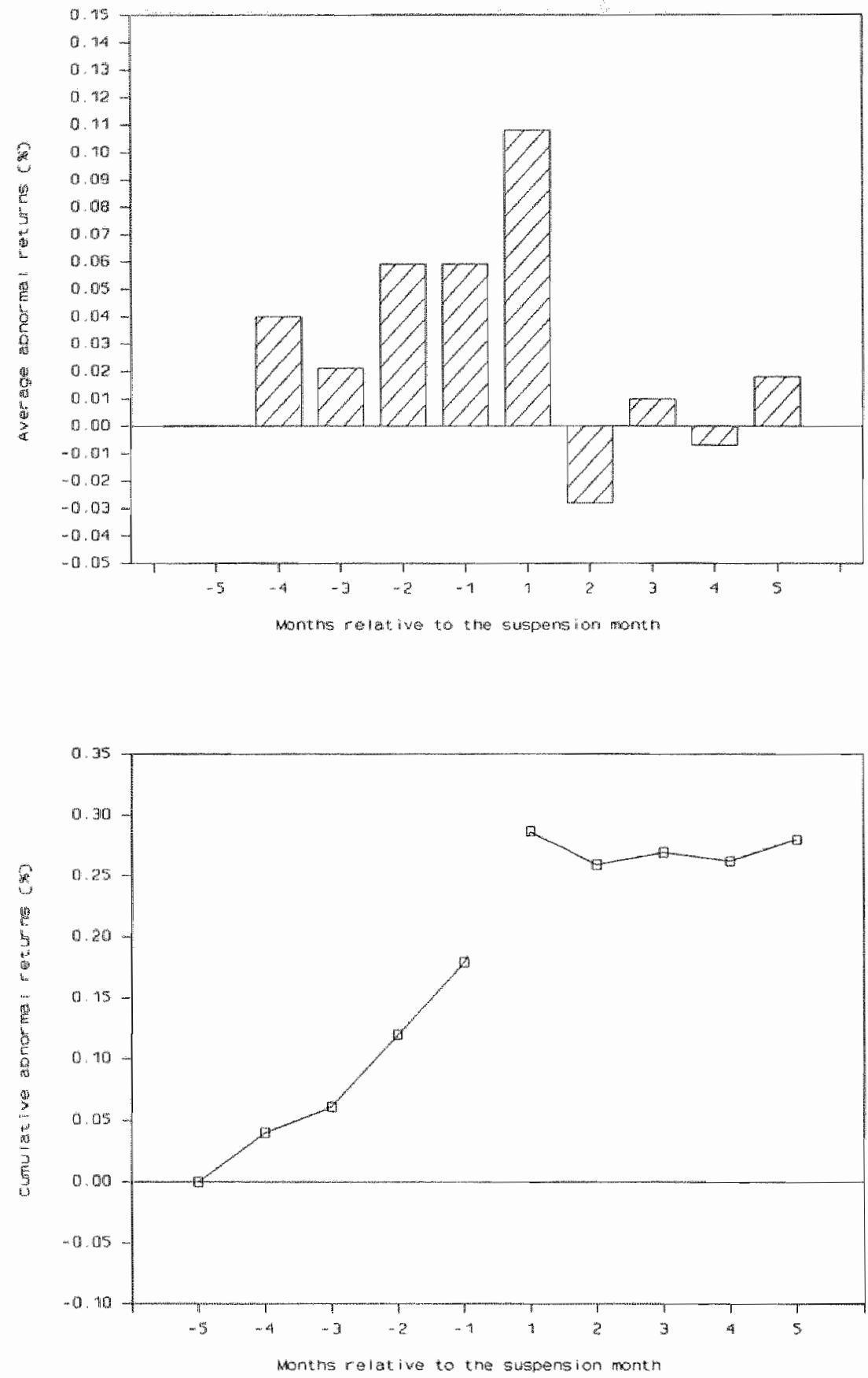
Figure 4.6

Average abnormal retums (upper panel) and cumulative abnormal retums (lower panel) around trading suspension (Dimson Method)
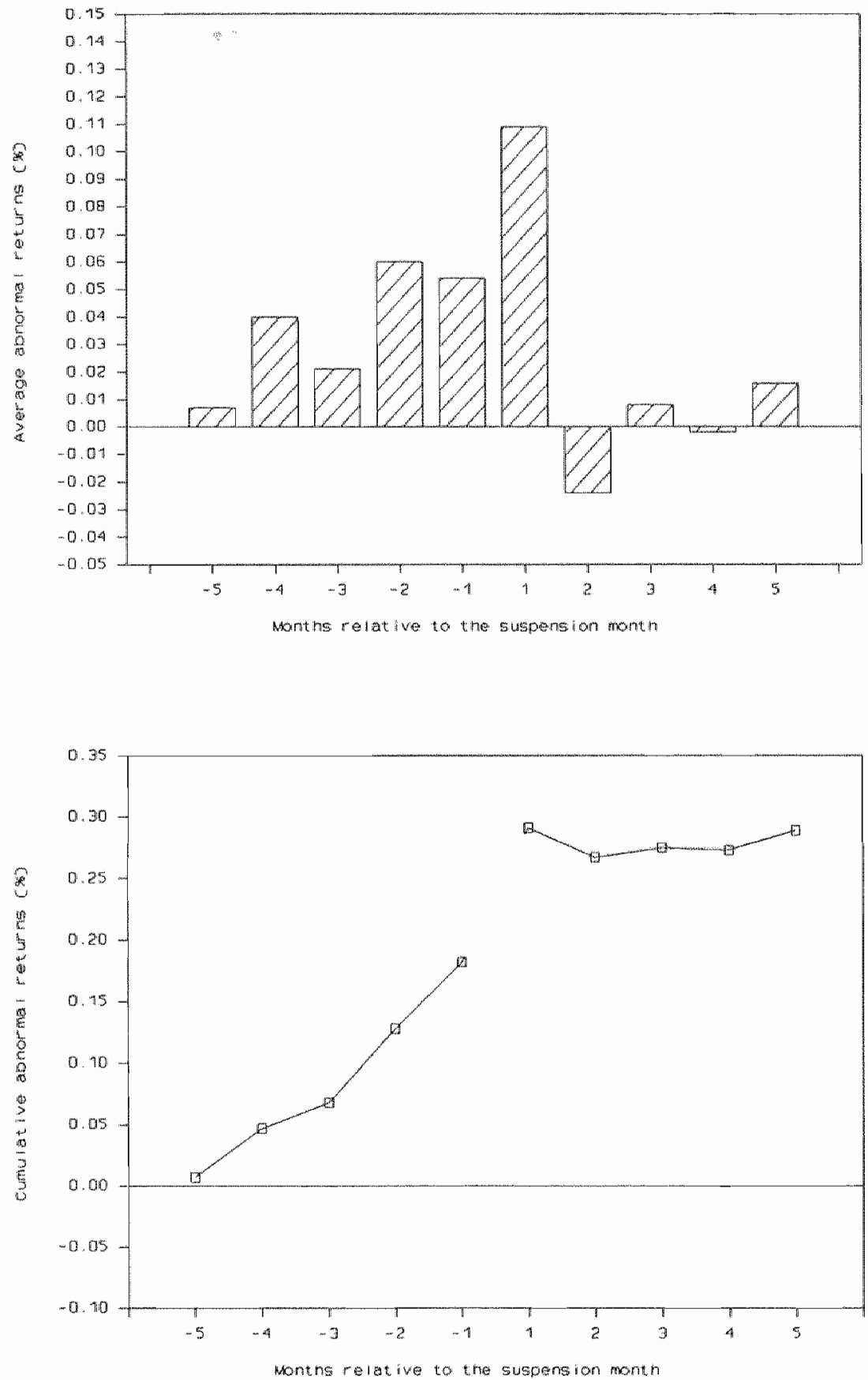
Market-adjusted abnormal returns are estimated for ten days surrounding each trading suspension, and the average of these abnormal returns are presented in table 4.12 . We observe that shareholders of the suspended companies earn abnormal positive returns before trading is suspended. During ten days before suspension, shareholders earn a cumulative abnormal return of 10.6 per cent. The pre-suspension positive abnormal returns indicate that much of the share price adjustment already takes place before the act of suspension. This conclusion is consistent with our findings from the monthly data. The suspended securities also experience a positive abnormal return over the suspension period. This suggests that new as well as favourable information was released during the period of suspension. Analysing the short-term price behaviours in the post-suspension days, we observe that an efficient share price adjustment to new information has taken place. The average abnormal returns for days +1 to +10 are all close to zero.

Table 4.12

Average Abnormal Returns Around Trading

Suspensions (Daily data, Sample size $=44$ )

\begin{tabular}{ccc}
\hline Period & AAR & CAAR \\
\hline 10 & 0.011 & 0.011 \\
-9 & 0.007 & 0.018 \\
-8 & 0.015 & 0.033 \\
\hline 7 & 0.010 & 0.043 \\
-6 & 0.002 & 0.045 \\
-5 & 0.007 & 0.052 \\
4 & 0.021 & 0.073 \\
3 & 0.012 & 0.085 \\
2 & 0.012 & 0.097 \\
1 & 0.009 & 0.106 \\
0 & 0.047 & 0.153 \\
+1 & 0.001 & 0.154 \\
+2 & 0.005 & 0.159 \\
+3 & 0.000 & 0.159 \\
+4 & -0.007 & 0.152 \\
+5 & 0.002 & 0.154 \\
+6 & 0.006 & 0.160 \\
+7 & -0.006 & 0.154 \\
+8 & 0.003 & 0.154 \\
+9 & 0.004 & 0.155 \\
+10 & -0.006 & 0.149 \\
\hline & & \\
\hline
\end{tabular}

Although this observation is somewhat contrary to the findings from monthly data, we have to keep in mind that here we are analysing a sub-sample of 44 suspensions (out of 83). Share price behaviour taking place subsequent to day +10 will probably lead to a different conclusion. ${ }^{15}$

${ }^{13}$ The econometric trade-offs of using daily versus monthly data are investigated by Morse (1984), Brown and Warner (1985). 
Fugure 4.7

Average abnormal retums (upper panel) and cumulative abnormal returns (lower panel) around trading suspension (Daily Sample)

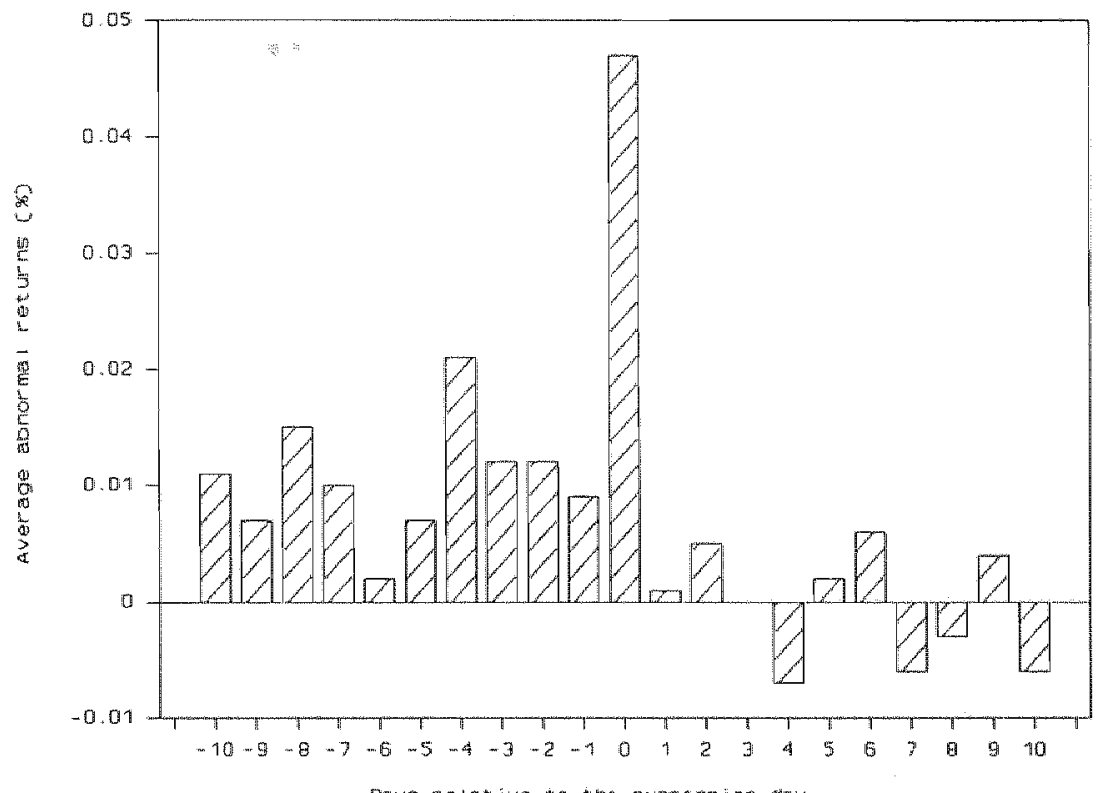

Days relatiwe to the suspens hon deay

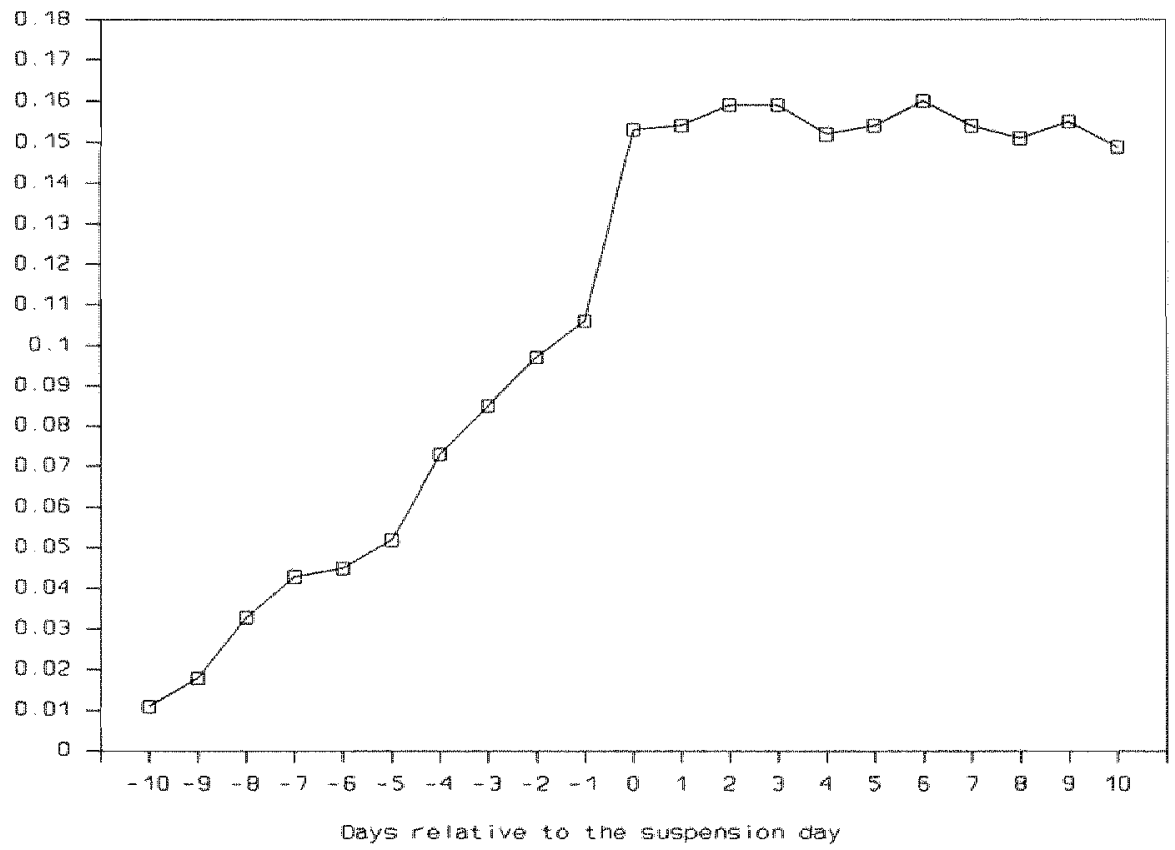




\subsubsection{Small Firm Effect}

It has been mentioned earlier that most of the firms included in our sample had a market capitalisation of less than 5 million pounds at the time of suspension. One would perhaps then feel the need of making small firm adjustment in our analysis because of the common belief that smaller flims tend to show positive abnormal returns in comparison with larger firms (See Dirnson and Marsh (1989) for various explanations for the performance of smaller companies). We feel that here such adjustment is not warranted. The size effect does not seem to prompt abnormal returns found in this study. Our reasoning is based on the following considerations.

Although the small firm effect has been well documented, Lakonishok (1988) expresses reservations about the idea that one should always make an adjustment for size. He points out that whether to perform the adjustment or not depends on the extent to which size was a decision variable. In case of trading suspensions we do not think that firm size plays an important role in stock exchange's decision to suspend trading. Besides this a priori reasoning we have three other motives for not making any size adjustment in our analysis.

The first comes from the empirical fact that the abnormal performance of small firms is particularly prevalent at the turns of the week (Keim and Stambaugh, 1984) and of the year (Keim, 1983). The results of Keim and Stambaugh indicate that the smaller the firm the greater is the tendency for average returns to be high on Friday. According to Keim, almost half of the average magnitude of the size effect is due to January abnormal returns, and more than half of the January premium is attributable to large abnormal returns during the first week of trading. The seasonal phenomenon of size effect in case of firms listed on the London Stock Exchange has been verified by Corhay, Hawawini and Michel (1988) and Levis (1985). Both studies find small firms earning a significant positive abnormal returns especially in May. Compared to these findings, our sample of trading suspensions does not at all indicate that suspensions are clustered in a particular time period. These are evenly spread over the months of the year. So we do not expect size variable to contribute significantly to the abnormal returns found in this study.

Secondly, it is generally believed that small firms are "riskier" than large firms, and therefore, have higher expected returns. But this is surprisingly not the case for firms listed on the London Stock Exchange. The average systematic risk estimated from our sample is well below one (it is 0.56 when Scholes-Williams thin trading adjustment method is used, and 0.76 when Dimson method is used). Smaller betas associated with smaller firms on the London Stock Exchange are also reported by Corhay et al. (1988) and Levis (1985).

Thirdly, it has been suggested that the small firm prenium comes from improper risk estimation. Roll (1981) conjectures that the apparent abnormal return for small firms might be attributed to improperly estimated systematic risk caused by trading infrequency. Thus, when the risks of small firms are adjusted for infrequent trading, the magnitude of the size effect decreases. In our work we already perform such an adjustment, and still find the presence of abnormal returns. Based on all these considerations, we conclude that the positive abnormal returns associated with trading suspensions on the LSE can not be attributed to the small firm phenomenon.

\subsection{CONCLUSIONS}

In this chapter we analysed the phenomenon of trading suspensions on the London Stock Exchange. Our purpose is to see how effective this measure is by investigating price behaviour of the concerned securities. Since during the period of suspension no trading in the security takes place, our interest lies especially in price behaviour surrounding this period. The study uses monthly as well as dailly returns data of 83 and 44 trading suspensions, respectively occurring on the London Stock Exchange. 
The results obtained from the study lead to the following conclusions. First, suspension of securities trading is preceded by a substantial increase in share price. The positive trend in abnormal returns is independent of monthly or daily data, or any particular model used, although the magnitude of these returns obviously waries slightly. Second, this study detects the presence of significant positive abnormal retum in the month immediatelly following the trading suspension month. The finding casts doubt on the belief that trading suspension uitimately improves market efficiency by making possible wide dissemination of information among all investors. Although this seems to happen in very short term once trading starts again (as we see from daily data), the results from using monthly data indicate otherwise. There we find that investors do earn abnormal returns following the suspension period - an indication of the fact that the market did not fully incorporate all information during the first days after suspension. It also indicates that either the complete impact of new information release - even after a suspension period of several months - takes place only gradually (a phenomenon hard to explain in an efficient market context), or not all relevant information is disclosed during the suspension period. Third, trading suspensions on the London Stock Exchange coincide, on average, with the dissemination of favourable information. We observe the occurrence of this event being preceded by share price increases, and positive news, on average, being conveyed to the investors during the period of suspension.

It may be useful to compare the evidence presented here with that from other work. ${ }^{14}$ On stock exchanges in the United Kingdom, the United States and Canada, large abnormal returns are earned in the pre-suspension period. This perhaps reflects, on the one hand, the sophistication of market participants in these exchanges, and on the other hand, the ill-equipped nature of decision making leading to suspension of security trading. The evidence is unequivocal as far as the release of new information during the suspension period is concerned: share price adjusts in response to the new information. The direction of adjustment depends whether the information is favourable or not. But the evidence is obscure as to the share price behavior in the post-suspension period. Both efficient as well as inefficient stock market reactions have been detected. Since, as mentioned by Hopewell and Schwartz (1978), efficient adjustment might have occurred even without suspension or with suspensions of shorter duration, we are hesitant to endorse the administration of trading suspensions.

${ }^{14}$ Comparison with the Amsterdam Stock Exchange will be made in chapter five. 
Appendix 4.A

Sumniary Statistics from the Market Model

\begin{tabular}{|c|c|c|c|c|c|c|}
\hline Number & 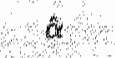 & $t(\alpha)$ & $B$ & $t(\beta)$ & $\overline{\mathbf{R}}^{2}$ & DW \\
\hline 1 & 0.021 & -1.085 & 0,409 & 2.044 & 0,050 & 2.172 \\
\hline 2 & -0.015 & 00486 & 0.607 & 1.868 & 0.039 & 2.113 \\
\hline 3 & 0.020 & -1.236 & 1.115 & 6.400 & 0.396 & 1.935 \\
\hline 4 & 0.006 & -0.363 & 0.841 & 0.457 & 0.001 & 2.667 \\
\hline 5 & $-0,068$ & -2.412 & 1.591 & 3.348 & 0.143 & 1.577 \\
\hline 6 & 0.037 & 0.633 & 0.697 & 0.737 & 0.008 & 2.869 \\
\hline 7 & 0,003 & 0.213 & 0.736 & 2.516 & 0.080 & 1.972 \\
\hline 8 & 0.026 & 0.991 & 1.217 & 4.482 & 0.238 & 2.279 \\
\hline 9 & 0.020 & 1.758 & 0.268 & 1.145 & 0.005 & 1.714 \\
\hline 10 & -0.005 & -0.106 & 0.119 & 0.158 & 0.016 & 3.196 \\
\hline $11 \%$ & 0.004 & 0.303 & 1.222 & 4.953 & 0.278 & 1.662 \\
\hline 12 & -0.011 & 0.839 & 1.186 & 5.727 & 0.343 & 2.228 \\
\hline 13 & -0.034 & -1.372 & 0.476 & 1.745 & 0,032 & 2.529 \\
\hline 14 & 0,001 & 0.070 & 0.397 & 1.203 & 0.007 & 1.857 \\
\hline 15 & -0.026 & -1.198 & 1.127 & 4.991 & 0.282 & 2.241 \\
\hline 16 & -0.026 & -2.252 & 1.238 & 5.537 & 0.327 & 1.820 \\
\hline 17 & 0,002 & 0.126 & 0.701 & 2.562 & 0.084 & 1.937 \\
\hline 18 & 0.012 & 0.356 & 0.418 & 0.790 & -0.006 & 2.709 \\
\hline 19 & 0.030 & 1.161 & 0.354 & 0.896 & -0.003 & 2.542 \\
\hline 20 & -0.014 & 0.802 & 0.323 & 1.150 & 0.005 & 1.881 \\
\hline 21 & 0.002 & -0.138 & 0.919 & 3.459 & 0.152 & 1.984 \\
\hline 22 & 0.003 & 0.273 & 0.106 & 0.783 & 0.006 & 2.426 \\
\hline 23 & 0010 & 0.570 & 0.985 & 3.892 & 0.188 & 2.560 \\
\hline 24 & 0.001 & 0,030 & 1.142 & 4.553 & 0.244 & 2.071 \\
\hline 25 & 0.028 & 1.846 & 0.063 & 0.359 & -0.014 & 2.229 \\
\hline 26 & -0.004 & 0.139 & 0.823 & 2.678 & 0.092 & 2.256 \\
\hline 27 & 0.038 & 2.062 & -0.243 & -0.673 & -0.009 & 2.812 \\
\hline 28 & -0.003 & -0.159 & 1.001 & 4.697 & 0.257 & 2.681 \\
\hline 29 & 0.014 & 0.451 & 0.228 & 0.391 & -0.014 & 2.323 \\
\hline 30 & -0.002 & -0.048 & 0.400 & 1.046 & 0.002 & 2.223 \\
\hline 31 & -0.001 & -0.076 & .0 .073 & -0.424 & -0.014 & 2.038 \\
\hline 32 & 0.021 & 1.129 & 0.633 & 1.733 & 0.032 & 1.984 \\
\hline 33 & 0.010 & 0.639 & 0.370 & 1.147 & 0.005 & 1.533 \\
\hline 34 & -0.004 & -0.181 & 0.689 & 2.666 & 0.091 & 1.952 \\
\hline 35 & -0.017 & 0.781 & -0.427 & -1.910 & 0.042 & 1.813 \\
\hline 36 & 0.011 & 0.675 & 0.247 & 1.445 & 0.018 & 1.948 \\
\hline 37 & -0.003 & -0.102 & 0.172 & 0.609 & -0.010 & 2.144 \\
\hline 38 & 0.003 & 0.154 & 0.488 & 1.279 & 0.010 & 2.163 \\
\hline 39 & 0.004 & 0.150 & 0.560 & 1.237 & 0.025 & 0.009 \\
\hline 40 & -0.061 & -2.125 & -0.142 & -0.472 & -0.013 & 2.062 \\
\hline
\end{tabular}


(Appendir 4.A, continued)

\begin{tabular}{|c|c|c|c|c|c|c|}
\hline Number & $\alpha$ & $\mathrm{t}(\sigma)$ & $\beta$ & $t(\beta)$ & $\mathrm{R}^{2}$ & DW \\
\hline 41 & 0.004 & 0.295 & 0.378 & 2.421 & 0.074 & 2,228 \\
\hline 42 & 0.026 & 1,120 & 0.916 & 2.267 & 0.064 & 2.250 \\
\hline 43 & 0.168 & 0.980 & 0.699 & 0.379 & 0.014 & 2,245 \\
\hline 44 & 0.015 & 0.508 & 0.799 & 1.570 & 0.023 & 2.504 \\
\hline 45 & 0.001 & 0.063 & 0.464 & 1.070 & 0.002 & 2549 \\
\hline 46 & -0.032 & 1.565 & 0.879 & 4.141 & 0.209 & 2483 \\
\hline 47. & 0.006 & 0.581 & 0.610 & 3.141 & 0.127 & 2,401 \\
\hline 48 & -0.011 & -0.812 & 1.150 & 8.305 & 0.527 & 2255 \\
\hline 49 & 0.027 & 1.591 & 0.590 & 2.067 & 0.051 & 2.176 \\
\hline 50 & 0.005 & 0.594 & 0.887 & 6.192 & 0,380 & 2.257 \\
\hline 51 & 0.015 & 0.871 & 0.719 & 3.815 & 0.182 & 2.311 \\
\hline 52 & 0.031 & -1.445 & 0.330 & 1.456 & 0.018 & 1.988 \\
\hline 53 & -0.007 & 0.479 & 0.200 & 1.238 & 0.009 & 2.149 \\
\hline 54 & -0.009 & 0.245 & 0.714 & 1.925 & 0.042 & 2.404 \\
\hline 55 & -0.009 & 0.179 & 1.008 & 1.905 & 0.041 & 2.880 \\
\hline 56 & 0.021 & 0.913 & 0.757 & 1.782 & 0.034 & 2.138 \\
\hline 57 & -0.017 & -0.705 & 0.566 & 1.246 & 0.009 & 2.197 \\
\hline 58 & -0.002 & -0.105 & 0.366 & 1.835 & 0.037 & 1.624 \\
\hline 59 & 0.016 & 1149 & -0.016 & -0.062 & 0.017 & 1.974 \\
\hline 60 & 0.027 & 0.970 & 1.560 & 3.435 & 0.150 & 1.179 \\
\hline 61 & 0.025 & 0.983 & 0.512 & 1.136 & 0.005 & 2.456 \\
\hline 62 & 0.021 & 1206 & 1.386 & 4.208 & 0.215 & 1.513 \\
\hline 63 & -0.013 & 0.396 & 1,487 & 3.892 & 0.188 & 2.227 \\
\hline 64 & 0.009 & 0.533 & -0.002 & -0.008 & -0.017 & 1.776 \\
\hline 65 & 0.001 & 0.045 & 0.292 & 1.187 & 0.007 & 2.155 \\
\hline 66 & 0.000 & 0.002 & 0.466 & 1.018 & -0.001 & 2.620 \\
\hline 67 & 0.018 & 1.439 & 0.647 & 2.685 & 0.092 & 2.296 \\
\hline 68 & -0.015 & -0.924 & 0.176 & 1.003 & 0.000 & 1.913 \\
\hline 69 & 0.005 & 0.301 & 0.328 & 1.885 & 0.040 & 2.291 \\
\hline 70 & 0.022 & 1.437 & 1.100 & 4.670 & 0.524 & 2.056 \\
\hline 71 & 0.016 & 1.154 & 0.615 & 2.732 & 0.096 & 2.231 \\
\hline 72 & $-0,013$ & -0.830 & 1.034 & 3.151 & 0.128 & 1.806 \\
\hline 73 & -0.182 & -1.107 & 0.962 & 0.557 & $=0.011$ & 1.044 \\
\hline 74 & -0.006 & -0.269 & 1.274 & 3.388 & 0.147 & 2.905 \\
\hline 75 & 0.001 & 0.168 & 0.285 & 1.724 & 0.031 & 2.197 \\
\hline 76 & 0.017 & 1.950 & 1.133 & 7.011 & 0.441 & 1.899 \\
\hline 77 & 0.007 & 0.446 & 0.410 & 1.437 & 0.017 & 2.445 \\
\hline 78 & -0.001 & -0.612 & -0.102 & .0 .262 & -0.016 & 1.994 \\
\hline 79 & -0.009 & -0.244 & 0.647 & 1.184 & 0.007 & 1.953 \\
\hline 80 & -0.013 & -0.739 & 0.357 & 1.100 & 0.0003 & 2.591 \\
\hline 81 & 0.015 & 0.860 & 0.043 & 0.124 & -0.016 & 2.145 \\
\hline 82 & -0.007 & -0.259 & -0.227 & -0.445 & -0.013 & 2.072 \\
\hline 83 & 0.001 & 0.037 & 0.414 & 0.994 & -0.000 & 2. 103 \\
\hline
\end{tabular}




\section{Appendix 4.B}

Descriptive Statistics of Average Abnormal Returns, Monthly Data

Panel A: Market Model Returns

\begin{tabular}{|c|c|c|c|c|c|}
\hline Perifod & Mean & Minimuin & Maximum & St. Dev, & Variance \\
\hline-3 & 0,007 & 0.446 & 0.666 & 0.190 & 0.036 \\
\hline 4 & 0.039 & 0.352 & 0.591 & 0.204 & 0.042 \\
\hline 3 & 0.025 & 0.683 & 0.374 & 0.172 & 0.029 \\
\hline 2 & 00063 & 0.470 & 0.922 & 0.209 & 0.044 \\
\hline 1 & 0,054 & 0,710 & 1.944 & 0.284 & 0.080 \\
\hline+1 & 0,110 & $-2,151$ & 1.540 & 0.536 & 0.287 \\
\hline+2 & 0.025 & 0.862 & 0.395 & 0.167 & 0.028 \\
\hline+3 & 0,010 & 0.361 & 0.455 & 0.144 & 0.021 \\
\hline+4 & 0,002 & $-0,485$ & 0.530 & 0.160 & 0.026 \\
\hline+5 & 0.017 & -0.296 & 0.330 & 0.123 & 0.015 \\
\hline
\end{tabular}

Panel B: Market-Adjusted Returns

\begin{tabular}{|c|c|c|c|c|c|}
\hline Period & Mean & Minimum & Maximum & St. Dev. & Variance \\
\hline-5 & 0.012 & 0,472 & 0.642 & 0.189 & 0.036 \\
\hline-4 & 0,027 & 0,362 & 0.566 & 0.201 & 0.040 \\
\hline-3 & 0.007 & 0,645 & 0.355 & 0.164 & 0.027 \\
\hline-2 & 0.055 & 0.460 & 0.881 & 0.207 & 0.043 \\
\hline 1 & 0.043 & 0.703 & 1.950 & 0.288 & 0.083 \\
\hline+1 & 0,099 & -21184 & 1.525 & 0.534 & 0.285 \\
\hline+2 & 0,032 & 0.891 & 0.364 & 0.163 & 0.027 \\
\hline+3 & 0.002 & 0.388 & 0.419 & 0.134 & 0.018 \\
\hline+4 & 0.008 & -0.511 & 0.540 & 0.167 & 0.028 \\
\hline+5 & 0,010 & 0.290 & 0.316 & 0.117 & 0.014 \\
\hline
\end{tabular}

Panel C: Returns from Estimated Alpha

\begin{tabular}{cccccc}
\hline Period & Mean & Minimum & Maximum & St. Dev. & Variance \\
\hline-5 & -0.005 & -0.459 & 0.667 & 0.192 & 0.037 \\
-4 & 0.033 & -0.338 & 0.592 & 0.205 & 0.042 \\
-3 & 0.013 & -0.640 & 0.351 & 0.169 & 0.028 \\
-2 & 0.061 & -0.447 & 0.913 & 0.210 & 0.044 \\
-1 & 0.050 & -0.715 & 1.950 & 0.288 & 0.083 \\
+1 & 0.106 & -2.171 & 1.523 & 0.530 & 0.281 \\
+2 & -0.026 & -0.865 & 0.369 & 0.166 & 0.028 \\
+3 & 0.008 & -0.373 & 0.451 & 0.145 & 0.021 \\
+4 & -0.002 & -0.485 & 0.530 & 0.164 & 0.027 \\
+5 & 0.016 & -0.284 & 0.341 & 0.124 & 0.015 \\
\hline
\end{tabular}


(Appendix 4.B, contimued)

Panel D: Estimation Using Scholes-Williams Method

\begin{tabular}{lccccc}
\hline Period & Mean & Mimimum & Maximum & St Dev & Variance \\
\hline-5 & 0.007 & -0.436 & 0.665 & 0.90 & 0.036 \\
\hline 4 & 0.040 & -0.357 & 0.591 & 0.203 & 0.041 \\
-3 & 0.021 & 0.646 & 0.381 & 0.167 & 0.027 \\
2 & 0.060 & 0.484 & 0.929 & 0.212 & 0.045 \\
1 & 0.054 & -0.721 & 1.959 & 0.284 & 0.081 \\
+1 & 0.109 & 2.145 & 0.543 & 0.541 & 0.293 \\
+2 & 0.024 & -0.838 & 0.452 & 0.168 & 0.028 \\
+3 & 0.008 & -0.378 & 0.458 & 0.140 & 0.020 \\
+4 & -0.002 & -0.484 & 0.531 & 0.160 & 0.026 \\
+5 & 0.016 & -0.301 & 0.279 & 0.121 & 0.015 \\
& & & & &
\end{tabular}

Panel E: Estimation using Dimson Method

(Three lags and one lead)

\begin{tabular}{llllll}
\hline Period & Mean & Minimum & Maximum & St Dev. & Variance \\
\hline 5 & 0.000 & -0.479 & 0.661 & 0.193 & 0.037 \\
\hline 4 & 0.040 & -0.346 & 0.594 & 0.201 & 0.041 \\
-3 & 0.022 & 0.595 & 0.367 & 0.166 & 0.028 \\
2 & 0.059 & -0.540 & 0.921 & 0.219 & 0.048 \\
1 & 0.059 & -0.715 & 1.946 & 0.285 & 0.081 \\
+1 & 0.108 & -2.069 & 1.540 & 0.546 & 0.299 \\
+2 & 0.028 & -0.879 & 0.505 & 0.193 & 0.037 \\
+3 & 0.010 & -0.389 & 0.466 & 0.124 & 0.015 \\
+4 & -0.007 & -0.492 & 0.523 & 0.165 & 0.027 \\
+5 & 0.018 & -0.291 & 0.313 & 0.127 & 0.016 \\
\hline
\end{tabular}

Panel F: Estimation From Non-Merger Sample

\begin{tabular}{lccccc}
\hline Period & Mean & Minimum & Maximum & St. Dev. & Variance \\
\hline-5 & -0.002 & -0.427 & 0.666 & 0.208 & 0.043 \\
-4 & 0.053 & -0.352 & 0.591 & 0.207 & 0.043 \\
-3 & 0.002 & -0.683 & 0.374 & 0.194 & 0.038 \\
-2 & 0.065 & -0.470 & 0.922 & 0.233 & 0.054 \\
-1 & 0.020 & -0.382 & 0.548 & 0.157 & 0.025 \\
+1 & 0.129 & -2.151 & 1.540 & 0.566 & 0.320 \\
+2 & -0.039 & -0.862 & 0.393 & 0.185 & 0.034 \\
+3 & -0.001 & -0.361 & 0.455 & 0.142 & 0.020 \\
+4 & -0.008 & -0.485 & 0.530 & 0.173 & 0.030 \\
+5 & 0.019 & -0.296 & 0.292 & 0.125 & 0.016 \\
\hline
\end{tabular}


Appendix 4.C

Alternative Estimation of Beta

\begin{tabular}{|c|c|c|c|c|c|c|c|}
\hline Number & $\begin{array}{l}\text { Simple } \\
\text { Regresion }\end{array}$ & Dimson & $\begin{array}{l}\text { Scholes } \\
\text { Williams }\end{array}$ & Number & $\begin{array}{l}\text { Simple } \\
\text { Regression }\end{array}$ & Dimson & $\begin{array}{l}\text { Scholles- } \\
\text { Williams }\end{array}$ \\
\hline 1 & 0,409 & 0,166 & 0,229 & 46 & 0.879 & 0.791 & 0.731 \\
\hline 2 & 0,607 & 1,282 & 0.691 & 47 & 0.610 & 1.040 & 0.761 \\
\hline 3 & 1,115 & 1,687 & 1,649 & 48 & 1.150 & 1.156 & 1.348 \\
\hline 4 & 0.084 & 0,266 & 0.099 & 49 & 0.590 & 1.136 & 0.903 \\
\hline 5 & 1.591 & 0,758 & 0.763 & 50 & 0.887 & 1.189 & 0.669 \\
\hline 6 & 0.697 & $1 / 770$ & 0.910 & 51 & 0.619 & 1.315 & 0.941 \\
\hline 7 & 0736 & 1,621 & 1.220 & 52 & 0.330 & 0,028 & 0.206 \\
\hline 8 & 1.217 & 1994 & 1.869 & 53 & 0.200 & 0.649 & 0.499 \\
\hline 9 & 0.268 & 0,162 & 0.296 & 54 & 0.714 & 1.274 & 1.299 \\
\hline 10 & 0.119 & 1,319 & 0.869 & 55 & 1.008 & 0.301 & 0,744 \\
\hline 11 & 1.222 & 1.018 & 1.146 & 56 & 0.757 & 0.566 & 0.644 \\
\hline 12 & 1.186 & 0.919 & 0.990 & 57 & 0.566 & 0.675 & 0.808 \\
\hline 13 & 0.476 & 0.020 & 0.279 & 58 & 0.366 & 1.543 & 1.046 \\
\hline 14 & 0.397 & -1.572 & -0.165 & 59 & -0.016 & -1.627 & -0.664 \\
\hline 15 & 1.127 & 1.182 & 1.507 & 60 & 1.560 & 1.572 & 0.966 \\
\hline 16 & 1.238 & 1.149 & 1.449 & 61 & 0.512 & 0.248 & 0.681 \\
\hline 17 & 0.701 & 0.418 & 0.206 & 62 & 1.386 & 1.734 & 1.484 \\
\hline 18 & 0.418 & 1.004 & 1.043 & 63 & 1.487 & 3.200 & 1.706 \\
\hline 19 & 0.354 & 0.575 & 0.844 & 64 & -0.002 & 0.190 & 0.535 \\
\hline 20 & 0.323 & 0.140 & 0.0118 & 65 & 0.292 & 0.461 & 0.421 \\
\hline 21 & 0.919 & 1.063 & 1.262 & 66 & 0.466 & 0.444 & 0.143 \\
\hline 22 & 0.106 & 0.178 & 0.207 & 67 & 0.647 & -0.131 & 0.046 \\
\hline 23 & 0.985 & 1390 & 0.045 & 68 & 0.176 & 0.619 & 0.530 \\
\hline 24 & 1.142 & 1.166 & 0.776 & 69 & 0.328 & 0.550 & 0.706 \\
\hline 25 & 0.063 & 1.257 & 0.564 & 70 & 0.100 & 0.647 & 0.386 \\
\hline 26 & 0.823 & 0.979 & 1.052 & 71 & 0.615 & 0.980 & 0.891 \\
\hline 27 & -0.243 & -0.257 & 0.285 & 72 & 1.034 & 1.662 & 0.544 \\
\hline 28 & 1.001 & 1.071 & 1.183 & 73 & 0.962 & 0.911 & 0.245 \\
\hline 29 & 0.228 & 2,601 & 0.750 & 74 & 1.274 & 1.190 & 1.383 \\
\hline 30 & 0.400 & -0.222 & -0.307 & 75 & 0.285 & -0.101 & 0.143 \\
\hline 31 & -0.073 & 0.128 & -0.153 & 76 & 1.133 & 0.725 & 0.518 \\
\hline 32 & 0.633 & 1.741 & 0.192 & 77 & 0.410 & 0.925 & 0.244 \\
\hline 33 & 0.370 & 1.595 & 0.785 & 78 & -0.102 & 1.214 & -0.175 \\
\hline 34 & 0.689 & 1.359 & 1.532 & 79 & 0.647 & $1.08 \pi$ & -0.120 \\
\hline 35 & -0.427 & -0.391 & -0.447 & 80 & 0.357 & 1.660 & 0.120 \\
\hline 36 & 0.247 & 0.592 & 0.537 & 81 & 0.043 & 0.056 & -0.171 \\
\hline 37 & 0.172 & 0.867 & 0.497 & 82 & -0.227 & 0.657 & -0.700 \\
\hline 38 & 0.488 & 0.108 & 0.383 & 83 & 0.414 & -0.856 & -0.013 \\
\hline 39 & 0.560 & -0.181 & 0.302 & & & & \\
\hline 40 & -0.142 & 0.405 & -0.166 & & & & \\
\hline 41 & 0.378 & 0.638 & 0.515 & & & & \\
\hline 42 & 0.916 & 2.237 & 0.262 & & & & \\
\hline 43 & 0.699 & -1.014 & 0.078 & & & & \\
\hline 44 & 0.799 & 2.497 & 0.419 & & & & \\
\hline 45 & 0.464 & -0.542 & -0.084 & Average & 0.578 & 0.76 & 0.561 \\
\hline
\end{tabular}


Appendix 4.D

Descriptive Statistics of Average Abnormal Returns, Daily Data

\begin{tabular}{|c|c|c|c|c|c|}
\hline Period & Mean & Minimum & Maximum & Sit. Dev. & Variance \\
\hline-10 & 0.011 & 0.281 & 0.353 & 0.075 & 0.006 \\
\hline 9 & 0.007 & 0.039 & 0.102 & 0.030 & 0.001 \\
\hline-8 & 0015 & 0.066 & 0.209 & 0,046 & 0.002 \\
\hline-7 & 0.010 & 0.200 & 0.307 & 0.063 & 0,004 \\
\hline-6 & 0.002 & 0.057 & 0.058 & 0.023 & 0.001 \\
\hline-5 & 0.007 & 0.120 & 0.073 & 0.033 & 0.001 \\
\hline 4 & 0.021 & -0.044 & 0.219 & 0.056 & 0.003 \\
\hline-3 & 0.012 & 0.068 & 0.165 & 0.041 & 0.002 \\
\hline-2 & 0,012 & 0.152 & 0.125 & 0.044 & 0.002 \\
\hline 1 & 0.009 & -0.229 & 0.200 & 0.061 & 0.004 \\
\hline 0 & 0.047 & -2.846 & 0.690 & 0.290 & 0.084 \\
\hline+1 & 0.001 & 0.074 & 0.213 & 0.047 & 0.002 \\
\hline+2 & 0.005 & -0.107 & 0.153 & 0.042 & 0.002 \\
\hline+3 & 0.000 & 0.076 & 0.085 & 0.030 & 0.001 \\
\hline+4 & -0.007 & 0.213 & 0.092 & 0.042 & 0.002 \\
\hline+5 & 0.002 & 0.246 & 0.320 & 0.074 & 0.005 \\
\hline+6 & 0,006 & 0.092 & 0.163 & 0.038 & 0.001 \\
\hline+7 & 0.006 & 0.177 & 0.091 & 0.038 & 0.001 \\
\hline+8 & 0.003 & 0.091 & 0.097 & 0.035 & 0.001 \\
\hline+9 & 0.004 & -0.072 & 0.117 & 0.036 & 0.001 \\
\hline+10 & 0.006 & 0.117 & 0.072 & 0.030 & 0.001 \\
\hline
\end{tabular}





\section{CHAPTER}

AMSTERDAM STOCK EXCHANGE

\section{$5.1 \quad$ INTRODUCTION}

We have seen in the previous chapter that trading suspension is in practice on many stock exchanges throughout the world. The Amsterdam Stock Exchange (ASE) is no exception. Here, too, the most important reasons include the failure of a firm to comply with the obligations imposed in the listing agreement, and the emergence of circumstances on the ground of which the Stock Exchange has the opinion that a normal and regular market for a security can not be maintained.

No study to date has been performed on trading suspension on the Amsterdam Slock Exchange. The present research is an effort in that direction. Its objective is to investigate the behaviour of stock prices as well as trading volumes around trading suspensions on the ASE, and to see how effective these suspensions are in making unexpected information available to the stock market. It differs from the previous chapter on the London Stock Exchange in two fundamental ways. First, daily share price data (compared to monthly data) are used in this analysis. Thus, we are now able to see short-term price behaviour (compared to long-term behaviour) around trading suspension. Second, the trading volume behaviour around suspension is also investigated in this study. Such an analysis might help us to assess information content of the suspension event more accurately.

The chapter is organised as follows. The following section describes institutional aspects of trading on the Amsterdam Stock Exchange. The practice of trading suspension is discussed in section three. Section four presents an empirical analysis of the sample of trading suspensions, and section five illustrates two examples of trading suspension. Section six outlines the research methodology, and describes the sample used for eventual analysis. The empirical results are presented in section seven. The chapter ends with some concluding remarks.

The Amsterdam Stock Exchange - the only stock exchange operating in the Netherlands - has three categories of corporate membership: banks, brokers ("commissionairs"), and specialists or jobbers ("hoeklieden"). This structure is quite unique in Europe due to the fact that a full range of market intermediaries has been integrated into the membership of the Exchange. The incorporation of banks is considered to be a strength of the Dutch capital market. In terms of financial resources and share of business the bank members dominate the brokerage market. The "hoeklieden" are intermediaries for floor transactions between other members, and are not 
permitted to deal directly with investors. Banks/brokers must transact through the "hoeklieden". There is no seat system on the Amsterdam Stock Exchange. Anybody satisfying all set requirements (mimimum capitalisation, undependence and skills) is eligible to membership. This is in contrast with many other stock exchanges where the number of members is limited. An entry fee and an annual membership foe are charged to the members."

There are at present 544 companies listed on the ASE; of these $313(58 \%)$ are domestic while the others 231 (42\%) are foreign companies. As can be seen from table 5.1, nearly 2000 different securities are officially traded on the Exchange. Almost $70 \%$ of these securities are domestic and foreign bonds. Close to $50 \%$ of the shares traded are foreign shares thus giving the Exchange an international flavour (a major portion of foreign shares are those of American companies). Looking at the trading volume figures, one can observe that during the last few years the bond market tumover has more than doubled. Dutch government bonds continued to play dominant role in the market. On the other hand, trading volume of shares had an increasing tendency up to 1987 . It decreased to Dfl. 123 billion in 1988 (probably due to "Black Monday" effect) from its peak of Df. 161 billion in 1987. Trading volume again increased in 1989 to Dn. 192 billion. The total market value of all Dutch common shares listed on the Amsterdam Stock Exchange at the end of 1989 amounts to almost Dfl. 300 billion.

Trading on the Amsterdam Stock Exchange takes place mostly on the official market in which firms" full share capital is listed. The official market is the first-tier market for listing of large domestic and foreign companies. Until the end of 1987 , within the official market a distinction was made for 40 most active shares, the trading of which used to begin an hour and a half earlier. A second market called the parallel market ${ }^{2}$ is operating since February 1982 with the aim to enable small and medium sized companies to trade publicly. On the parallel market, listing requirements are less stringent: (a) a minimum of 10\% of a firm's shares valued at least 2.5 million Dutch guilders should be floated; (b) a disclosure record of three years (compared to five) is required.

In addition to the official and the parallel markets, there is an over-the-counter market to deal in securities which are not officially listed. This market is not under official supervision of the Stock Exchange. Trading of some multinationals" securities, which are also listed on foreign exchanges, also takes place (by telephone) beyond the official trading hours (from 10 a.m. to 4-30 p.m.). The system of after-hours trade is now being expanded to include all stocks with traded options.

Until 1985, most securities were traded on the basis of one price fixed at the end of first or/and second round of dealing. But since then all securities are being traded and quoted continuouslly. The Stock Exchange operates on a cash basis; forward trading is not customary in the Netherlands. An automated information system has been installed in 1988 thus making electronic contacts among the ASE members possible. The system provides trade information and business data to stockbrokers, the trading floor and the securities clearing system.

Each transaction on the Exchange is executed by a jobber ("hoekman") who until July 1990 worked with fixed commission. Trading commissions were fixed for stock transactions of up to Dfl. 1 million and bond transactions of up to Dfl. 2.5 million. Commissions on larger transactions were negotiable. Besides commissions, on every transaction a handling fee of Dfl. 7.50 is charged together with $0.12 \%$ stamp duty (with a maximum of Dfl. 1,200 since 1987 ) on the effective value of transaction. Since July 1990 , minimum commission system has been scrapped, and stamp duty is abolished too. Banks and brokers are permitted on a trial basis to operate as market makers in bonds for transactions of more than Dfl. 2.5 million, enabling them to trade directly with each other without using an intermediary ("hoekman").

\footnotetext{
For a detailed description on the organization of the ASE see Cross and Diephuis (1988).
}

${ }^{2}$ With effect from July 1990 it is termed as the official parallel market. 
Table 5.1

Highlights on the Amsterdam Stock Exchange

Panel A. Number of Listed Securities

\begin{tabular}{|c|c|c|c|c|c|c|c|c|}
\hline & \multicolumn{4}{|c|}{ Officlal Market } & \multicolumn{4}{|c|}{ Parallel Market } \\
\hline & 1989 & 1988 & 1987 & 1986 & 1989 & 1988 & 1987 & 1986 \\
\hline \multicolumn{9}{|l|}{ DOMESTIC } \\
\hline Bonds & 1073 & 1144 & 1166 & 1254 & 2 & 2 & 3 & 3 \\
\hline Shares & 205 & 209 & 223 & 225 & 47 & 48 & 46 & 42 \\
\hline Shares in & & & & & & & & \\
\hline Investment Companies & 95 & 70 & 60 & 47 & 23 & 19 & 11 & 12 \\
\hline Sub-Total & 1373 & 1423 & 1449 & 1526 & 72 & 69 & 60 & 57 \\
\hline \multicolumn{9}{|l|}{ FOREIGN } \\
\hline Bonds & 173 & 165 & 159 & 163 & 1 & 1 & 1 & 1 \\
\hline Shares & 269 & 266 & 265 & 272 & 2 & 2 & 3 & 2 \\
\hline Shares in & & & & & & & & \\
\hline Investment Companies & 26 & 24 & 24 & 28 & 0 & 1 & 1 & 1 \\
\hline Sub-Total & 468 & 455 & 448 & 463 & 3 & 4 & 5 & 4 \\
\hline TOTAL & 1841 & 1878 & 1897 & 1989 & 75 & 73 & 65 & 61 \\
\hline
\end{tabular}

Panel B. Total Trading Volume (in billions of Guilders)

\begin{tabular}{|c|c|c|c|c|c|}
\hline s & 1989 & 1988 & 1987 & 1986 & 1985 \\
\hline \multicolumn{6}{|l|}{ SHARES } \\
\hline Domestic & 190.5 & 122.5 & 160.3 & 152.5 & 113.9 \\
\hline Foreign & 1.7 & 0.7 & 0.9 & 1.2 & $\mathbb{1} .2$ \\
\hline Sub-Total & 192.2 & 123.2 & 161.2 & 153.7 & 115.1 \\
\hline \multicolumn{6}{|l|}{ BONDS } \\
\hline Domestic & 169.2 & 198.4 & 167,1 & 98.6 & 86.5 \\
\hline Foreign & 3.9 & 8.2 & 6.4 & 5.4 & 5.0 \\
\hline Sub-Total & 173.1 & 206.6 & 173.5 & 104.0 & 91.5 \\
\hline TOTAL & 365.3 & 329.8 & 334.7 & 257.7 & 2066 \\
\hline
\end{tabular}


(Table 5.1, conthued)

Panel C. Trading Volwme of Shares (in Gulders)

\begin{tabular}{|c|c|c|c|c|c|c|c|}
\hline 4 & 1989 & 1988 & 1987 & 1986 & 1985 & 1984 & 1983 \\
\hline \multicolumn{8}{|c|}{$\begin{array}{l}\text { TOTAL VOLUME } \\
\text { (in billions) }\end{array}$} \\
\hline Official Market & 18898 & 121,32 & 159.31 & 148.53 & 113.27 & 80.23 & 59.91 \\
\hline \multirow[t]{2}{*}{ Parallel Market } & 328 & 1,84 & 1.91 & 523 & 1.89 & 0.62 & 0.35 \\
\hline & 192.26 & 123.16 & 161.30 & 153.76 & 115.16 & 80.85 & 60.26 \\
\hline $\begin{array}{l}\text { A VERAGE DA } \\
\text { (in millions) }\end{array}$ & $\mathrm{UME}$ & & 8 & & & & \\
\hline Official Market & 744 & 474 & 630 & 589 & 451 & 317 & 232 \\
\hline Parallel Market & 13 & 7 & 8 & 21 & 7 & 2 & 1 \\
\hline
\end{tabular}

Panel D. Market Value of Dutch Common Shares (in billions of Guilders)

\begin{tabular}{|c|c|c|c|c|c|c|c|}
\hline & 1989 & 1988 & 1987 & 1986 & 1985 & 1984 & 1983 \\
\hline Official Market & 2959 & 207.2 & 154.8 & 183.5 & 164.6 & 125.7 & 103.4 \\
\hline Parallel Market & 30 & 2.6 & 1.2 & 19 & 19 & 0.8 & 0.5 \\
\hline & 2989 & 209.8 & 156.0 & 195.4 & 166.5 & 126.5 & 103.9 \\
\hline
\end{tabular}

Source: Annual Reports of the Ansterdam Stock Exchange.

The cost of transacting securities on the ASE was relatively high due to the presence of mandatory use of an intermediary, fixed commission, and the stamp duty. So a significant amount of bond trading has been taking place outside the Stock Exchange, with London as its centre. This was the reason that in May 1986 the Amsterdam Interprofessional Market (AIM) has started to deal with block trades which do not have to go through the Stock Exchange's floor (although they must be reported within 15 minutes). The AIM trading takes place between banks and institutions on a net basis (without commission). The transactions must relate to shares or bonds quoted on the official market, and have a value of at least Dfl. 1 million in case of shares, and Df. 2.5 million in case of bonds. 
Admission of securities to listing on a stock exchange means that the issuers of securities have to follow the rules laid down by the exchange authority. If these rules are not properly followed, then measures like trading suspension could be taken. A special supervisory body has been set up by the Amsterdam Stock Exchange to look after the development of security prices, and if necessary, to regulate trading on the Exchange. The regulatory measures related to trading are the following:

(a) Trading Halt - this happens for a short period (minimum one hour) when the Exchange thinks that a soon to arrive material information needs to be widely circulated among investors.

(b) Trading Prohibition - this regulatory measure is taken for a longer period (with a maximum of two days) when it is believed by the Exchange that insufficient information prevails in the market, or important information is being expected which might affect the price of the security.

These two measures are taken by the quotations officer of the Exchange, and sometimes after prior consultation with the affected firm. They have the objective of promoting orderly price formation in the interest of all parties. The direct consequence of both measures is in fact the same: it is forbidden for the Stock Exchange members to engage in any trading of such securities during the period of suspension. In this chapter, the word suspension will be used in a broad sense to include the above mentioned two kinds of measures. Thus, with suspension, trading on the official listing is interrupted for a time period varying from one hour to a few days.

The two regulatory measures related to trading of securities could be distinguished from two other measures related to listing of securities. These are taken by the Stock Exchange Council (in place of the usual supervisory body).

(i) Listing Postponement - If it is believed that facts or developments have arisen with relation to a security that form an impediment to continuation of official listing, or if a firm fails to fulfil its obligations imposed by the listing agreement made with the Exchange, then this sanction is applied. During the whole period of postponement (which can last several days), trading of the security may take place on the over-the-counter market.

(ii) Listing Cancellation - The Stock Exchange has the ultimate power to cancel the listing of a security. This extreme sanction is applied when it is felt by the Exchange authority that continuation of official listing is not possible anymore.

\subsection{AN EMPIRICAL ANALYSIS OF TRADING SUSPENSION}

There exists no database, to our knowledge, which contains information on trading suspension on the Amsterdam Stock Exchange. Therefore, the only way to collect such data was to go through different publications. We consulted the daily publication of the Amsterdam Stock Exchange: 'De Officiele Prijscourant'. Our search identified 193 trading suspensions between January 1983 and December 1988 affecting a total number of 112 firms. The yearly distribution is presented in the following table.. We see an increasing tendency in the use of the

${ }^{3}$ Annual Report of the Amsterdam Stock Exchange, 1986. 
suspension measure. Out of the total affected 112 securities, 96 were listed on the 'Official Market", 13 were listed on the "Parallel Market", and the other 3 were foreign securities.

It is also found that 71 firms were the target of suspension on one occasion, 23 on two occesions, elight on three occasions, four on four occasions, two firms five times, three firms six times and one firm on as much as eight occasions. One notable phenomenon that we uncover is that $48(43 \%)$ of the 112 firms affected by trading suspension are not listed on the Exchange anymore. These firms disappeared from listing because of various reasons like merger, takeover, delisting, bankruptcy, etc.

Table 5.2

Yearly Distribution of Trading Suspensions on the Amsterdam Stock Exchange

\begin{tabular}{cc}
\hline Year & Number \\
\hline 1983 & 31 \\
1984 & 21 \\
1985 & 22 \\
1986 & 29 \\
1987 & 42 \\
1988 & 48 \\
\hline Total & 193 \\
\hline
\end{tabular}

We also collected information on some other aspects of each trading suspension. The findings are presented in the following tables. One important element we would like to mention here is that, despite our best efforts, we were not able to collect reliable information on every suspension. This resulted to a group of suspensions being labelled under the heading "unknown".

In table 5.3 we present our findings regarding the duration of the 193 suspensions. We see that $63 \%$ of the trading suspensions occurring on the Amsterdam Stock Exchange were single-day suspensions. It means that in these cases, once suspension takes place, trading of the security concerned is reinstated on the same day or the day after. Whereas in the other $37 \%$ of the cases, suspension continues at least to the following day. Our findings indicate that on no occasion trading suspension for a security lasted more than a week. In case of a lengthy suspension trading of the security on the non-official market is permitted.

As far as the reasons for trading suspension is concerned, we could not collect reliable information from official sources of the Exchange. We found that the reason for suspension was not officially mentioned in many cases. If any mention of the reason is provided at the time of suspension, then in almost all cases the following reason is cited: expected arrival of information. Therefore, we consulted the daily' newspaper 'Het Financieele Dagblad' to look for any conceivable reason for trading suspension. Table 5.4 provides the result of our search. It appears that a major reason associated with trading suspension is the possibility of a merger or takeover of the affected firm(s). The next important reasons for suspension seem to be the events related to publication of company results and company restructuring. Among other important reasons for trading suspension, we could identify the following ones: issue of new securities, and likelihood of trading based on inside information. 
Table 5.3

Number and Type of Trading Suspensions

\begin{tabular}{|c|c|c|}
\hline Type & Number & o \\
\hline $\begin{array}{l}\text { Single-Day Suspension } \\
\text { Multi-Day Suspension }\end{array}$ & $\frac{122}{71}$ & 63 \\
\hline & 193 & 100 \\
\hline
\end{tabular}

Table 5.4

Reasons for Trading Suspension

\begin{tabular}{|c|c|c|}
\hline Reason & Number & 8 \\
\hline Inside Information & 11 & 6 \\
\hline Company Restructuring & 22 & 11 \\
\hline Merger/Takeover Possibility & 91 & 47 \\
\hline \multicolumn{3}{|l|}{ Publication of Company } \\
\hline Results & 37 & 19 \\
\hline Security Issue & 8 & 4 \\
\hline Miscellaneous & 15 & 8 \\
\hline Unknown & 9 & 5 \\
\hline \% & 193 & 100 \\
\hline
\end{tabular}

After collecting information on number, duration, and reasons for trading suspension on the $\mathrm{ASE}$, our intention was to look for any bias, concerning particular types of firms. We tried to analyse the firms affected by suspension on the basis of size and industry type. In our sample, we could collect market value figures for 67 companies. Thirty of these can be characterised as small firms having less than Df. $100 \mathrm{~m} / \mathrm{n}$ as market value of equity, 23 are medium firms falling within the range of Dfl. $100 \mathrm{mln}-1 \mathrm{bln}$, and 14 are large firms having equity value of more than Dfl, 1 bln.

In order to see whether there is any particular industry bias in trading suspension, we categorised all these suspensions and firms according to industry classification. Our results are shown in the following table. We do not find the presence of any specific industry pattern among the suspensions. Firms from diverse types of industry were exposed to the suspension measure. 
Table 5.5

Industry Classification of Trading Suspension

\begin{tabular}{|c|c|c|c|c|}
\hline \multirow[t]{2}{*}{ Type } & \multicolumn{2}{|c|}{ Per Suspension } & \multicolumn{2}{|c|}{ Per Firm } \\
\hline & No & $\%$ & No. & \% \\
\hline Construction & 25 & 13 & 9 & 8 \\
\hline Chemical & 7 & 4 & 4 & 4 \\
\hline Electronics & 8 & 4 & 5 & 4 \\
\hline Financial Institutions & 22 & 11 & 14 & 13 \\
\hline Food & 12 & 6 & 7 & 6 \\
\hline Hiledh & 7 & 4 & 5 & 4 \\
\hline Investment & 14 & 7 & 11 & 10 \\
\hline Metal \& Machinery & 20 & 10 & 11 & 10 \\
\hline Printing \& Publishing & 25 & 13 & 10 & 9 \\
\hline Textiles & 5 & 3 & 3 & 3 \\
\hline Trade & 20 & 10 & 12 & 11 \\
\hline Transport & 9 & 5 & 5 & 4 \\
\hline Others & 19 & 10 & 16 & 14 \\
\hline Total & 193 & 100 & 112 & 100 \\
\hline
\end{tabular}

\section{$5.5 \quad$ TWO EXAMPLES OF TRADING SUSPENSION}

In this section two trading suspensions are selected to illustrate possible patterns in share price movements around the suspended period. Figure 5.1 depicts daily closing prices of two suspended stocks: Amev and Hoogovens. The upper panel corresponds to the price of Amev shares the trading of which was suspended on March 9, 1989. We can see that prices for the five days preceding trading suspension were fluctuating within a narrow range of Dfl. 55-56. During the suspension period, no trading was allowed. Normal trading of the share started again on the following day. Comparing day +1 price with day -1 price, we see that price has dropped by about Dfl. 3 - a clear response to new unfavourable information (decrease in expected profit) released during the suspended period. Looking at Amev share prices for the five days following suspension we find that the share price remained close to its new level throughout the period. The stock market seemed to react in an efficient way.

Let us turn to the second example. The trading of Hoogovens shares was suspended on February 17, 1989. Closing prices for five days around suspension are shown in the lower panel. Here we see that the share was fluctuating around Dfl. 81 during the pre-suspension period. On the day before suspension, the price of the Hoogovens share went up by two guilders to $\mathrm{Dfl} .82 .60$, and at that price the Stock Exchange announced suspension. Share trading was reinstated on the following trading day with the opening price at Dfl. 87.50 , up by almost five guilders from prior to the suspension. Once again we can observe that the stock was clearly responding to new information released during the suspension period, and in this case the information (increasing equity through divestiture) is favourable. Looking at the increase in share price just before suspension, it seems that the Exchange was rather late in taking its action. The closing price of a Hoogovens share on the first day following suspension was Dn. 86.70. Afterwards, a gradual decline in Hoogovens share price took place suggesting perhaps a re-evaluation over time of information released during the suspension period. These two examples of trading suspension illustrate only two out of many different possible patterns of share price movements associated with suspensions. 
Figure 5.1

Daily closing prices of AMEV (upper pannel) and

Hoogovens (lower panel) around trading suspension
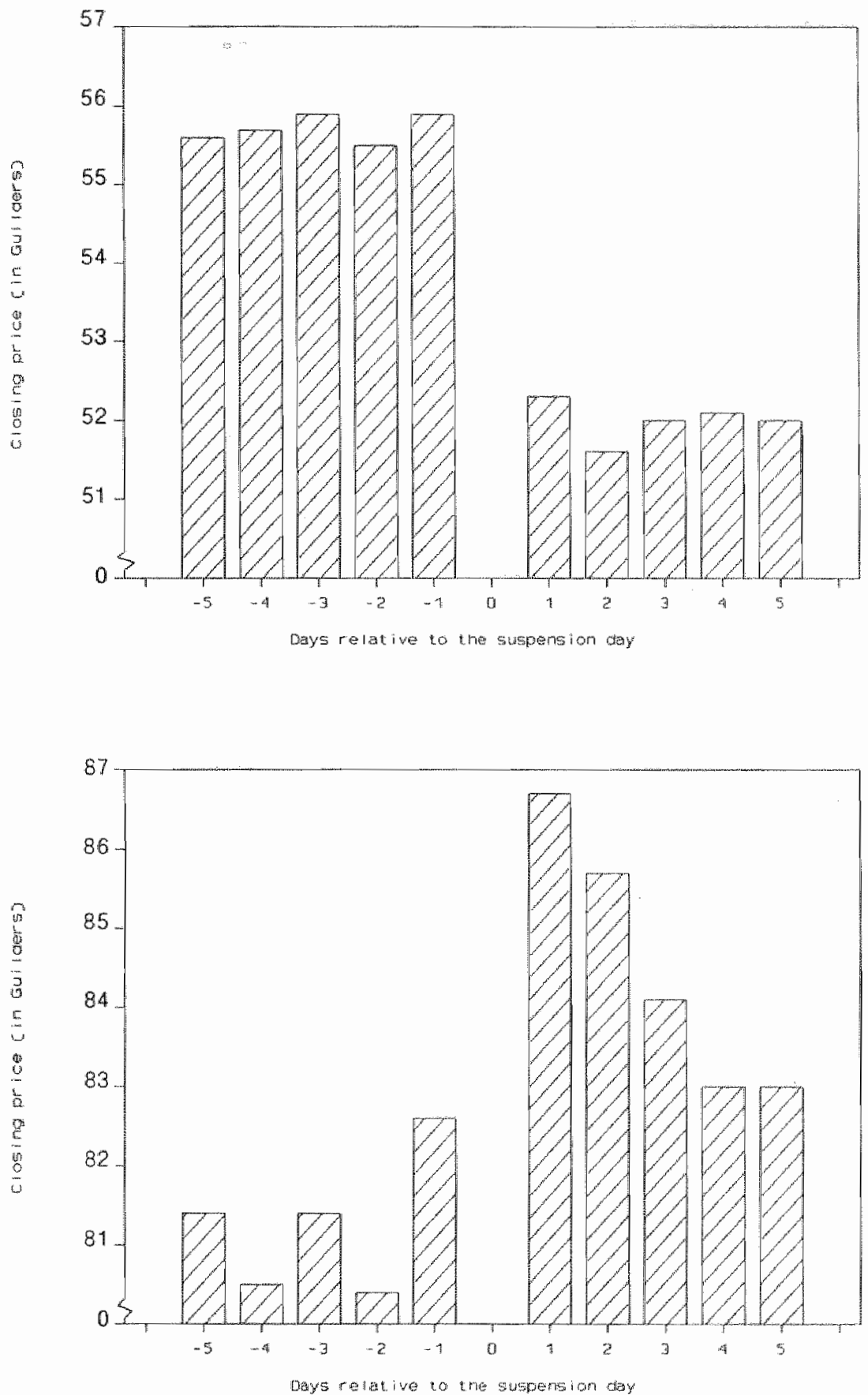


\subsection{RESEARCH DESIGN}

\subsubsection{Methodology}

Standard event study methodology (the extensively used procedure in the finance literature, as mentioned earlier) is employed here, too, to analyse the stock price behaviour around trading suspension. We first use the Market Model to measure abnormal stock price performance, and then examine the sensitivity of our findings to the choice of Market Model by making additional analyses. According to the Market Model, the return on an individual stock is expressed as a linear function of the return on the market and an error term that reflects company-specific information (see chapter 4 for a detailed description of the model). To determine the estimates of the Market Model parameters $\alpha_{i}$ and $B_{i}$ we use the ordinary least square regression technique. Our estimation period is from trading day -100 through trading day -21 with respect to the suspension day. Daily stock returns are calculated as the continuously compounded returns, adjusted for cash dividends and capital structure changes. We use the CBS total return index (a value-weighted index for all stocks officially listed on the Amsterdam Stock Exchange, those of parallel market excluded) developed by the Central Bureau of Statistics as the proxy for the market return. Wijmenga (1990) observes that the use of alternative stock market indices does not result in a different conclusion.

Daily abnormal returns during the event period are then determined by subtracting individual-firm returns predicted by the Market Model from achual returns. These abnormal returns on each event day are then averaged across firms and cumulated over the event window. The cumulative average abnormal return represents the average total effect of trading suspension. Standard t-test, using standard error from the estimated period abnormal returns, are used to find whether the abnormal returns are statistically significant from zero.

\subsubsection{Sample Selection and Data}

In this study, we examine the stock price response of 59 trading suspensions on the Amsterdam Stock Exchange taking place between January 1983 and March 1989. These suspensions meet only two selection criteria. First, share prices of the suspended firms are available in Datastream (delisted firms are also delisted from the database!). Second, absence of successive suspensions within the estimation and the event period (this criterion permits us to evaluate the impact of one suspension only). These 59 trading suspensions consist of 38 single-day suspensions and 21 multi-day suspensions. 24 suspensions were associated with merger and takeover possibilities, 14 were associated with publication of company results, six were associated with company reorganisations and security issues, and four were associated with possibility of insider trading.

While share price data were available for 59 suspensions, daily trading volume data were available for 29 trading suspensions only. Volume data were collected from Stockdata and, when necessary, from the financial press like 'De Officiele Prijscourant' and 'Het Financieele Dagblad". To make trading volume comparable over time, the actual number of shares traded

"The Market Model as a benchmark has also been used by Wijmenga (1990).

"There exists no a priori consensus among researchers as to the choice of the estimation period. Jarrell and Poulsen (1989), Linn and Pinegar (1988), and Kalay and Shimrat (1987) use 150, 110 and 60 trading days respectively to estimate the model parameters. Besides, Brown and Warner $(1980,1985)$ suggest that, in many cases, relatively straightforward procedures are as powerful as more elaborate tests in detecting abnormal performances.

6 See the 1988 Annual Report of the Amsterdam Stock Exchange for eventual details on this index. 
in each day was divided by the total number of shares outstanding on that day. "This series was collected from Datastream.

\subsection{EMPIRICAL RESULTS}

\subsubsection{Market Model}

The findings obtained from using the Market Model for our full sample of 59 trading suspensions are presented in table 5.6. Column one of the table presents days relative to the suspension period. Columns 2 and 3 show the average abnormal returns (AAR) and the corresponding $t$-values. The cumulative average abnormal returns (CAAR) are presented in column 4 of the table. The returns data are also shown graphically in figure 5.2., The estimates of the Market Model parameters are reported in appendix 5.A.

Table 5.6

Average Abnormal Returns Around Trading Suspension; Market Model (Figures in percent)

\begin{tabular}{cccc}
\hline Day & AAR & t-Statistic & CAAR \\
\hline-10 & 0.235 & $4.605^{*}$ & 0.235 \\
\hline 9 & 0.150 & $2.939^{*}$ & 0.385 \\
-7 & 0.013 & $0.255^{*}$ & 0.398 \\
-6 & 0.287 & $5.624^{*}$ & 0.685 \\
5 & 0.088 & -1.724 & 0.597 \\
4 & 0.549 & $-10.757^{*}$ & 0.048 \\
-3 & 0.156 & $-3.057^{*}$ & -0.108 \\
2 & 0.593 & $-11.620^{*}$ & 0.701 \\
-1 & -0.435 & $-8.524^{*}$ & -1.136 \\
0 & 1.142 & $22.377^{*}$ & 0.006 \\
+1 & -3.217 & $-63.036^{*}$ & -3.211 \\
+2 & 0.556 & $10.895^{*}$ & -2.655 \\
+3 & -0.036 & -0.705 & -2.691 \\
+4 & 0.669 & $-13.109^{*}$ & -3.360 \\
+5 & -0.808 & $-15.833^{*}$ & -4.168 \\
+6 & 0.050 & $0.980^{*}$ & 4.118 \\
+7 & 0.226 & $4.428^{*}$ & -3.892 \\
+8 & 0.102 & $1.999^{*}$ & -3.790 \\
+9 & -0.592 & $11.600^{*}$ & -4.382 \\
+10 & 0.901 & $17.655^{*}$ & -3.481 \\
\hline & -0.536 & $-10.503^{*}$ & -4.017 \\
\hline & & &
\end{tabular}

* Significant at the 1 percent level.

"Since the published trading wolume data count both buy and sell transactions of the same security as separate trades, we adjusted the series to calculate the actual number of shares traded. 
Figure 5.2

Average abnormal retums (upper panel) and cumulative abnormal returns (lower panel) around trading suspension (Market Model)

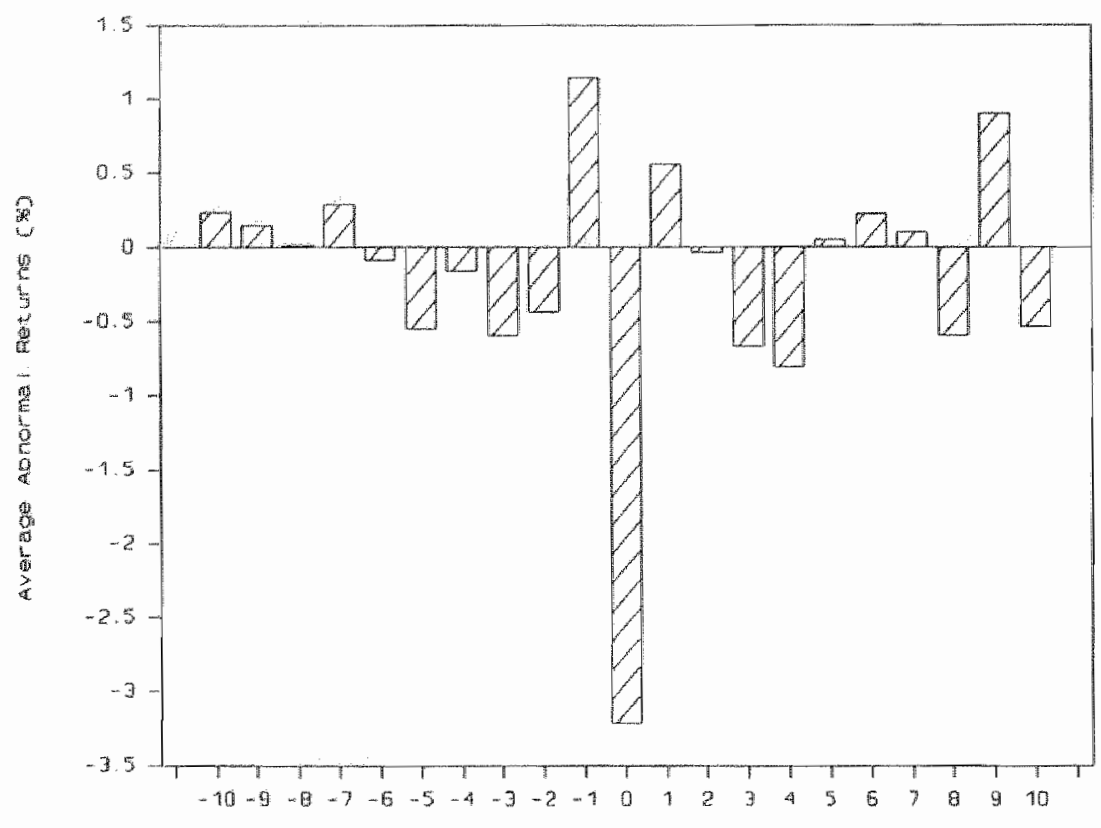

Days: retat ive to the suspension toy

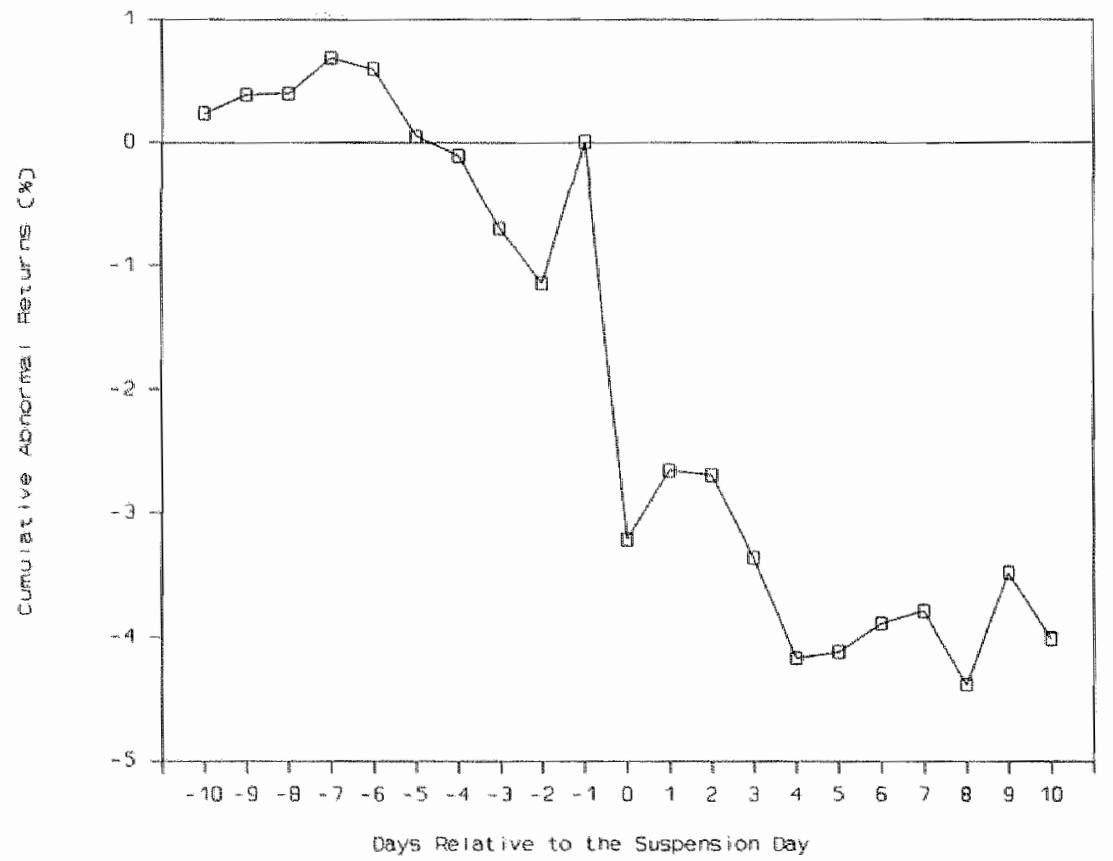


We see from table 5.6 and figure 5.2 that in the ten day period preceding trading suspension the stocks experience sometimes positive and sometimes negative abnormal returns of small magnitudes. These returns appear to reflect quite normal activities of the stock market. The cumulative average abnormal return obtained from these ten days in the pre-suspension period is almost equal to zero. There seems to be no anticipation at all of any trading suspension.

But as trading suspension occurs, a significant change in stock price takes place. The average abnormal retum from all 59 suspensions over the suspended period is -3.22 percent, and this downward drift is statistically very sigmificant (t-statistic $=63.04)$. It can be undoubtedly argued that trading suspension on the Amsterdam Stock Exchange is associated with significant informational content.

Once the suspension period is over, stock prices do not follow any particular pattern. There are again cases of both positive and negative abnormal returns. An efficient adjustment of newly released information appears to have taken place. Although there is a rebound of abnormal return in day +1 this increase falls short of the large decline over the suspension period. The ten day cumulative post-suspension abnormal return is -0.81 percent. This postsuspension behaviour suggests nearly complete adjustment to the information released during the suspended period.

The above results indicate that share price behaviour prior to and subsequent to trading suspension on the Amsterdam Stock Exchange does not exhibit any systematic pattern. Trading suspension appears to take place without any anticipation from the stock market; and share price behaviour after resumption of trading does not indicate any possibility of abnormal profitmaking. However, we find that a significant change in stock price takes place over the suspension period. This suggests that trading suspension is associated with disclosure of material information, and the Amsterdam Stock Exchange was successful in doing that. "The action of the Exchange was not expected by market participants and share price adjustments after suspension do not provide any superior profit opportunities. It also appears from our study that share price decline during trading suspension dominates the total results of our sample.

The results of this study can be compared with results obtained from other stock markets. We observe that a diversity of empirical results exists which can perhaps be explained by the diversity of stock markets with respect to size, institutional practices, regulation, etc. Hopewell and Schwartz $(1976,1978)$ reported that on the New York Stock Exchange trading suspensions are associated with substantial price adjustments, and these adjustments are rapid and virtually complete at the end of the suspension. But Howe and Schlarbaum (1986) and Kryzanowski (1978, 1979) found evidence of U.S. and Canadian stock markets reacting slowly to unfavourable information released during a trading suspension. De Ridder (1988) studying the Swedish stock market, again provided evidence of no departures from market efficiency. And the results of trading suspensions on the London Stock Exchange, as reported in the previous chapter, show that suspensions are preceded by an increase in share price.

\subsubsection{Market Adjusted Model}

We now examine the sensitivity of the above mentioned empirical findings to the choice of a particular methodology (in our case, the Market Model). So, the above analysis is repeated using the Market Adjusted Model (in which $B=1$; see chapter four for details). Table 5.7 reports the abnormal performance around ten days of trading suspensions. The returns are shown graphically in figure 5.3 .

We observe that the average abnormal returns are largely insensitive to the choice of the Market Model. For our sample of trading suspensions on the Amsterdam Stock Exchange, there seems to be no evidence of large abnormall performance both before or after suspension. The cumulative average abnormal return from day -10 through day -1 is -0.60 percent, whereas 
that from day +1 through day +10 is -0.68 percent. Thus, no particular pattern in the return behaviour could be identified. However, there is a large share price reaction associated with the suspension itself - an indication of the fact that new information is conveyed to the market. The average abnormal retum over the suspension period is -3.22 percent, and this is the same as found in the previous analysis. The conclusions drawn earlier remain unchanged.

Table 5.7

Average Abnormal Returns Around Trading Suspension;

Market Adjusted Model (Figures in percent)

\begin{tabular}{cccc}
\hline & & & \\
\hline Day & AAR & t-Statistic & CAAR \\
\hline 10 & 0.138 & $2.650^{*}$ & 0.138 \\
-9 & -0.065 & -1.248 & 0.073 \\
-8 & 0.028 & 0.538 & 0.101 \\
-7 & 0.099 & 1.901 & 0.200 \\
-6 & 0.143 & $-2.746^{*}$ & 0.057 \\
-5 & 0.549 & $-10.542^{*}$ & -0.492 \\
4 & -0.155 & $-2.976^{*}$ & -0.647 \\
-3 & 0.609 & $-11.695^{*}$ & -1.256 \\
-2 & 0.498 & $-9.563^{*}$ & -1.754 \\
-1 & 1.150 & $22.080^{*}$ & -0.604 \\
0 & -3.225 & $-61.929^{*}$ & -3.829 \\
+1 & 0.498 & $9.563^{*}$ & -3.331 \\
+2 & 0.072 & -1.383 & -3.403 \\
+3 & -0.563 & $-10.811^{*}$ & -3.966 \\
+4 & -0.860 & $-16.514^{*}$ & -4.826 \\
+5 & 0.063 & 1.210 & -4.763 \\
+6 & 0.006 & 0.115 & -4.757 \\
+7 & 0.137 & $2.631^{*}$ & -4.620 \\
+8 & -0.581 & $-11.157^{*}$ & -5.201 \\
+9 & 1.174 & $22.544^{*}$ & -4.027 \\
+10 & -0.480 & $-9.217^{*}$ & -4.507 \\
\hline
\end{tabular}

* Significant at the 1 percent level. 
Figure 5.3

Average abnormal returns (upper panel) and cumulative abnormal returns (lower panel) around trading suspension (Market-Adjusted Model)
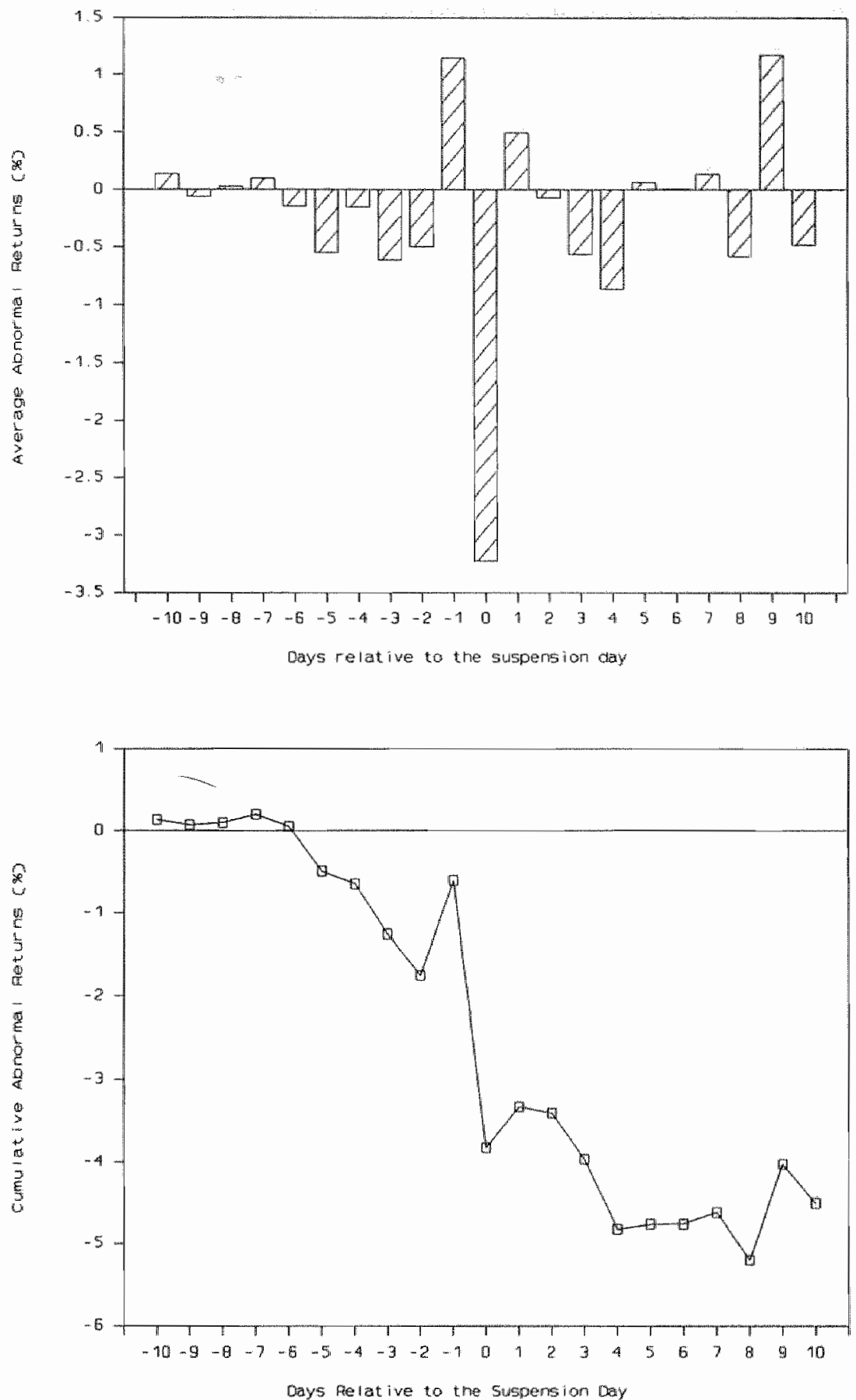


\subsubsection{Serial Correlation Adjustment}

The residuals of the Market Model are believed to be serially correlated. Fama and French (1988), French and Roll (1986) document the presence of negative serial correlation in stock returns. Conrad and Kaul (1988) also find large significant first-order autocorrelation. Besides, performing the Durbin-Watson test, we find that the hypothesis of no positive autocorrelation in our data can be rejected in 11 out of 59 cases. The presence of autocorrelation implies that the usual ordinary least square technique produces inefficient but still unbiased estimators, and invalid t-statistics. Therefore, we adjust for serial correlation by using a Cochrane-Orcutt procedure (see Johnston (1984), ch.8), and then estimate the abnormal returns. Appendix 5.B provides the new regression estimates of the Market Model parameters while table 5.8 presents the results. The abnormal returns are shown graphically in figure 5.4 .

Table 5.8

Average Abnormal Returns Around Trading Suspension;

Serial Correlation Adjustment (Figures in percent)

\begin{tabular}{cccc}
\hline Day & AAR & t-Statistic & CAAR \\
\hline 10 & 0.228 & $4.537^{*}$ & 0.228 \\
-9 & 0.156 & $3.104^{*}$ & 0.384 \\
-8 & -0.004 & -0.080 & 0.380 \\
-7 & 0.286 & $5.691^{*}$ & 0.666 \\
-6 & -0.103 & -2.050 & 0.563 \\
-5 & 0.571 & $-11.363^{*}$ & -0.008 \\
-4 & -0.156 & $-3.104^{*}$ & -0.164 \\
-3 & -0.615 & $-12.238^{*}$ & -0.779 \\
-2 & -0.435 & $-8.656^{*}$ & -1.214 \\
-1 & 1.155 & $22.984^{*}$ & -0.059 \\
0 & -3.219 & $-64.056^{*}$ & -3.278 \\
+1 & 0.531 & $10.567^{*}$ & -2.747 \\
+2 & -0.048 & -0.955 & -2.795 \\
+3 & -0.668 & $13.293^{*}$ & -3.463 \\
+4 & -0.830 & $-16.516^{*}$ & -4.293 \\
+5 & 0.031 & 0.617 & -4.262 \\
+6 & 0.221 & $4.398^{*}$ & -4.041 \\
+7 & 0.092 & 1.831 & -3.949 \\
+8 & -0.595 & $-11.840^{*}$ & -4.544 \\
+9 & 0.881 & $17.531^{*}$ & -3.663 \\
+10 & -0.560 & $-11.144^{*}$ & -4.223 \\
\hline
\end{tabular}

* Significant at the 1 percent level.

The comparison of abnormal returns with those of the previous analyses reveals very little difference. The cumulative abnormal returns in both the pre-suspension and the post-suspension periods do not exhibit any particular pattern, whereas over the suspension period itself a significantly negative abnormal average return is found. The abnormal returns seem to be insensitive to particular model used. The conclusions drawn earlier again remain unchanged. 
Figure 5.4

Average abnormal returns (upper panel) and cumulative abnormal returns (lower panel) around trading suspension (Serial Correlation Adjustment)

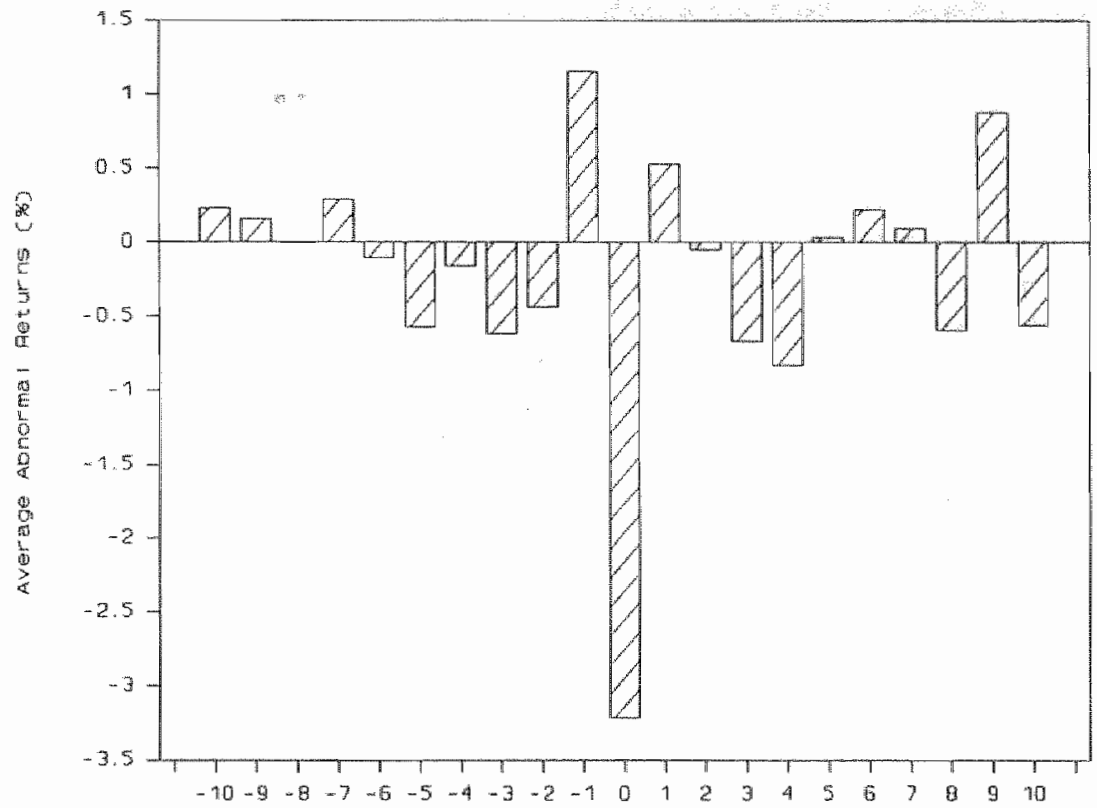

Days relat ive to the suspens ior day

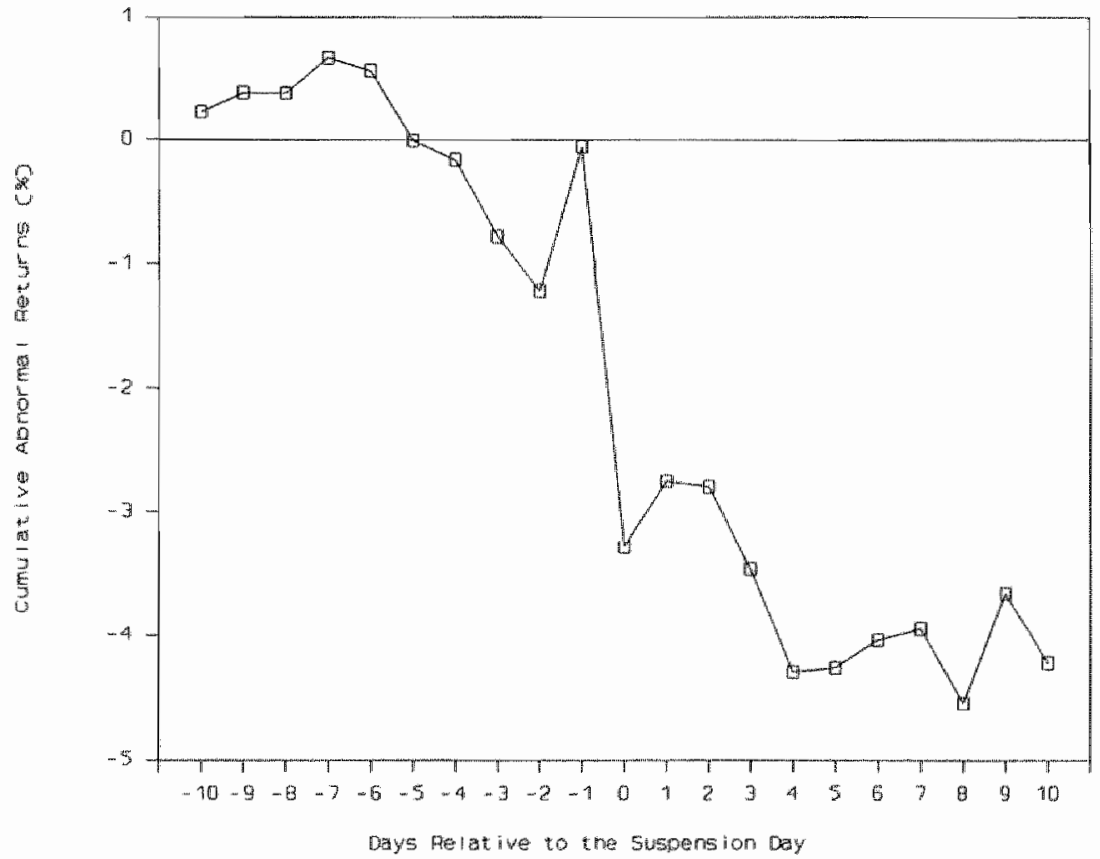




\subsubsection{Trading Volwme Analysis}

Besides investigating share price performance around trading suspensions on the Amsterdam Stock Exchange, the behaviour of trading volume is also analysed in this study. If large trading volumes are associated with trading suspensions, then these suspensions have information content. As pointed by Holthausen and Verrecchia (1990), both price and volume studies are equally relevant means of assessing the information content of a news announcement. Jang and Ro (1989) also argue that a price effect study alone is not sufficient to accurately assess the information content of an event; a simultaneous volume effect study is necessary. Surveying the relationship between price changes and trading volume, Karpoff (1987) observes that simultaneous large volumes and large price changes can be traced to the flow of information. In another paper, Karpoff (1986) argues that unusually high volumes can result from heterogeneous reactions to information, but it does not necessarily reflect disagreement among traders; it can reflect consensus with diverse prior expectations. Evidence of information releases being associated with higher trading volume is provided by Beaver (1968) and Morse $(1980,1981)$.

Table 5.9

Average Daily Trading Volume of Suspended Shares (Figures in percent)

\begin{tabular}{|c|c|c|c|c|}
\hline $\mathrm{No}_{\text {. }}$ & Normal & Around & Pre & Post \\
\hline 1 & 0,312 & 0.490 & 0.248 & 0.999 \\
\hline 2 & 0.178 & 0.492 & 0.456 & 0.328 \\
\hline 3 & 0.215 & 0.257 & 0.185 & 0.293 \\
\hline 4 & 0.270 & 1.542 & 2.103 & 2.010 \\
\hline 5 & 0.174 & 0.235 & 0.112 & 0.301 \\
\hline 6 & 0.732 & 0.642 & 0.263 & 0.688 \\
\hline 7 & 0.378 & 1.139 & 0.608 & 0.978 \\
\hline 8 & 0.695 & 0.189 & 0.267 & 0.161 \\
\hline 9 & 0241 & 0.441 & 0.422 & 0.342 \\
\hline 10 & 0.387 & 0.591 & 0.316 & 0.637 \\
\hline 1. 1 & 0.415 & 1.196 & 0.421 & 1.164 \\
\hline 12 & 0.164 & 0.304 & 0.140 & 0.403 \\
\hline 13 & 0.141 & 0.346 & 0.237 & 0.253 \\
\hline 14 & 0.196 & 0.602 & 0.523 & 0.432 \\
\hline 15 & 0.254 & 0.728 & 0.593 & 0.656 \\
\hline 16 & 0.456 & 0.452 & 0.181 & 0.662 \\
\hline 17 & 0.157 & 0.556 & 0.062 & 0.740 \\
\hline 18 & 0.319 & 0.518 & 0.504 & 0.856 \\
\hline 19 & 0.403 & 0.554 & 0.108 & 0.848 \\
\hline 20 & 0.259 & 0.702 & 0.033 & 0.755 \\
\hline 21 & 0.250 & 0.658 & 0.269 & 0.627 \\
\hline 22 & 0.282 & 0.360 & 0.165 & 0.435 \\
\hline 23 & 0.155 & 0.187 & 0.072 & 0.226 \\
\hline 24 & 0.250 & 0.750 & 0.650 & 0.944 \\
\hline 25 & 0.393 & 0.563 & 0.202 & 0.751 \\
\hline 26 & 0.304 & 6.627 & 2.841 & 5.221 \\
\hline 27 & 0.616 & 0.983 & 1.041 & 0.777 \\
\hline 28 & 0.088 & 0.192 & 0.120 & 0.203 \\
\hline 29 & 0.213 & 0.216 & 0.195 & 0.177 \\
\hline Average & 0.307 & 0.776 & 0.460 & 0.789 \\
\hline
\end{tabular}


Table 5.9 documents the evidence regarding the trading volume behaviour around suspensions. The first column of the table lists the 29 trading suspensions included in the sample; the second column shows the normal trading volume of each suspended stock (here normal is defined as the average trading volume in the estimation period which is from day -100 through day -21 with respect to the suspension day); the third column presents the mean trading volume around ten days of each suspension; the fourth and the fifth columns of table 5.9 contain the percentages of average trading volume in ten days before and after trading suspensions, respectively.

Our results suggest that higher than normal trading volume is associated with the event of trading suspension. While on a normal trading day, on average, 0.31 percent of shares are traded on the Amsterdam Stock Exchange, a trading day immediately around suspension is associated with a trading volume of, on average, 0.77 percent. This more than doubling of trading volume figure reflects arrival of new information to the stock market through trading suspension.

Table 5.10

Average Daily Trading Volume Around Suspension (Figures in percent)

\begin{tabular}{|c|c|c|}
\hline Day & Volume & St. Dev, \\
\hline 10 & 0.434 & 0.691 \\
\hline 9 & 0.306 & 0.453 \\
\hline-8 & 0.683 & 1.267 \\
\hline 7 & 0.362 & 0.561 \\
\hline 6 & 0.288 & 0.412 \\
\hline-5 & 0.314 & 0.426 \\
\hline 4 & 0,371 & 0.414 \\
\hline 3 & 0,500 & 0.746 \\
\hline 2 & 0.803 & 2.034 \\
\hline 1 & 0.538 & 0.685 \\
\hline 0 & 0.000 & 0.000 \\
\hline+1 & 1.580 & 2.2112 \\
\hline+2 & 1.102 & 1.342 \\
\hline+3 & 1.240 & 3.204 \\
\hline+4 & 0.718 & 0.929 \\
\hline+5 & 0.597 & 0.838 \\
\hline+6 & 0.531 & 0.600 \\
\hline+7 & 0.530 & 0.525 \\
\hline+8 & 0.692 & 1.482 \\
\hline+9 & 0.427 & 0.640 \\
\hline+10 & 0.470 & 0.556 \\
\hline Average & 0.624 & \\
\hline
\end{tabular}

When we split the period around trading suspension into ten days each of pre- and postsuspension periods, we observe that trading activity is, on average, higher in the postsuspension period. The average trading volume in the ten day period following suspension is 0.79 percent per day compared to that of 0.46 percent per day in the pre-suspension period. 
We also analyse the cross-sectional behaviour (average trading volume on each day across the 29 suspensions) of trading volume around trading suspension. The results, reported in table 5.10 , reinforce our previous findings. The days after suspension are associated with a greater than normal trading volume. Day +1 witnesses the largest volume, with 1.58 percent of common shares traded. It suggests that new information was indeed released during the suspension period. This higher than normal trading volume has a decreasing trend as can be seen from the numbers in table 5.10 from day +1 through day +10 . Normal market activity appears to occur once the suspension period is over. These results from trading volume analysis do confirm our findings from share price data.

\section{$5.8 \quad$ CONCLUSIONS}

This chapter presents an empirical analysis of trading suspensions on the Amsterdam Stock Exchange. Our analysis of 193 suspensions during 1983-1988 indicates, among other things, the following; an increasing number of suspensions occurring over the last few years; a majority of these suspensions do not exceed the length of one day; merger/takeover activities, publication of company results, and company restructuring are mostly associated with trading suspension.

Investigating daily share price behaviour of a sample of suspended securities, we find that trading suspensions are associated with significant price changes, thus reflecting arrival of new information; in our sample, share price decline dominates the average performance over the suspended period; no anticipatory price behaviour is present during the pre-suspension period; and the post-suspension price behaviour does not show any peculiar trend. It is worth mentioning here that empirical results obtained in this study are almost identical for the three different models used in the analysis.

Looking at the trading volume behaviour of stocks experiencing suspension, we observe that, on average, an increase in volume takes place with the occurrence of suspension. This can be interpreted as the evidence of significant information release during suspension. Trading volume goes back gradually to its normal level once the suspension period is over.

A by-product of this study is that the efficiency of the Amsterdam stock market is also tested. We find that the event of trading suspension has a pronounced effect on stock price, and there is no evidence of any anticipatory or lagged price adjustment. These results support the hypothesis that the Amsterdam stock market is efficient. ${ }^{8}$

Comparing the evidence from the Amsterdam Stock Exchange with that of the London Stock Exchange, we find that trading suspensions on both Exchanges are associated with the release of material information. However, major differences are observed too. On the ASE, no anticipatory price behaviour is found during the pre-suspension period, and the post-suspension behaviour is consistent with an efficient adjustment. On the other hand, pre-suspension anticipatory price behaviour is present on the LSE, and investors earn abnormal returns after the suspension. These differences can be attributed to the type of data used (daily versus monthly), type of suspensions (short-term versus long-term), and different institutional nature of the Exchanges.

In this chapter, we examine price and volume behaviour associated with trading suspension. No attempt was made to analyse the costs and the benefits of trading suspension due to lack of operational criteria. The finding that efficient adjustment to newly released information takes place after trading suspension does not mean that suspension is always warranted.

The efficiency of the Amsterdam stock market has been examined by, among others, Ankum and Dorsman (1987), Dorsman and Post (1989). 
Appendix 5.A

Summary Statistics from the Market Model

\begin{tabular}{|c|c|c|c|c|c|c|}
\hline Number & $\alpha$ & $t(\alpha)$ & $\beta$ & $t(\beta)$ & $\mathbf{R}^{2}$ & DW \\
\hline 1 & -0.001 & -0.641 & 0.643 & 4997 & 0.235 & 1.516 \\
\hline 2 & 0.001 & 0257 & 0.086 & 0.428 & -0.011 & 1851 \\
\hline 3 & 0,001 & 0.519 & 0.078 & 0,418 & 0.011 & 1.943 \\
\hline 4 & 0,004 & 1.43 & 0.255 & 0.953 & 0,001 & 2.282 \\
\hline 5 & 0.001 & 0.499 & 0.732 & 4180 & 0.174 & 1.849 \\
\hline 6 & 0,001 & 1304 & 0.437 & 5.445 & 0.269 & 1,307 \\
\hline 7 & -0.003 & $-1: 092$ & 0.637 & 3.141 & 0.102 & 2.182 \\
\hline 8 & 0.000 & 0.091 & 0.077 & 0.376 & 0.011 & 1,738 \\
\hline 9 & -0.009 & -2.411 & 0.220 & 0.798 & 0.005 & 1,719 \\
\hline 10 & 0.004 & 1.086 & -0.228 & -0.968 & 0,001 & 2,005 \\
\hline 11 & 0.004 & 1.869 & 1.081 & 4.174 & 0.174 & 1.798 \\
\hline 12 & -0.003 & -1.430 & 0.645 & 2.114 & 0,043 & 1.802 \\
\hline 13 & 0.003 & 1.138 & -0.225 & -0.589 & 0,008 & 1.646 \\
\hline 14 & 0.001 & 0.207 & 0.199 & 0.249 & 0.012 & 1.661 \\
\hline 15 & 0.000 & -0.064 & 1,402 & 9.962 & 0.557 & 1.619 \\
\hline 16 & 0.006 & -1.425 & 0.013 & 0.029 & 0.013 & 2.033 \\
\hline 17 & 0.002 & 1.051 & 0.882 & 3.628 & 0.135 & 1.596 \\
\hline 18 & -0.002 & -1.244 & 1.104 & 6.017 & 0,311 & 2.121 \\
\hline 19 & -0.011 & 1.664 & 0.973 & 1.250 & 0.007 & 1.508 \\
\hline 20 & 0.006 & -1.162 & 0.499 & 0.828 & -0.004 & 2.034 \\
\hline 21 & 0.001 & 0.366 & 0.852 & 1.972 & 0.036 & 1.817 \\
\hline 22 & 0.002 & 0.466 & 0.447 & 1.035 & 0.001 & 2.081 \\
\hline 23 & 0.002 & 0.911 & -0.037 & -0.168 & -0.013 & 1.963 \\
\hline 24 & 0,000 & $-0,040$ & 0.574 & 2.465 & 0.061 & 2.391 \\
\hline 25 & 0.002 & 0.943 & 0.661 & 3.521 & 0.127 & 2.216 \\
\hline 26 & -0.001 & -0.284 & 0.912 & 4.784 & 0.219 & 1.980 \\
\hline 27 & 0.001 & 0,369 & 0.258 & 1.108 & 0.003 & 2.191 \\
\hline 28 & -0.004 & -0.907 & 0.520 & 0.864 & -0.003 & 2.015 \\
\hline 29 & 0.000 & 0.016 & -0.056 & -0.164 & -0.013 & 1.516 \\
\hline 30 & 0.000 & 0.119 & 0.328 & 1.984 & 0.036 & 2.326 \\
\hline 31 & -0.002 & -0.382 & 0.877 & 1.201 & 0.006 & 1.362 \\
\hline 32 & 0,000 & -0.211 & -0.008 & -0.062 & -0.013 & 1.941 \\
\hline 33 & 0.006 & 0.609 & -0.781 & -0.942 & -0.001 & 1.546 \\
\hline 34 & 0.001 & 0.413 & -0.114 & -0.423 & -0.011 & 2,166 \\
\hline 35 & 0.002 & 0.729 & 0.599 & 1.950 & 0.035 & 1.799 \\
\hline 36 & 0.001 & 0.845 & 0.258 & 1.405 & 0.012 & 1.859 \\
\hline 37 & 0.000 & -0.231 & 0.136 & 1.192 & 0.005 & 1.799 \\
\hline 38 & 0.000 & 0.192 & 0.010 & 0.045 & -0.013 & 1.945 \\
\hline 39 & 0.004 & 0.826 & 0.172 & 0.333 & -0.012 & 1.646 \\
\hline 40 & -0.001 & -0.322 & -0.091 & -0.203 & -0.012 & 2.411 \\
\hline
\end{tabular}


(Appendit 5.A, continued)

\begin{tabular}{|c|c|c|c|c|c|c|}
\hline Mumber & $\alpha$ & $t(\alpha)$ & $\beta$ & $(6)$ & $\mathrm{R}^{2}$ & DW \\
\hline 41 & 0.000 & 0.100 & 0.177 & 0,582 & 0.009 & 2.046 \\
\hline 42 & 0.004 & 0.844 & 0.404 & 2,735 & 0.077 & 2.088 \\
\hline 43 & 0002 & 0.531 & 0993 & 10.884 & 0,601 & 2.222 \\
\hline 44 & 0.001 & 0.268 & 1234 & 11988 & 0.647 & 1.968 \\
\hline 45 & 0,000 & 0126 & 1322 & 12,009 & 0,647 & 2.408 \\
\hline 46 & 0.000 & 0,151 & 0,419 & 4.449 & 0.194 & 1.789 \\
\hline 47 & 0.002 & 1,307 & 0.201 & 2394 & 0.057 & 1.890 \\
\hline 48 & 0,000 & 0,032 & 1312 & 5.960 & 0.307 & 1.525 \\
\hline 49 & 00004 & 0.891 & 0.659 & 1.601 & 0020 & 1.276 \\
\hline 50 & 0.001 & 0.571 & 0,371 & 1222 & 0,006 & 1.200 \\
\hline 51 & 0.001 & 0.453 & 0.485 & 2.952 & 0,090 & 1.689 \\
\hline 52 & 0,001 & 0,457 & 0.670 & 2.107 & 0.042 & 1.705 \\
\hline 53 & 0,002 & -0.774 & 0.422 & 1.717 & 0.024 & 2.412 \\
\hline 54 & $-0,001$ & -1187 & 0282 & 1.925 & 0,034 & 2.350 \\
\hline 55 & 0,001 & 0.435 & 0.744 & 4.781 & 0219 & 2.162 \\
\hline 56 & 0,001 & 0.433 & 0.121 & $-0,270$ & -0.012 & 1.912 \\
\hline 57 & 0.000 & 0,186 & 1356 & 5.250 & 0.254 & 1,380 \\
\hline 58 & 0.001 & 0760 & 1.084 & 4.995 & 0.235 & 2.066 \\
\hline 59 & 0.002 & 1365 & 0.508 & 3.740 & 0.143 & 1.965 \\
\hline Average & 0.000 & & 0.411 & & 0.101 & \\
\hline
\end{tabular}


Appendix 5.B

Summary Statistics with Serial Correlation Adjustment

\begin{tabular}{|c|c|c|c|c|c|c|}
\hline Number & $\alpha$ & $t(c)$ & $\hat{\beta}$ & $t(\hat{\beta})$ & $\bar{R}^{2}$ & P \\
\hline 1 & 0.001 & 0.481 & 0.691 & 5.628 & 0.285 & 0.246 \\
\hline 2 & -0.001 & -0312 & 0.101 & 0.502 & 0.010 & 0.073 \\
\hline 3 & 0.001 & 0.491 & 0.076 & 0405 & -0.011 & 0.026 \\
\hline 4 & 0.004 & 1536 & 0,303 & 0.152 & 0.004 & 0.141 \\
\hline 5 & 0.001 & 0.501 & 0,705 & 4018 & 0.164 & 0.075 \\
\hline 6 & 0.001 & 0.884 & 0.412 & 5811 & 0.299 & 0.341 \\
\hline 7 & -0.003 & 1.193 & 0.645 & 3.158 & 0.104 & 0.091 \\
\hline 8 & 0.000 & -0.114 & $-0,036$ & 0,181 & 0.013 & 0.140 \\
\hline 9 & -0.009 & -2.239 & 0.222 & 0.763 & -0.005 & 0.055 \\
\hline 10 & 0.004 & 1.118 & -0.148 & -0.625 & 0,008 & -0.004 \\
\hline 11 & 0.004 & 1,670 & 1,037 & 3.933 & 0.158 & 0.100 \\
\hline 12 & -0.003 & -1.485 & 0.609 & 1.967 & 0.036 & 0.012 \\
\hline 13 & 0.002 & 0.667 & -0.219 & -0.638 & -0.008 & 0.078 \\
\hline 14 & 0.000 & 0.029 & 0.227 & 0.292 & -0.012 & 0.158 \\
\hline 15 & 0.000 & 0.059 & 1.469 & 10.897 & 0.605 & 0.190 \\
\hline 16 & 0,006 & $-1,337$ & 0.042 & 0.090 & -0.013 & -0.023 \\
\hline 17 & 0.002 & 0,780 & 0.861 & 3.603 & 0.135 & 0,185 \\
\hline 18 & -0.002 & 1.362 & 1.109 & 6.078 & 0.318 & -0.065 \\
\hline 19 & -0001 & 1280 & 0.751 & 0.999 & 0.000 & 0.245 \\
\hline 20 & 0.005 & 1,160 & 0.529 & 0.870 & -0.003 & -0.022 \\
\hline 21 & 0.001 & 0.190 & 0.796 & 1.833 & 0.030 & 0.076 \\
\hline 22 & 0,002 & 0.429 & 0,355 & 0.802 & $=0.005$ & -0.044 \\
\hline 23 & 0,002 & 0.801 & 0.037 & -0.167 & -0.013 & 0.014 \\
\hline 24 & 0,000 & 0.028 & 0.466 & 2.090 & 0.042 & -0.212 \\
\hline 25 & 0.001 & 0.980 & 0.760 & 4,060 & 0.167 & -0.131 \\
\hline 26 & -0.001 & -0.300 & 0.921 & 4.818 & 0.224 & -0.031 \\
\hline 27 & 0.000 & 0.302 & 0.266 & 1.150 & 0.004 & -0.101 \\
\hline 28 & -0.003 & -0.749 & 0.509 & 0.858 & -0.0003 & -0.026 \\
\hline 29 & 0.001 & 0.256 & -0.177 & -0.512 & -0.010 & 0.222 \\
\hline 30 & 0.000 & 0.040 & 0.345 & 2.121 & 0.043 & -0.169 \\
\hline 31 & 0.001 & 0.129 & 0.803 & 1.263 & 0.008 & 0.239 \\
\hline 32 & 0.000 & -0.332 & -0.003 & -0.031 & -0.013 & 0.022 \\
\hline 33 & 0.004 & 0.351 & -0.460 & -0.583 & -0.009 & 0.232 \\
\hline 34 & 0.001 & 0.455 & -0.051 & -0.188 & -0.012 & -0.095 \\
\hline 35 & 0.002 & 0.712 & 0.564 & 1.832 & 0.030 & 0.099 \\
\hline 36 & 0.002 & 0.079 & 0.266 & 1.496 & 0.016 & 0.024 \\
\hline 37 & 0.000 & -0.203 & 0.128 & 1.119 & 0.0003 & 0.100 \\
\hline 38 & 0.000 & 0.182 & 0.021 & 0,093 & -0.013 & 0.021 \\
\hline 39 & 0.004 & 0.748 & -0.064 & 0.127 & -0.013 & 0.190 \\
\hline 40 & $-0,001$ & -0.162 & -0.097 & -0.233 & -0.012 & -0.239 \\
\hline
\end{tabular}


(Appendix 5.B, continwed)

\begin{tabular}{|c|c|c|c|c|c|c|}
\hline Number & $\alpha$ & $t(c)$ & 8 & $(\beta)$ & $\overline{\mathrm{R}}^{2}$ & $\rho$ \\
\hline 41 & 0,000 & 0,059 & 0.154 & 0,506 & 0.010 & 0.034 \\
\hline 42 & 000 & 0.848 & 0,432 & 2.889 & 0.087 & -0.052 \\
\hline 43 & 0.001 & 0.392 & 1,043 & 11,352 & 0.624 & 0.139 \\
\hline 44 & 0.001 & 10,231 & 1234 & 11948 & 0.648 & 0.015 \\
\hline 45 & 0.001 & 0.200 & 1317 & 12.098 & 0.654 & -0.207 \\
\hline 46 & 0.000 & 0,065 & 0.404 & 4,323 & 0.187 & 0.101 \\
\hline 47 & 0,002 & 1,067 & 0220 & 2640 & 0.072 & 0.034 \\
\hline 48 & 0,000 & 0.015 & 271 & 5906 & 0.306 & 0,223 \\
\hline 49 & 0.004 & 0.627 & 0.928 & 2.544 & 0.066 & 0.370 \\
\hline 50 & 0.001 & 0.290 & 0.347 & 1315 & 0,009 & 0.397 \\
\hline 51 & 0,001 & 0.607 & 0.388 & 2.323 & 0.054 & 0.160 \\
\hline 52 & 0001 & 0.401 & 0.665 & 2,094 & 0,042 & 0.146 \\
\hline 53 & 0.002 & 1,059 & 0.581 & 2.487 & 0.063 & -0.230 \\
\hline 54 & -0.001 & $-1,429$ & 0,290 & 2.034 & 0.039 & -0.180 \\
\hline 55 & 0,000 & 0390 & 0.780 & 4,441 & 0.196 & $-0,084$ \\
\hline 56 & 0,002 & 0,548 & -0.037 & 0.081 & 0.013 & 0.023 \\
\hline 57 & 0.000 & 0.134 & 1.343 & 5.674 & 0.288 & 0,309 \\
\hline 58 & 0.001 & 0.758 & 1.079 & 4921 & 0.232 & 0,035 \\
\hline 59 & 0,002 & 1,372 & 0.505 & 3.684 & 0.140 & 0.017 \\
\hline Average & 0.000 & & 0.463 & & 0.105 & \\
\hline
\end{tabular}




\section{INSIDER TRADING RESTRICTION ON THE AMSTERDAM STOCK EXCHANGE}

\subsection{INTRODUCTION}

The consequence of insider trading on the behaviour of security markets is one of the more controversial issues in finance. Although controversial among academics, there exists a popular consensus that insider trading is bad, and therefore, should be restricted. Regulations restricting insider trading are already prevalent in many different countries, and new regulations are being adopted in others. The Netherlands is obviously of no exception. On January 1, 1987, the Amsterdam Stock Exchange (ASE) adopted a Model Code, restricting insider trading before major announcements such as earnings, dividends and new equity issues. The main purpose of this study is to test whether the introduction of this regulation had any material impact on the behaviour of trading volume and stock prices on the ASE. Indirectly, the results will enable us to obtain an estimate of the alleged costs and benefits from insider trading.

\subsection{THE MODEL CODE TO PREVENT INSIDER DEALING}

On January 1, 1987 the Amsterdam Stock Exchange adopted a Model Code which restricts insider trading before the most common company-specific announcements. Insiders (managing directors, supervisory directors or other designated employees) are no longer allowed to trade in the company's stock during (a) the two months preceding the announcement of annual earnings reports; (b) the three weeks preceding the announcement of semi-annual or quarterly earnings reports; and (c) the one month preceding the announcement of new equity issues.

All insider transactions are registered by the company, but are not made public (unlike in the U.S where the Official Summary of Insider Transactions is publicly available). The company official charged with recording the transactions is supposed to warn insiders that a 'forbidden trading period' has started (van Ittersum, 1989). In order to detect violations of the Code, a Stock Watch committee looks for abnormal movements in price and trading volume. When the committee suspects a violation, it will conduct an investigation. In 1987, 1988 and 198914,17 and 10 (respectively) suspect cases were investigated. If a violation is found, the company's name is made public; in case of a serious violation the company is reprimanded. In 1987, 1988 and 1989 three, one, and two (respectively) offences were identified. Repeat offenders could be delisted from the Stock Exchange. On February 2, 1989 legislation was passed by the Dutch parliament which imposes heavy fines and jail terms (up to two years) for insiders who violate the law. 


\subsection{REGULATION OF INSIDER TRADING}

\subsubsection{Theoreticall Insights}

As mentioned earlier, there exists controversy regarding the consequences of insider trading. Arguments have been made reflecting both the positive and the negative sides of insider trading (see also Berkman and Herst (1988), Hannigan (1988), Rietkerk (1989), Weston et al. (1990)).

On the benefit side, it is argued that insider trading makes stock market efficient (Manne, 1966), because traders will affect prices through their trades or have large incentives to reveal information after taking positions in the underlying stock. Of course, it would be preferable (as Manove (1989) argues) that the insider directly communicated his information to the public, in the same way as the world would be a better place if there were only nice, altruistic people. However, one could question whether it is really in the interest of the current shareholders (whose wealth, as is standard in Finance, the insiders-managers are assumed to maximise) to make markets efficient. To illustrate this point, assume that at time 0 insiders receive information which, without their trading activities, would become available at time $\mathrm{T}>0$. If insiders trade, their trading activity will speed up the adjustment to this information. Consider the following three catagories of current shareholders: (1) Investors who hold their stock until after time T; (2) Investors who would have sold their stock before time $T$, whether the insider traded or not; and (3) Investors who sell their stock before time $T$ because of the buying pressure of insiders. While the first category would be unaffected by insider trading, some of the shareholders in the second category will benefit if the trading speeds up the release of good information. However, if insider trading speeds up the release of bad information (i.e. the insider sells short) the shareholders in the second category will be made worse off. Finally, the third category (which is only relevant when the insider acts on positive information) will be made worse off if the trades are only partially revealing. In short, insider trading on the basis of negative information will always hurt current shareholders, while the net effect of insider buying is unclear: it depends on the ratio of 'normal" versus 'insider induced" trading volume, and on the extent and speed of information revelation.

On the negative side, the aversion to insider trading among regulators, lawyers, financial columnists, etc. is based on the argument that it discourages ordinary investors to trade and hence reduces liquidity. Amihud and Mendelson $(1986,1988)$ formalise this argument by showing that the presence of informed traders will increase the bid-ask spread and hence reduce liquidity. The argument that the adverse selection problem reduces trading volume ignores the liquidity enhancing role of informed traders themselves (see e.g. Grossman (1986)). Although trading against an insider may be unpleasant, it still may be better than operating in a market only dominated by uninformed liquidity traders, especially, if part of the liquidity traders are 'discretionary' traders (see Admati and Pfleiderer (1988)), i.e. traders with liquidity demands that need not be satisfied immediately. If, without insider trading, markets become less efficient prior to earnings announcements, discretionary traders may well prefer to wait until earnings announcements (i.e. when the information asymmetry is reduced), so that liquidity prior to such announcements will fall.

\subsubsection{The Hypotheses}

The purpose of this chapter is to test the consequences of restricting insider trading on (a) the liquidity of stock market; and (b) the speed of adjustment to information revealed in annual and semi-annual earnings announcements. The regulation also restricted trading before dividend announcements and new issues. However, because dividends are typically announced on the 
same day as earnings, no independent test of dividend announcements is possible." Announcements of new equity issues were also ignored because we want to focus on the behaviour of markets before predictable events: annual and semi-anmual earnings are typically announced in the same callendar week.

Specifically, we want to test the following hypotheses:

Hypothesis 1: After insider trading was restricted, stock market became more liquid in the restricted period (prior to eamings announcement).

Hypothesis 2: After insider trading was restricted, the speed of adjustment to annual and semiannual earnings information was reduced.

Hypothesis 3: These effects are more pronounced for small firms.

The first hypothesis tests whether the increased willingness of outsiders to trade compensated for the loss of trading volume normally generated by insiders. The alternative hypothesis is that stock market did not become more liquid. The second hypothesis tests the traditional argument that 'insider trading makes stock market efficient'. The alternative hypothesis is that the speed of adjustment to earnings information was not reduced due to the restriction. ${ }^{2}$ The third hypothesis tests whether small firms, which are generally perceived to offer more profit potential to insiders, are more affected by restrictions on insider trading. The alternative hypothesis is that the effects are not more pronounced for small firms.

Note that testing these hypotheses is only meaningful if the Model Code deters insider trading. There exists a lot of evidence (Jaffe, 1974a; Finnerty, 1976; Seyhun, 1986; Lin and Howe, 1990) that insiders (officers and directors) buy before price increases and sell prior to price declines in U.S. capital markets. One interpretation of these results is that exploitation of inside information is widespread and that insiders violate Rule $10 \mathrm{~b}-5$ of the Securities and Exchange Act of 1934. Considering that these violations carry heavy fines and jail sentences, it seems questionable whether the comparatively mild sanctions (before February 1989) were sufficient to enforce the Dutch Model Code. However, Givoly and Palmon (1985) find no association between purchase (sale) transactions and the release of subsequent good (bad) news. They argue that the price changes subsequent to insider trading transactions are mainly reflecting the publication of the trades themselves. One explanation for their results is that insider purchases (sales) are a sign of increased (decreased) managerial commitment to shareholder value maximisation (i.e. a reduction in agency costs), and not activities rellated to inside information. Hence, the requirement to publish insider transactions (in the Official Summary) and the stiff legal penalties may be a sufficient deterrent to widespread exploitation of inside information in U.S. capital markets. Whether the Dutch Model Code of 1987 with its mild sanctions has a similar effect is an interesting empirical issue.

On a more general level, this study adds to growing literature on trading volume and its relationship to stock price behaviour. Karpoff (1987) provides an extensive review of theory and empirical work before 1987. On the empirical front, two findings stand out. First, there is

' Venkatesh (1989) argues that dividends and earnings are partial, but not perfect, information substitutes.

${ }^{2}$ Empirical research on the speed of adjustment to news announcements has been performed by several authors, for example, Hillmer and Yu (1979), Pincus (1983), Patell and Wolfson (1984), Jennings and Starks (1985), Defeo (1986). 
atrong positiwe correlation between absolute price changes and trading volume. Second, because the relationship is much weaker for price declines than for price increases, there is also a positive relationship between volume and price changes per se. ${ }^{3}$

Although these findings can be explained by often heavily formalised models, they are also consistent with common sense: price changew reflect (1) the release of new information, which in turn alters investors" demands, or (2) the speculative activity of information traders which creates excess trading volume. Because of restrictions on shortselling, speculation on the basis of negative information is more difficult, which explains the smaller correlation between volume and negative price changes. An even more simple explanation may be the fact that limit orders get executed when prices change, and, that, on average, there are more limit orders to sell than to buy. Because restrictions on insider trading elliminated (or at least reduced) one type of trader which plays a crucial role in some of the more advanced models of trading behaviour (e.g. Admati and Pfleiderer (1988), Kyle (1985)), the Dutch regullatory reform provides an interesting experimental setting for these and other noisy rational expectations models.

\subsection{SAMPLE SELECTION AND DATA}

Daily price and daily trading volume data of all 136 common stocks continuously listed on the Amsterdam Stock Exchange from January 1984 to June 1989 are first considered. The dailly series like adjusted share price and the number of common shares outstanding are obtained from Datastream Inc. Share prices are then transformed to continuously compounded returns by taking the natural logarithms. These returns are adjusted for cash dividends too. Most of the trading volume data is provided by Stockdata, while the rest is collected from the financial press like 'De Officiele Prijscourant' and 'Het Financieele Dagblad'. The data has been checked and cross-checked whenever deemed necessary. Since the published volume data in the Netherlands count both buy and sell transactions of the same security as separate trades, we adjust the series to calculate the actual number of shares traded on each day. Out of the 136 stocks initially considered, complete price as well as volume series of 11 of them for the whole period 1984-1989 were not available.

In addition, we collected data on all annual and semi-annual earnings announcements. The earnings announcement dates for the years 1987-89 are collected from the press release files of the 'Algemeen Nederlands Persbureau" (Dutch Press Bureau). Because the Bureau only preserves the previous two years press releases, the remaining announcement dates are collected by searching the financial newspaper 'Het Financieele Dagblad'. In doing so, we could find only less than half of all announcement dates for 11 companies. These companies were omitted from the sample. Our final sample is thus reduced to 114 stocks. The sample selection procedure is shown in table 6.1.

In total, we were able to collect 561 annual earnings and 554 semi-annual earnings announcement dates. The time distribution of these announcements is shown in table 6.2. Most annual earnings are announced in March and April, while most semi-annual earnings announcements take place in August and September. We consider the announcement date as the day a company issues its press release related to annual and semi-annual results or the preceding day of such announcements appearing in the daily newspaper.

${ }^{3}$ See also Jain and Joh (1988). 
Table 6.1

Selection of Working Sample

Number of common stocks officially listed throughout the period January 1984 - June 1989:

less

Complete price and volume data not available in Datastream/Stockdata:

Nonavailability of earnings related information like announcement dates, earnings per share

Table 6.2

Monthly Distribution of Earnings Announcements

\begin{tabular}{lcc}
\hline Month & Annual & Semi-Annual \\
\hline January & 32 & 0 \\
February & 70 & 0 \\
March & 218 & 3 \\
April & 163 & 6 \\
May & 33 & 6 \\
June & 21 & 10 \\
July & 4 & 22 \\
August & 1 & 235 \\
September & 2 & 221 \\
October & 6 & 34 \\
Novenber & 6 & 17 \\
December & 5 & 0 \\
\hline TOTAL & 561 & 554 \\
\hline
\end{tabular}


Besides the announcement dates, we also collected information from these firms" financial statements. The earnings per share (EPS) and the dividend per share (DPS) data for the years 1984-1988 are gathered from the publication 'Financieel Economisch Lexicon'. Descriptive statistics of these data are reported in table 6.3. Note that almost one-third of earnings is distributed as dividends by Dutch companies.

Table 6.3

Descriptive Statistics of EPS and DPS

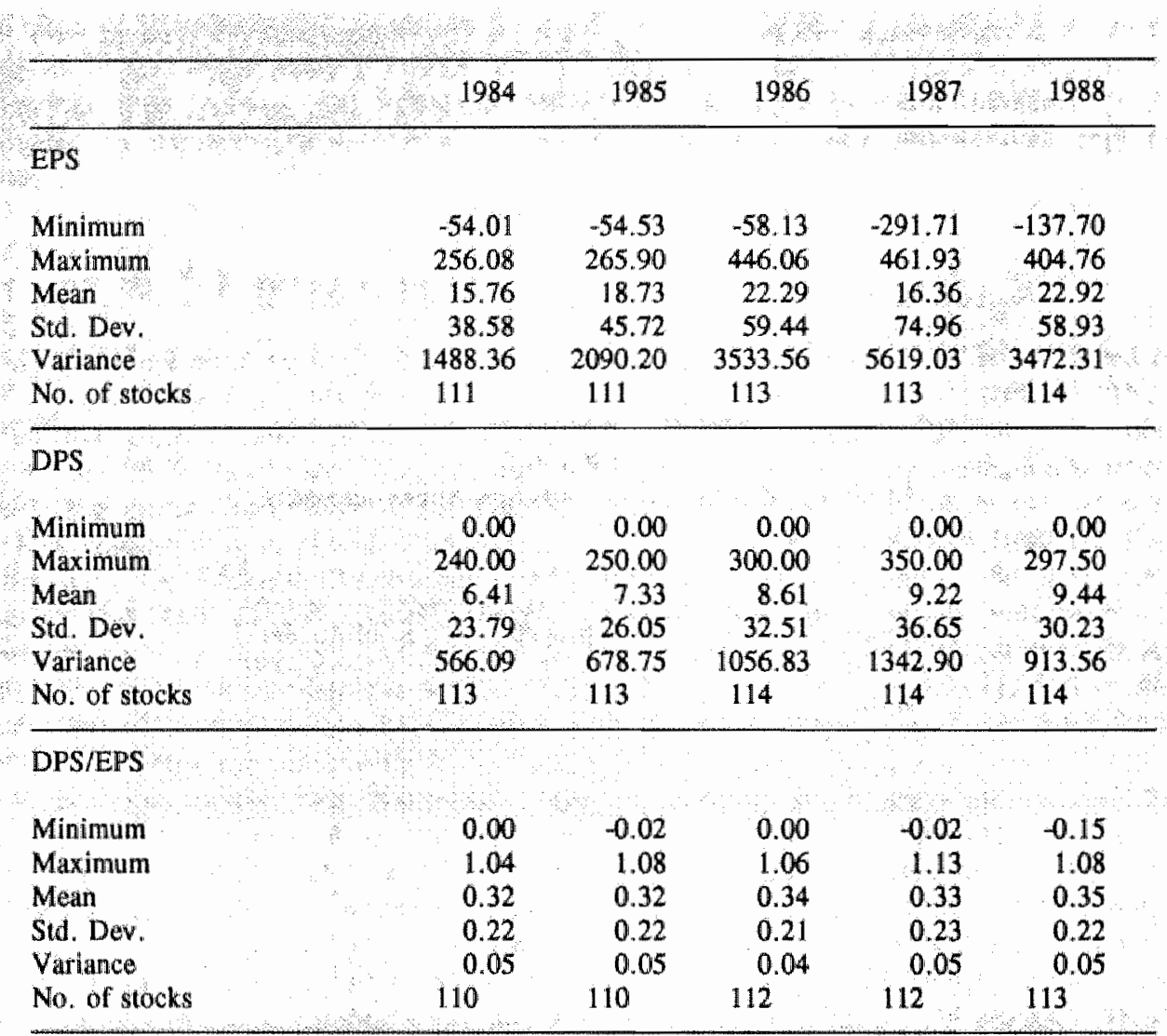

\subsection{TRADING VOLUME ANALYSIS}

\subsubsection{Methodology}

The purpose of this section is to test whether the Model Code increased liquidity before annual earnings and semi-annual earnings announcements. Because the regulation restricted insider trading two months (or 40 trading days) before an annual eamings announcement, and three weeks (or 15 trading days) before a semi-annual announcement, we consider the following event periods: day -50 to day +10 for annual earnings announcements, and day -25 to day +10 for semi-annual eamings announcements. The ten extra days on both sides of the restric- 
ted trading period are added to test for potential shifts in trading behawiour. Beside event periods, we also define the estimation period as the 100 data periods covering day -100 until day -51 and day +11 until day +60 for annual eamings announcements, and covering day -75 until day -26 and day +11 until day +60 for semi-annul eamings announcements. To make trading volume comparable over time, the number of shares traded in each day was divided by the number of shares outstanding on that day (see e.g. Beaver (1968) and Morse (1981) for a similar procedure).

In order to compute the Model Code induced change in trading volume in the event period, we first need a model of expected 'normal." (unrelated to earnings announcements) trading volume. The "abnormal" (earnings related) trading volume in the event period can then be compared before and after the introduction of the Model Code. In this chapter, we are using three alternative model specifications.

The first expectation model (model 1 in the tables and figures below), the Mean Adjusted Model, assumes that the expected trading volume for the stock $i$ is equal to a constant, which is estimated by the average volume in the estimation period:

$$
E\left(V_{i v}\right)=\bar{V}_{i}
$$

The second expectation model (model 2 in the tables and figures below), the Market Model, assumes that the expected volume has a company specific component and a market component:

$$
E\left(V_{i t}\right)=a_{i}+b_{i} V_{m}
$$

where $a_{i}$ and $b_{i}$ are constants estimated using data in the estimation period, and $V_{m t}$ is the average trading volume of our market portfolio of 114 securities on day $t$.

The third model (model 3 in the tables and figures below), the Adjusted Market Model, adjusts for serial correlation (using a Cochrane-Orcutt procedure) in the Market Model residuals. Ajinkya and Jain (1989) find that residuals in the Market Model are serially correlated (the average estimated first-order serial correlation coefficient in their sample is 0.3 ). The Cochrane-Orcutt procedure takes the autocorrelation structure in the residuals into account.

Note that the volume models which adjust for market-wide events are theoretically superior to the Mean Adjusted Model. As the purpose of the study is to compare trading volume around a company-specific event (earnings announcements), before and after a regulatory change, one should adjust for contemporaneovis market-wide volume changes. On the other hand, the Market Model approach requires more specific distributional assumptions than the relatively simple Mean Adjusted Model.

On the basis of these three models, average abnormal and cumulative average abnormal trading volume are computed on each day in the event period, and compared before and after the 1987 regulation. In order to test for statistically significant differences in the trading volume behaviour for different subsamples, we need an estimate (for each subsample) of the standard deviation of the average daily trading volume (for the first expectation model) and the average daily abnormall trading volume (for the other two expectations models). This standard deviation is computed using data in the 100 day estimation period. A similar procedure (for security retums) is deweloped in Brown and Warner (1985). By using time series of average (abnormal) trading volume, the tests incorporate cross-sectional dependence in the security specific (abnormal) trading volume. 
Figure 6.1

Design of the study (annual earnings)

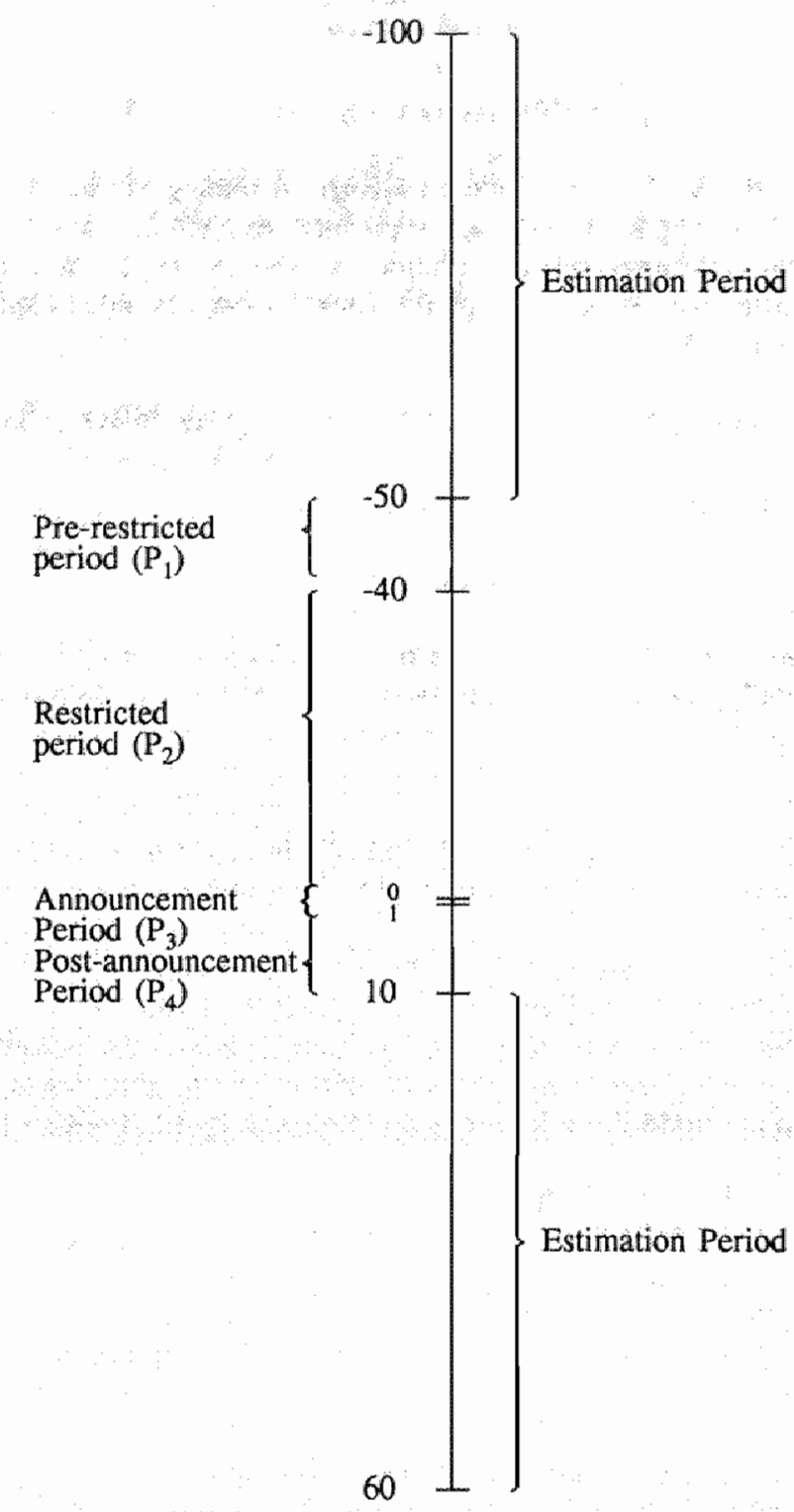


The event period is split up in four sub-periods:

A. The Pre-Restricted Period: day -50 to day -41 for annul amnouncements; and day 25 to day -16 for semi-annual announcements.

B. The Restricted Period: day -40 to day -1 for annual announcements, and day -15 to day -1 for semi-annual announcements.

C. The Announcement Period: day 0 plus day +1 .

D. The Post-Announcement Period: day +2 to day +10 .

Figure 6.1 provides a schematic overview of the estimation and event-(sub) periods around annual earnings announcements.

\subsubsection{Results: Annual Earmings}

Table $6.4^{4}$ provides some descriptive statistics for our daily volume data (i.e. the fraction of shares traded) from January 1984 to June 1989, for four periods: the entire year (panel $A$ ), the Pre- and Post-Restriction period (panel B), the estimation period (panel C) and the event period (panel D). On average, 0.244 percent of the outstanding shares were traded per day (or 61 percent of the outstanding shares per year). After restrictions on insider trading were introduced (i.e. after 1986) trading volume seems to have declined from 0.268 percent per day to 0.216 percent per day. Panel $C$ and Panel $D$ show that this decline in average trading occurs also in the estimation period and the event period, respectively. For annual announcements, trading volume declined, on average, from 0.293 percent per day to 0.214 percent per day in the estimation period, and from 0.339 percent per day to 0.244 percent per day in the event period. For semi-annual announcements, the decline was from 0.225 percent per day to 0.18 percent per day in the estimation period, and from 0.268 percent per day to 0.22 percent per day in the event period. The figures also show that for annual earnings announcements, daily trading volume is, on average, 15 percent larger in the event period than in the estimation period. The corresponding number for semi-annual earnings announcements is 20 percent. Note that all panels show a rather dramatic decline in trading volume in 1987. Note also that the distribution of trading volume is skewed (the mean is higher than the median).

Table 6.5 (which corresponds with figure 6.2) shows the average abnormal trading volume and the cumulative average abnormal trading volume around annual earnings announcements in the event period, for each of the three models of "equilibrium' trading volume. Panel A shows the results for the Mean Adjusted Method (model 1), panel B for the Market Model (model 2) and panel $\mathrm{C}$ for the Adjusted Market Model (model 3). The left-hand side of the table is based on data prior to the restriction on insider trading, while the right-hand side shows the postregulation results. Table 6.6 summarises the results of table 6.5 by computing the average daily abnormal trading volume around annual earnings announcements in each of the four subperiods: the 10-day pre-restricted period $\left(\mathrm{P}_{1}\right)$, the 40 -day restricted period $\left(\mathrm{P}_{2}\right)$, the two-day announcement period $\left(\mathrm{P}_{\mathfrak{y}}\right)$ and the nine-day post-announcement period $\left(\mathrm{P}_{4}\right)$.

The results can be summarised as follows. First, for all models, both before and after the introduction of insider trading regulation, trading wolume increases significantly in the announcement period and in the post-announcement period, a result also reported by others on U.S. data (see e.g. Beaver (1968), Morse (1981), Bamber (1986)). The fact that trading

"The tables and figures are presented at the end of the chapter. 
vollume increases when eamings are announced is typically explained as a 'lack of consensus' effect: caminges amnouncements typically contain information that changes prices, which may create different assessments of the future (and/or differences in behaviour or risk aversion), and hence increase trading volume (see e.g. Karpoff (1986)). Holthausen and Verrechia (1990) argue that besides the consensus effect, an "informedness effect" could generate excess trading volume: if an announcement contains a lot of information "agents' demands become more extreme as agents become more knowledgeable. The fact that trading volume is significantly positive several days after eamings announcements is more puzzling. Karpoff (1986) suggests that this may be a result of market frictions that keep all demands from instantaneously clearing. Alternatively, these trades may be executed by (1) speculative traders who trade around earnings announcements, or (2) (discretionary) liquidity traders who prefer to wait until the information asymmetry is reduced. Or, if stock markets would tend to over- or under-react to earnings news, the abnormal trading volume could merely reflect the activities of traders who want to exploit this inefficiency.

The results in table 6.6 also show that after the introduction of insider trading restriction, the abnormal trading volume in the post-announcement period fell, on average, from 0.11 percent per day to 0.06 percent per day. This is consistent with the hypothesis that the regulation (1) reduced the number of 'informed' investors, and (2) increased the willingness of liquidity traders to trade prior to earnings announcements. However, table 6.6 shows that trading volume in the restricted period did not increase after 1986, and (for the two Market Model specifications) actually declined significantly by 0.028 percent per day (or 1.12 percent in the total 40 day restricted period, which corresponds roughly to 4.5 days of average trading). This result is not caused by a few outliers: for example, employing the Market Model, in 31 out of the 40 days in the restricted period, the number of firms that experienced abnormal volume increases was smaller after the introduction of insider trading regulation than before. This suggests that, (in contrast to hypothesis 1), the regulation did not increase liquidity, because the reduction in trading volume initiated by insiders was not compensated by an increase in liquidity traders.

In order to test for hypothesis 3 , tables 6.7 and 6.8 (and the corresponding figure 6.3) report the results for a subset of 28 "small' firms. Firms were ranked on the basis of market value of equity at the beginning of each year. Next, each year a portfolio containing the bottom 33 percent of firms was formed. In order to make a comparison possible, only the 28 firms that remained "small" from 1985 to 1989 are retained. Panel B of table 6.4 shows that small firms are, on average, more actively traded (at least relative to the number of shares outstanding): 0.368 percent per day before 1987 and 0.299 percent per day afterwards (compared to 0.268 percent and 0.216 percent for the total sample). A similar negative correlation between trading volume and firm size is also reported by Ajinkya and Jain (1989) in U.S. data.

The results for the behaviour of abnormal volume of small firms are similar to the ones reported for the total sample, but, because of the small sample size, less statistically significant (especially for the Mean Adjusted Model). We find that for small firms abnormal trading volume is significantly positive during and after the announcement period. As in the total sample, post-announcement abnormal trading volume (using model 2 and model 3 ) falls after the introduction of the Model Code by approximately 0.10 percent per day (compared to the pre-1987 period). There is also no evidence that outlawing insider trading had any positive effect on liquidity in the restriction period. Specifically, for all model specifications, abnormal trading volume was smaller after 1986 than before. This result may seem surprising, considering that insider trading restrictions are especially aimed at improving liquidity in small firms, where the potential for insider trading is larger. However, the regulation could actually reduce the trading volume by discouraging information traders, especially immediately before the earnings announcement when the Stock Watch Committee pays careful attention to price and volume behaviour. Note also (from figure 6.3, especially panels B and C) that, in general, 
investors apparently are reluctant to trade before earnings announcements of small firms.

The results differ from the ones reported by Morse (1981) employing U.S quarterly eamings announcements and a Market Model adjustment. Morse finds no abnormal trading volume in the 15 days prior to the announcements. However, his analysis is based on 25 actively traded companies in the period 1973-1976, so that his results are not entirely comparable.

\subsubsection{Results: Semi-Annual Earmings}

Tables $6.9,6.10,6.11$, and 6.12 (and figures 6.4 and 6.5 ) are similar to tables $6.5,6.6,6.7$, and 6.8 (and figures 6.2 and 6.3 ), respectively, but are now based on 554 semi-annual eamings announcements.

In some ways, the results for semi-annual earnings are similar to the ones reported for annual earnings. First, abnormal trading volume tends to be significantly positive in the announcement period and the post-announcement period. Second, small firms do not become more liquid (in the restricted period) after insider trading regulation, and, for models 2 and 3 , are relatively illiquid during the restricted period.

However, in many other ways the results for annual and semi-annual earnings are different. First, for the total sample, after the introduction of insider trading regulations, trading volume increased during the restricted period. Table 6.9 shows that post-regulation trading volume, regardless of the equilibrium model specification, is significantly positive on days $-9,-8,-6$, and -2 . Comparing table 6.9 and table 6.11 (post-regulation columns) shows that this result is almost entirely due to the behaviour of relatively large firms: except for day -2, small firms do not experience significant abnormal trading volume in the two weeks preceding the announcement. A second difference with the results for annual earnings is the postannouncement behaviour (both for small and all firms): trading volume does not fall after 1986.

One interpretation of these results is the following. Insider trading regulation encouraged liquidity traders to trade prior to semi-annual earnings announcements; the corresponding reduction in informed investors transactions was not important enough to offset this increase for relatively large firms. However, in small firms, where insiders typically represent a significant fraction of the trading volume, the increased willingness to trade (by outside investors) was offset by reduction in informed traders.

In summary, hypothesis 1 is rejected, except for relatively large firms around semi-anmal earnings announcements. Hypothesis 3 is also rejected (at least as far as the volume behaviour is concerned): regardless of the model of market equilibrium used, the results show that small firms, if anything, became less liquid after the introduction of restriction on insider trading. As Grossman (1986) has pointed out, the argument that insider trading restriction increases liquidity ignores the liquidity enhancing role of informed traders themselves.

\subsection{STOCK RETURN ANALYSIS}

\subsubsection{Methodology}

In order to test for the effect of the regulation on the speed of adjustment of stock prices to earnings news (hypothesis 2), we adopted the classic Ball and Brown (1968) approach. First, the sample was split in two subsamples: companies that experienced an increase in annual (semi-annual) earnings per share and companies that experienced a decrease in annual (semi- 
annual) earning per share. If earnings follow a random walk, then this procedure divides the sample in companies with unexpected eamings increases and decreases. Although time series model or models based on analyst and managerial forecasts are better than nave random walk models (for an overview, see e.g. Foster (1986), Brown et al. (1987), Chatfield et al. (1990)), no such data was available to us.

Table 6.13 provides an overview of our sample. The results are based on 389 anmual camings increases, 160 annual eamings decreases, 254 semi-annual earnings increases and 137 semi-annual earmings decreases. Except for the 1987 semi-annual earnings announcements (announced mainly in the two months prior to the stock market crash) and the 1988 annual earnings reports, warnings increases are always twice as numerous as earnings decreases.

Next, for each subsample of annual (and semi-annual) earnings increases and decreases, a standard event study was performed using the Market Model to compute 'normal' returns, employing data in the estimation period. The market index is an equally weighted index of all securities in the sample. Estimates of $\alpha$ and $\beta$ were obtained from simple OLS regressions, without adjustment for thin trading. Brown and Warner (1985) show that the failure to take into account nonsynchronous trading in estimating Market Model coefficients does not result in misspecification of event study methodologies: by construction, OLS residuals for a security sum to zero in the estimation period so that a bias in $\alpha$ is compensated for by a bias in $B$. As with the volume data, the standard deviation of the average abnormal returns in the estimation period is used to perform significance tests in the test period. Note that this method incorporates cross-sectional dependencies in security-specific returns, which may be important if events are clustered.

\subsubsection{Results: Annwal Eamings}

The results for annual amnouncements are shown in figure 6.6 which is based on table 6.14, panel A (earnings increases) and panel B (earnings decreases). Before the introduction of insider trading restriction, earnings increase announcements are preceded by significant stock price increase on days $-10,-9$, and -7 . The 1.89 percent cumulative abnormal return in the 10 days prior to the announcement is highly significant $(t=3.7)$. Although the announcement return ( 0.65 percent) is significantly positive, the earnings news was largely anticipated. For earnings declines, the 10 -day pre-announcement return $(-0.73$ percent $)$ is not significantly different from zero $(t=-1,03)$. However, the cumulative excess return of -3.2 percent in the restricted period (day -40 to day -1 ) is marginally significant $(t=-1.59)$. Earnings declines are unexpected: stock prices fall by 3.68 percent in a two-day period. After day +1 , abnormal returns are not significantly different from zero.

Interestingly, after the introduction of the Model Code, earnings news was not preceded by abnormally positive or negative returns. The cumulative average abnormal return in 10 days preceding annual earnings announcements is 0.21 percent and 0.66 percent for earnings increase and decrease, respectively. Annual earnings decreases are actually preceded by a small (one percent in 50 days) positive abnormal return and the market's response to eamings news is uniquely confined to a two day negative return of -2.23 percent. The statistically significant positive abnormal return on day +2 of 0.46 percent is difficult to explain in an efficient market. In a similar way, the significant positive response to earnings increases is largely limited to the announcement day when stock prices increase by 0.52 percent. These results are consistent with hypothesis 2: the Model Code reduced the speed of adjustment to information, although it should be pointed out that there was not much to anticipate. The small information content of earnings after 1986 is a puzzle.

"The earnings forecast, for example, for the year 1989 equals the most recently reported earnings, i.e. of 1988 . 
It is tempting to relate the stock price behaviour to the trading wolume behaviour reported abowe. From table 6.5 , we can infer that, before 1987 , the cumulative abnormal trading volume in the 10 days prior to annual earnings announcements is equal to 0.58 percent $(t=$ 3.16) employing model $1,0.38$ percent $(t=2.81)$ employing model 2 , and 0.47 percent $(t=$ 3.4) using model 3. After the introduction of the Model Code, the cumulative abnormal volume falls, and is statistically significant when we use model 2 or model 3 . This suggests that the pre-announcement returns and pre-announcement trading volumes are positively correlated (which is consistent with the positive relation between stock retums and trading volume in the U.S. (Karpoff, 1987).

Table 6.15 and figure 6.7 show the same cumulative average abnormal returns data as table 6.14 and figure 6.6 , but now for the 28 small firms in the sample. The general conclusions we made on the basis of the results for the total sample also apply to small firms, although, because of the small sample size, it is difficult to detect statistically significant abnormal retums. From day -10 until day -1 , stock prices increase by 0.93 percent $(t=0.80)$ before earnings increases in the pre-1987 period. Onlly on day 0 the abnormal return is significantly positive (at the 10 percent level). After the introduction of insider trading restriction, the corresponding number falls to 0.56 percent $(t=0.61)$, but the announcement of earnings increases apparently does not generate a lot of enthusiasm. For earnings decreases, the corresponding numbers are -2.47 percent $(t=-1.16)$ in the pre-regulation period and -0.17 percent $(t=-0.1)$ afterwards. Note also that in the pre-regulation period, average abnormal returns were negative in 8 out of 10 days prior to the announcement, and that during the 40 days prior to the announcement, stock prices fell by 6.68 percent $(t=-1.55)$. Note the very strong response to earnings decrease announcements both in the pre-and post-regulation period (with t-statistics of -5 and -6 on day +1 ). The fact that the stock market responds very strongly to earnings decreases and very weakly to earnings increases suggests that the market has typically higher expectations about earnings per share than implied by a naive random walk model.

With respect to the volume data for small firms, table 6.7 shows that, prior to the regulation, the cumulative average abnormal volume in the 10 days before the annual eamings announcement is significantly positive: 1.41 percent $(t=2.78)$ with model $1,0.83$ percent $(t$ $=1.96)$ with model 2 , and 1.13 percent $(t=2.66)$ with model 3 . After 1986 , the abnormal trading volume falls to 0.52 percent $(t=1.18)$ with model $1,-0.537$ percent $(t=1.34)$ with model 2 , and -0.68 percent $(t=1.69)$ with model 3 . Hence, as before, we conclude that the volume results are consistent with the return results: abnormal trading and price anticipation go together.

Summarising, the results based on average earnings are in some ways consistent with hypothesis 2: the regulation reduced incentives for informed traders to trade on the basis of forthcoming earnings news. This in itself reduced the speed of adjustment to this information. Howewer, this conclusion has to be qualified: the rather puzzling small information content of earnings announcements per se after 1986 suggests that there was not much to anticipate in the first place. Alternatively, one could argue that the regulation had no significant effect on insider behaviour, but less trading went on because insiders anticipated that the earnings news would generate not much price response.

\subsubsection{Results: Semi-Anmual Eamings}

The results of semi-annual earnings are shown in table 6.16 and figure 6.8 . In contrast to annual earnings changes, semi-annual announcements are not preceded by substantial positive or negative abnormal returns, before or after regulation. Statistically significant abnormal returns are mostly observed at the announcement day and afterwards. As with annual earnings, we find a significant positive abnormal return after earnings declines, a result which is 
anomalous and may explain why trading volume is abnormally high in the post-announcement period.

A similar picture emerges form table 6.17 and figure 6.9 , which describe the same results, but now for small firms. Except for a rather anomalous significant negative abnormal return on day 8 preceding annual earnings increases, no significant abnormal returns are obserwed prior to wemi-annual earnings news. Earnings decreases generate significant negative excess retums in the announcement period, and as in the total sample, sometimes significant positive excess returns afterwards. The stock price behaviour for earnings increases is rather unexpected: after 1986, eamings increase announcements generated significant negative excess returns on day +1 . Further investigation reveals that this is due to two outliers: on day $+1,20$ out of the 25 observations experienced positive excess returns.

Unlike the case of annual earnings, price and volume behaviour are not always correlated. In the 10 days prior to semi-annual earnings announcements (total sample), and prior to the introduction of the Model Code, cumulative abnormal volume is 0.41 percent $(t=3.00)$ for model $1,0.07$ percent $(t=0.67)$ for model 2 , and 0.03 percent $(t=0.27)$ for model 3 (see table 6.9). This relatively small (and, for the Market Model specifications, insignificant) increase in trading volume corresponds with the insignificant price anticipation displayed in figure 6.8. Moreover, the small positive or significantly negative abnormal volume before and after the regulation in the restricted period (table 6.8 ) experienced by small firms is consistent with the absence of information traders. However, other findings are not consistent. For the total sample, table 6.9 shows that, after 1986 , cumulative abnormal trading volume became significantly positive in the 10-day period, for all model specifications: 0.64 percent $(t=5.77)$ for model $1,0.61$ percent $(t=5.51)$ for model 2 , and 0.62 percent $(t=5.97)$ for model 3 . This excess volume did not coincide with faster incorporation of semi-annual earnings news. Hence, we conclude that, for relatively large firms, after the restriction on insider trading, liquidity increased prior to semi-annual earnings announcements. Considering that this trading did not effect security prices one has to conclude that (1) the restriction made liquidity traders more willing to trade, and/or (2) insiders were hiding their trades from the Stock Watch Committee.

\subsection{CONCLUSIONS}

The main findings of this chapter can be summarised as follows: (1) after the introduction of restriction on insider trading, trading volume before and after annual earnings announcements fell significantly; (2) after the introduction of restriction on insider trading, the speed of adjustment to annual earnings announcements was reduced; (3) these results do not depend on firm size; (4) with respect to semi-annual earnings announcements, trading volume in relatively large firms during the restricted period increased following the introduction of insider trading restriction; (5) semi-annual earnings changes were not preceded by abnormal stock price behaviour.

The results are consistent with the following joint hypotheses. While insider trading restriction may have increased the willingness of discretionary liquidity traders to trade before earnings announcements, as a result of reducing insider trading, stock prices became less informative (at least prior to anmual earnings announcements). The smaller price changes prior to earnings announcements, combined with the elimination of a large group of informed traders led to a net reduction in trading volume before annual earnings announcements. For small firms, where such information traders may represent a larger fraction of the normal trading volume, this reduction was more pronounced, so that for this subgroup, the volume decline occurs both before annual and semi-annual earnings announcements. For relatively large firms, the elimination of insiders did not outweigh the increased liquidity provided by outsiders, at least 
before semi-annual eamings announcements, where, as the pre-announcement price behaviour demonstrates, insiders did not have a major impact, even when insider trading was allowed.

The regulatory implications are clear: the argument that eliminating insiders will increase liquidity because of increased confidence of outside investors, ignores the liquidity enhancing role of insiders per se. Insiders make markets, influence prices and generate volume. This is especially the case for relatively small firms. 
Table 6.4

Average daily trading volume of stocks on the Amsterdam Stock Exchange (Figures in percent of shares outstanding)

PANEL A: YEARLY ANALYSIS: (JAN. 1984-JUNE 1989)

\begin{tabular}{|c|c|c|c|c|c|c|c|}
\hline & 1984 & 1985 & 1986 & 1987 & 1988 & 1989 & Total \\
\hline Mean & 0.187 & 0315 & 0.302 & 0.192 & 0.198 & 0.300 & 0.244 \\
\hline Median & 0.153 & 0237 & 0.218 & 0.164 & 0.152 & 0.206 & 0.196 \\
\hline St.Dev. & 0.168 & 0.339 & 0.263 & 0.200 & 0.171 & 0.326 & 0.182 \\
\hline Minimum & 0.000 & 0,003 & 0.003 & 0.004 & 0.002 & 0.000 & 0.005 \\
\hline Maximum & 1.087 & 2,424 & 1.530 & 1.216 & 0.959 & 2.014 & 1.003 \\
\hline
\end{tabular}

PANEL B: PRE-AND POST-RESTRICTION ANALYSIS

\begin{tabular}{lll}
\hline & PRE & POST \\
\hline Total Sample (114) & & \\
Mean & 0.268 & 0.216 \\
Median & 0.238 & 0.169 \\
St. Dev. & 0.214 & 0.176 \\
Minimum & 0.007 & 0.002 \\
Maximum & 1.285 & 0.892 \\
\hline
\end{tabular}

Large Firms (35)

$\begin{array}{lll}\text { Mean } & 0.171 & 0.168 \\ \text { Median } & 0.156 & 0.139 \\ \text { St. Dev. } & 0.130 & 0.142 \\ \text { Minimum } & 0.010 & 0.005 \\ \text { Maximum } & 0.488 & 0.700\end{array}$

Medium Firms (23)

\begin{tabular}{lll} 
Mean & 0.219 & 0.148 \\
Median & 0.189 & 0.121 \\
St. Dew. & 0.131 & 0.098 \\
Minimum & 0.039 & 0.019 \\
Maximum & 0.592 & 0.379 \\
\hline Sinall Finms (28) & & \\
Mean & & \\
Median & 0.368 & 0.299 \\
St. Dev. & 0.359 & 0.224 \\
Minimum & 0.278 & 0.235 \\
Maximum & 0.007 & 0.002 \\
Sation & 1.285 & 0.892
\end{tabular}


(Table 6.4, continued)

PANEL C: ESTMMATION PERIOD ANALYSIS

\begin{tabular}{|c|c|c|c|c|c|c|c|c|}
\hline 1. Anmual & $\begin{array}{l}\text { mings } \\
1985\end{array}$ & $\begin{array}{l}\text { की } \\
1986\end{array}$ & 1987 & 1988 & 1989 & PRE & POST & TOTAL \\
\hline $\begin{array}{l}\text { Mean } \\
\text { Median } \\
\text { St.Dev. } \\
\text { Minimum } \\
\text { Maximum }\end{array}$ & $\begin{array}{l}0.255 \\
0.182 \\
0.356 \\
0.000 \\
3.330\end{array}$ & $\begin{array}{l}0.332 \\
0.256 \\
0.269 \\
0.000 \\
1233\end{array}$ & $\begin{array}{l}0.206 \\
0.145 \\
0.271 \\
0.000 \\
2.165\end{array}$ & $\begin{array}{l}0.187 \\
0.147 \\
0.164 \\
0.000 \\
0.988\end{array}$ & $\begin{array}{l}0.248 \\
0.153 \\
0.298 \\
0.000 \\
2.096\end{array}$ & $\begin{array}{l}0.293 \\
0.217 \\
0.318 \\
0.000 \\
3.330\end{array}$ & $\begin{array}{l}0.214 \\
0.154 \\
0.252 \\
0.000 \\
2.165\end{array}$ & $\begin{array}{l}0.245 \\
0.177 \\
0.283 \\
0.000 \\
3.330\end{array}$ \\
\hline \multicolumn{9}{|c|}{ 2. Semi-Annual Earnings } \\
\hline $\begin{array}{l}\text { Mean } \\
\text { Median } \\
\text { St.Dev. } \\
\text { Minimum } \\
\text { Maximum }\end{array}$ & $\begin{array}{l}0.148 \\
0.113 \\
0.218 \\
0.000 \\
1.253\end{array}$ & $\begin{array}{l}0.274 \\
0.217 \\
0.281 \\
0.000 \\
1,979\end{array}$ & $\begin{array}{l}0.253 \\
0.178 \\
0.262 \\
0.000 \\
1.682\end{array}$ & $\begin{array}{l}0.177 \\
0.141 \\
0.186 \\
0.000 \\
1.577\end{array}$ & $\begin{array}{l}0.183 \\
0.133 \\
0.222 \\
0.000 \\
1.909\end{array}$ & $\begin{array}{l}0.225 \\
0.156 \\
0.249 \\
0.000 \\
1.979\end{array}$ & $\begin{array}{l}0.180 \\
0.136 \\
0.205 \\
0.000 \\
1.909\end{array}$ & $\begin{array}{l}0.207 \\
0.145 \\
0.233 \\
0.000 \\
1.979\end{array}$ \\
\hline
\end{tabular}

PANEL D: EVENT PERIOD ANALYSIS

1. Annual Earnings

\begin{tabular}{lcccccccc} 
& 1985 & 1986 & 1987 & 1988 & 1989 & PRE & POST & TOTAL \\
\hline Mean & 0.319 & 0.359 & 0.218 & 0.218 & 0.298 & 0.339 & 0.244 & 0.282 \\
Median & 0.235 & 0.250 & 0.146 & 0.141 & 0.207 & 0.240 & 0.159 & 0.183 \\
St.Dev. & 0.344 & 0.323 & 0.423 & 0.242 & 0.366 & 0.334 & 0.353 & 0.349 \\
Minimum & 0.002 & 0.003 & 0.000 & 0.000 & 0.000 & 0.000 & 0.000 & 0.000 \\
Maximum & 2.648 & 1.697 & 4.343 & 1.605 & 2.745 & 2.648 & 4.343 & 4.343 \\
\hline
\end{tabular}

2. Semi-Annual Earnings

\begin{tabular}{lcccccccc} 
& 1984 & 1985 & 1986 & 1987 & 1988 & PRE & POST & TOTAL \\
\hline Mean & 0.191 & 0.301 & 0.310 & 0.247 & 0.193 & 0.268 & 0.220 & 0.249 \\
Median & 0.104 & 0.205 & 0.204 & 0.142 & 0.137 & 0.173 & 0.139 & 0.154 \\
St.Dev. & 0.280 & 0.293 & 0.308 & 0.403 & 0.260 & 0.299 & 0.341 & 0.317 \\
Minimum & 0.000 & 0.003 & 0.011 & 0.001 & 0.000 & 0.000 & 0.000 & 0.000 \\
Maximum & 1.824 & 1.548 & 1.982 & 3.446 & 2.312 & 1.982 & 3.446 & 3.446 \\
\hline
\end{tabular}


Table 6.5

Abnormal trading volume around annual earnings announcements

(Total sample)

Panel A: Mean Adjusted Model

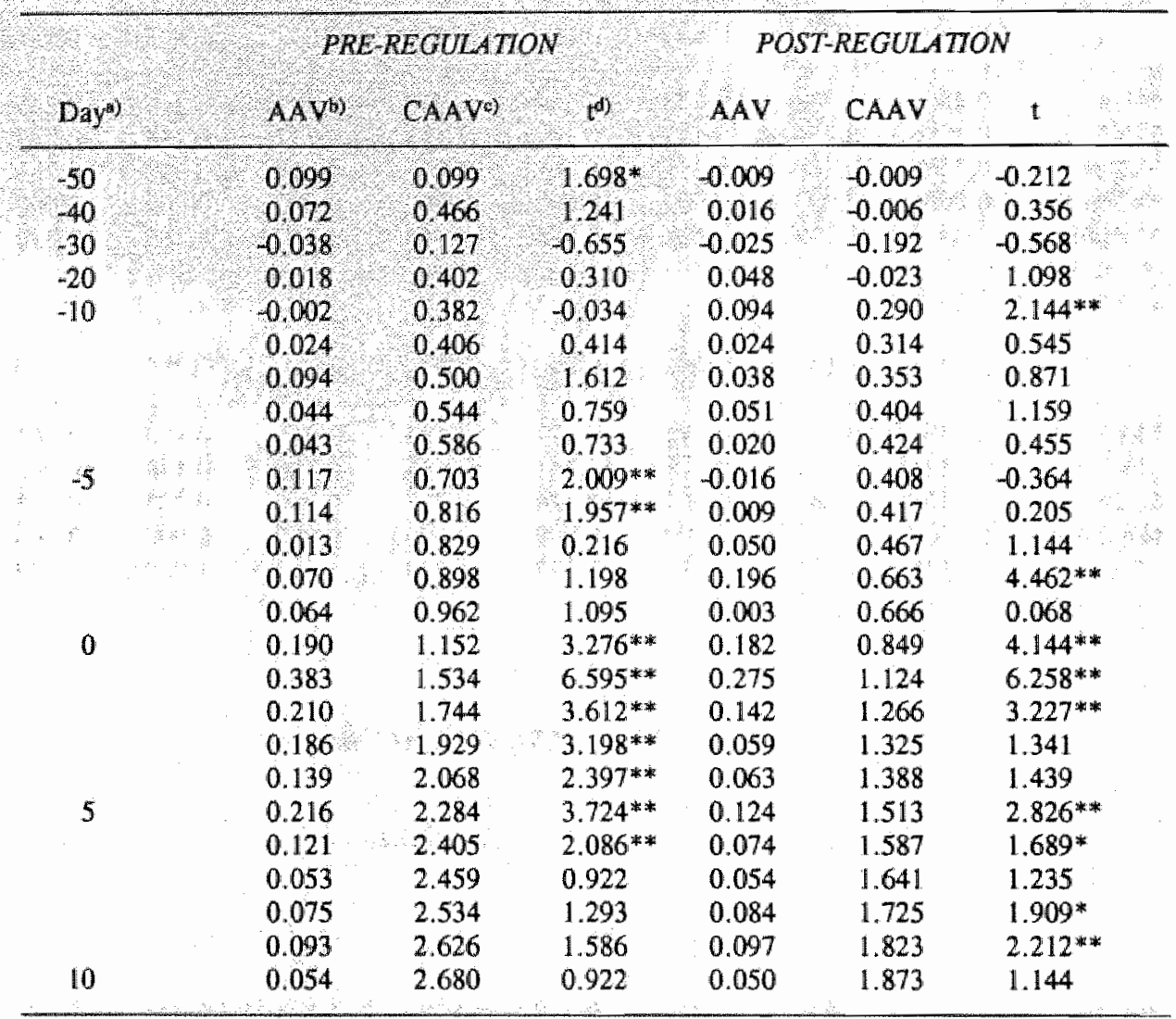


(Table 6.5, continued)

Panel B: Market Model

\begin{tabular}{|c|c|c|c|c|c|c|}
\hline \multirow[b]{2}{*}{ Day $y^{(8)}$} & \multicolumn{3}{|c|}{ PRE-REGULATION } & \multicolumn{3}{|c|}{ POST-REGULATION } \\
\hline & $A A V^{b}$ & CAAY & $t^{d}$ & $\mathrm{AAV}$ & CAAV & 1 \\
\hline-50 & 0.063 & 0.063 & 1.453 & -0.020 & -0.020 & -0.504 \\
\hline-40 & 0.038 & 0.078 & 0.872 & 0.005 & 0.181 & 0.120 \\
\hline-30 & 0.042 & -0.482 & -0.988 & -0.021 & -0.449 & -0.547 \\
\hline-20 & 0.017 & -0.205 & 0.407 & -0.015 & -0.513 & -0.385 \\
\hline \multirow[t]{5}{*}{-10} & -0.003 & -0.259 & -0.070 & 0.067 & -0.857 & $1.718^{k}$ \\
\hline & 0.012 & -0.247 & 0.267 & 0.0008 & -0.850 & 0.197 \\
\hline & 0.070 & -0.177 & 1.628 & -0.013 & -0.863 & -0.342 \\
\hline & 0.024 & -0.153 & 0.558 & 0.002 & -0.861 & 0.060 \\
\hline & 0.028 & -0.125 & 0.651 & -0.017 & -0.878 & -0.436 \\
\hline \multirow[t]{5}{*}{-5} & 0.089 & -0.036 & $2.070^{*}$ & -0.126 & -1.004 & $-3.239^{*}$ \\
\hline & 0.092 & 0.056 & $2.140^{* * *}$ & -0.039 & -1.043 & $-1,000$ \\
\hline & 0.007 & 0.049 & -0.163 & 0.012 & -1.031 & 0.316 \\
\hline & 0,048 & 0.096 & 1.105 & 0.133 & -0.897 & 3.419 * \\
\hline & 0,025 & 0.121 & 0.581 & -0.072 & -0.969 & $-1.838 *$ \\
\hline \multirow[t]{5}{*}{0} & 0,150 & 0.271 & $3.488^{* * *}$ & 0.138 & -0.831 & $3.530^{* * *}$ \\
\hline & 0,329 & 0.600 & $7.640^{*}$ & 0.257 & -0.574 & $6.590^{* *}$ \\
\hline & 0.178 & 0.778 & 4. $140^{*}$ & 0.100 & -0.474 & $2.573 *$ \\
\hline & 0.156 & 0.934 & $3.628 * *$ & 0.022 & -0.452 & 0.573 \\
\hline & 0.094 & 1028 & $2.186^{* *}$ & 0,022 & -0.430 & 0.564 \\
\hline \multirow[t]{5}{*}{5} & 0.179 & 1207 & $4.163^{* *}$ & 0.107 & -0.322 & $2.752 *$ \\
\hline & 0.096 & 1.303 & $2.221 *$ & 0.035 & -0.287 & 0.897 \\
\hline & 0.037 & 1.340 & 0.860 & 0.010 & -0.277 & 0.265 \\
\hline & 0.052 & 1.391 & 1.198 & 0.065 & -0.212 & 1.658 \\
\hline & 0.066 & 1.457 & 1.523 & 0.076 & -0.136 & $1.957^{*}$ \\
\hline 10 & 0.043 & 1.499 & 0.988 & 0.022 & -0.11 .4 & 0.564 \\
\hline
\end{tabular}


(Table 6.5, continued)

Panel C: Adjusted Market Model

\begin{tabular}{|c|c|c|c|c|c|c|}
\hline \multirow[b]{2}{*}{ Day } & \multicolumn{3}{|c|}{ PRE-REGULATION } & \multicolumn{3}{|c|}{ POST-REGULATTON } \\
\hline & AAY & CAAV & $t^{d)}$ & AAV & CAAV & t \\
\hline-50 & 0,066 & 0.066 & 1.535 & -0.021 & -0.021 & -0.547 \\
\hline-40 & 0,046 & 0188 & 1.058 & 0.008 & -0.143 & 0.205 \\
\hline-30 & 0.037 & -0.254 & -0.849 & -0.026 & -0.438 & -0.658 \\
\hline-20 & 0.022 & 0.097 & 0.512 & -0.021 & -0.549 & -0.538 \\
\hline \multirow[t]{5}{*}{-10} & 0.001 & 0.122 & 0.023 & 0.065 & -0.911 & 1.667 \\
\hline & 0.019 & 0.141 & 0.442 & 0.005 & -0.905 & 0.137 \\
\hline & 0.082 & 0.223 & $1.895^{*}$ & -0.003 & -0.908 & -0.077 \\
\hline & 0.035 & 0.257 & 0.802 & 0.002 & -0.906 & 0.060 \\
\hline & 0.032 & 0.289 & 0.733 & -0.016 & -0.922 & -0.410 \\
\hline \multirow[t]{5}{*}{-5} & 0.101 & 0.390 & $2.349 *$ & -0.133 & -1.055 & $-3.402 * *$ \\
\hline & 0.103 & 0.492 & $2.384 *$ & -0.047 & -1.101 & -1.197 \\
\hline & 0.012 & 0.504 & 0.279 & 0.005 & -1.096 & 0.137 \\
\hline & 0.060 & 0.564 & 1.395 & 0.130 & -0.966 & 3.325 \\
\hline & 0.031 & 0.595 & 0.709 & -0.059 & -1.025 & -1.504 \\
\hline \multirow[t]{5}{*}{0} & 0.162 & 0.756 & $3.756^{* *}$ & 0.138 & -0.887 & $3.530^{* *}$ \\
\hline & 0.346 & 1.102 & $8.035^{* *}$ & 0.252 & -0.636 & $6.453^{* *}$ \\
\hline & 0.193 & 1.295 & $4.488^{*}$ & 0.096 & -0.539 & $2.470^{* *}$ \\
\hline & 0.172 & 1.467 & $4,000^{* *}$ & 0.017 & -0.523 & 0.427 \\
\hline & 0.105 & 1.572 & $2.442 * *$ & 0.018 & -0.504 & 0.470 \\
\hline \multirow[t]{5}{*}{5} & 0.200 & 1.772 & $4.651 * *$ & 0.105 & -0.399 & $2.701 *$ \\
\hline & 0.113 & 1.884 & $2.616^{* *}$ & 0.031 & -0.368 & 0.795 \\
\hline & 0.052 & 1.936 & 1.198 & 0.009 & -0.359 & 0.239 \\
\hline & 0.061 & 1.997 & 1.419 & 0.066 & -0.292 & $1.701^{*}$ \\
\hline & 0.073 & 2.069 & $1.686^{*}$ & 0.079 & -0.213 & 2.034 \\
\hline 10 & 0.048 & 2.117 & 1.105 & 0.025 & -0.188 & 0.632 \\
\hline
\end{tabular}

a) Day = Day relative to the announcement day

b) $\mathrm{AAV}=$ Average abnormal volume

c) $\mathrm{CAAV}=$ Cumulative average abnormal volume

d) $t \quad$ t-statistic to test whether the average abrormal volume is significantly different from zero

* indicates significance at the $10 \%$ level

* indicates significance at the $5 \%$ level 
Table 6.6

Average abnormal daily trading volume around anmal eamings announcements (t-statistic within parentheses)

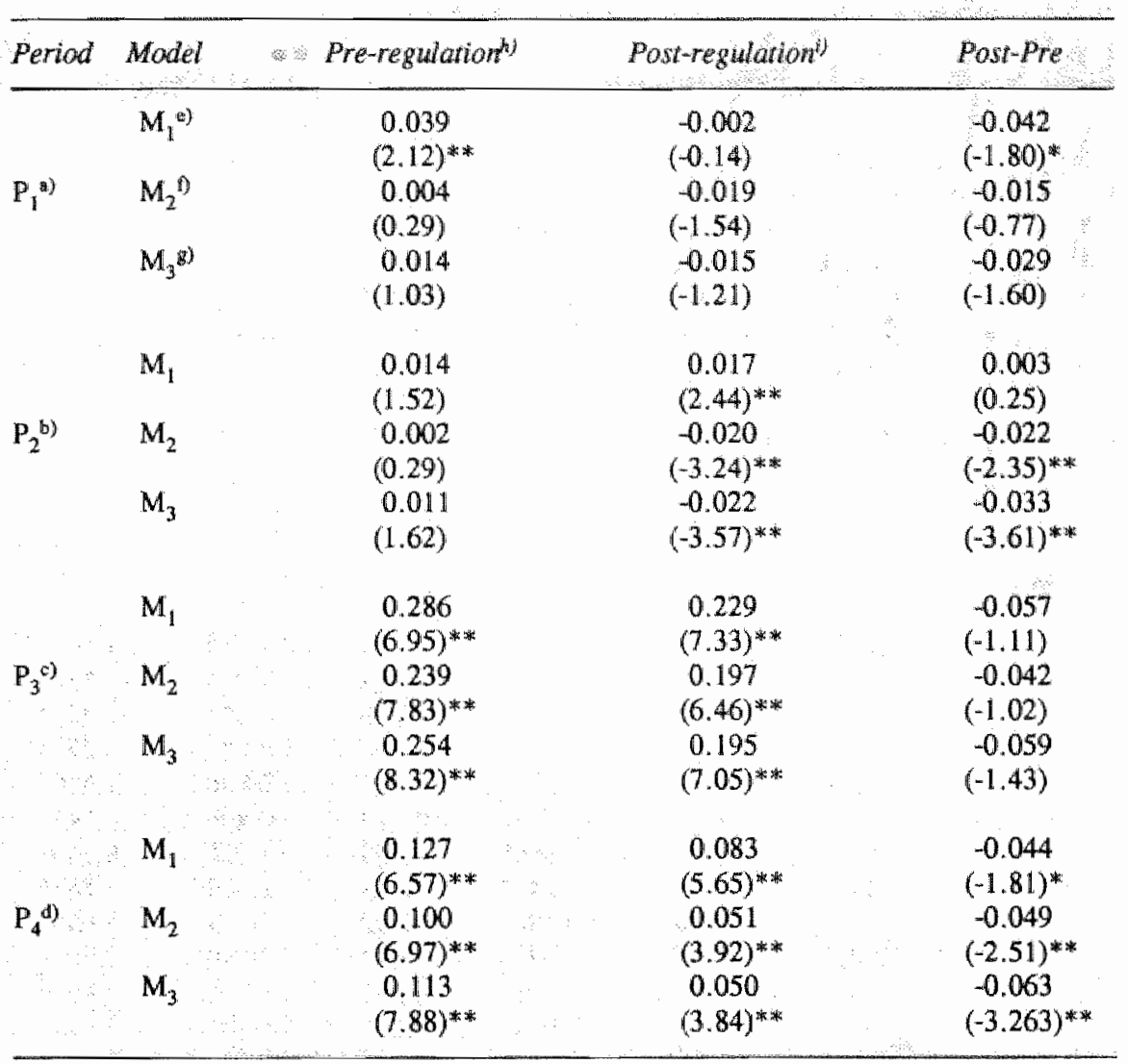

a) $P_{1}$ includes the 10 trading days preceding the restricted period $P_{2}$

b) $P_{2}$ is the restricted period which includes the 40 trading days preceding the earnings announcement

c) $P_{3}$ includes the announcement day and the day after

d) $\mathrm{P}_{4}$ includes the 9 trading days after $P_{3}$

e) $M_{1}$ assumes that the abnormal trading volume is equal to the average trading volume in a 100 day estimation pertiod

f) $\mathrm{M}_{2}$ assumes that the abnormal trading volume is generated by the Market Model

g) $\mathrm{M}_{3}$ assumes that the abnormal trading volume is generated by a Market Model adjusted for first-order serial correlation

b) includes all data before 1987

i) includes all data after 1986

* = significantly different from zero at the $10 \%$ level

** = significantly different from zero at the $5 \%$ level 
Table 6.7

Abnormal trading volume around anmual eamings announcements of small fims

Panel A: Mean Adjusted Model (small firms)

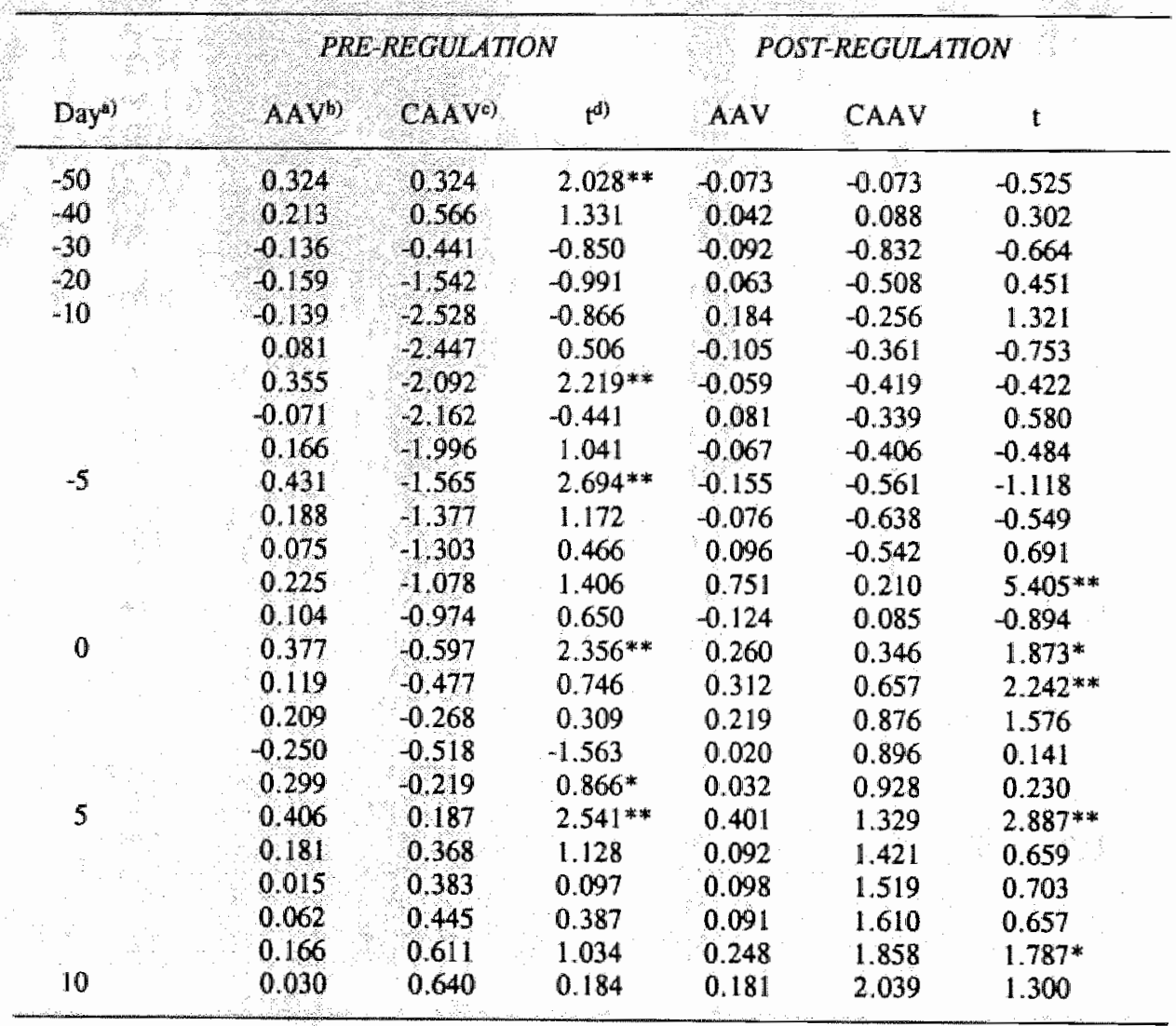


(Table 6.7, continued)

Panel B: Market Model (small firms)

\begin{tabular}{|c|c|c|c|c|c|c|c|}
\hline \multirow{2}{*}{\multicolumn{2}{|c|}{ Day ${ }^{a ! l}$}} & \multicolumn{3}{|c|}{ PRE-REGULATION } & \multicolumn{3}{|c|}{ POST-REGULATTON } \\
\hline & & AAVb) & CAAV & d) & $\mathrm{AAV}$ & CAAV & t \\
\hline-50 & & 0.241 & 0.241 & $1.795^{*}$ & -0.119 & -0.119 & 0.942 \\
\hline & $\therefore$ & 0.129 & -0.042 & 0.963 & 0.027 & -0.555 & 0.214 \\
\hline-30 & 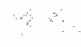 & -0.141 & -1.354 & -1.052 & -0.044 & -1.200 & -0.347 \\
\hline-20 & & -0.121 & -2.388 & -0.899 & -0.073 & -1.390 & -0.579 \\
\hline-10 & $\therefore$ & 0.141 & -3.357 & -1.052 & 0.100 & -2.539 & 0.796 \\
\hline & & 0.076 & -3.281 & 0.567 & -0.152 & -2.692 & -1.209 \\
\hline & & 0.342 & -2.939 & $2.552 * *$ & -0.153 & -2.844 & 4.212 \\
\hline & + & 0.133 & -3.072 & -0.993 & 0.008 & -2.836 & 0.063 \\
\hline & 8 & 0.105 & 2.967 & 0.784 & -0.126 & -2.963 & -1.003 \\
\hline-5 & 14: & 0.323 & $-2,644$ & $2.410^{*} *$ & -0.213 & -3.175 & $-1.688^{*}$ \\
\hline & & 0,117 & -2.528 & 0.869 & -0.209 & -3.384 & -1.656 \\
\hline & 8 & 0.035 & -2.493 & 0.257 & 0.004 & -3.380 & 0.032 \\
\hline & $\therefore: 8$ & 0.176 & -2.317 & 1.313 & 0.550 & -2.830 & $4.368 * *$ \\
\hline & की & 0.060 & 2.377 & -0.448 & -0.346 & -3.176 & $-2.746^{* *}$ \\
\hline 0 . & & 0.240 & 2137 & $1.791^{*}$ & 0.119 & -3.057 & 0.942 \\
\hline & बs. & 0.672 & -1.465 & $5.015^{* *}$ & 0.236 & -2.821 & $1.870^{*}$ \\
\hline & 8 & 0.179 & 1287 & 1.332 & 0.080 & -2.741 & 0.635 \\
\hline & & 0.189 & 1.097 & 1.414 & -0.057 & -2.799 & -0.455 \\
\hline & 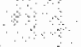 & 0.191 & 0.906 & 1.425 & -0.084 & -2.883 & -0.667 \\
\hline 5 & 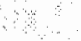 & 0.357 & 0.550 & $2,660^{*}$ & 0.372 & -2.510 & $2.955 *$ \\
\hline & \% & 0.201 & -0.349 & 1.500 & -0.020 & -2.531 & -0.161 \\
\hline & & 0.003 & -0.346 & 0.022 & 0.012 & -2.519 & 0.093 \\
\hline & a & 0.035 & -0.311 & 0.261 & 0.062 & -2.457 & 0.489 \\
\hline & & 0.105 & -0.206 & 0.784 & 0.191 & -2.266 & 1.516 \\
\hline 10 & $\cdots$ & 0.021 & 0.185 & 0.153 & 0.122 & -2.145 & 0.966 \\
\hline
\end{tabular}


(Table 6.7. continued)

Panel C: Adjusted Market Model (small fims)

\begin{tabular}{|c|c|c|c|c|c|c|}
\hline \multirow[b]{2}{*}{ Day } & \multicolumn{3}{|c|}{ PRE-REGULATTON } & \multicolumn{3}{|c|}{ POST-REGULATION } \\
\hline & $A_{A} A v^{b}$ & CAAV & $f^{d j}$ & AAV & CAAV & $\mathrm{t}$ \\
\hline-50 & 0.249 & 0.248 & 1.854 & -0.129 & -0.129 & -1.024 \\
\hline-40 & 0.165 & 0.270 & 1.231 & 0.033 & -0.434 & 0.259 \\
\hline-30 & $=0.122$ & -0.708 & -0.907 & -0.057 & -1.170 & -0.450 \\
\hline-20 & -0.115 & 1.526 & -0.858 & -0.090 & -1.546 & -0.717 \\
\hline \multirow[t]{5}{*}{-10} & 20.133 & -2.255 & -0.993 & 0.087 & 2.791 & 0.688 \\
\hline & 0.084 & 2.171 & 0.631 & -0.176 & -2.967 & -1.399 \\
\hline & 0.364 & -1.807 & $2.713^{*}$ & -0.140 & -3.107 & -1.111 \\
\hline & -0.093 & -1.900 & -0.690 & -0.012 & -3.119 & -0.093 \\
\hline & 0.120 & -1.780 & 0.896 & -0.140 & -3.259 & -1.111 \\
\hline \multirow[t]{5}{*}{-5} & 0.361 & -1.419 & $2.690^{* *}$ & -0.235 & -3.494 & $-1.868^{*}$ \\
\hline & 0.148 & -1.272 & 1.101 & -0.254 & -3.748 & $-2.013^{* * *}$ \\
\hline & 0.097 & -1.175 & 0.720 & -0.033 & -3.781 & -0.262 \\
\hline & 0.219 & -0.956 & 1.634 & 0.530 & 3.251 & $4.206^{* *}$ \\
\hline & -0.036 & -0.992 & -0.265 & -0.311 & -3.562 & $-2.468 *$ \\
\hline \multirow[t]{5}{*}{0} & 0.277 & -0.715 & $2.063^{* *}$ & 0.100 & -3.462 & 0.794 \\
\hline & 0.712 & -0.003 & $5.313^{*}$ & 0.202 & -3.260 & 1.603 \\
\hline & 0.214 & 0.210 & 1.593 & 0.039 & 3.221 & 0.310 \\
\hline & 0.238 & 0.448 & $1.772^{*}$ & 0.088 & -3.309 & -0.701 \\
\hline & 0.215 & 0.663 & 1.604 & -0.118 & -3.427 & -0.934 \\
\hline \multirow[t]{5}{*}{5} & 0.419 & 1.082 & $3.127 *$ & 0.354 & -3.073 & $2.810^{*}$ \\
\hline & 0.243 & 1325 & $1.813^{*}$ & -0.053 & -3.125 & -0.418 \\
\hline & 0.057 & 1.382 & 0.425 & -0.007 & -3.133 & -0.058 \\
\hline & 0.055 & 1.437 & 0.410 & 0.058 & -3.075 & 0.458 \\
\hline & 0.123 & 1.559 & 0.914 & 0.191 & -2.884 & 1.513 \\
\hline 10 & 0.043 & 1.602 & 0.317 & 0.109 & -2.775 & 0.865 \\
\hline
\end{tabular}

a) Day = Day relative to the announcement day

b) $\mathrm{AVV}=$ Average abnormal wolume

c) $\mathrm{CAAV}=$ Cumulative average abnormal volume

d) $\mathrm{t}=$ istatistie to test whether the average abnormal volume is significantly different from zero

* indicates significance at the $10 \%$ level

** indicates significance at the $5 \%$ level 
Table 6.8

Average abnormal daily trading volume for small fims around annual earnings announcements (t-statistic within parentheses)

\begin{tabular}{|c|c|c|c|c|}
\hline Periad & Model & Pre-regulariom & Post-regulation & Post-Pre \\
\hline \multirow{3}{*}{$P_{1}^{*}$} & $M_{1}^{e)}$ & $\begin{array}{r}0.035 \\
(0.69)\end{array}$ & $\begin{array}{c}0.013 \\
(-0.25)\end{array}$ & $\begin{array}{c}-0.048 \\
(-0.72)\end{array}$ \\
\hline & $\mathrm{M}_{2}$ & $\begin{array}{r}-0.017 \\
(-0.40)\end{array}$ & $\begin{array}{c}0.058 \\
(-1.46)\end{array}$ & $\begin{array}{c}0.041 \\
(-0.69)\end{array}$ \\
\hline & $\mathrm{M}_{3}{ }^{\mathrm{g})}$ & $\begin{array}{r}0.011 \\
(0.23)\end{array}$ & $\begin{array}{r}-0.047 \\
(-1.18)\end{array}$ & $\begin{array}{r}-0.036 \\
(-0.62)\end{array}$ \\
\hline \multirow{3}{*}{$\mathrm{P}_{2}^{\mathrm{b})}$} & $M_{1}$ & $\begin{array}{r}0.033 \\
(1.30)\end{array}$ & $\begin{array}{r}0.005 \\
(0.22)\end{array}$ & $\begin{array}{r}-0.038 \\
(-1.13)\end{array}$ \\
\hline & $\mathrm{M}_{2}$ & $\begin{array}{c}-0.055 \\
(-2.59)^{* *}\end{array}$ & $\begin{array}{c}-0.065 \\
(-3.26)^{* *}\end{array}$ & $\begin{array}{c}-0.01 \\
(-0.35)\end{array}$ \\
\hline & $\mathbf{M}_{3}$ & $\begin{array}{r}-0.027 \\
(-1.27)\end{array}$ & $\begin{array}{c}-0.077 \\
(-3.86)^{*}\end{array}$ & $\begin{array}{c}-0.05 \\
(-1.72)^{4}\end{array}$ \\
\hline \multirow{3}{*}{$P_{3}$} & $\mathrm{M}_{1}$ & $\begin{array}{c}0.248 \\
(2.19)^{* * *}\end{array}$ & $\begin{array}{c}0.286 \\
(2.90)^{2 * *}\end{array}$ & $\begin{array}{c}0.038 \\
(0.25)\end{array}$ \\
\hline & $\mathrm{M}_{2}$ & $\begin{array}{c}0.456 \\
(4.79)^{* *}\end{array}$ & $\begin{array}{c}0.178 \\
(1.91)^{*}\end{array}$ & $\begin{array}{c}-0.285 \\
(-2.19)^{*}\end{array}$ \\
\hline & $\mathrm{M}_{3}$ & $\begin{array}{c}0.495 \\
(5.20)^{* * *}\end{array}$ & $\begin{array}{c}0.151 \\
(1.68)^{*}\end{array}$ & $\begin{array}{c}0.344 \\
(-2.64)^{*}\end{array}$ \\
\hline \multirow{5}{*}{$P_{4}^{d j}$} & $M_{1}$ & 0.124 & 0.153 & 0.029 \\
\hline & & $(2.32)^{* *}$ & $(3.30)^{* * * *}$ & $(0.41)$ \\
\hline & $\mathrm{M}_{2}$ & 0,142 & 0.075 & 0.067 \\
\hline & $\mathrm{M}_{3}$ & $\begin{array}{l}(3.17)^{*} \\
0.178\end{array}$ & $\begin{array}{c}(1.78)^{-16} \\
0.054\end{array}$ & $\begin{array}{l}(-1.09) \\
-0.124\end{array}$ \\
\hline & & $(3.99)^{* *}$ & $(1.28)$ & $(-2.03)^{* * *}$ \\
\hline
\end{tabular}

a) $P_{1}$ includes the 10 trading days preceding the restricted period $P_{2}$

b) $P_{2}$ is the restricted period which includes the 40 trading days preceding the earnings announcement

c) $\mathrm{P}_{3}$ includes the announcement day and the day after

d) $\mathrm{P}_{4}$ includes the 9 trading days after $\mathrm{P}_{3}$

e) $M_{1}$ assumes that the abnormal trading volume is equall to the average trading volume in a 100 day estimation period

f) $M_{2}$ assumes that the abnormal trading volume is generated by the Market Model

g) $M_{3}$ assumes that the abnormal trading volume is generated by a Market Model adjusted for first-order serial correlation

h) includes all data before 1987

i) includes all data after 1986

* = significantly different from zero at the $10 \%$ level

** = significantly different from zero at the $5 \%$ level 
Table 6.9

Abnormal trading wolume around semi-anmul earnings announcements

(Total Sample)

Panel A: Mean Adjusted model

\begin{tabular}{|c|c|c|c|c|c|c|c|}
\hline \multirow[b]{2}{*}{ Day $y^{4}$} & & \multicolumn{3}{|c|}{ PRE RE GULATION } & \multicolumn{3}{|c|}{ POST-REGULATION } \\
\hline & & $\mathrm{AAYb}$ & CAAVe & $t^{d)}$ & $\mathrm{AAY}$ & CAAV & $\mathrm{t}$ \\
\hline-25 & & -0.031 & -0.031 & -0.721 & 0.019 & 0.019 & 0.543 \\
\hline-20 & & -0.055 & -0.225 & -1.287 & -0.025 & -0.026 & -0.714 \\
\hline-15 & & -0.005 & 0.218 & -0.124 & -0.010 & -0.105 & -0.300 \\
\hline \multirow[t]{5}{*}{-10} & & 0029 & -0.194 & -0.682 & -0.005 & -0.181 & -0.157 \\
\hline & & -0.016 & 0.210 & -0.380 & 0.153 & -0.028 & $4.357^{* *}$ \\
\hline & & 0.073 & 0.137 & $1.698 *$ & 0.223 & 0.195 & $6.386^{* * *}$ \\
\hline & & 0.031 & 0.106 & 0.729 & 0.007 & 0.202 & 0.200 \\
\hline & & 0.022 & 0.084 & 0.512 & 0.134 & 0.336 & $3.829 * *$ \\
\hline \multirow[t]{5}{*}{-5} & & 0.034 & 0.050 & 0.783 & 0.020 & 0.357 & 0.586 \\
\hline & & 0.138 & 0.087 & $3.202 * *$ & 0.004 & 0.361 & 0.114 \\
\hline & & 0.021 & 0.108 & 0.481 & 0.010 & 0.370 & 0.271 \\
\hline & & 0.054 & 0,162 & 1.264 & 0.076 & 0.446 & 2.17 \\
\hline & & 0.089 & 0.251 & $2.070 *$ & 0.019 & 0.466 & 0.557 \\
\hline \multirow[t]{5}{*}{0} & & 0.144 & 0.396 & $3.357 *$ & 0.082 & 0.548 & $2.343^{*} *$ \\
\hline & & 0.302 & 0.698 & $7.031 *$ & 0.366 & 0.914 & $10.457 *$ \\
\hline & & 0.173 & 0.871 & $4.023 * *$ & 0.151 & 1.065 & $4.314^{*}$ \\
\hline & & 0.112 & 0.983 & $2.605^{* *}$ & 0.211 & 1.275 & $6.014^{* *}$ \\
\hline & & 0.067 & 1.050 & 1.550 & 0.036 & 1.311 & $\mathbb{1} .029$ \\
\hline \multirow[t]{5}{*}{5} & & 0.120 & 1.169 & $2.783^{* *}$ & 0.077 & 1.388 & $2.186^{* *}$ \\
\hline & & 0.050 & 1.220 & 1.171 & -0.001 & 1.387 & -0.029 \\
\hline & & 0.072 & 1.291 & 1.667 & 0.023 & 1.410 & 0.671 \\
\hline & & 0.090 & 1.382 & $2.101 * *$ & 0.020 & 1.430 & 0.571 \\
\hline & & 0.028 & 1.410 & 0.659 & -0.026 & 1.405 & -0.729 \\
\hline 10 & & 0.013 & 1.423 & 0.295 & 0.048 & 1.452 & 1.357 \\
\hline
\end{tabular}


(Table 6.9, continued)

Panel B: Market Model

\begin{tabular}{|c|c|c|c|c|c|c|}
\hline \multirow[b]{2}{*}{ Day } & \multicolumn{3}{|c|}{ PRE-REGULATION } & \multicolumn{3}{|c|}{ POST-REGULATTON } \\
\hline & $\mathrm{AAV}^{\mathrm{b}}$ & CAAV & $t^{(1)}$ & AAN & CAAV & $t$ \\
\hline-25 & $-0,033$ & -0.033 & -0.990 & 0.028 & 0.028 & 0.814 \\
\hline-20 & -0.059 & -0.226 & $-1.788 *$ & -0.022 & 0.020 & -0.614 \\
\hline-15 & -0.025 & 0.309 & -0.747 & -0.048 & 0.090 & -1.371 \\
\hline-10 & $-0,067$ & 0.446 & $-2.020 * *$ & -0.036 & -0.254 & -1.014 \\
\hline & 0.045 & -0.490 & -1.354 & 0.150 & -0.105 & $4271 *$ \\
\hline & 0.040 & -0.450 & 1.222 & 0.220 & 0.115 & $6.271 * *$ \\
\hline & 0.007 & 0.457 & -0.222 & 0.028 & 0.142 & 0.786 \\
\hline & 0.007 & 0.464 & -0.212 & 0.131 & 0.273 & $3.729 *$ \\
\hline-5 & 0.000 & 0.465 & -0.010 & 0.026 & 0.299 & 0.743 \\
\hline & 0.096 & -0.368 & $2.919 * *$ & 0.001 & 0.301 & 0.043 \\
\hline & 0.010 & -0.378 & $=-0.303$ & 0.002 & 0.302 & 0.043 \\
\hline & 0.026 & -0.352 & 0.798 & 0.072 & 0.374 & $2.043^{* * *}$ \\
\hline \& & 0.047 & 0.305 & 1.414 & 0.021 & 0.395 & 0.600 \\
\hline 0 & 0.104 & -0.202 & 3. $141^{* *}$ & 0.085 & 0.479 & 2.414 \\
\hline मे & 0.246 & 0.044 & $7.455^{* * *}$ & 0.349 & 0.828 & $9.957 * *$ \\
\hline & 0.148 & 0.193 & $4.495^{* *}$ & 0.137 & 0.965 & $3.914^{* *}$ \\
\hline & 0.083 & 0.275 & $2.505 *$ & 0.189 & 1.154 & $5.400^{* *}$ \\
\hline & 0.033 & 0.309 & 1.010 & 0.038 & 1.192 & 1.086 \\
\hline 5 & 0,077 & 0.386 & $2.333^{* *}$ & 0.076 & 1.268 & $2.171 * *$ \\
\hline$\quad+$ & 0.027 & 0.413 & 0.818 & -0.003 & 1.265 & $-0,086$ \\
\hline & 0.050 & 0.463 & 1.525 & 0.036 & 1.301 & 1.029 \\
\hline & 0.051 & 0.514 & 1.535 & 0.023 & 1.323 & 0.643 \\
\hline$\therefore$ & 0.015 & 0.528 & 0.444 & -0.019 & 1.305 & -0.529 \\
\hline 10 & -0.002 & 0.527 & -0.051 & 0.054 & 1.358 & 1.529 \\
\hline
\end{tabular}


(Table 6.9 conimued)

Panel C: Adjusted Market Model

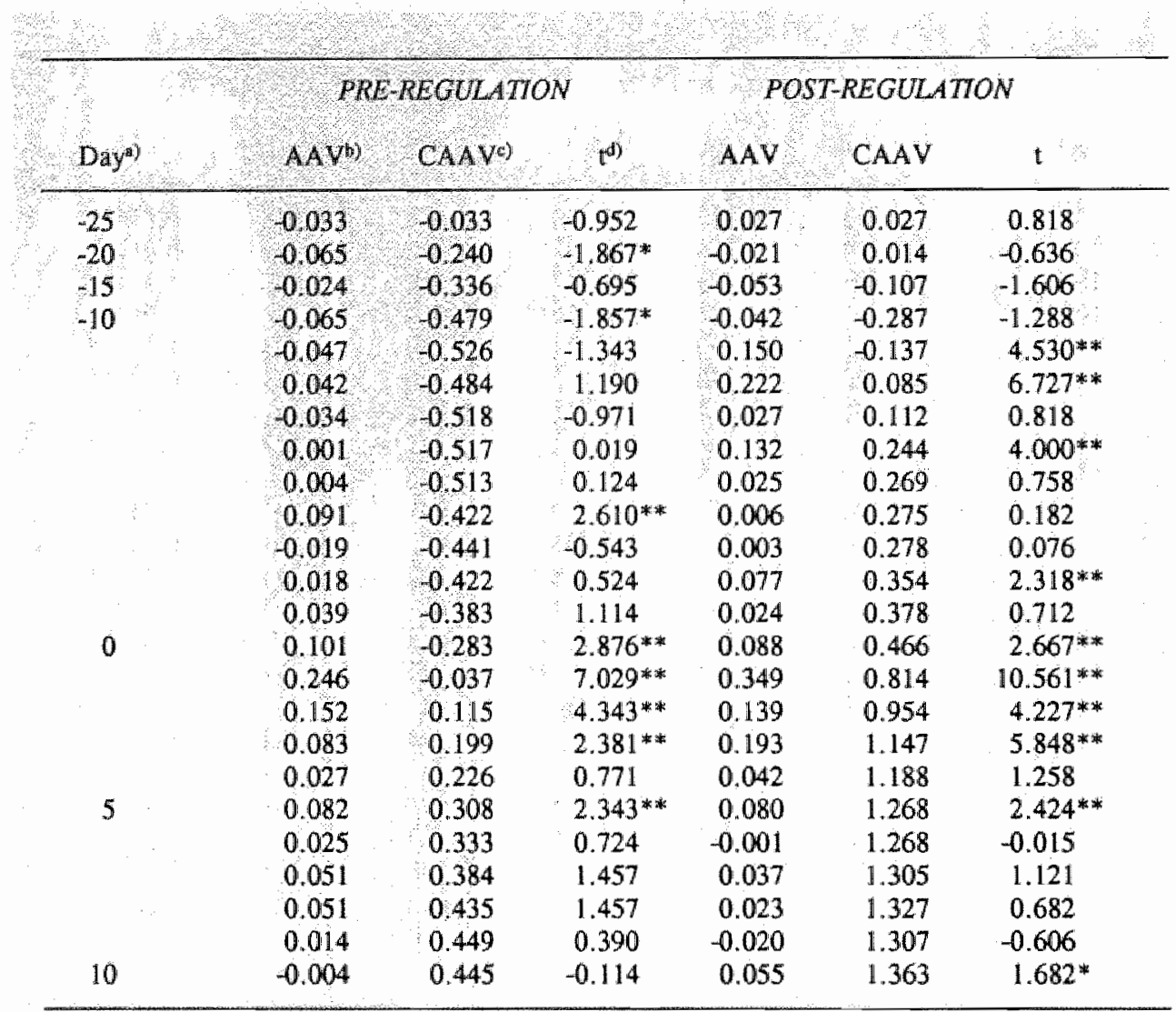

a) Day = Day relative to the announcement day

b) $\mathrm{AAV}=$ Average abnormal volume

c) $\mathrm{CAAV}=$ Cumulative average abnormal volume

d) $t=$ istatistic to test whether the average abnormal volume is significantly different from zero

* indicates significance at the $10 \%$ level

** indicates significance at the $5 \%$ level 
Table 6. 10

Average abnormall daily trading volume around sem-ammal earnings announcements (t-statistic within parentheses)

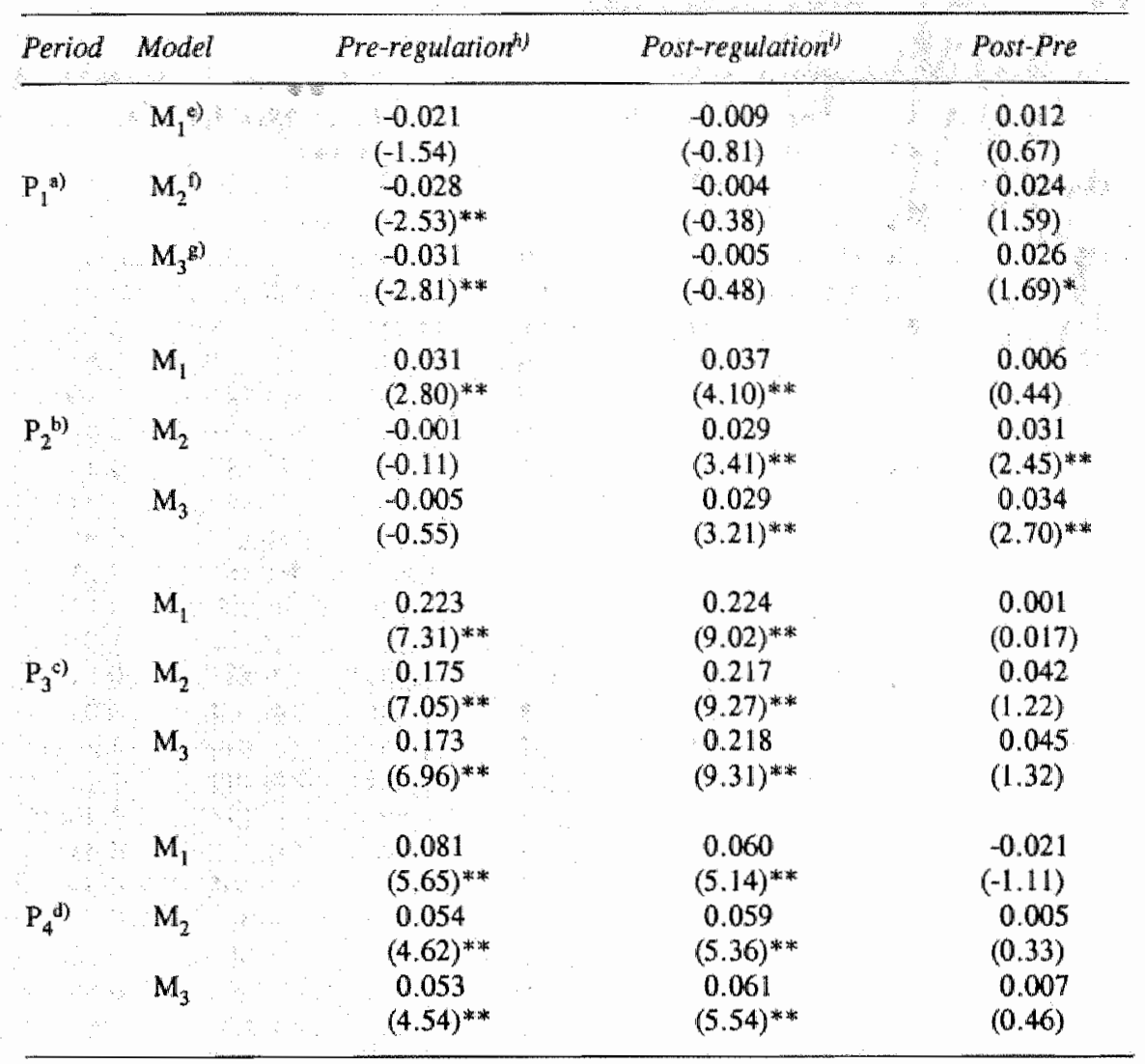

a) $P_{1}$ includes the 10 trading days preceding the restricted period $P_{2}$

b) $P_{2}$ is the restricted period which includes the 15 trading days precedirig the earnings announcement

c) $P_{3}$ includes the announcement day and the day after

d) $P_{4}$ includes the 9 trading days after $P_{3}$

e) $M_{1}$ assumes that the abnormal trading wolume is equal to the average trading volume in a 100 day estimation period

f) $\mathrm{M}_{2}$ assumes that the abnormal trading volume is generated by the Market Model

g) $M_{3}$ assumes that the abnormal trading volume is generated by a Market Model adjusted for first-order serial correlation

h) includes all data before 1987

i) includes all data after 1986

* = significantly different from zero at the $10 \%$ level

** = significantly different from zero at the $5 \%$ level 
Table 6.11

Abnormal trading volume around semi-anmal earnings announcements of small firms

Panel A.: Mean Adjusted Model (small firms)

\begin{tabular}{|c|c|c|c|c|c|c|}
\hline \multirow[b]{2}{*}{ Day } & \multicolumn{3}{|c|}{ PRE-REGULATION } & \multicolumn{3}{|c|}{ POST-REGULATION } \\
\hline & AAY'B & CAAVO & t) & AAV & CAAV & $t$ \\
\hline 25 & 0042 & 0,042 & -0.149 & $-0,108$ & -0.108 & -0.532 \\
\hline 20 & 0,084 & 0.312 & 0.302 & -0.085 & -0.265 & 0.419 \\
\hline-15 & 0112 & 0,392 & 0.401 & 0.144 & -0.615 & -0.706 \\
\hline \multirow[t]{5}{*}{-10} & -0.092 & 0.502 & 0.329 & -0.120 & -1.184 & -0.588 \\
\hline & 0.036 & -0.538 & 0.129 & -0.102 & -1.286 & -0.500 \\
\hline & 0.329 & 0.209 & 1.179 & -0.007 & -1.293 & -0.034 \\
\hline & 0.084 & 0125 & 0.301 & -0.092 & -1.385 & -0.453 \\
\hline & 0.048 & -0.077 & 0.173 & 0.081 & -1.305 & 0.395 \\
\hline \multirow[t]{5}{*}{-5} & 0,036 & -0.040 & 0.130 & 0.070 & -1.235 & 0.341 \\
\hline & 0,436 & 0.396 & 1.564 & 0.052 & -1.183 & 0.252 \\
\hline & 0.092 & 0.304 & 0.330 & -0.026 & -1.209 & -0.125 \\
\hline & 0,040 & 0.264 & $=0.145$ & 0.357 & -0.852 & $1.748^{*}$ \\
\hline & 0,132 & 0.396 & 0.473 & 0.021 & -0.831 & 0.105 \\
\hline \multirow[t]{5}{*}{0} & 0.161 & 0,557 & 0.578 & 0.006 & -0.824 & 0.032 \\
\hline & 0261 & 0.818 & 0.937 & 0.864 & 0.039 & $4.235 * *$ \\
\hline & 0.242 & 1.060 & 0.866 & 0.439 & 0.479 & 2. $154 * *$ \\
\hline & 0.037 & 1.097 & 0.134 & 0.695 & 1.174 & $3.404^{* *}$ \\
\hline & 0.059 & 1.157 & 0.213 & 0.088 & 1.262 & 0.431 \\
\hline \multirow[t]{5}{*}{5} & 0.161 & 1.317 & 0.576 & 0.143 & 1.404 & 0.699 \\
\hline & -0.039 & 1.278 & -0.140 & -0.035 & 1.369 & -0.172 \\
\hline & 0.097 & 1.375 & 0.346 & 0.018 & 1.387 & 0.088 \\
\hline & 0.060 & 1.435 & 0.216 & 0.103 & 1.490 & 0.502 \\
\hline & 0.011 & 1.446 & 0.039 & -0.013 & 1.476 & -0.066 \\
\hline 10 & -0.083 & 1.364 & -0.296 & 0.166 & 1.643 & 0.816 \\
\hline
\end{tabular}


Table 6.11 , continued)

Panel B: Marker Model (small firms)

\begin{tabular}{|c|c|c|c|c|c|c|}
\hline \multirow[b]{2}{*}{ Day $^{\mathbf{a})}$} & \multicolumn{3}{|c|}{ PRE-REGULATION } & \multicolumn{3}{|c|}{ POST-REGULATION } \\
\hline & AAY & (AAV & di) & $\mathrm{AAV}$ & CAAV & t \\
\hline-25 & 0.072 & 0.072 & -0.670 & -0.082 & -0.082 & 0.595 \\
\hline-20 & 0.123 & -0.467 & -1.139 & -0.068 & 0.155 & $-0,496$ \\
\hline-15 & -0.161 & 0.805 & 1.494 & -0.308 & -0.725 & -2.248 \\
\hline-10 & 0.154 & 1306 & -1.426 & -0.257 & 1.650 & -1.872 \\
\hline & 0.096 & 1.402 & -0.889 & 0.059 & 4.709 & -0.427 \\
\hline & 0.270 & 1132 & $2.500 *$ & 0.014 & -1.695 & 0.102 \\
\hline & 0.014 & 1,118 & 0.127 & -0.023 & -1.717 & -0.164 \\
\hline & 0.046 & 1.072 & 0.426 & 0.097 & -1.620 & 0.708 \\
\hline-5 & 0.018 & 1.054 & 0.164 & 0.109 & -1.511 & 0.796 \\
\hline & 0.362 & -0.692 & $3.352^{* * *}$ & 0.056 & -1.455 & 0.412 \\
\hline & 0.123 & -0.816 & -1.142 & -0.022 & -1.477 & -0.161 \\
\hline & 0.072 & 0.887 & -0.664 & 0.348 & -1.129 & $2.540^{* *}$ \\
\hline & 0.065 & -0.822 & 0.605 & 0.023 & -1.106 & 0.168 \\
\hline 0 & 0.132 & -0.690 & 1.225 & 0.040 & -1.066 & 0.288 \\
\hline & 0.215 & 0.475 & $1.991^{* *}$ & 0.841 & -0.226 & $6.135^{* * *}$ \\
\hline & 0.227 & 0.247 & $2.105^{* *}$ & 0.431 & 0.205 & $3,146^{*}$ \\
\hline & 0.010 & $-0,237$ & 0.093 & 0.643 & 0.848 & $4.690 *$ \\
\hline & 0,008 & -0.230 & 0.071 & 0.136 & 0.983 & 0.989 \\
\hline 5 & 0.099 & 0.131 & 0.917 & 0.170 & 1.153 & 1.237 \\
\hline & 0.064 & 0.195 & -0.593 & 0.027 & 1.181 & 0.201 \\
\hline & 0.098 & 0.097 & 0.907 & 0.076 & 1.257 & 0.555 \\
\hline & 0.008 & -0.089 & 0.071 & 0.145 & 1.402 & 1.058 \\
\hline & 0.044 & -0.045 & 0.410 & 0.020 & 1.422 & 0.146 \\
\hline 10 & -0.068 & -0.112 & -0.627 & 0.212 & 1.633 & 1.544 \\
\hline
\end{tabular}


(rable 6.11. conthued)

Panel C: Adjusted Market Model (small firms)

\begin{tabular}{|c|c|c|c|c|c|c|}
\hline \multirow[b]{2}{*}{ Daye) } & \multicolumn{3}{|c|}{ PRE-REGULATION } & \multicolumn{3}{|c|}{ POST-REGULATION } \\
\hline & $\left.A A V^{b}\right)$ & CAAVO & $t^{d y}$ & AAV & CAAV & $t$ \\
\hline-25 & 00071 & 0.071 & 0.654 & 0.079 & -0.079 & -0.577 \\
\hline-20 & 0.137 & 0,469 & 1.272 & 0.067 & -0.128 & -0.489 \\
\hline-15 & 0.172 & 0.867 & -1.590 & 0.319 & -0.692 & $-2328^{*}$ \\
\hline-10 & 0.170 & 1.441 & 1.574 & 0.279 & -1.632 & $-2.036^{*}$ \\
\hline " & 0,105 & 1.545 & -0.969 & 0.056 & 1.688 & -0.405 \\
\hline & 0.264 & -1.281 & 2.448 & 0.026 & -1.662 & 0.186 \\
\hline & 0.018 & 1.263 & 0.167 & 0.015 & -1.677 & -0.106 \\
\hline & 0.052 & 1211 & 0.481 & 0.101 & -1.575 & 0.741 \\
\hline-5 & 0.020 & 1,191 & 0.182 & 0.109 & 1.466 & 0.796 \\
\hline & 0.342 & -0.850 & $3.164 *$ & 0,073 & -1.393 & 0.533 \\
\hline & -0.142 & 0.992 & 1,315 & 0.011 & $-1,404$ & -0.080 \\
\hline & $=0.097$ & 1,089 & -0.901 & 0.372 & -1.032 & $2.715^{* *}$ \\
\hline & 0.031 & 1.058 & 0.284 & 0.037 & 0.996 & 0.266 \\
\hline 0 & 0.108 & 0.950 & 1.003 & 0.045 & -0.951 & 0.325 \\
\hline & 0.205 & 0.745 & $1.901^{*}$ & 0.844 & -0.107 & $6.161^{* *}$ \\
\hline & 0.233 & -0.512 & $2.154 *$ & 0.437 & 0.330 & $3.190^{* * *}$ \\
\hline & -0.011 & -0.523 & -0.105 & 0.658 & 0.988 & $4.803^{* *}$ \\
\hline & -0.040 & 0.563 & -0.370 & 0.148 & 1.136 & 1.080 \\
\hline 5 & 0.089 & $-0,474$ & 0.827 & 0.171 & 1.307 & 1.252 \\
\hline & -0.063 & -0.537 & -0.586 & 0.033 & 1.340 & 0.237 \\
\hline & 0.083 & -0.454 & 0.772 & 0.080 & 1.420 & 0.584 \\
\hline & -0.023 & -0.477 & -0.210 & 0.149 & 1.568 & 1.084 \\
\hline & 0.036 & 0.441 & 0.333 & 0.017 & 1.586 & 0.128 \\
\hline 10 & -0.085 & -0.526 & -0.787 & 0.210 & 1.795 & 1.529 \\
\hline
\end{tabular}
a) Day = Day relative to the announcement day
b) $\mathrm{AAV}=$ Average abnormal volume
c) $\mathrm{CAAV}=$ Cumulative average abnormal volume
d) $\mathrm{t}=\mathrm{t}$-statistic to test whether the average abnormal volume is significantly different from zero
* indicates significance at the $10 \%$ level
* * indicates significance at the $5 \%$ level 
Table 6.12

Average abnormal daily trading wolume for small firms around semiammal earrings announcements ( $t$-statistic within parentheses)

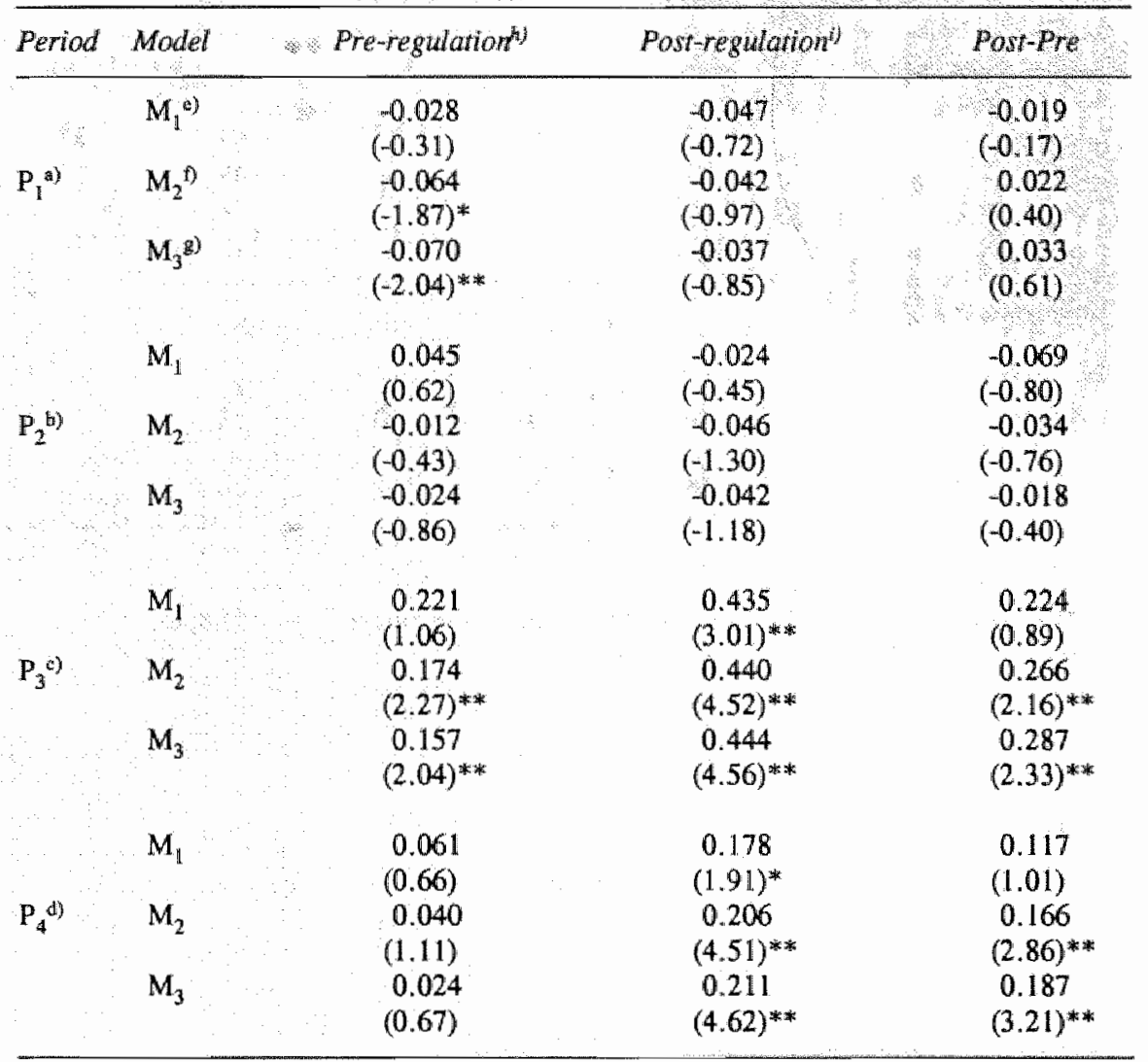

a) $P_{1}$ includes the 10 trading days preceding the restricted period $P_{2}$

b) $P_{2}$ is the restricted period which includes the 15 trading days preceding the earnings announcement

c) $\mathbb{P}_{3}$ includes the announcement day and the day after

d) $P_{4}$ includes the 9 trading days after $P_{3}$

e) $\mathrm{M}_{1}$ assumes that the abnormal trading volume is equal to the average trading volume in a 100 day estimation periou

f) $\mathrm{M}_{2}$ assumes that the abnormal trading volume is generated by the Market Model

g) $M_{3}$ assumes that the abnormal trading volume is generated by a Market Model adjusted for first-order serial correlation

h) includes all data before 1987

i) includes all data after 1986

* = significantly different from zero at the $10 \%$ level

** = significantly different from zero at the $5 \%$ level 
Table 6.13

Number of furms with eamings changes relatiwe to the previous year

\begin{tabular}{|c|c|c|c|c|c|}
\hline & 1985 & 1986 & 1987 & 1988 & 1989 \\
\hline \multicolumn{6}{|c|}{ Annual Earnings } \\
\hline \multirow{3}{*}{$\begin{array}{l}\text { Increase } \\
\text { Decreass }\end{array}$} & 83 & 80 & $\begin{array}{r}72 \\
\end{array}$ & 67 & 87 \\
\hline & 27 & 31 & 134 & 45 & 23 \\
\hline & 110 & 111 & 106 & 112 & 110 \\
\hline \multicolumn{6}{|c|}{ Semi-Annual Earnings } \\
\hline \multirow{3}{*}{$\begin{array}{l}\text { Increase } \\
\text { Decrease }\end{array}$} & 67 & 65 & 51 & 71 & \\
\hline & 29 & 30 & 50 & 28 & \\
\hline & 96 & 95 & 101 & 99 & \\
\hline
\end{tabular}

* Semi-annual earnings announcements of 1989 are not included in our sample. 
Table 6.14

Average and cumulative average abnormal returns around ammal earnings announcements (total sample)

Panel A: Annual Earmings Increase

\begin{tabular}{|c|c|c|c|c|c|c|}
\hline \multirow[b]{2}{*}{ Day } & \multicolumn{3}{|c|}{ PRE-REGULATION } & \multicolumn{3}{|c|}{ POST-REGULATTON } \\
\hline & $A A^{b}$ & CAAR & $\left.t^{d}\right)$ & AAR & $\mathrm{CAAR}$ & $t$ \\
\hline-50 & 0.006 & $=0.006$ & -0.034 & 0.124 & 0.124 & 0.971 \\
\hline-40 & 0.182 & 0.462 & 1.117 & -0.001 & 0.532 & -0.005 \\
\hline-30 & 0.184 & 1.181 & 1.129 & -0.033 & -0.130 & -0.255 \\
\hline-20 & 0.105 & 1.661 & -0.641 & 0.051 & -0.152 & 0.396 \\
\hline-10 & 0.292 & 1.929 & $1.788^{*}$ & -0.071 & 0.365 & -0.557 \\
\hline$\vdots \vdots$ & 0.323 & 2.252 & $1.979^{* * *}$ & 0.080 & -0.285 & 0.625 \\
\hline$\ldots$ & 0.039 & 2.290 & 0.236 & 0.250 & -0.035 & $1.953^{*}$ \\
\hline & 0.342 & 2.632 & $2.098 * *$ & -0.014 & -0.049 & -0.112 \\
\hline$\cdots$ & 0.138 & 2.770 & 0.847 & 0.030 & -0.019 & 0.237 \\
\hline-5 & 0.177 & 2.947 & 1.083 & -0.184 & -0.203 & -1.438 \\
\hline$\because 3$ & 0.135 & 3.082 & 0.828 & -0.213 & -0.416 & -1.664 \\
\hline \% & 0.067 & 3.149 & 0.411 & 0.095 & -0.321 & 0.742 \\
\hline 8 & $0: 189$ & 3.337 & 1.158 & 0.185 & -0.136 & 1.448 \\
\hline$\alpha$ & 0.184 & 3.521 & 1.129 & 0.056 & -0.079 & 0.440 \\
\hline 0 & 0.647 & 4.168 & $3.969^{\text {* * * }}$ & 0.516 & 0.436 & 4.029 * \\
\hline & 0.258 & 3.910 & -1.583 & 0.064 & 0.500 & 0.500 \\
\hline 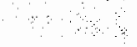 & 0.152 & 3.759 & -0.929 & 0.112 & 0.388 & -0.875 \\
\hline & 0.067 & 3.826 & 0.411 & -0.209 & 0.179 & -1.635 \\
\hline & 0.010 & 3.816 & -0.061 & -0.206 & -0.027 & -1.607 \\
\hline 5 & 0,164 & 3.652 & -1.003 & -0.072 & -0.098 & -0.560 \\
\hline & 0.077 & 3.576 & -0.469 & 0.150 & 0.052 & 1.174 \\
\hline & 0.128 & 3.448 & -0.782 & -0.007 & 0.045 & -0.052 \\
\hline & 0.108 & 3.340 & -0.663 & $-0,063$ & -0.017 & -0.490 \\
\hline$\therefore$ & -0.213 & 3.127 & 1.307 & -0.238 & -0.256 & -1.862 \\
\hline 10 & 0.091 & 3.219 & 0.561 & 0.135 & -0.121 & 1.055 \\
\hline
\end{tabular}


rable 6.14, cominued)

Panel B: Annual Eamings Decrease

\begin{tabular}{|c|c|c|c|c|c|c|}
\hline \multirow[b]{2}{*}{ Daya) } & \multicolumn{3}{|c|}{ PRE REGULATION } & \multicolumn{3}{|c|}{ POST-REGULATION } \\
\hline & $A A^{b}$ & $\left(A A^{\circ}\right)$ & $\pi^{d)}$ & $\mathrm{AAR}$ & CAAR & $t$ \\
\hline-50 & 0.044 & 0.044 & -0.136 & 0.244 & 0.244 & 1.204 \\
\hline 40 & 0.041 & 1418 & 0.127 & 0.222 & 0.826 & 1.094 \\
\hline-30 & 0,563 & -3165 & $-1.736^{*}$ & 0.030 & 1.594 & 0.146 \\
\hline-20 & 0,131 & -4.230 & 0.404 & -0.401 & 1.271 & $-1.977 * *$ \\
\hline \multirow[t]{5}{*}{-10} & 0.105 & -3.827 & 0.324 & -0.184 & 0.928 & -0.908 \\
\hline & -0.673 & 4.499 & $-2.076 *$ & -0.132 & 0.796 & -0.652 \\
\hline & 0.128 & -4.371 & 0.395 & 0.204 & 1.000 & 1.003 \\
\hline & 0.002 & 4.373 & -0.006 & -0.092 & 0.908 & -0.452 \\
\hline & -0.017 & -4.390 & -0.051 & 0.072 & 0.980 & 0.355 \\
\hline \multirow[t]{5}{*}{-5} & 0.298 & -4.687 & -0.918 & 0.156 & 1.136 & 0.768 \\
\hline & 0.118 & -4.570 & 0.363 & 0.149 & 1.285 & 0.732 \\
\hline & 0.155 & 4.415 & 0.477 & -0.023 & 1.262 & -0.113 \\
\hline & 0.052 & -4.363 & 0.160 & 0.223 & 1.485 & 1.100 \\
\hline & -0.295 & -4.658 & 0.910 & 0.288 & 1.773 & 1.420 \\
\hline \multirow[t]{4}{*}{0} & -0.884 & -5.542 & -2.728 & -0.717 & 1.056 & $-3.532 * *$ \\
\hline & -2.793 & -8.335 & $-8.620 *$ & -1.515 & -0.459 & $-7.465^{* *}$ \\
\hline & -0.128 & -8.463 & -0.395 & 0.465 & 0.006 & $2.292^{*}$ \\
\hline & 0.498 & .7 .965 & 1.537 & -0.153 & -0.146 & -0.752 \\
\hline . & -0.133 & -8.098 & -0.409 & -0.246 & -0.392 & -1.210 \\
\hline \multirow[t]{5}{*}{5} & 0.575 & -7.523 & $1.775^{*}$ & -0.246 & -0.638 & -1.212 \\
\hline & -0.022 & -7.545 & -0.068 & -0.042 & -0.680 & -0.205 \\
\hline & 0.119 & -7.663 & -0.366 & 0.089 & -0.591 & 0.438 \\
\hline & -0.193 & -7.857 & -0.597 & 0.250 & -0.340 & 1.233 \\
\hline & 0.035 & -7.892 & -0.108 & 0.308 & -0.032 & 1.519 \\
\hline 10 & 0.409 & -7.483 & 1.262 & -0.117 & -0.149 & -0.576 \\
\hline
\end{tabular}

a) Day = Day relative to the announcement day

b) $\mathrm{AAR}=$ Average abnormal return using the Market Model

c) $\mathrm{CAAR}=$ Cumulative average abnormal return

d) $t \quad=$ t-statistic to test whether the average abnormal return is significantly different from zero

* indicates significance at the $5 \%$ level

** indicates significance at the $10 \%$ level 
Table 6.15

Average and cumulative average abnormal retums around annual earnings announcements of small firms

Panel A: Annual Earmings Increase (small fims)

\begin{tabular}{|c|c|c|c|c|c|c|}
\hline \multirow[b]{2}{*}{ Day } & \multicolumn{3}{|c|}{ PRE-REGULATION } & \multicolumn{3}{|c|}{ POST-REGULATION } \\
\hline & $\mathrm{AAR}^{\mathrm{b})}$ & CAAR & $t^{d)}$ & AAR & CAAR & 1 \\
\hline-50 & -0.524 & -0.524 & -1.452 & -0.104 & -0.104 & -0.361 \\
\hline-40 & 0.151 & 2.129 & 0.417 & -0.001 & 1.425 & -0.002 \\
\hline-30 & 0.708 & 2.732 & $1.960 *$ & 0.020 & 0.516 & 0.069 \\
\hline-20 & 0.079 & 2.234 & 0.219 & -0.021 & 1.278 & -0.073 \\
\hline \multirow[t]{5}{*}{-10} & 0.221 & 3.023 & 0.612 & -0.142 & 1.191 & -0.491 \\
\hline & -0.073 & 2.951 & -0.201 & 0.457 & 1.648 & 1.582 \\
\hline & -0.073 & 2.878 & 0.201 & 0.380 & 2.029 & 1.316 \\
\hline & 0.406 & 3.284 & 1.125 & 0.365 & 2.394 & 1,264 \\
\hline & 0.042 & 3.326 & 0.116 & 0.147 & 2.541 & 0.509 \\
\hline \multirow[t]{5}{*}{-5} & 0.418 & 3.744 & 1.157 & -0.521 & 2.020 & -1.803 \\
\hline & -0.244 & 3.500 & -0.676 & -0.328 & 1.692 & -1.134 \\
\hline & 0.253 & 3.752 & 0.699 & 0.277 & 1.969 & 0.957 \\
\hline & 0.515 & 4.267 & 1.427 & 0.207 & 2.176 & 0.715 \\
\hline & -0.534 & 3.733 & -1.479 & -0.281 & 1.895 & -0.971 \\
\hline \multirow[t]{5}{*}{0} & 0.627 & 4.360 & $1.737^{*}$ & 0.332 & 2.227 & 1.149 \\
\hline & 0.596 & 4.956 & 1.651 & $-0,000$ & 2.227 & -0.001 \\
\hline & -0.365 & 4.592 & -1.010 & 0.130 & 2.357 & 0.451 \\
\hline & 0.299 & 4.890 & 0.827 & -0.418 & 1.939 & -1.446 \\
\hline & 0.496 & 5.386 & 1.373 & 0.144 & 2.083 & 0.499 \\
\hline \multirow[t]{5}{*}{5} & -0.390 & 4.996 & -1.079 & -0.140 & 1.943 & -0.486 \\
\hline & 0.685 & 4.311 & $-1.898^{*}$ & 0.419 & 2.362 & 1.449 \\
\hline & 0.264 & 4.575 & 0.731 & 0.133 & 2.494 & 0.459 \\
\hline & -0.252 & 4.324 & -0.697 & -0.260 & 2.234 & -0.900 \\
\hline & -0.122 & 4.202 & -0.338 & -0.072 & 2.162 & -0.250 \\
\hline 10 & -0.059 & 4.143 & -0.163 & 0.110 & 2.272 & 0.381 \\
\hline
\end{tabular}


(Table 6.15, continued)

Panel B: Annual Earnings Decrease (small firms)

\begin{tabular}{|c|c|c|c|c|c|c|}
\hline \multirow[b]{2}{*}{$D a y^{*}$} & \multicolumn{3}{|c|}{ PRE-REGULATTON } & \multicolumn{3}{|c|}{ POST-KEGULATTON } \\
\hline & $\left(A A R^{b)}\right.$ & CAAR & td) & $\mathrm{AAR}$ & CAAR & $\mathrm{t}$ \\
\hline-50 & 0.078 & 0.078 & -0.114 & 0.365 & 0.365 & 0.738 \\
\hline-40 & 0,361 & -3.243 & 0.529 & 0.188 & 2.153 & 0.380 \\
\hline-30 & $-0,642$ & -5.370 & -0.943 & -0.613 & 3.783 & -1.241 \\
\hline-20 & -0.247 & -7.474 & -0.362 & -0.376 & 2.743 & -0.761 \\
\hline \multirow[t]{5}{*}{-10} & -0.293 & -8.069 & -0.430 & $-0,309$ & 1.792 & -0.625 \\
\hline & -0.386 & -8.454 & -0.566 & -0.058 & 1.734 & -0.118 \\
\hline & -0.387 & -8.842 & -0.569 & 0.343 & 2.077 & 0.694 \\
\hline & -0.525 & -9.367 & -0.771 & 0.152 & 2.228 & 0.307 \\
\hline & 0.237 & -9.604 & -0.348 & -0.229 & 1.999 & -0.464 \\
\hline \multirow[t]{5}{*}{-5} & -0.353 & -9.957 & -0.518 & -0.476 & 1.523 & -0.964 \\
\hline & 0.538 & -9.419 & 0.790 & -0.440 & 1.083 & -0.891 \\
\hline & 0.249 & -9.169 & 0.366 & -0.076 & 1.006 & -0.155 \\
\hline & -0.090 & -9.259 & -0.132 & 0.864 & 1.870 & $1.748 *$ \\
\hline & -1.026 & -10.285 & -1.506 & 0.058 & 11.928 & 0.117 \\
\hline \multirow[t]{5}{*}{0} & -1.216 & -11500 & $-1.785^{*}$ & -0.069 & 1.859 & -0.139 \\
\hline & -3.398 & -14.898 & $-4.989 *$ & -3.039 & -1.179 & $-6.151 *$ \\
\hline & 0.188 & -14.710 & 0.276 & 1.085 & -0.094 & $2.196 * *$ \\
\hline & 0.591 & -14.119 & 0.868 & -0.764 & -0.858 & -1.547 \\
\hline & -0.063 & -14.182 & -0.093 & -0.771 & -1.629 & -1.560 \\
\hline \multirow[t]{5}{*}{5} & 0.677 & -13.505 & 0.993 & -0.749 & -2.378 & -1.516 \\
\hline & -0.106 & -13.611 & -0.155 & 0.160 & -2.218 & 0.325 \\
\hline & -0.592 & -14.203 & -0.869 & 0.411 & -2.629 & -0.832 \\
\hline & -0.609 & -14.811 & -0.894 & 0.121 & -2.508 & 0.245 \\
\hline & -0.146 & -14.957 & -0.214 & 0.789 & -1.719 & 1.596 \\
\hline 10 & 0.508 & -14.449 & 0.746 & -0.150 & -1.869 & -0.303 \\
\hline
\end{tabular}

a) Day $=$ Day relative to the announcement day

b) $\mathrm{AAR}=$ Average abmormal return using the Market Model

c) $\mathrm{CAAR}=$ Cumulative average abnormall return

d) $\mathrm{t}=\mathrm{t}$-statistic to test whether the average abnormal return is significantly different from zero

* indicates significance at the $5 \%$ level

* indicates significance at the $10 \%$ level 
Table 6.16

Average and cumulative average abnormall returns

around semi-anmal earnings announcements (total sample)

Panel A: Semi-annual Eamings Increase

\begin{tabular}{|c|c|c|c|c|c|c|}
\hline \multirow[b]{2}{*}{ Days) } & \multicolumn{3}{|c|}{ PRE-REGULATION } & \multicolumn{3}{|c|}{ POST-REGULATION } \\
\hline & $\mathrm{AAR}^{\mathrm{b}}$ & $\left(\mathrm{AAR}^{\mathrm{C}}\right.$ & $t^{d)}$ & AAR & CAAR & t: \\
\hline-25 & 0.184 & -0.184 & -1.269 & -0.096 & -0.096 & -0.568 \\
\hline-20 & 0.121 & -0.479 & 0.834 & -0.143 & 0.393 & -0.851 \\
\hline-15 & -0.031 & -0.601 & -0.214 & 0.246 & -0.671 & 1.461 \\
\hline-10 & 0.163 & -0.905 & -1.124 & -0.075 & -0.835 & -0.446 \\
\hline & -0.181 & $-1: 085$ & -1.245 & 0.032 & -0.803 & 0.188 \\
\hline & -0.215 & -1.300 & -1.483 & 0.169 & 0.634 & 1.009 \\
\hline & 0.073 & -1.373 & -0.503 & -0.069 & -0.703 & -0.411 \\
\hline$\cdots$ & 0.026 & -1.347 & 0.179 & 0.002 & -0.701 & 0.009 \\
\hline$\therefore$ & 0.192 & -1.156 & 1.321 & 0.142 & -0.559 & 0.845 \\
\hline & 0.073 & -1.083 & 0.503 & 0.059 & -0.500 & 0.351 \\
\hline & 0.014 & -1.097 & -0.097 & 0.290 & -0.210 & $1.726^{*}$ \\
\hline & 0.163 & -0.934 & 1.121 & 0.077 & -0.133 & 0.458 \\
\hline & 0.128 & 0.807 & 0.879 & -0.103 & -0.235 & -0.610 \\
\hline 0 & 0.507 & -0.300 & $3.497 * *$ & 0.546 & 0.310 & $3.247 * *$ \\
\hline & 0.994 & 0.695 & $6.859 * *$ & -0.236 & 0.074 & -1.405 \\
\hline & 0.209 & 0.903 & 1.438 & -0.053 & 0.021 & -0.315 \\
\hline & 0.285 & 1.189 & $1.966^{* *}$ & 0.048 & 0.070 & 0.289 \\
\hline & 0.150 & $1: 039$ & -1.034 & 0.005 & 0.075 & 0.030 \\
\hline 5 & 0.068 & 1.107 & 0.469 & 0.067 & 0.008 & 0.396 \\
\hline & 0.113 & 0.993 & -0.783 & 0.016 & 0.024 & 0.095 \\
\hline & 0.026 & 1019 & 0.179 & 0.077 & 0.101 & 0.458 \\
\hline & 0.354 & 1373 & $2.441^{* *}$ & 0.005 & 0.106 & 0.027 \\
\hline & -0.029 & 1.344 & -0.203 & 0.120 & 0.225 & 0.711 \\
\hline 10 & 0.111 & 1.454 & 0.762 & 0.244 & -0.018 & -1.449 \\
\hline
\end{tabular}


Table 6.16, continued)

Panel B: Semi-annual Eamings Decrease

\begin{tabular}{|c|c|c|c|c|c|c|}
\hline \multirow[b]{2}{*}{ Datya) } & \multicolumn{3}{|c|}{ PRE-REGULATION } & \multicolumn{3}{|c|}{ POST-REGULATTON } \\
\hline & $A A \mathbb{R}^{6)}$ & CAAR & $\mid$ & AAR & CAAR & $\mathrm{t}$ \\
\hline-25 & -0.093 & -0.093 & -0.293 & -0.060 & -0.060 & -0.225 \\
\hline-20 & 0.020 & 0.334 & -0.062 & 0.177 & 0.098 & 0.666 \\
\hline-15 & -0.029 & 0.600 & -0.091 & 0.013 & -0.097 & 0.047 \\
\hline \multirow[t]{5}{*}{-10} & 0.392 & 1.234 & 1.235 & 0.246 & 0.210 & 0.926 \\
\hline & 0.051 & 1.183 & -0.159 & 0.313 & 0.523 & 1.181 \\
\hline & 0.198 & 1382 & 0.626 & 0.234 & 0.757 & 0.881 \\
\hline & -0.136 & 1.246 & -0.429 & 0.018 & 0.774 & 0.066 \\
\hline & -0.141 & 1.105 & -0.445 & -0.005 & 0.770 & -0.017 \\
\hline \multirow[t]{2}{*}{-5} & 0.002 & 1.107 & 0.006 & -0.182 & 0.588 & -0.685 \\
\hline & 0.091 & 1.197 & 0.285 & -0.128 & 0.461 & -0.481 \\
\hline & -0.318 & 0.880 & -1.002 & -0.121 & 0.340 & -0.455 \\
\hline & 0.029 & 0.909 & 0.091 & 0.037 & 0.378 & 0.142 \\
\hline & 0,231 & 1.139 & 0.727 & -0.245 & 0.133 & -0.925 \\
\hline \multirow[t]{5}{*}{0} & -2.449 & -1.310 & $-7.726^{*}$ & -0.296 & -0.163 & -1.115 \\
\hline & 4.074 & -5384 & $-12.850 *$ & -2.016 & -2.178 & $-7.606^{* *}$ \\
\hline & 0.277 & $-5,660$ & -0.872 & 0.242 & -1.937 & 0.911 \\
\hline & 0.021 & -5.639 & 0.068 & 0.346 & -1.591 & 1.304 \\
\hline & 0.097 & -5.542 & 0.304 & 0.266 & -1.325 & 1.004 \\
\hline \multirow[t]{5}{*}{5} & -0.253 & -5.795 & -0.798 & 0.641 & -0.685 & $2.417 * *$ \\
\hline & 0.655 & -5.140 & $2.066 *$ & 0.319 & -0.366 & 1.202 \\
\hline & 0.119 & -5.022 & 0.374 & 0.002 & -0.365 & 0.006 \\
\hline & 0.330 & -4.692 & 1.041 & 0.112 & -0.253 & 0.423 \\
\hline & 0.270 & -4.422 & 0.850 & -0.001 & -0.254 & -0.0066 \\
\hline 10 & 0.309 & 4.113 & 0.976 & -0.138 & -0.392 & -0.519 \\
\hline
\end{tabular}

a) Day = Day relative to the announcement day

b) $\mathrm{AAR}=$ Average abnormal return using the Market Model

c) $\mathrm{CAAR}=$ Cumulative average abnormal return

d) $\mathrm{t}=\mathrm{t}$-statistic to test whether the average abnormal return is significantly different from zero

* indicates significance at the $5 \%$ level

* indicates significance at the $10 \%$ level 
Table 6.17

Average and cumulative average abnormal returns around semi-amnual earnings announcements of small firms

Panel A: Seni-anmal Earmings Increase (small firms)

\begin{tabular}{|c|c|c|c|c|c|c|}
\hline \multirow[b]{2}{*}{ Day ${ }^{a}$} & \multicolumn{3}{|c|}{ PRE-REGULATION } & \multicolumn{3}{|c|}{ POST-REGULATION } \\
\hline & $A A R^{b}$ & $\left(A A R^{c)}\right.$ & $t^{d)}$ & AAR & CAAR & 1 \\
\hline-25 & 0.158 & -0.158 & -0.378 & -0.161 & -0.161 & -0.336 \\
\hline-20 & -0.003 & 0.428 & -0.007 & -0.223 & -0.245 & -0.466 \\
\hline-15 & 0.167 & 0.892 & 0.399 & $-0,096$ & -1.040 & 40.200 \\
\hline \multirow[t]{5}{*}{-10} & -0.575 & 0.287 & -1.378 & -0.094 & -0.856 & -0.196 \\
\hline & 0.043 & 0.330 & 0.102 & 0,289 & -0.567 & 0.603 \\
\hline & -1.546 & -1.216 & $-3.707 * *$ & 0.009 & 0.576 & -0.019 \\
\hline & 0.046 & -1.262 & -0.109 & -0.185 & 0.762 & -0.387 \\
\hline & 0.325 & 0.936 & 0.781 & 0.550 & -0.212 & 1.148 \\
\hline \multirow[t]{5}{*}{-5} & 0.102 & -0.835 & 0.243 & 0.127 & -0.085 & 0.265 \\
\hline & 0.216 & -0.618 & 0.519 & 0.083 & -0.002 & 0.172 \\
\hline & -0.683 & -1.301 & -1.637 & 0.230 & 0.227 & 0.479 \\
\hline & 0.106 & -1.196 & 0.253 & -0.015 & 0.213 & -0.030 \\
\hline & 0.461 & 0.735 & 1.106 & -0.565 & -0.352 & -1.178 \\
\hline \multirow[t]{5}{*}{0} & 1.486 & 0.752 & $3.564 * *$ & 0.439 & 0.087 & 0.918 \\
\hline & 1.612 & 2.363 & $3.865^{* * *}$ & -1.974 & -1.886 & -4.120 \\
\hline & 0.199 & 2.165 & -0.476 & 0.717 & -1.169 & 1.497 \\
\hline & 0.680 & 2.845 & 1.631 & 0.283 & -0.886 & 0.591 \\
\hline & 0.476 & 3.321 & 1.141 & -0.043 & -0.929 & -0.090 \\
\hline \multirow[t]{5}{*}{5} & 0,133 & 3.188 & -0.319 & -0.559 & -1.488 & -1.167 \\
\hline & 0.785 & 2.403 & $-1.882^{*}$ & 0.135 & -1.354 & 0.281 \\
\hline & -0.046 & 2357 & -0.109 & 0.389 & -0.965 & 0.812 \\
\hline & 0.026 & 2.383 & 0.062 & 0.439 & -0.526 & 0.916 \\
\hline & -0.267 & 2.116 & -0.640 & 0.017 & -0.509 & 0.035 \\
\hline 10 & 0.037 & 2.153 & 0.089 & -0.488 & -0.996 & -1.018 \\
\hline
\end{tabular}


(Table 6.17, continued)

Panel B: Semi-annual Earnings Decrease (small firms)

\begin{tabular}{|c|c|c|c|c|c|c|}
\hline \multirow[b]{2}{*}{ Day ${ }^{i 1}$} & \multicolumn{3}{|c|}{ PRE-REGULATION } & \multicolumn{3}{|c|}{ POST-REGULATION } \\
\hline & $\mathrm{AAR}^{\mathrm{bj}}$ & CAAR & $t^{d)}$ & AAR & CAAR & $t$ \\
\hline-25 & 0.340 & 0.340 & 0.397 & 0.075 & 0.075 & 0.155 \\
\hline-20 & 0.409 & 1.218 & 0.477 & 0.690 & -0.076 & 1.413 \\
\hline-15 & -0.476 & 0.122 & -0.555 & -0.380 & -1.443 & -0.779 \\
\hline \multirow[t]{5}{*}{-10} & 0.609 & 0.591 & 0.711 & -0.041 & -1.487 & -0.083 \\
\hline & 0.030 & 0.621 & 0.035 & 0.012 & -1.475 & 0.025 \\
\hline & 1.138 & 1.759 & 1.328 & 0.328 & -1.147 & 0.672 \\
\hline & -0.465 & 1.294 & -0.543 & -0.461 & -1.608 & -0.945 \\
\hline & -0.837 & 0.457 & -0.977 & 0.025 & -1.583 & 0.051 \\
\hline \multirow[t]{5}{*}{-5} & 0.385 & 0.842 & 0.449 & 0.399 & -1.184 & 0.818 \\
\hline & -0.721 & 0.121 & -0.841 & -0.314 & -1.498 & -0.643 \\
\hline & -1.038 & -0.917 & -1.211 & -0.201 & -1.700 & -0.413 \\
\hline & -0.780 & -1.697 & -0.910 & -0.132 & -1.832 & -0.272 \\
\hline & -0.277 & -1.974 & -0.324 & -0.369 & -2.201 & -0.756 \\
\hline \multirow[t]{5}{*}{0} & -3.553 & -5.527 & $-4.146^{*}$ & 0.275 & -1.926 & 0.564 \\
\hline & -3.790 & -9.317 & $-4.422^{*}$ & -2.257 & -4.183 & $-4.625^{* *}$ \\
\hline & -0.428 & -9.745 & -0.499 & 0.480 & -3.703 & 0.984 \\
\hline & 0.129 & -9.616 & 0.150 & -0.162 & -3.865 & -0.332 \\
\hline & -0.111 & -9.727 & -0.129 & 0.009 & -3.856 & 0.018 \\
\hline \multirow[t]{5}{*}{5} & -1.023 & -10.749 & -1.193 & 0.216 & -3.640 & 0.444 \\
\hline & 1.453 & -9.296 & $1.695^{*}$ & -0.338 & -3.977 & -0.692 \\
\hline & 1.418 & -7.879 & 1.654 & 0.178 & -3.800 & 0.364 \\
\hline & 0.706 & -7.173 & 0.823 & 0.526 & -3.274 & 1.077 \\
\hline & 0.041 & $-7,132$ & 0.048 & 0.008 & -3.266 & 0.016 \\
\hline 10 & 1.010 & -6.122 & 1.179 & -0.927 & -4.193 & $-1.899 *$ \\
\hline
\end{tabular}
a) Day = Day relative to the announcement day
b) $\mathrm{AAR}=$ Average abnormal return using the Market Model
c) $\mathrm{CAAR}=$ Cumulative average abnormal return
d) $\mathrm{t}=$ t-statistic to test whether the average abnormal return is significantly different from zero
* indicates significance at the $10 \%$ level
** indicates significance at the $5 \%$ level 
Figure 6.2

Cumulative average abnormal trading volume (as a percentage of total shares outstanding) around annual earnings announcements

Panel A: Model 1

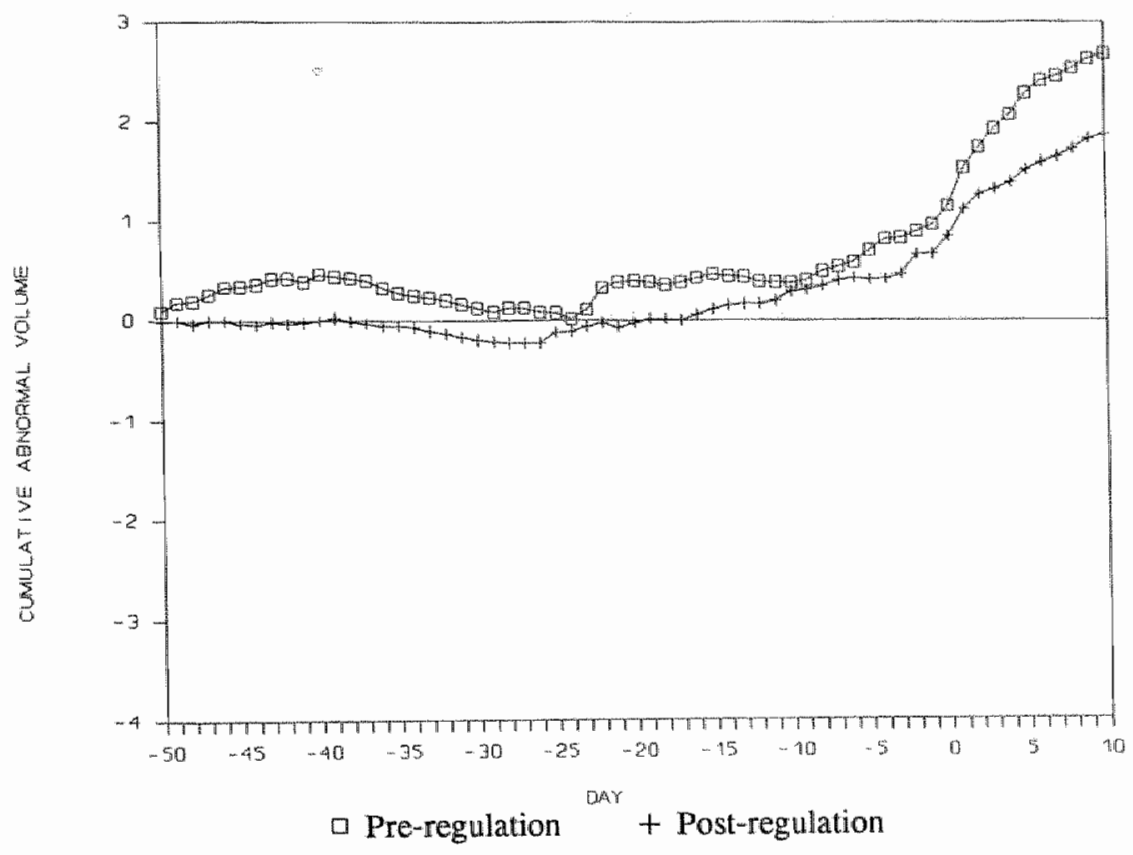

Panel B: Model 2

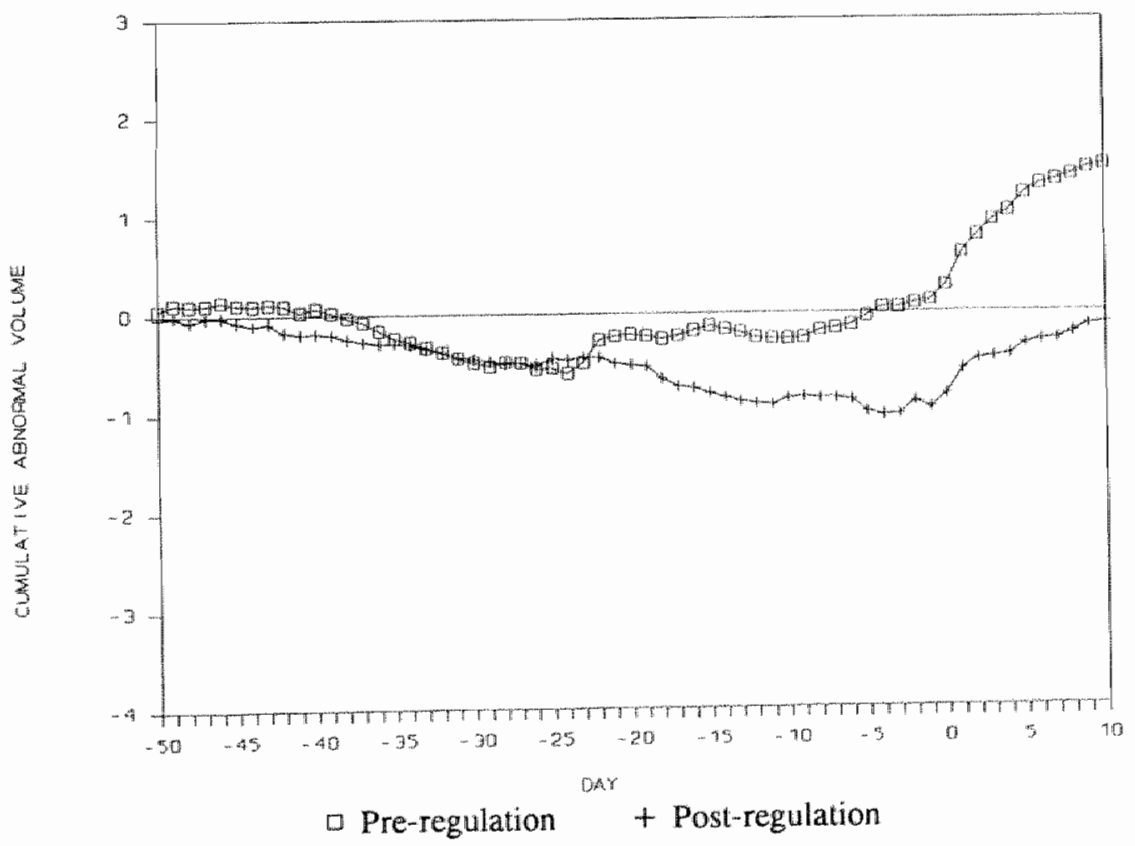


(Figure 6.2, coninued)

Panel C: Model 3

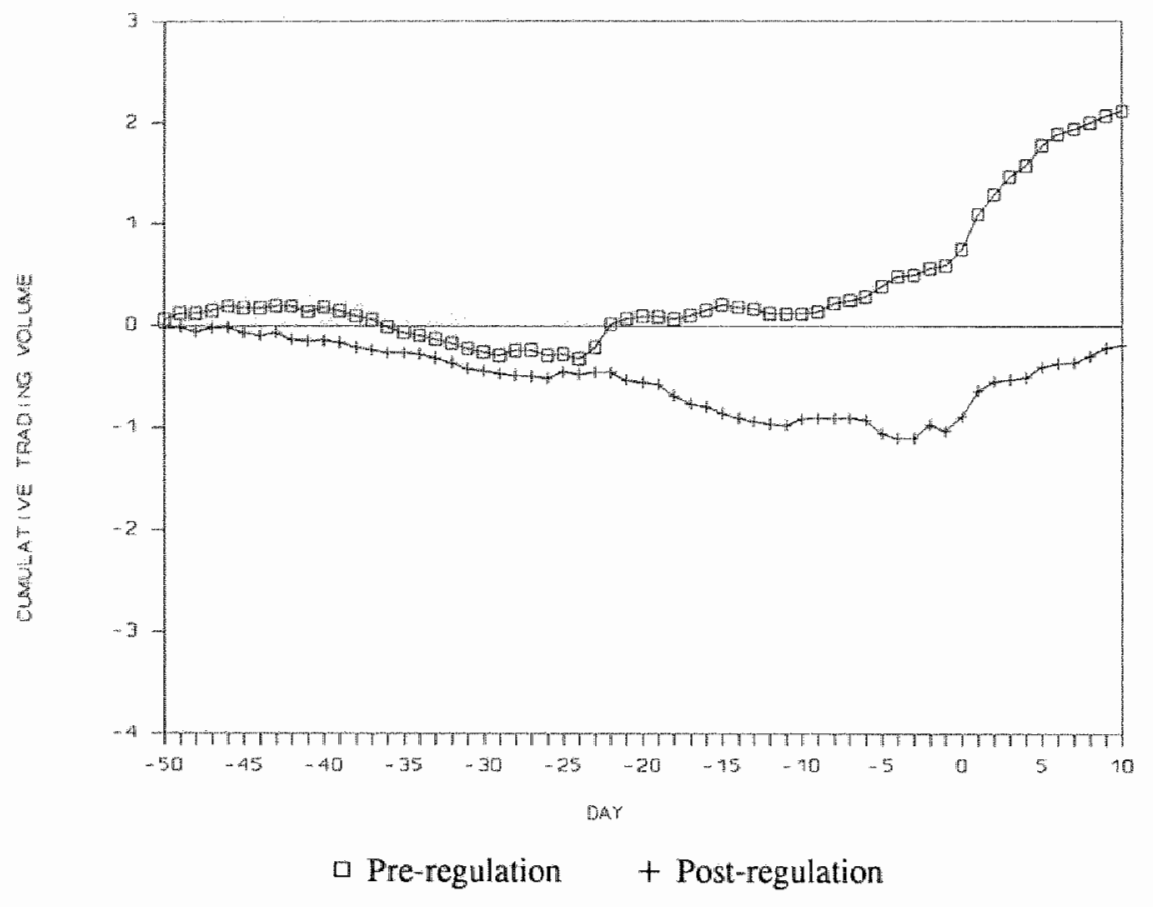


Figure 6.3

Cumulative average abnormal trading volume (as a percentage of total shares outstanding) around annual earning s announcements of small firms

Panel A: Model I

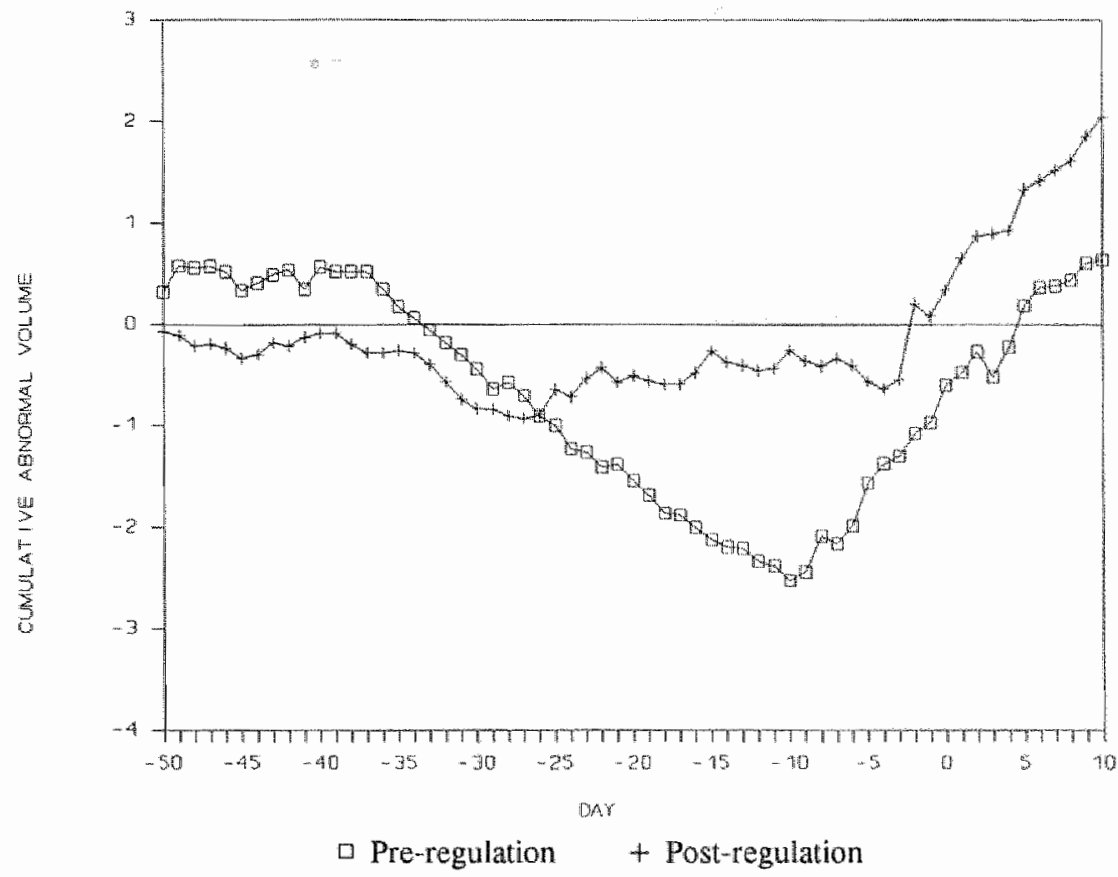

Panel B: Model 2

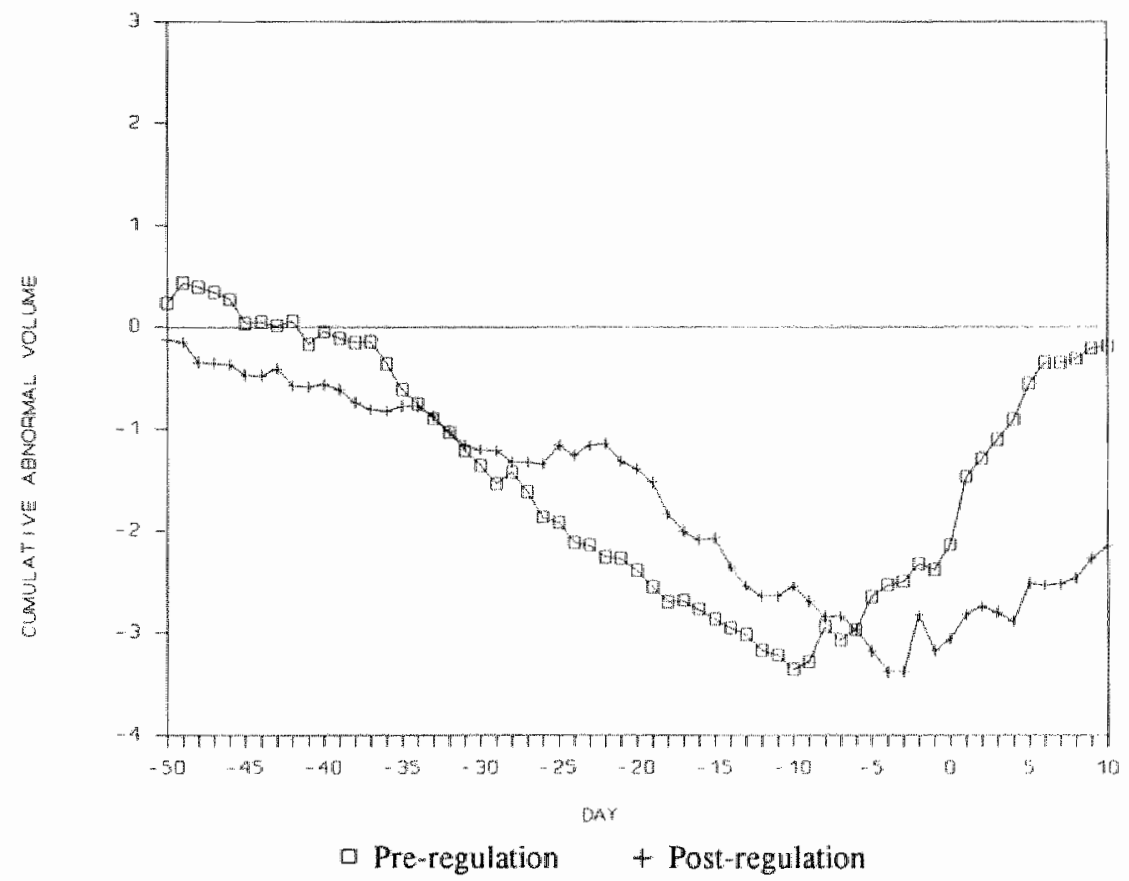


(Figure 6.3, continued)

Panel C: Model 3

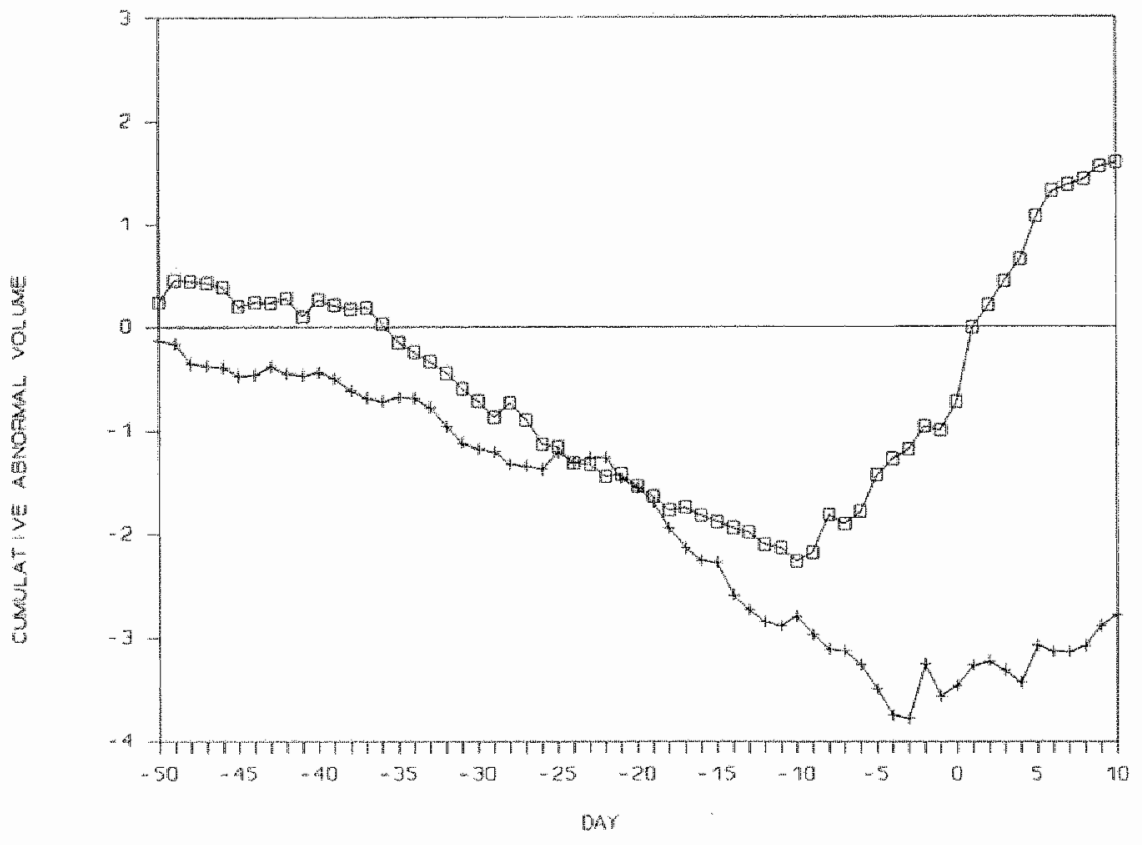

$\square$ Pre-regulation + Post-regulation 
Figure 6.4

Cumulative average abnormal trading volume (as a percentage of total shares outstanding) around semi-annual earnings announcements

Panel A: Model 1

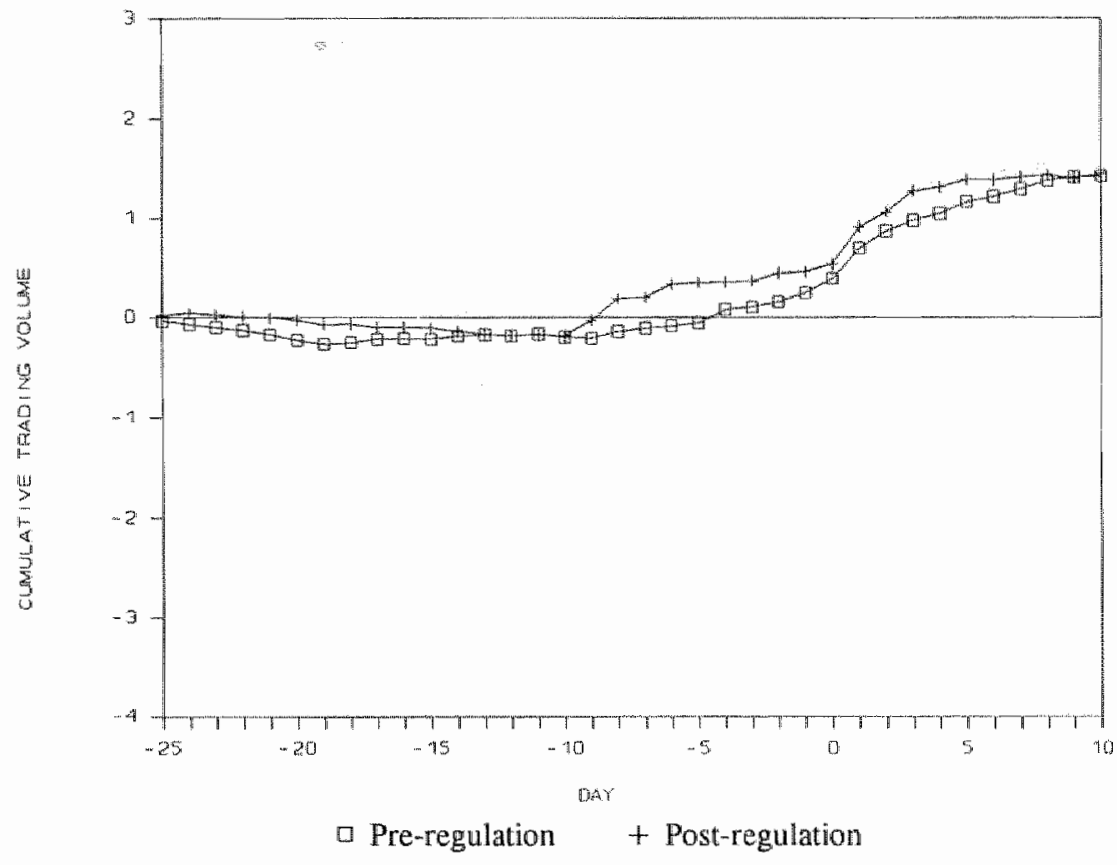

Panel B: Model 2

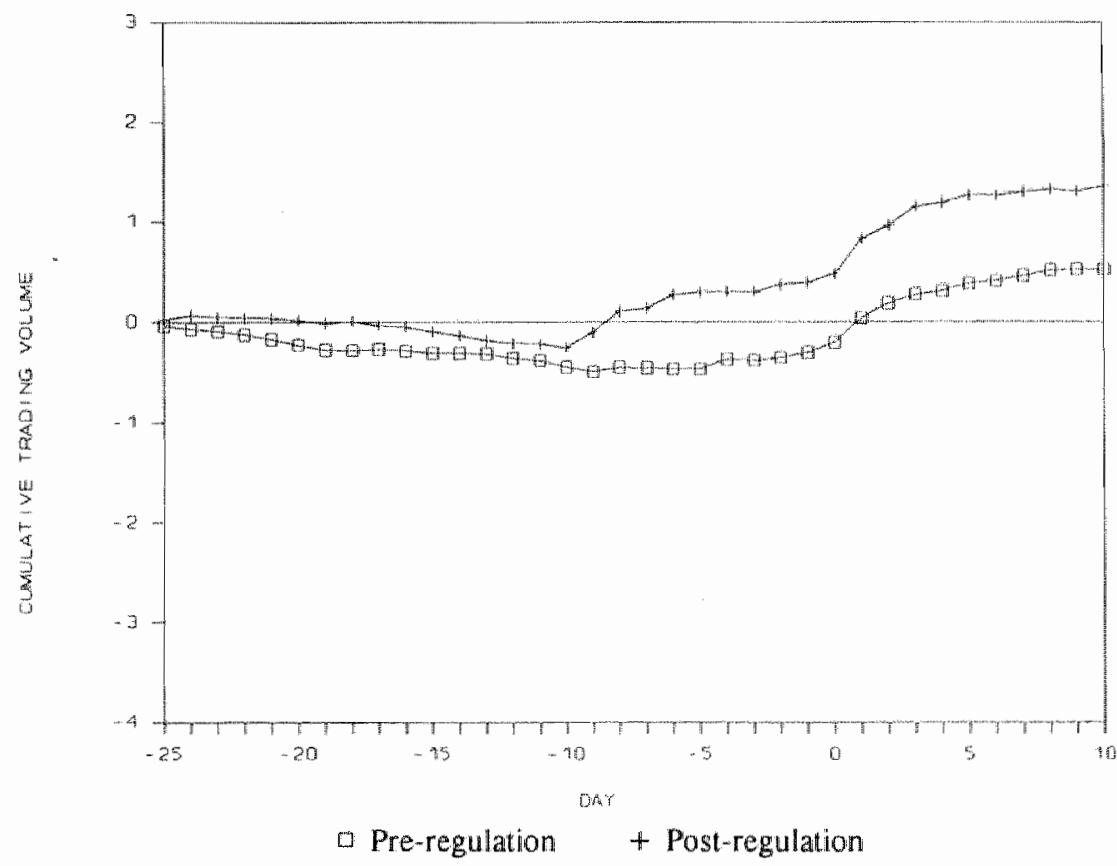


(Figure 6. 4, conthued)

Panel C: Madel 3

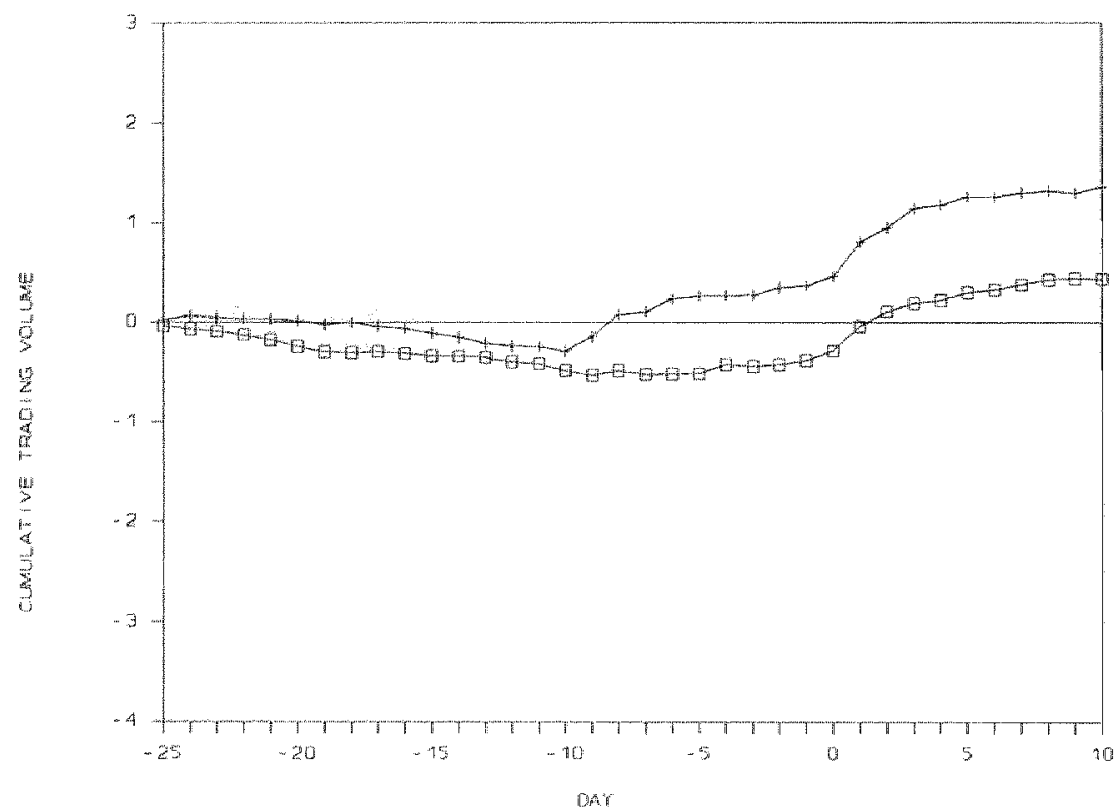

$\square$ Pre-regulation + Post-regulation 
Figure 6.5

Cumulative average abnormal trading volume (as a percentage of total shares outstanding) around semi-annual earnings announcements of small firms

Panel A: Model 1

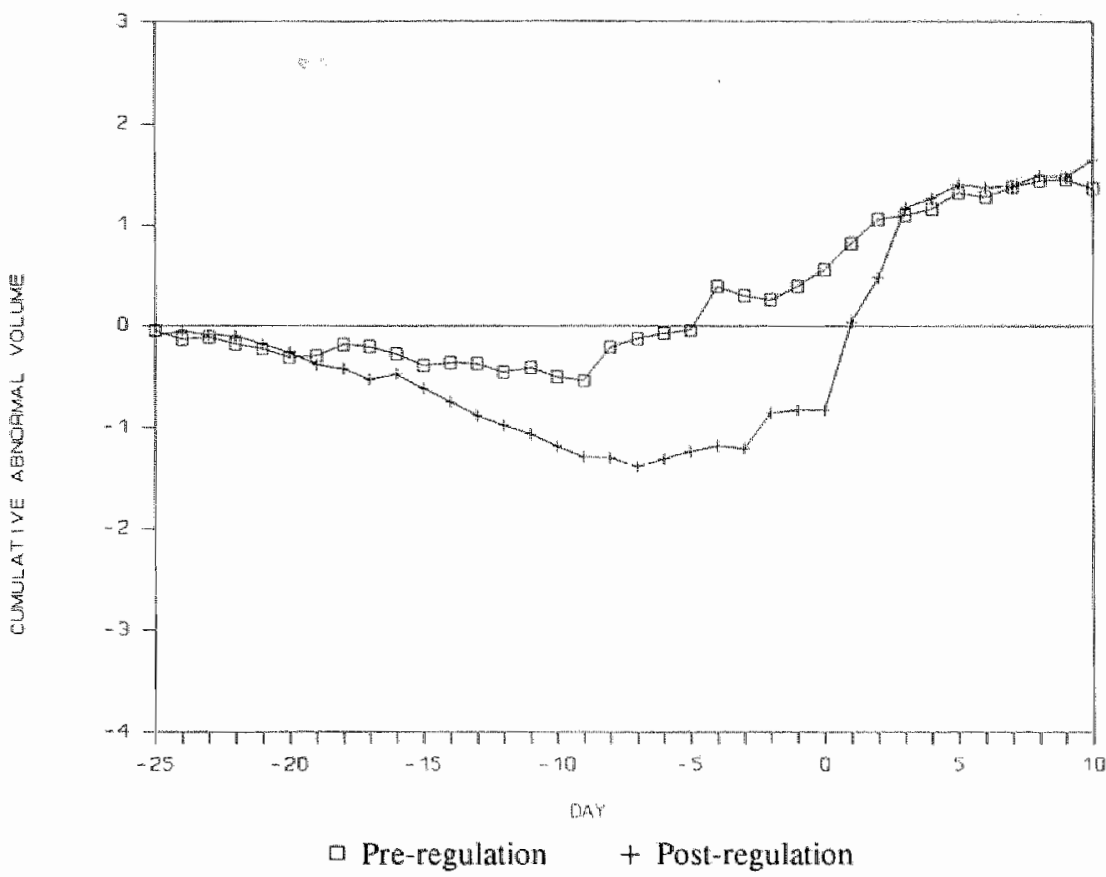

Panel B: Model 2

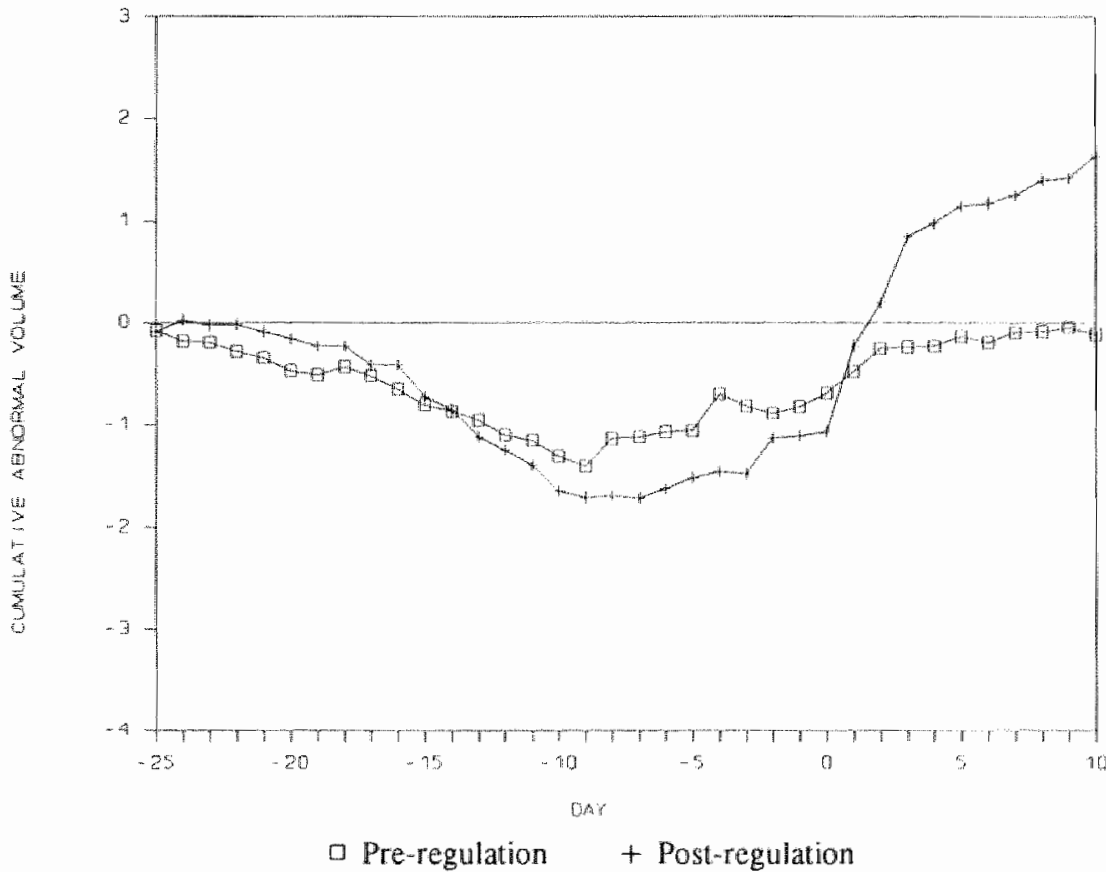


(Figure 6.5, continued)

Panel C: Model 3

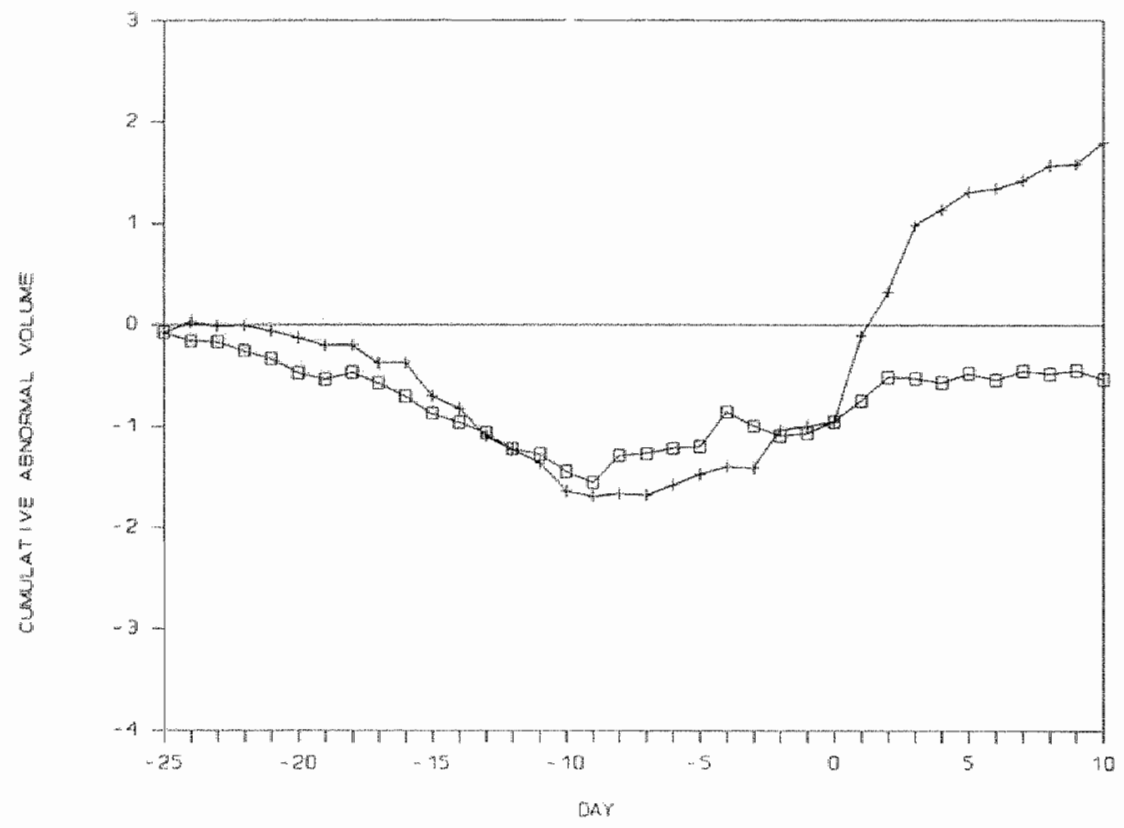

口 Pre-regulation + Post-regulation 
Figure 6.6

Cumulative abnormal returns around annual earnings announcements

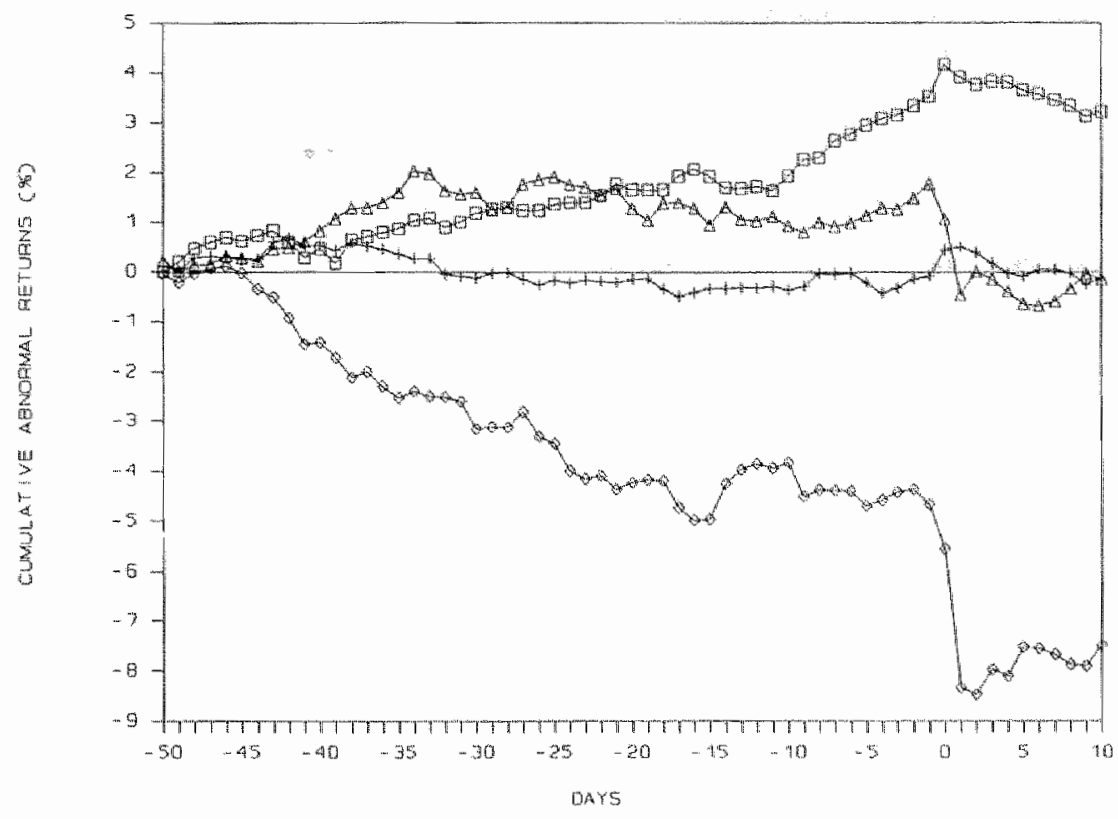

+ Increase-post $\diamond$ Decrease-pre $\Delta$ Decrease-post $\square$ Increase-pre

Figure 6.7

Cumulative abnormal returns around annual earnings announcements (small firms)

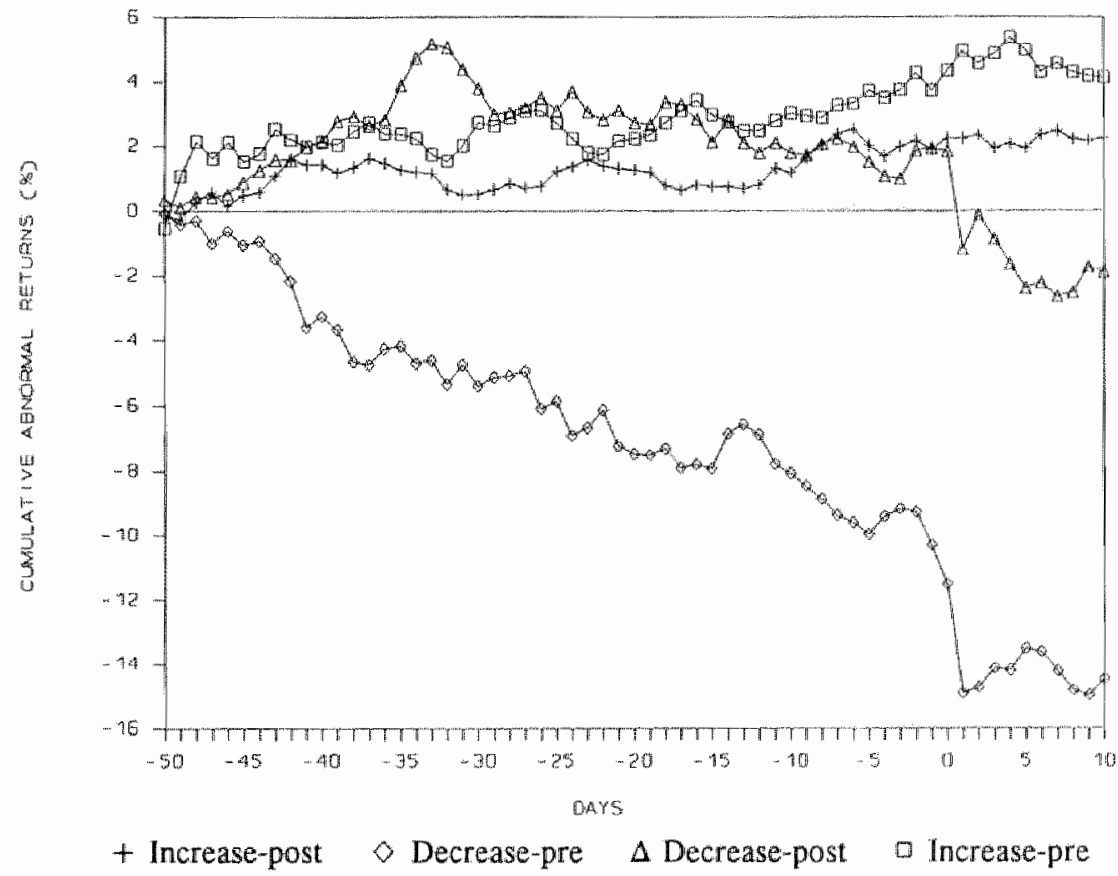


Figure 6.8

Cunulative abnormal retums around semi-annual earnings announcements

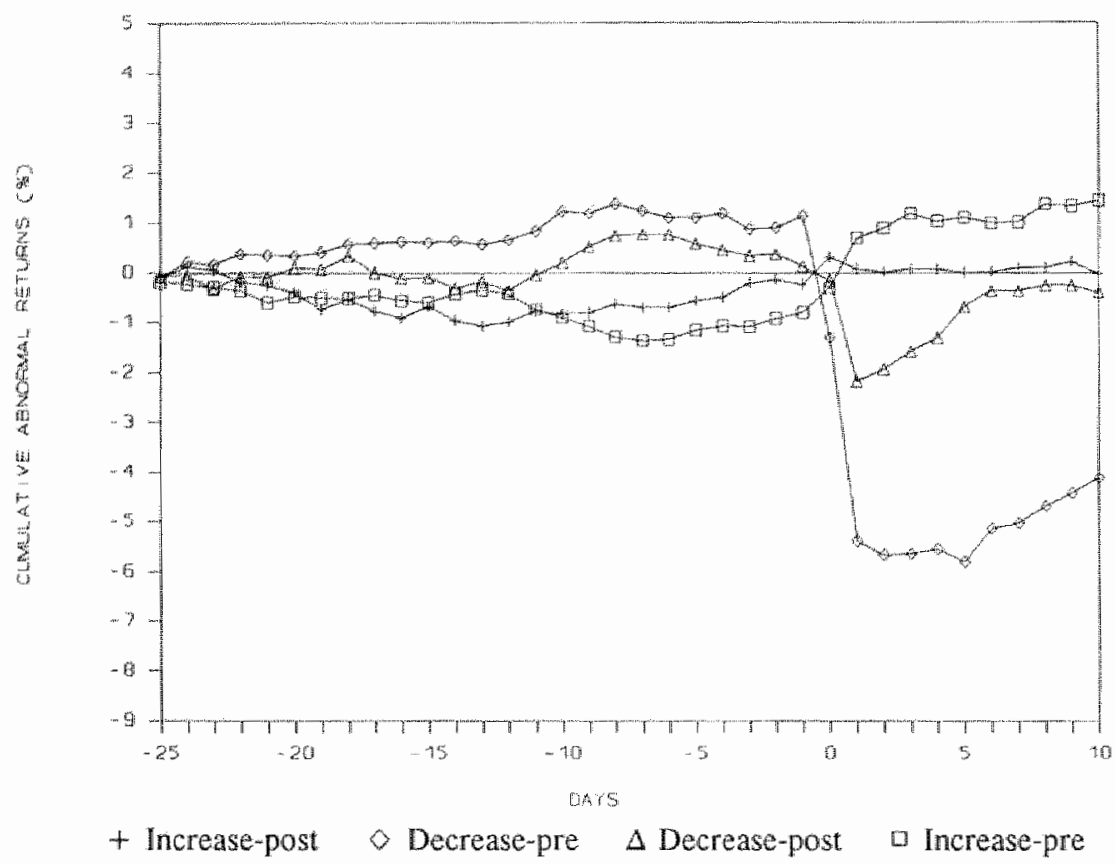

Figure 6.9

Curnulative abnormal returns around semi-anual earnings announcements of small firms.

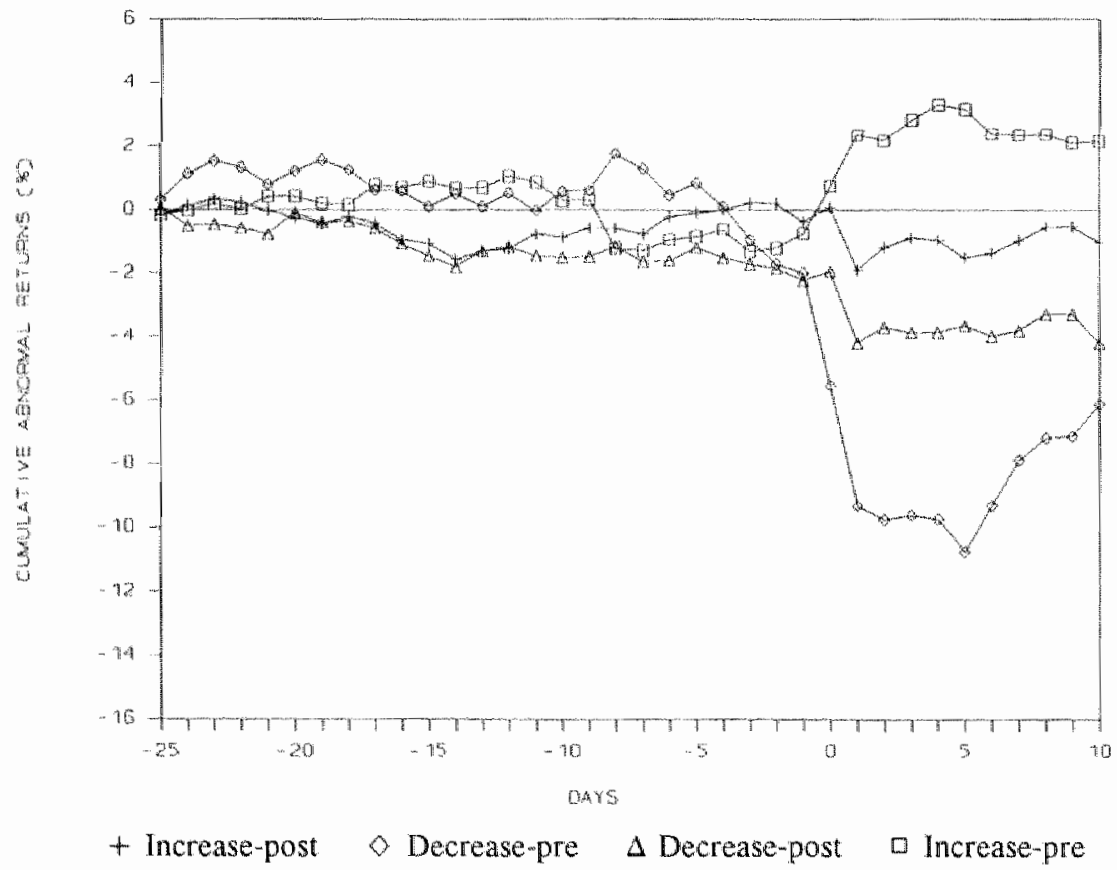




\section{CHAPTER}

7

\section{SUMMARY AND CONCLUSIONS}

This study focuses on the issues related to security market regulation, and intends to serve two objectives: to provide a brief discussion on regulation in general and security regulation in particular; and to investigate empirically the effects of two specific types of security market regulation, namely, trading suspension and insider trading restriction.

In chapter one, regulation and the regulatory system are briefly discussed. rhen, three dominant theories of regulation, namely, the public interest theory, the capture theory, and the economic theory of regulation are explained, together with evidence on their empirical validity. It is concluded from the discussion that there exists no single theory that can explain each and every regulation prevailing in our society. "This is perhaps due to the fact that regulation encompasses not only various economic but also many legal and political factorsi.

Chapter two first describes the principal focus of security market regulation, which is mostly directed at three aspects: issuance of securities, trading of securities, and financial intermediation. Security regulations in the Netherlands and the United Kingdom are then outlined. A distinction is made between public and private regulation to emphasise the fact that the presence of effective private regulation eliminates to a large extent the need for public regulation. The chapter ends with a discussion of security regulation by the European Economic Community.

A survey of some empirical studies analysing the effects of five different types of security market regulation is presented in chapter three. These regulations are: disclosure regulation, insider trading regulation, trading suspension regulation, market making regulation, and margin regulation. The conclusion reached from the survey is that regulation can not be taken as a guaranteed cure to some of the problems in securities markets. Many regulations are not able to achieve their intended objectives.

The phenomenon of trading suspension - a sudden compulsory break in the normal process of buying and selling securities - on the London Stock Exchange is investigated in chapter four. Working criteria to evalluate the costs and the benefits of trading suspension are hard to find. But, for our purpose, trading suspension is considered effective if it happens prior to any anticipation, and new and material information is revealed as well as widely disseminated during the period of suspension. We follow the event study methodology, and use several alternative model specifications to investigate share price behaviour before and after 83 trading suspensions involving 78 companies. The results indicate that trading suspension on the London Stock Exchange is, on average, preceded by a substantial increase in share price; trading 
suspension coincides, on average, with the dissemination of favourable information; either the complete impact of new information release takes place gradually or not all relevant information is disclosed during the suspended period.

An analysis of trading suspensions on the Amsterdam Stock Exchange is performed in chapter five. A total of 193 suspensions affecting 1.12 companies are analysed first. We find an increasing tendency in the use of the suspension measure. Thirty-seven percent of these suspensions continued at least to the following day. Forty-three percent of the affected companies are not listed on the Stock Exchange anymore. The specific reason for trading suspension is not provided in most of the cases. In this chapter, two trading suspensions are used to illustrate patterns in share price movements around the suspended period. Then, share price behaviour of 59 trading suspensions is investigated following the event study methodollogy and alternative model specifications.

We observe that no anticipatory price behaviour is present during the pre-suspension period; suspensions are associated with significant price changes, thus reflecting arrival of new and material information to the stock market; and the post-suspension price behaviour does not show any particular trend. We also analyse the trading volume behaviour around suspensions to verify information content of the suspension event. We find that an increase in trading volume takes place with the occurrence of trading suspension. This reinforces the earlier conclusion that material information is released during the suspended period.

The Amsterdam Stock Exchange adopted a new regulation in 1987 restricting insiders to trade during the two months preceding annual earnings announcements and the three weeks preceding semj-annual earnings announcements. The consequences of this restriction are investigated in chapter six. We analyse 561 annual earnings and 554 semi-annual earnings announcements during the period 1984-89 involving 114 common stocks listed on the Amsterdam Stock Exchange. Dailly share price and trading volume data of these stocks are used in our analysis.

We find that after the introduction of restriction on insider trading, trading volume both before and after annual earnings announcements has decreased. Except for relatively large firms around semi-annual earnings announcements, trading volume declined particularly in the restricted period, suggesting that stock market liquidity was not increased by the regulation. One explanation could be that although insider trading restriction may have increased the willingness of outsiders to trade before earnings announcements, this increase in liquidity is offset by the reduction in trading volume generated by insiders, especially in small firms. We also find evidence consistent with the hypothesis that the introduction of insider trading restriction reduced the stock market's speed of adjustment to annual earnings announcements. Our results indicate that semi-annual earnings changes were not preceded by any abnormal stock price behaviour. 


\section{NEDERLANDSE SAMENVATTING (Summary in Dutch)}

Dit proefschrift richt zich op de regulering van effectenmarkten. Het bestaat uit twee delen: enerzijds een uiteenzetting over regulering in het algeneen, en met betrekking tot effectenmarkten in het bijzonder. Anderzijds bevat het drie empirische deelonderzoeken naar de gevolgen van twee specifieke vormen van regelgeving op de effectenmarkt, namelijk: de opschorting van de beursnotering en het verbod op handelen met voorwetenschap.

Hoofdstuk $\mathbb{1}$ geeft een beknopt overzicht van regulering en het systeem van regelgeving. Drie belangrijke regelgevingstheorieën worden uiteengezet. Het gaat hier om de algemeen belang theorie, de "capture" theorie en de economische theorie omtrent regelgeving. De conclusie luidt dat geen van de theorieën alle vormen van regulering in onze maatschappij kan verklaren. Waarschijnlijk is dit een gevolg van het feit dat regelgeving niet alleen door economische, maar ook ondermeer door juridische en politieke factoren wordt beïnvloed.

Het tweede hoofdstuk behandelt de voornaamste aandachtsgebieden van effectenmarktregulering. Effectenmarktregulering heeft vooral betrekking op de volgende zaken: de emissie van aandelen, de handel in aandelen en de financiële bemiddeling. Vervolgens wordt de regelgeving in Nederland en in het Verenigde Koninkrijk besproken. Hierbij wordt onderscheid gemaakt tussen publieke en private regulering. Dit orn te benadrukken dat een effectieve private regelgeving de noodzaak van een publieke regelgeving kan wegnemen. Het hoofdstuk besluit met een bespreking van de regelgeving die door de Europese Gemeenschap wordt ontwikkeld.

In hoofdstuk 3 wordt een overzicht gegeven van het empirisch onderzoek op het gebied van regelgeving. Vijf vormen van regelgeving worden besproken: regelgeving met betrekking tot het verschaffen van informatie, het handelen met voorkennis, het opschorten van de beursnotering, "market making", en, tenslotte, "margin regulation". De conclusie van dit overzicht luidt dat regulering geen voldoende oplossing biedt voor bepaalde problemen in de effectenmarkt. Veel vormen van regelgeving beantwoorden niet aan hun doelstelling.

In hoofdstuk 4 wordt het opschorten van de beursnotering, d.w.z. een plotselinge, gedwongen onderbreking van de handel in aandelen, onderzocht op de Londense Effectenbeurs. Bruikbare criteria om de kosten en opbrengsten van het opschorten van de handel in aandelen te evalueren, ontbreken over het algemeen. Voor het doel van dit onderzoek is het voldoende dat opschortingen wel als effectief beschouwd kunnen worden wanneer: (a) ze zijn ingesteld voordat erop kan worden geanticipeerd, en (b) belangrijke nieuwe informatie tijdens de opschortingsperiode wordt verspreid. In het onderzoek wordt de "event study" methode gehanteerd en wordt gebruik gemaakt van verschillende alternatieve modelspecificaties om zo het verloop van de aandelenkoersen voor en na opschorting te onderzoeken.

De resultaten van het onderzoek naar 83 opschortingen onder 78 ondernemingen laten zien dat een opschorting op de Londense Effectenbeurs in het algemeen wordt voorafgegaan door een aanzienlijke stijging van de aandelenkoers. Ten tweede, dat opschorting van de notering in het algemeen samengaat met de bekendmaking van positieve informatie. En ten derde, dat de bekendmaking van nieuwe informatie ofwel geleidelijk plaatsvindt, ofwel dat niet alle informatie tijdens de opschortingsduur wordt verstrekt. 
In hoofdstuk 5 wordt eentzelfde analyse uitgevoerd met betrekking tot opschortingen op de Amsterdamse Effectenbeurs. Honderddrieernegentig opschortingen, waarbij 112 ondernemingen waren betrokken, werden onderzocht. We constateren een neiging om de opschortingsmaatregel in toenemende mate te gebruiken. Zevenendertig procent van de onderzochte opschortingen duurde ten minste tol en met de volgende dag. Drieenweertig procent van de betreffende ondernemingen is inmiddels niet meer aan de Beurs genoteerd. De exacte reden voor opschorting werd in de meeste gevallen door het beursbestuur niet gegeven. In dit hoofdstuk worden twee opschortingen nader besproken om zo de patronen in de fluctuaties van de aandelenkoersen te illustreren. Vervolgens wordt het verloop van het aandelenrendement bij 59 opschortingen geanalyseerd, waarbij andermaal gebruik gemaakt wordt van de "event study" methode en alternatieve modelspecificaties.

Het blijkt dat in de periode voorafgaand aan de opschorting geen anticiperend koersgedrag valt te ontdekken en dat de opschorting gepaard gaat met belangrijke koersveranderingen. Dit laatste duidt op het vrijkomen van nieuwe, essentiële informatie op de effectenmarkt. Daarnaast blikt ook dat het koersverloop in de periode na de opschorting geen specifiek patroon laat zien. Tevens werd er een analyse gemaakt van het verloop van de omzet in aandelen in de periode rond de opschortingsdatum. Dit om de informatie-inhoud van de opschorting na te gaan. Het blijkt dat er inderdaad eerl stijging in de omzet plaatsvindt bij opschorting. Dit versterkt de conclusie dat gedurende de opschortingstermijn essentiële informatie vrijkomt.

In 1987 woerde de Amsterdamse Effectenbeurs een nieuw reglement in dat "insiders" verbood om the handelen gedurende de twee maanden voor de bekendmaking van het jaarresultaat, alsmede drie weken voor de bekendmaking van het halfjaarlijkse resultaat. De gevolgen van dit verbod worden onderzocht in hoofdstuk 6. Aankondigingen van 561 jaarresultaten en 554 halfjaar-resultaten gedurende de periode 1984 1989 van 114 aan de Amsterdamse Effectenbeurs genoteerde fondsen, werden geanalyseerd. Hier werd gekeken naar de dagelijkse aandelenrendementen en de dagelijkse aandelenomzet.

Het blijkt dat na de invoering van het verbod op handel met voorwetenschap, de omzet voor en na aankondigingen van jaarresultaten is gedaald. Bij aankondigingen van halfjar-resultaten daalde, behalve bij relatief grote ondernemingen, de omzet vooral in de verboden periode. Dit wijst erop dat door de nieuwe regelgeving de liquiditeit van de aandelenmarkt niet is vergroot. Een mogelijke verklaring hiervan is dat, hoewel het verbod op handel met voorkennis de bereidheid van "'outsiders" on te handelen heeft vergroot, deze stijging aan de andere kant teniet wordt gedaan door een vermindering in de omzet van "insiders". Dit is vooral zichtbaar bij kleine ondernemingen.

Tevens wordt in het onderzoek ondersteuning gevonden voor de hypothese die stelt dat de invoering van thet verbod de aanpassingssnelheid van de aandelenmarkt op bekendmakingen van jaarresultaten heeft werkleind. De onderzoeksresultaten wijzen er eveneens op dat veranderingen in halfjaar-resultaten niet worden voorafgegaan door een buitengewoon aandelenkoersverloop. 


\section{BIBLIOGRAPHY}

Admati, A.R. and P. Pfleiderer, "A Theory of Intraday Patterns: Volume and Price Variability", Review of Financial Siudies, Vol. 1, 1988, pp. 3-40.

Ajinkya, B.B. and P.C. Jain, "The Behaviour of Daily Stock Market Trading Volume", Journal of Accounting and Economics, Vol, 11, 1989, pp. 331-359.

A mihud, Y. and H. Mendelson, "Asset Pricing and the Bid-Ask Spread", Journal of Finoncial Economics, Vol. 17, 1986, pp. 223-249.

- . "Liquidity and Asset Prices". Financial Management Implications", Financial Management, Vol. 17, 1988, pp. 5-15.

Ankum, L.A. and A.B. Dorsman, "De Uitkomsten van Twee Beleggingsstrategieen en de Efficientie van de Amsterdamse Aandelenmarkt", in Dorsman A.B. et al., eds., De Amsterdamse Aandelenmarkt: Theorie en Praktijk, Samson, 1987, pp. 107-118.

Ball, R. and P. Brown, "An Empirical Evaluation of Accounting Income Numbers", Journal of Accounting Research, Vol. 6, Autumn 1968, pp. 159-178.

Bamber, L.S., "The Information Content of Annual Earnings Release: A Trading Volume Approach", Joumal of Accouming Research, Vol. 24, 1986, pp. 40-56.

Banz, R., "The Relationship Between Return and Market Value of Common Stocks", Joumal of Financial Economics, Vol. 9, 1981, pp. 3-18.

Baumol, W.J., The Stock Market and Economic Efficiency, Fordham University Press, 1965.

Beaver, W., "The Information Content of Annual Earnings Announcements", Journal of Accounting Research (Supplement - Empirical Research in Accounting: Selected Studies), Vol. 6, 1968, pp. 67-92.

-----, Financial Reporting: An Accounting Revolution, Prentice-Hall, 1989.

Beckers, S., "Performance Measurement and Performance Attribution in Less Than Efficient Markets: a Case Study", in E. Dimson, ed., Stock Market Anomalies, Cambridge University Press, 1988, pp. 240-253.

Beghin, P., "De Informatieve Waarde wan Winstgegevens: Een Onderzoek op de Beurs van Brussel", Accountancy en Bedrifskunde, Vol. 9, 1984, pp. 2-15.

Benston, G.J., "The Effectiveness and Effects of the SEC's Accounting Disclosure Requirements", in H. G. Manne, ed., Economic Policy and the Regulaton of Corporate Securities, American Enterprise Institute, Washington, 1969, pp. 23-79.

-......., "Required Disclosure and the Stock Market: An Evaluation of the Securities Exchange Act of $1934^{\star}$, American Economic Review, Vol. 63, 1973, pp. 133-155.

-...-.-, "Required Disclosure and the Stock Market: Rejoinder", American Economic Review. Vol. 65,1975 , pp. 473-477.

Berkman, H. and A.C.C. Herst, "Handel met Voorwetenschap", De Naumloze Vennootschap, Vol. 66,1988 , pp. $71-75$.

Black, F., M.C. Jensen and M. Scholes, "The Capital Asset Pricing Model: Some Empirical Tests", in M. Jensen, ed., Studies in the Theory of Capital Markets, Praeger Publishers, 1972 .

Bloch, E. and R.A. Schwartz, eds., Impending Changes for Securities Markets; What Role for the Exchanges?, Jai Press, 1979.

Born, J.A. "Insider Ownership and Signals: Evidence from Dividend Announcement Effects", Financial Management, Vol. 17, 1988, pp. 38-45. 
Bowman, R.G., "Understanding and Conducting Event Studies", Joumal of Business Finance \& Accownting, Vol. 10, 1983, pp. $561-584$.

Boyer, K.D. and W.G. Shepherd, eds., Economic Regulation: Essays in Honour of James $R$. Nelson, Michigan State University, 1981.

Brealley, R.A., "The Changing Structure and Regulation of the UK Securities Market" Working Paper No. 85, London Business School, 1985.

Brown, L.D., R.L. Hagerman, P.A. Griffin, and M.E. Zmijewski, "An Evaluation of Alternative Proxies for the Market's Assessment of Unexpected Earnings" "Journal of Accounting and Economics, Vol. 9, 1987, pp. 159-193.

Brown, S.J. and J.B. Warner, "Measuring Security Price Performance", Journal of Financial Economics, Vol. 8, 1980, pp. 205-253.

_..., "Using Daily Stock Returns: The Case of Event Studies", Journal of Financial Economics, Vol. 14, 1985, pp. 3-31.

Campbell, T.S., Money and Capital Markets, Scott, Foresman and Company, 1988.

Chatfield, R.E., S.E. Hein and R.C. Moyer, "Long-Term Earnings Forecasts in the Electrical Utility Industry: Accuracy and Valuation Implications", Financial Review, Vol. 25, 1990, pp. 421-439.

Collins, D.W. and W.T. Dent, "A Comparison of Alternative Testing Methodologies Used in Capital Market Research", Journal of Accounting Research, Vol. 22, 1984, pp. 48-84.

Conrad, I. and G. Kaul, "Time Variation in Expected Returns", Joumal of Business, Vol. 61, 1988, pp. 409-425.

Copeland, T.E. and J.F. Weston, Financial Theory and Corporate Policy, Addison-Wesley, 1988.

Corhay, A., G. Hawawini and P. Michel, "The Pricing of Equity on the London Stock Exchange: Seasonality and Size Premium", in E. Dimson, ed., Stock Market Anomalies, Cambridge University Press, 1988, pp. 197-212.

Cornett, M.M. and H. Tehranian, "An Examination of the Impact of the Garn-St.Germain Depository Institutions Act of 1982 on Commercial Banks and Savings and Loans", Journal of Finance, Vol. 45, 1990, pp. 95-111.

Cross, D.H. and J.H. Diephuis, De Amsterdamse Effectenbeurs, Kluwer, 1988.

Defeo, V.J., "An Empirical Investigation of the Speed of the Market Reaction to Earnings Announcements", Journal of Accounting Research, Vol. 24, 1986, pp. 349-363.

Demsetz, H., "Perfect Competition, Regulation and the Stock Market", in H.G. Manne, ed., Economic Policy and the Regulation of Corporate Securities, American Enterprise Institute, Washington, $1969, \mathrm{pp}, 1-22$.

Dimson, E., "Risk Measurement When Shares are Subject to Infrequent Trading", Journal of Financial Economics, Vol. 7, 1979, pp. 197-226.

- Stock Market Anomalies, ed., Cambridge University Press, 1988.

and P.R. Marsh, "Event Study Methodologies and the Size Effect: The Case of UK Press Recommendations", Jowmal of Financial Economics, Vol. 17, 1986, pp. 113-142.

-........, "The Smaller Companies Puzzle", Investment Analyst, No. 91, 1989, pp. 16-24.

Dorsman, A.B. and C. Post, "Het Financieel Systeem en de Wijziging van de Rentestand", Bedrifiskunde, Vol. 61, 1989, pp. 190-197.

Dougall, H.E. and J.E. Gaumnitz, Capital Market and Institutions, Prentice-Hall, 1986.

Dreese, A., Misbruik van Voorwetenschap bij Effectenbeurstransacties, Kluwer Post Scriptum Reeks, 1986.

Duesenberry, J.S., "Criteria for Judging the Performance of Capital Markets", reprinted in H.K. Wu and A.J. Zakon, eds., Elements of Investments: Selected Readings, Holt, Rinehart and Winston, 1972, pp. $1-9$.

Dyckman, T.R and D. Morse, Efficient Capital Markets and Accounting: A Critical Analysis, Prentice-Hall, 1986. 
Eisenach, J.A. and J.C. Miller III, "Price Competition on the NYSE", Regulation, 1981, pp. $17-19$.

Fabozzi, F.J. and C.K. Ma, "The Over-The-Counter Market and New York Stock Exchange Trading Halts", Financial Review, Vol. 23, 1988, pp. 427-437.

Fama, E.F., "Efficient Capital Markets: A Review of Theory and Empirical Work" ,Journal of Finance, Vol. 25, 1970, pp. 383-417.

-...-..-, Foundations of Finance, Basic Books, 1976.

and K.R. French, "Permanent and Temporary Components of Stock Prices", Joumal of Political Economy, Vol. 96, 1988, pp. 246-273.

-.-.-, L. Fisher, M. Jensen and R. Roll, "The Adjustment of Stock Prices to New Information", International Economic Review, Vol. 10, 1969, pp. 1-21.

Finnerty, J.E., "Insiders and Market Efficiency", Journal of Finance, Voll. 31, 1976, pp. 11411148.

Foster, G., Financial Statement Analysis, Prentice-Hall, 1986.

Franks, J.R. and R.S. Harris, "Shareholder Wealth Effects of Corporate Takeovers": The U. $\mathbb{K}$. Experience 1955-1985", Journal of Financial Economics, Vol. 23, 1989" pp. 225-249.

French, K.R. and R. Roll, "Stock Return Variances: The Arrival of Information and the Reaction of Traders", Journal of Financial Economics, Vol 17,1986, pp. 5-26.

Friend, I., "The SEC and the Economic Performance of Securities Markets", in H.G. Manne, ed., Economic Policy and the Regularion of Corporate Securities, American Enterprise Institute, Washington, 1969, pp. 185-216.

1964, pp. 382-405.

Economic Review, Vol. 65, 1975, pp. 467-472.

Givoly, D. and D. Palmon, "Insider Trading and the Exploitation of Inside Information: Some Empirical Evidence", Journal of Business, Vol. 58, 1985, pp. 69-87.

Gowland, D., "The Regulation of Financial Markets in the 1990s", Edward Elgar, 1990.

Granger, C.W.J., "A Survey of Empirical Studies on Capitall Markets", in E.J. Elton and M.J. Gruber, eds., International Capital Markets, (Studies in Financial Economics, Vol. 1), North-Holland, 1975, pp. 3-36.

Grossman, S., "An Analysis of the Role of Insider Trading on Futures Markets", Journal of Business, Vol. 59,1986 , pp. 129-146.

Grube, R.C., O.M. Joy and D.B. Panton, "Market Responses to Federal Reserve Changes in the Initial Margin Requirement", Joumal of Finance, Vol. 34, 1979, pp. 659-674.

Hannigan, B., Insider Dealing, Kluwer Law Publishers, 1988.

Hardouvelis, G.A., "Margin Requirements, Volatility, and the Transitory Component of Stock Prices", American Economic Review, Vol. 80, 1990, pp. 736-762.

Hawawini, G., "European Equity Markets: A Review of the Evidence on Price Behaviour and Efficiency", in G.A. Hawawini \& P.A. Michel, eds., European Equity Markets; Risk. Return, and Efficiency, Garland Publishing, 1984, pp. 5-80.

and P. Michel, Mandatory Financial Information and Capilal Market Equilibrium in Belgium, Garland Publishing, 1987.

Hillmer, S.C. and P.L. Yu, "The Market Speed of Adjustment to New Information", Journal of Financial Economics, Vol. 7, 1979, pp. 321-345.

Hogan, W.P., "Insider Trading: Implications and Responses", Abacus, Vol. 25, 1989, pp. 8596.

Holthausen, R.W. and R.E. Verrechia, "The Effect of Informedness and Consensus on Price and Volume Behavior", The Accounting Review, Vol. 65, 1990, pp. 191-208.

Hopewell, M.H. and A.L. Schwartz Jr., "Stock Price Movement Associated With Temporary Trading Suspensions: Bear Market versus Bull Market", Journal of Financial and Quantitative Analysis, Vol. 11, 1976, pp. 577-590. 
"Temporary Trading Suspensions in Individual NYSE Securities"', Journal af Finance, Vol. 33,1978, pp. 1355-1373.

Howe, J.S. and G.G. Schlarbaum, "SEC Trading Suspensions: Empirical Evidence", Joumal of Financial and Quantitative Analysis, Vol. 21, 1986, pp. 323-333.

Hsieh, D.H. and M.H. Miller, "Margin Regulation and Stock Market Vollatility", Journal of

Finance, Vol. $45,1990, \mathrm{pp} .3-29$.

Ittersum, B.F. Baron vam, "Regelgeving van de Vereniging voor de Effectenhandel ter Voorkoming van Misbruik van Voorwetenschap", in Misbruik van Voorwetenschap, Kluwer, 1989, pp. 39-53.

Jaffe, J.F., "Special Information and Insider Trading", Journal of Business, Vol. 47, 1974a, pp. $410-428$.

_. Management Science, Vol. 5, 1974b, pp. 93-121.

Jain, P.C. and G.H. Joh, "The Dependence between Hourly Prices and Trading Volume", Journal of Financial and Quantitative Analysis, Vol. 23, 1988, pp. 269-283.

James, C.M., "An Analysis of Intra-Industry Differences in the Effect of Regulation: The Case of Deposit Rate Ceilings", Journal of Monetary Economics, Vol. 12, 1983, pp. 417-432.

Jang, H.J. and B.T. Ro, "Trading Volume Theories and Their Implications for Empirical Information Content Studies", Contemporary Accounting Research, Vol. 6, 1989, pp. 242262.

Jarrell, G.A., "The Demand for State Regulation of the Electrical Utility Industry", Journal of Law \& Economics, Vol. 21, 1978, pp. 269- 295.

......., "The Economic Effects of Federal Regulation of the Market for New Security Issues", Joumal of Law \& Economics, Vol. 24, 1981, pp. 613-675.

-......., "Changes at the Exchange: The Causes and Effects of Deregulation", Joumal of Law \& Economics, Vol. 27, 1984, pp. 273-312.

........-, and A.B. Poulsen, "Stock Trading Before the Announcement of Tender Offers: Insider Trading or Market Anticipation?", Journal of Law, Economics, and Organization, Vol. 5, 1989, pp. 225-248.

Jennings, R, and L. Starks, "Information Content and the Speed of Stock Price Adjustment", Journal of Accouning Research, Vol. 23, 1985, pp. 336-350.

Jensen, M., "Capital Markets: Theory and Evidence", Bell Journal of Economics and Management Science, Vol. 3, 1972, pp. 357-398.

John, R. and B. Mishra, "Information Content of Insider Trading Around Corporate Announcements: The Case of Capital Expenditures", Journal of Finance, Vol. 45, 1990, pp. 835-855.

Johnston, J., Econometric Methods, McGraw-Hill, 1984.

Jordan, W.A., "Producer Protection, Prior Market Structure and The Effects of Government Regulation", Joumal of Law" and Economics, Vol. 15, 1972, pp. 151-176.

Joskow, P.L. and R.C. Noll, "Regulation in Theory and Practice: An Overview" in G. Fromm, ed., Srudies in Public Regulation, MTT Press, 1981, pp. 1-65.

Kahn, A.E., The Economics of Regulation: Principles and Institutions, Vol. 1." Economic Principles, John Willey \& Sons, 1970.

-...-., The Economics of Regulation: Principles and Institutions, Vol. 2: Institutional Issues, John Wiley \& Sons, 1971.

Kalay, A. and A. Shimrat, "Firm Value and Seasoned Equity Issues", Journal of Financial Econowics, Vol. 19, 1987, pp. 109-126.

Kane, E.I., "Impact of Regulation on Economic Behavior", Journal of Finance, Vol. 36, 1981, pp. 355-367.

Karpoff, J.M., "A Theory of Trading Volume", Joumal of Finance, Vol. 41 * 1986, pp. 10691087. 
-non-..., "The Relation Between Price Changes and Trading Volume: A Survey", Journal of Financial and Quanitative Amalysis, Vol. 22, 1987, pp. 109-126.

Keane, S.M., Stock Market Efficiency: Theory, Evidence and Mmpliomions, Philip Allan, 1983.

Keim, D.B., "Size-Related Anomalies and Stock Return Seasonality: Further Empirical Evidence", Joumal of Financial Economics, Vol. 12, 1983, pp. 13-32.

- - and R.F. Stambaugh, "A Further Investigation of the Weekend Effect in Stock Returns", Journal of Finunce, Vol. 39, 1984, pp. 819-835.

Keulen, B.F. and J.L. van der Neut, Voorwerenschap en Srafnech, Wolters-Noordhof, 1989.

Kryzanowski, L., "Misinformation and Regulatory Actions in the Canadian Capital Markets:

Some Empirical Evidence", Bell Journal of Economics, Vol. 9, 1978, pp. 355-368.

-......., "The Efficacy of Trading Suspensions: A Regulatory Action Designed to Prevent the Exploitation of Monopoly Information", Journal of Finance, Vol. 34, 1979, pp. $1187-1200$.

Kyle, A.S., "Continuous Auctions and Insider Trading", Economerica, Vol. 53, 1985, pp. $1315-1336$.

-..-. "Trading Halts and Price Limits", Review of Furures Makkers, Vol. 7, 1988, pp. 427434.

Laffont, J.J. and E.S. Maskin, "The Efficient Market Hypothesis and Insider Trading on the Stock Market", Journal of Political Economy, Vol. 98, 1990, pp.70-93.

Lakonishok, J., "The Size Effect and Event Studies: A Discussion", in E. Dimson, ed., Stock Market Anomalies, Cambridge University Press, 1988, pp. 215-219.

Largay III, J.A. and R.R. West, "Margin Changes and Stock Price Behaviour", Joumal of Political Economy, Vol. 81, 1973, pp. 328-339.

Levis, M., "Are Smal! Firms Big Performers?", Investment Analyst, No. 76, 1985, pp. 21-27.

Lin, J. and J.S. Howe, "Insider Trading in the OTC Market", Jounnal of Finance, Vol. 45, 1990 , pp. 1273-1284.

Linn, S.C. and J.M. Pinegar, "The Effect of Issuing Preferred Stock on Common and Preferred Stockholder Wealth", Journal of Financial Economics, Vol. 12, 1988, pp. 155184.

Lipton, D.A., "Governance of Our Securities Markets and The Failure to Allocate Regulatory Responsibility", Catholic University Law Review, Vol. 34, 1985, pp. 397-423.

Lorie, J.H., P. Dodd and M. H. Kimpton, The Stock Market: Theories and Evidence, Dow Jones-Irwin, 1985.

Manne, H.G., Insider Trading and the Stock Market, Free Press, 1966.

Manove, M., "The Harm From Insider Trading and Informed Speculation", Quarterly Journal of Economics, Vol. 104, 1989, pp. 823-844.

McCraw, T.K., "Regulation in America: A Review Article", Business History Review, Vol. 49, 1975, pp. 159-183.

Merino, B.D. and M.D. Neimark, "Disclosure Regulation and Public Policy" A Sociohistorical Reappraisal", Journal of Accounting and Public Policy, Vol. 1, 1982, pp. 33-57.

Mendelson, M., "From Automated Quotes to Automated Trading: Restructuring the Stock Market in the U.S.", The Bulletin, Institule of Finance, New York Uniwersity, March 1972, pp. 101 .

Mikkelson, W.H. and M.M. Partch, "Withdrawn Security Offerings", Joumal of Financial and Quantitative Analysis, Vol. 23, 1988, pp. 119-133.

Mitnick, B.M., The Political Economy of Regulation, Columbia University Press, New York, 1980.

Moore, T.G., "Stock Market Margin Requirements", Journal of Political Economy, Vol. 74, 1966 , pp. 158-167.

Morse, D., "Asymmetrical Information in Securities Markets and Trading Volume", Journal of Financial and Quantitative Analysis, Vol. 15, 1980, pp. 1129-1143. Financial and Quamtitarive Analysis,
Examination", Journal of Accouming Research, Vol. 19, 1981, pp. 374-383. 
"An Econometric Analysis of the Choice of Daily versus Monthly Retums in Tests of Information Content", Joumal of Accouming Research, Vol. 22, 1984, pp. 605-623.

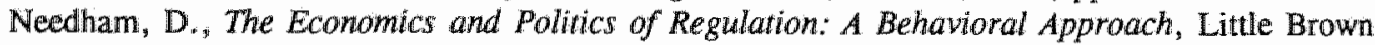
and Company, 1983.

Ogus, A.I. and C.G. Veljanovski, eds., Readings in the Economics of Law and Regulation, Clarendon Press, 1984.

Oppenheimer, H.R. and T.E. Dielman, "Firm Dividend Policy and Insider Activity: Some Empirical Results", Journal of Business Finance \& Accounting, Vol.. 15, 1988, pp. 525-541.

Organisation for Economic Cooperation and Development, Financial Market Trends, No. 41, 1988.

Patell, J.M. and M.A. Wolfson, "The Intraday Speed of Adjustment of Stock Prices to Earnings and Dividend Announcements", Joumal of Financial Economics, Vol. 13, 1984, pp. 223-252.

Peltzman, S., "Toward A More General Theory of Regulation", Journal of Law \& Economics, Vol. 19, 1976, pp. 211-240.

1981, pp. 403-448.

Philips, S.M. and J.R. Jecher, The SEC and the Public Interest, MIT Press, 1981.

Phillips, A., ed., Promoting Competition in Regulated Markets, Brookings Intitutions, 1975.

Pincus, M., "Information Characteristics of Earnings Announcements and Stock Market Behavior", Journal of Accounting Research, Vol. 21, 1983, pp. 155-183.

Pope, P.F., R.C. Morris and D.A. Peel, "Insider Trading: Some Evidence on Market Efficiency and Directors' Share Dealings in Great Britain", Journal of Business Finance \& Accounting, Vol. 17, 1990, pp. 359-380.

Posner, R.A., "Taxation by Regulation", Bell Journal of Economics and Management Science, Vol. 2, 1971, pp. 22-50.

-...-.-"Theories of Economic Regulation", Bell Journal of Economics and Management Science, Vol. 5, 1974, pp. 335-358.

Pownall, G. and G. Waymire, "Voluntary Disclosure Credibility and Security Prices: Evidence from Management Earnings Forecasts, 1969-73", Joumal of Accounting Research, Vol. 27, 1989, pp. 227-244.

Reiss, A.J. Jr., "Selecting Strategies of Social Control Over Organizational Life", in K. Hawkins and J. M. Thomas, eds., Enforcing Regulation, Kluwer-Nijhoff, 1984.

Ridder, de A., "Borsstopp och Kursutveckling pa Stockholmborsen", Stockhoims Fondbors, Stockholm, 1988, pp. 54-61.

Rietkerk, G., "Wetsontwerp Misbruik van Voorwetenschap is Misslag", in Misbruik van Voorwetenschap, Kluwer, 1989, pp. 133-147.

Robbins, S. and W. Werner, "Professor Stigler Revisited", Journal of Business, Vol. 37, 1964, pp. $406-413$.

Robinson, J.M., ed., Comparative Survey of Securities Laws, Kluwer, 1980.

Robinson, R.I. and D. Wrightsman, Financial Markets. The Accumulation and Allocation of Wealth, McGraw-Hill, 1980.

Roll, R., "A Possible Explanation of the Small Firm Effect", Journal of Finance, Vol. 36, 1981 , pp. $879-888$.

Rose, P.S., Money and Capital Markers, Business Publications, 1986.

Ross, S.A., "Disclosure Regulation in Financial Markets: Implications of Modern Finance Theory and Signaling Theory", in F.R. Edwards, ed., Issues in Financial Regulation, McGraw-Hill, 1979, pp. 177-202.

-...-, R.W. Westerfield and J.F. Jaffe, Corporate Finance, Irwin, 1990.

Saari, C.P., "The Efficient Capital Market Hypothesis, Economic Theory and the Regulation of the Securities Industry", Stanford Law Review, Vol. 29, 1977, pp. 1031-1076. 
Sanger. G.C. and J.D. Peterson, "An Empirical Aralysis of Common Stock Delistings" Joumal of Financial and Quamitative Analysis, Vol. 25, 1990, pp. $261-272$.

Scholes, $\mathrm{M}$. and $J$. Willams, "Estimating Betas from Nonsynchronous Data", Journal of Financial Economics, Vol. 5,1977, pp. $309-327$.

Schwartz, R.A., Equiry Markets: Struchure, Trading, and Pejfomance, Harper \& Row, 1988.

Schwert, G.W., "Public Regulation of National Securities Exchanges: A Test of the Capture Hypothesis" Bell Joumal of Economics, Vol. 8, 1977, pp. 128-150.

- "Size and Stock Returns, and Other Empirical Regularities", Jowmal of Financial Economics, Vol. 12, 1983, pp. 3-12.

Seligman, J., "The SEC and Accounting: A Historical Perspective", Jownal of Comparative Business and Capital Market Law, Vol. 7, 1985, pp. 241-266.

Seyhun, H.N., "Insiders Profits, Cost of Trading and Market Efficiency" ,Journal of Financial Economics, Vol. 16, 1986, pp. 189-212.

Simon, C.J., "The Effect of the 1933 Securities Act on Investor Information and the Performance of New Issues", American Economic Review, Vol. 79, 1989, pp. 295-318.

Smidt, S., "Which Road to an Efficient Stock Market: Free Competition or Regulated Monopoly?", Financial Analysts Joumal, Vol. 27, 1971, pp. 18-20, 64-69.

Stigler, G.J., "Public Regulation of the Securities Market", Joumal of Business, Vol. 37 , $1964 \mathrm{a}$, pp. 117-142.

- . "Comment", Jownal of Business, Vol. $37,1964 \mathrm{~b}$, pp. $414-422$.

- "The Theory of Economic Regulation", Bell Journal of Economics and Management Science, Vol. 2, 1971, pp. 3-21.

Stiglitz, J.E. "The Allocation Role of the Stock Market: Pareto Optimality and Competition", Journal of Finance, Vol. 36, 1981, pp. 235-251.

Stoll, H.R., "Regulation of Securities Markets: An Examination of the Effects of Increased Competition", Monograph Series in Finance and Economics, New York University, No. 2 , 1979.

Thomas, W.A., The Securities Market, Philip Allan, 1989.

Thompson, R., "Conditioning the Return-Generating Process on Firm-Specific Events: A Discussion of Event Study Methods", Joumal of Financial and Quamitative Analysis, Vol. 20, 1985 , pp. 151-168.

Tinic, S.M. and R.R. West, "Competition and the Pricing of Dealer Service in the Over-TheCounter Stock Market", Joumal of Financial and Quantitative Analysis, Vol. 7, 1972, pp. $1707-1727$.

- 17m-.-. "Economics of Market Making: Regulation versus Competition", Journal of Contemporary Business, Vol. 5, 1976, pp. 51-70.

Tobin, J., "On the Efficiency of the Financial System", Lloyds Bank Review, No. 153, 1984, pp. $1-15$.

Van Horne, J.C., Financial Market Rates and Flows, Prentice-Hall, 1984.

Venkatesh, P.C., "The Impact of Dividend Initiation on the Information Content of Earnings Annoucements and Returns Volatility", Joumal of Business, Vol. 62, 1989, pp. 175-197.

Vermaelen, T., "Encouraging Information Disclosure", Tijdschriff woor Economie en Management, Vol. 31,1986, pp. 435-449.

Warmer, J.B. and R.L. Watts, "Stock Prices and Top Management Changes", Journal of Financial Economics, Vol. 20, 1988, pp. 461-492.

Weston, J.F., K.S. Chung and S.E. Hoag, Mergers, Restructuring, and Corporate Control, Prentice-Hall, 1990.

Werhane, P.H., "The Ethics of Insider Trading", Journal of Business Ethics, Vol. 8, 1989, pp. $841-845$.

Wijmenga, R.Th., "The Performance of Published Dutch Stock Recommendations", Journal of Banking and Finance, Vol. 14, 1990, pp. 559-581. 


\section{AUTHOR INDEX}

Admati 86,88

Ajinkya 91,94

Amihud 86

Ankum 80

Ball 16,95

Bamber 93

Beaver $78,91,93$

Beckers 37

Beghin 16

Benston 16-18

Berkman 86

Bowman 36

Brealey 12

Brown $16,33,34,50,70,91,95,96$

Campbell 8

Chatfield 96

Chung 86

Collins 36

Conrad 76

Copeland 34

Corhay 52

Cornett 5

Cross 62

Defeo 87

Demsetz 19,20

Dent 36

Diephuis 62

Dimson $37,46,47,49,52$

Dorsman 80

Dougall 7

Eisenach 21

Fabozzi 26

Fama 34,76

Finnerty 19,87

Fisher 34

Foster 16,96

Franks 34,37

French 76

Friend 15-17

Gaumnitz 7

Givoly 19,87

Griffin 96

Grossman 86,95

Grube 22

Hagerman 96

Hannigan 86
Hardouvelis 22

Harris 34,37

Hawawini $17,34,52$

Hein 96

Herman 15,16

Herst 86

Hillmer 87

Hoag 86

Holthausen 78,94

Hopewell $26,30,31,53,73$

Howe $20,26,73,87$

Hsieh 22

Ittersum 85

Jaffe $19,20,34,87$

Jain $88,91,94$

James 5

Jang 78

Jarrell $5,16,70$

Jecher 18

Jennings 87

Jensen 34

Joh 88

John 19

Johnston 76

Jordan 5

Joskow 5

Joy 22

Kahn 1

Kalay 70

Kane 8

Karpoff $78,87,94,97$

Kaul 76

Keim 52

Kryzanowski $20,26,73$

Kylle 20,88

Lakonishok 52

Largay 22

Levis 52

Lin 87

$\operatorname{Linn} 34,70$

Lipton 6

Ma 26

Marne 19,86

Manove 86

Marsh 37, 52

McCraw 5 
Mendelson 30,86

Merino 18

Michel 17,52

Mikkelson 34

Miller 21,22

Mishra 19

Mitnick 1,2

Moore 22

Morris 19

Morse $50,78,91,93-95$

Moyer 96

Needham 1, 3

Neimark 18

Noll 5

Palmon 19,87

Panton 22

Partch 34

Patell 87

Peel 19

Peltzman 4

Peterson 33

Pfleiderer 86,88

Philips 18

Phillips 3

Pincus 87

Pinegar 34,70

Pope 19

Posner 3-5

Post 80

Poulsen 70

Pownall 17

Reiss 3

Ridder 26,73

Rietkerk 86

Ro 78

Robbins 15

Roll. $34,52,76$

Ross 18, 34

Sanger 33

Schlarbaum $20,26,73$

Scholes $46-48,52$

Schwartz $26,30,31,53,73$

Schwert 35

Seligman 18

Seyhun 87

Shimrat 70

Simon 16

Smidt 21

Stambaugh 52

Starks 87

Stigler $4,5,15,16,30$
Stoll 21

Tehranian 5

Thomas 13

Thompson 36

Tinic 21

Van Horne 7

Venkatesh 87

Vermaelen 20

Verrechia 94

Warner $33,34,50,70,91,96$

Watts 34

Waymire 17

Werner 16

West 21, 22

Westerfield 17, 34

Weston 34,86

Wijmenga 70

Williams $46-48,52$

Wolfson 87

Yu 87

Zmijewski 96 
Abnomal retum $26,34-53,70,73,74$, $96-98,119-127$

Abnormal trading volume $91,93-95,97,98$, $102,105,106,109,110$, $113,114,117,127,129$. 130,133

Accounting $8,16-18$

Acquisition $32,33,44$

Act $3,8-10,12,13,15-18,22,26,28,29$, 50,87

Adjusted Market Model 91, 93, 104, 108, 112,116

AIM $14,62,64$

Allocation 3-6

Alpha 28, 42, 43, 56

American Stock Exchange 20,26

Amsterdam Interprofessional Market 64

Amsterdam Stock Exchange (see also ASE)

$9-12,21,22,53,61-66,70$,

Analyst 96

$73,78-80,85,88,100,138$

Announcement $12,13,25,29,37,78,85$, $87-90,92-99,104-106$, $108-110,112-114,116$. $117,119-126$

Annual earnings $16,85-88,90-93,95-99$. $101,102,105,106,109$, $118-122,127,129,131$, $135,136-138$

Appendix $38,46,54-59,71,76,81-84$

Arbitrage Pricing Theory 34

ASE $61,62,64,67,80,85$

Autocorrelation $46,76,91$

Bank $12,22,61$

Bankruptcy 66

Belgium 17

Benefit $3,10,18,34,86$

Beschikking Beursnotering 9

Besluit Effectenhandel 9

Beta 28, 35, 46, 58

Beurswet 9

Bond $28,62,64$

Bond market 28,62

Broker 9,22

Broker-dealer 22

CAAR $36,38,40,42,44,47,50,71,74$, $76,119-126$

Canada $20,26,53$

Capital $7 \cdot 11,14,16,19,34,37,47,61,62$, 70,87

Capital Asset Pricing Model (see also CAPM)
Capital structure 37,70

Capture theory 4,137

Cartel 4, 21

Central Burean of Statistics 70

Cochrane-Orcutt 76,91

Commission $9,15,16,18,20,21,26,28$, $29,62,64$

Commissionairs 11,61

Companies Act 12

Company $1,8,10,12-14,29,30,47,66$, $67,70,80,85,88,91$

Conclusion $3,16,17,19,34,50,70,97$, 137,138

Consensus $70,78,85,94$

Consequence $18,65,85$

Cost $4,8,18,19,30,64$

Council 11, 13, 14, 25, 27, 65

Credit 22

Criminal 10,13

Cross-sectional $35,80,91,96$

Cumulative average abnormal retum (see also CAAR) $36,70,73$, $96,119-127$

Data $15-19,22,30,35-37,46,50,52,53$, $56,59,61,62,65,70$ $71,76,80,88-91,93$, $94,96,97,105,109$, $113,117,138$

Datastrearn $70,71,88,89$

Decree 9,17

Delisting 66

Delta 28

Deregulation 21

Design 27, 33, 70, 92

Detertance 3

Directive 14

Disappeared $32,37,44,66$

Disclosure $8,10,12,13,15-19,23,62$, 73,137

Discretionary $86,94,98$

Dissemination $20,28-30,38,42,53,138$

Distribution $3,14,15,31,32,65,66,88$. 89.93

Disturbance 34

Dividend $16,37,86,90$

Domestic $13,62,63$

DPS 90

Duration $37,53,66,67$

Durbin-Watson 76

Economic theory $4,5,137$

EEC 14 
Effective $6,9,12,13,17,19,20,22,26,30$. $31,35,52,61,62,137$

Efficiency $26,28,53,73,80$

Efficient adjustment $53,73,80$

Empirical $3-5,15-17,20-23,33,34,37,52$, $61,65,71,73,80,87,137$

End-of month $31,32,36$

Enforcenicht $3,13,20,22,29$

EPS 90

Equilibrium 34, 93, 95

Equily $7,16,67,68,85,87,94$

Estimation period $36,70,79,91-93,96$, $101,105,109,113,117$

European Economic Community (see also EEC) 14,137

Event study $33,34,36,70,96,137-140$

Evidence $3-5,15-22,26,31,34,38,53,73$, $78-80,87,94,137,138$

Excess return $34,35,40,96$

Expected $4,10,13,20,22,29,30,34,52$, $65,66,68,73,91$

Fair Trading Act 12

Favourable information $26,50,53,138$

Federal Reserve Board 22

Financial markets $6,7,18$

Financial Services Act 13,18

Financial "Times 37,47

Financicele Dagblad $66,70,88$

Firm-specific 34,35

Fixed commission $21,62,64$

Fondsenreglement 11

Foreign $62,63,66$

Fraud $7,8,12,13,18$

Gumma 28

Government $1,3-5,7,9,10,13,25,27,28$, 62

Hocklieden $11,61,62$

Hypothesis $4,17,38,76,80,87,94-97,138$

Index $35,37,70,96$

Industry $1-5,9,10,13,16,21,23,30,33$, 67,68

Inefficient $3,38,53,76$

Information $1,3,8,10-20,26-31,38,42$, $50,53,61,62,65-68,70$, $73,74,78-80,86-90,94$, $96-98,137,138$

Information content $16,61,78,96,97,138$ Intormedness 94

Infrequent trading 46,52

Insider $1,10,12,14,19,20,23,25,37,38$, $70,85-88,90,93-99,137$. 138
Insider trading $1,10,12,14,19,20,23$, $25,37,38,70,85-88$, $90,93-99,137,138$.

Institutional $1,28,29,61,73,80$

Intermediation 8,137

Investigation $20,22,26,85,98$

Investment companies 8,63

Investor 8

Investor confidence 8

Issues $1,15,16,26,31,70,85-88,137$

Jobber 62

Lack of consensus 94

Law $3,8,10,12,17-20,85$

Liquidation $32,33,37$

Liquidity $21,86,90,94,95,98,99,138$

Listed companies $10 \times 14,28,33$

Listing $9,11,13,14,16,25,27,29,32$, $33,37,44,61,62,65$. 66

Listing cancellation 65

Listing postponement 65

Literature $3,15,18,33,46,70,87$

London Share Price Database (see also LSPD) 30,36

London Stock Exchange (see also LSE) $13,21,25-29,31,37$,

$52,53,61,73,80,137$

Long-term $37,61,80$

LSE $27,31,52,80$

LSPD 30,31

Mandatory $15-18,23,26,28,64$

Manipulation $7,8,18,20,25,26$

Margin $22,137,139$

Market adjusted $40,73,74$

Market capitalisation $27-29,37,52$

Market efficiency 26, 53, 73

Market making $21,28,137,139$

Market model $33-35,37,39,40,44,46$, $54,56,70-73,76,81$, $91,93-96,98,103,105$, $107-109,111-113$, $115-117,120,122,124$, 126

Market value $27,37,62,64,67,94$

Material information $29,30,65,73,80$, 137,138

Mean adjusted $91,93,94,102,106,110$. 114

Merger $12,32,33,44,45,57,66,67,70$, 80

Methodology $15,33,36,61,70,73,90$, $95,137,138$

Minimum commission 21,62 
Ministry of Finance 6,12

Model code $12,13,85,87,90,91,94$, 96.98

Model specification 35,95

Monthly $36,37,46,47,50,52,53,56,61$,

Multi-day 67,70

$$
80,89
$$

Negative $17,26,38,73,76,86,88,94$, $96-98$

Netherlands $5,8-10,61,62,85,88,137$

New information $26,29,38,50,53,68,74$, $79,80,88,138$

New York Stock Exchange (see also NYSE) $16,17,20,21,26,29,31$, 73

NYSE $16,17,29$

Objective $3,23,61,65$

Officiall market $11,62-64,66$

Ordinary least squares 37

Organisation for Economic Cooperation and Development 7

Over-the-counter $26,33,62,65$

Parallel market $62-64,66,70$

Parameter $34,35,37$

Portfolio $19,34,91,94$

Positive $17,38,40,42,47,50,52,53,73$, $76,86,88,94-98$

Post-regulation $93,95,97,102-117, \| 19-126$

Pre-regulation $97,102-117,119-126$

Price behaviour $22,26,50,52,61,70,73$, $80,87,97-99,137,138$

Primary market 7,8

Private regulation $5,6,10,13,137$

Prospectus $9,11,12,14,15$

Protection 1, 4, 8, 9

Public interest theory 3,137

Public regulation $9,10,12,137$

Quality $1,8,15,16,21,28$

Quarterly eamings 85,95

Random walk 96.97

Reason $4,19,29,30,32,33,64,66,67$. 138

Regression $35,42,46,58,70,76$

Regulation $1-10,12-23,73,85,86,90,91$, $93-95,97,98,102-117$. $119-126,137-139$

Regullatory system $1,2,137$

Reorganisation $11,29,37$

Research design $27,33,70$

Restriction $2,13,85,87,93-98,100,137$, 138
Result $3-6,22,38,46,66,70,78,93-98$

Sample $36,44,57,89 ; 100$

Sample selection $36,70,88$

SEC $15,16,18,21,26,29$

Secondary manket 7,8

Securities $7-22,25-31,33,34,36-38,44$, $46,50,52,53,62-66$.

$80,87,91,96,137$

Securities Act $8,15-17$

Securities and Exchange Commission (see also SEC) $9,15,16$ $18,20,26,29$

Securities Board 10

Securities transactions 11

Security market $1,19,20,22,23,30$, 137

Selection criteria 70

Semi-annual earnings $86-88,90,91,93$, $95-99,101,110,113$. $114,117,118,123-126$. $131,133,136 \div 138$

Serial correlation $76,77,83,91,105$, $109,113,117$

Share price $26,30,36,50,53,61,68$, $70,73,74,78,80,88$, 137,138

Stuareholder 14,87

Significant $16,17,26,29,36,38,40,42$, $47,52,53,64,70,71$, $73,74,76,80,91$, $94-98,138$

Single-day $66,67,70$

Size $8,21,31,35,37,38,40,42,44,47$. $50,52,67,73,94,97$, 98

Small firm 52, 99, 106-109, 114-117, $121,122,125,126,129$ $133-136$

Specialist 29

Specification $18,35,95$

Stamp duty 62,64

Standardisation 18

Statistically significant $36,38,70,91,94$, 96.97

STE 10

Stock $6,7,9-17,19-22,25-32,35-38,42$, $44,46,52,53,61-66$, $68,70,73,76,78-80$, $85-88,91,94-98,100$, 137. 138

Stock exchange $9-14,16,17,20-22$, $25-32,37,38,44,46$, $52,53,61-66,68,70$, $73,78-80,85,88,100$, 137,138 
Stock Exchange Automatcd

Quotations 27,28

Voluntary $17,18,32$

Stock market $7,10,15,16,19,21,22,26$, $30,53,61,68,70,73,79$,

Wet Effectenhandel 9 $80,86,87,96,97,138$

Window $36,37,70$

Stock walch $12,29,85,94,98$

Stockdata $70,88,89$

Strong form $26,29,30$

Suspension $1,13,20,25-27,29-45,47-53$, $61,65-77,79,80,137,138$

Sweden 26

System $1-3,6,8,9,18,21,22,28,62,137$

Systematic $17,34,46,52,73$

t-test 36,70

Takeover $8,12-14,32,33,66,67,70,80$

Theoretical insights 29,86

Third market 28

Trading $1,8-12,14,19-21,23,25-53$, $61.80,85-88,90,91$, $93-99,100,102,105,106$. $109,110,113,114,117$. $127,129,131,133,137$, 138

Trading halt 65

Trading infrequency 52

Trading prohibition 65

Trading suspension $1,20,25-27,29,30,32$, $33,35-43,45,47-51,53$, $61,65-77,79,80,137,138$

Trading volume $12,19,28,61-64,70,71$, $78-80,85 \sim 88,90,91$, $93-95,97,98,100,102$, $105,106,109,110,113$, $114,117,127,129,131$, 133,138

Turnover $22,28,62$

Unbiased 46,76

Uncommon 26,31

Undesirable 9,30

Unexpected $16,34,61,96,98$

Unfavourable 26, 68, 73

Unique $26,31,37,61$

United Kingdom $12,13,53,137$

United States $9,15,16,18-22,26,29,53$

Unlisted 28

Value-weighted 37,70

Variance $16,38,56,57,59,90$

Vereniging 10

Volume $12,19,28,61-64,70,71,78-80$, $85-91,93-99,100,102$, 104-106, 108-110, 112-114, $116,117,127,129,131$. 133,138 


\section{CURRICULUM VITAE}

Rezaul Kabir received his BA with Honours in Economics and MBA degrees from the University of Dhaka (Bangladesh). While he was working for a multinational company in Bangladesh, he obtained a scholarship to study at the University of Leuven (Belgium), where he received MBA and MA (Econ.) degrees. From May 1986 until July 1990, he worked on his dissertation, besides teaching assignments, at the University of Limburg in Maastricht (the Netherlands). Since then, he is employed at the Department of Finance, Faculty of Economics, Tilburg University (the Netherlands). 